\author{
UNIVERSIDADE DE SÃO PAULO \\ ESCOLA DE ENGENHARIA DE SÃO CARLOS \\ DEPARTAMENTO DE ENGENHARIA DE TRANSPORTES
}

Avaliação Econômica de Concessões Rodoviárias no Estado de São Paulo Utilizando os Custos Operacionais Decorrentes da Condição do Pavimento

Rosuel Krum Mathias de Assis 



\section{Avaliação Econômica de Concessões Rodoviárias no Estado de São Paulo Utilizando os Custos Operacionais Decorrentes da Condição do Pavimento}

Rosuel Krum Mathias de Assis

Dissertação apresentada ao Departamento de Engenharia de Transportes da Escola de Engenharia de São Carlos da Universidade de São Paulo, como parte dos requisitos para obtenção do Título de Mestre em Ciências - Programa de Pós-graduação em Engenharia de Transportes.

Área de concentração: Infra-Estrutura de Transportes.

Orientador: Prof. Dr. José Leomar Fernandes Júnior

São Carlos

2017 
AUTORIZO A REPRODUÇÃO TOTAL OU PARCIAL DESTE TRABALHO, POR QUALQUER MEIO CONVENCIONAL OU ELETRÔNICO, PARA FINS DE ESTUDO E PESQUISA, DESDE QUE CITADA A FONTE.

Assis, Rosuel Krum Mathias de

A848a Avaliação Econômica de Concessões Rodoviárias no Estado de São Paulo Utilizando os Custos Operacionais Decorrentes da Condição do Pavimento / Rosuel Krum Mathias de Assis; orientador José Leomar Fernandes Júnior. São Carlos, 2017.

Dissertação (Mestrado) - Programa de Pós-Graduação em Engenharia de Transportes e Área de Concentração em Infraestrutura de Transportes -- Escola de Engenharia de São Carlos da Universidade de São Paulo, 2017.

1. concessões rodoviárias. 2. análise econômica. 3. custos de operação dos veículos. 4. irregularidade longitudinal dos pavimentos. 5. sistemas de gerência de pavimentos. 6. HDM-4. I. Título. 
Candidato: Engenheiro ROSUEL KRUM MATHIAS DE ASSIS.

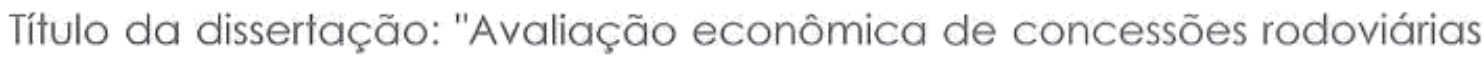
no Estädo de Säo Páulo vilizando os custos operacionális decorientes da condiç̣̂̃o do pävimento".

Datá dá defesa: 22:06.2017

Comissão Julgadora:

Resulfado:

Prof. Titular José Leomar Fernandes Júnior

APROVIDO

(Orientador)

(Escolla de Engenharia de Săo Carlos/EESC)

Prof. Dr. Humberto Filipe de Andrade Januário Bettini

(Escolä de Engenhauria de São Carlos/EESC)

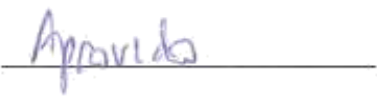

Dr. Gilmar Cardoso

(Agência Nacional de Transportes Terrestres/ANTT)

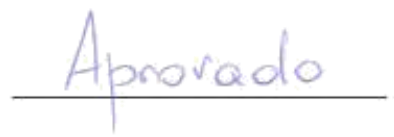

Coordenadora do Programa de Pós-Graduação em Engenharia de Transportes:

Prof Associada Ana Paula Camargo Larocca

Presidente da Comissão de Pós-Graduação:

Prof. Asśociado Luis Fernando Costa Alberto 
Para minha mãe Rosana, meu pai Samuel e meus irmãos Ruan e Syellen: os pilares que me mantiveram sempre em pé 


\section{AGRADECIMENTOS}

Primeiramente, ao Pai Celestial, por manter sempre o meu caminho iluminado, mesmo nos momentos em que a vida pareceu tão escura.

Ao meu orientador, professor José Leomar Fernandes Júnior, por todo o ensinamento transmitido, pela paciência, atenção, e também pelos puxões de orelha quando estes se fizeram necessários, sendo com toda a certeza um autêntico pai acadêmico.

A todos os professores e funcionários do Departamento de Engenharia de Transportes da Escola de Engenharia de São Carlos, da Universidade de São Paulo, pelos valiosos momentos convividos e ensinamentos tirados, onde eu aprendi muito, profissionalmente e pessoalmente.

À Coordenação de Aperfeiçoamento de Pessoal de Nível Superior (CAPES), pela bolsa de estudos concedida durante o período do mestrado.

À família Krum e à família Mathias de Assis, por serem os alicerces sobre os quais eu apoiei a formação do meu caráter, e me tornei o homem que eu sou hoje.

Ao meu pai Samuel e minha mãe Rosana, por não medirem esforços e permitirem que eu realizasse os meus sonhos, pelo amor quase infinito que sempre deram a mim e ao meu irmão, e pelo melhor abraço desse mundo. Aos meus irmãos, Ruan e Syellen, por serem os mais novos e me deixarem menos sério quando eu estava preocupado demais com trabalho e com a vida.

Ao meu avô Rubens (in memorian), pela nossa última conversa, onde o senhor disse: "Você é muito novo e não pode desanimar, meu filho". O seu último conselho foi valioso demais.

Ao ex-chefe, conselheiro, mentor e amigo José Alberto Salceda, por ter sido o primeiro a me sugerir fazer um mestrado na USP.

Ao professor Gilmar Cardoso, por ter sido o primeiro a sugerir que esse mestrado fosse na USP de São Carlos.

Ao professor Humberto Bettini, pela conversa que estabeleceu as bases deste trabalho.

Aos meus amigos da turma de engenharia civil da UNIVALI, Alan, Carolina, Cláudio, Felipe, Malko e Yuri, por serem os melhores amigos que uma pessoa poderia desejar, e pela parceria que eu tenho certeza irá continuar por toda a minha vida.

À minha amiga Daniela, que tem sempre a palavra certa, no momento certo, e da forma correta.

Aos meus colegas, amigos e irmãos do STT, por fazerem da experiência do mestrado uma das melhores que eu já tive na vida, extrapolando a obtenção do título acadêmico, e por contribuírem sempre comigo, seja na pesquisa, seja no aspecto pessoal.

A todos os que de alguma forma me ajudaram ou contribuíram para que eu me tornasse quem sou, e que não foram citados anteriormente.

A todos os professores que contribuíram com a minha formação, desde a pré-escola até a pósgraduação. Que esses ensinamentos se espalhem por todo o mundo, e que eu possa fazer a minha parte para que isso aconteça. 
"[...] Se você quer que a verdade se apresente claramente diante de você, nunca seja nem a favor nem contra. A luta entre "a favor" $e$ "contra" é a pior das doenças da mente. Quando o profundo significado das coisas não é compreendido, a essencial paz da mente é perturbada inutilmente.[...]"

Seng-ts'an 
ASSIS, R. K. M. Avaliação Econômica de Concessões Rodoviárias no Estado de São Paulo Utilizando os Custos Operacionais Decorrentes da Condição do Pavimento. 2017. Dissertação (Mestrado) - Escola de Engenharia de São Carlos da Universidade de São Paulo.

O número de concessões rodoviárias tem aumentado em todo o mundo. Somente no Brasil, desde 1995, três etapas de concessão já foram realizadas pelo governo federal. No estado de São Paulo, as concessões estão em sua segunda etapa. Uma das principais justificativas para as concessões rodoviárias é a melhoria da condição dos pavimentos. Sendo assim, este trabalho buscou avaliar os benefícios oriundos da melhor conservação dos pavimentos, em termos da irregularidade longitudinal, diretamente relacionada com os custos de operação dos veículos (custos dos usuários: consumo de combustível, desgaste de pneus, tempo de viagem etc.), comparando com os custos por pagamento de pedágio. Para tanto, foram selecionados, através da análise de cluster, três trechos distintos, de tal forma que se tivesse, pelo menos, um segmento do modelo da ANTT da primeira etapa, um segmento do modelo da ANTT da segunda etapa e um segmento do modelo da ARTESP. Os custos de operação dos veículos foram determinados com uso do software HDM-4 e a análise econômica considerou o Valor Presente Líquido (VPL), a Taxa Interna de Retorno (TIR) e a Relação Benefício/Custo (B/C). As alternativas consideradas na análise simularam as exigências contratuais presentes no programa CREMA e no Programa de Exploração da Rodovia (PER) da ANTT. A condição "base" para as análises simulou um cenário limite para intervenção no pavimento, onde a mesma só ocorria com irregularidades muito elevadas. Após a realização das simulações, concluiu-se que o método do VPL era o mais adequado para as análises, pois todos os trechos apresentaram custos aos usuários maiores do que os benefícios observados. Ao se realizar análise complementar, com limites de irregularidade ainda maiores para a condição "base", somente o modelo da ANTT da segunda etapa justificou economicamente a concessão, do ponto de vista dos usuários. Conclui-se, portanto, que existem evidências de que as concessões rodoviárias no Brasil não têm melhorado a condição dos pavimentos a ponto de ser justificada economicamente, decorrendo a sugestão para que as próximas concessões acarretem custos de pedágio menores ou apresentem um maior número de obras com impacto significativo na redução do tempo de viagem e no aumento da segurança dos usuários.

Palavras-chave: concessões rodoviárias; análise econômica; custos de operação dos veículos; irregularidade longitudinal dos pavimentos; sistemas de gerência de pavimentos; HDM-4. 

ASSIS, R. K. M. Economic Evaluation of Road Concessions in the State of São Paulo Using Operating Costs Due to Pavement Condition. 2017. Dissertation (Master) - São Carlos School of Engineering, University of São Paulo, 2017.

The number of road concessions has increased worldwide. Only in Brazil, since 1995, three concession stages have already been carried out by the federal government. In the state of São Paulo, the concessions are in its second stage. One of the main justifications for road concessions is the improvement of pavement condition. Therefore, this study sought to evaluate the benefits of better pavement conservation in terms of longitudinal roughness, directly related to vehicle operating costs (user costs: fuel consumption, tire wear, travel time, etc.), comparing it to toll payment costs. In order to do so, three distinct sections were selected through the cluster analysis, so that there was at least one segment of the ANTT model of the first stage, a segment of the ANTT model of the second stage and a segment of the model of ARTESP. Vehicle operating costs were determined using the HDM-4 software and the economic analysis considered the Net Present Value (NPV), the Internal Rate of Return (IRR) and the Benefit/Cost Ratio $(\mathrm{B} / \mathrm{C})$. The alternatives considered in the analysis simulated the contractual requirements present in the CREMA program and in the ANTT Highway Exploration Program (HEP). The "base" condition for the analyzes simulated a limit scenario for intervention in the pavement, where it only occurred with very high roughness. After the simulations, it was concluded that the NPV method was the most appropriate for the analyzes, since all the stretches presented costs to users greater than the observed benefits. When performing complementary analysis, with even greater limits of roughness for the "base" condition, only the ANTT model of the second stage economically justified the concession, from the users point of view. It is concluded, therefore, that there is evidence that the road concessions in Brazil have not improved the condition of the pavements to the point of being economically justified, suggesting that the next concessions bring lower toll costs or present a greater number of works with significant impact on reducing travel time and increasing user safety.

Key-words: road concessions; economic analysis; vehicle operation costs; longitudinal pavement roughness; pavement management systems; HDM-4. 



\section{LISTA DE FIGURAS}

Figura 1: Classificação do pavimento das rodovias brasileiras, na extensão avaliada pela CNT (2014) .11

Figura 2: Efeitos das estratégias de manutenção dos pavimentos nos custos dos usuários......13

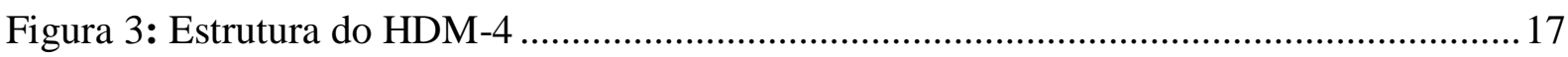

Figura 4: Gráfico de dispersão de dados aleatórios .............................................................. 19

Figura 5: Gráfico indicativo dos clusters formados.......................................................... 19

Figura 6: Exemplo de um dendograma, com a indicação dos métodos aglomerativo e divisivo

Figura 7: Gráfico interpretativo do dendograma gerado (dados de 2012) ..............................22

Figura 8: Gráfico interpretativo do dendograma gerado (dados de 2013) ..............................23

Figura 9: Gráfico de dispersão dos dados e clusters formados (4 clusters, dados de 2013).....24

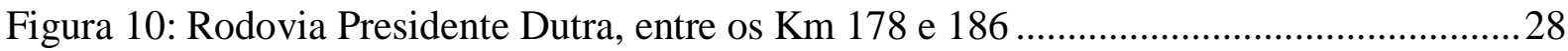

Figura 11: Rodovia Fernão Dias, entre os Km 2 e 10 .........................................................29

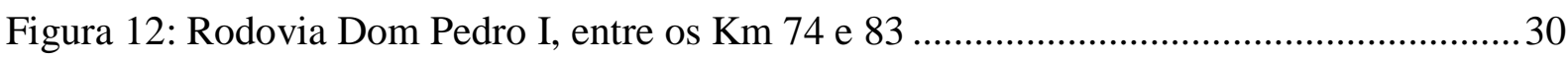

Figura 13: Evolução das tarifas de pedágio cobradas nas praças .............................................32

Figura 14: Evolução das tarifas cobradas por quilômetro, nos trechos selecionados................32

Figura 15:Evolução das tarifas pagas pelos usuários, proporcionalmente aos trechos percorridos

Figura 16:Evolução das tarifas pagas pelos usuários, proporcionalmente aos trechos percorridos

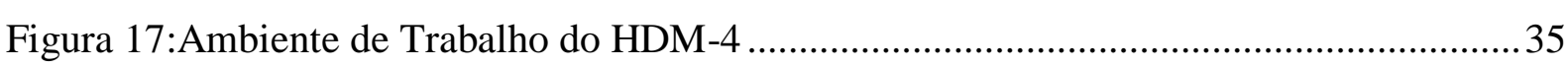

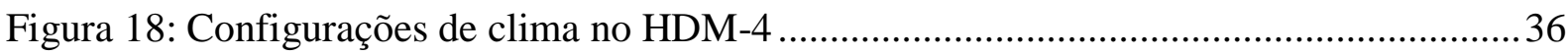

Figura 19: Configuração da Rede Rodoviária no HDM-4 ...................................................40

Figura 20: Configuração da Análise de Projeto no HDM-4 ....................................................42

Figura 21: Caracterização do Tráfego Durante o Período de Análise .......................................42

Figura 22: Estratégias de Manutenção Utilizadas nas Simulações..........................................45

Figura 23: Evolução do $n^{\circ}$ de eixos equivalentes nos trechos em estudo..................................48

Figura 24: Evolução da área total de trincas no trecho da rodovia Dom Pedro I .....................49

Figura 25: Evolução do afundamento médio da trilha de roda, trecho da Dom Pedro I ..........50

Figura 26: Evolução do afundamento médio da trilha de roda, trecho da Dom Pedro I ..........51

Figura 27: Redução do consumo de combustível em relação aos valores máximos da condição

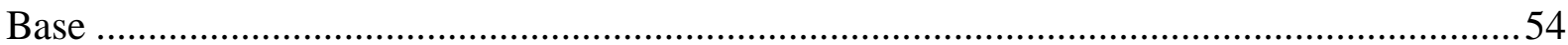

Figura 28: Redução do consumo de pneus em relação aos valores máximos da condição Base

Figura 29: Redução do consumo de peças em relação aos valores médios da condição Base.58

Figura 30: Variação da Velocidade Média Anual do Fluxo de Tráfego ..................................59

Figura 31: Redução do atraso médio em veículos de carga ..................................................60

Figura 32: Redução do atraso médio em veículos de passageiros .........................................61

Figura 33: Tela do HDM-4 com o relatório de custos anuais médios dos usuários .................63

Figura 34: Custos Totais dos Usuários, com taxa de desconto igual a 6\% a.a........................64

Figura 35: Custos Totais dos Usuários, com taxa de desconto igual a 12\% a.a......................64 
Figura 36: Custos Totais dos Usuários, com taxa de desconto igual a $18 \%$ a.a.

Figura 37: Benefícios Totais dos Usuários pela redução de custos operacionais, taxa de desconto igual a $6 \%$ a.a.

Figura 38: Benefícios Totais dos Usuários pela redução de custos operacionais, taxa de desconto igual a $12 \%$ a.a. 66

Figura 39: Benefícios Totais dos Usuários pela redução de custos operacionais, taxa de desconto

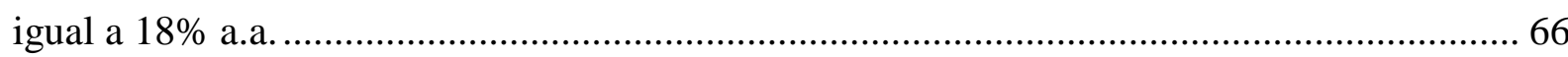

Figura 40: Custos Totais dos Usuários devido ao Pagamento de Pedágio .............................. 67

Figura 41: VPL das Estratégias Empregadas, com taxa de desconto de $6 \%$ a.a...................... 68

Figura 42: VPL das Estratégias Empregadas, com taxa de desconto de $12 \%$ a.a.................... 69

Figura 43: VPL das Estratégias Empregadas, com taxa de desconto de 18\% a.a.................... 69

Figura 44: Redução Percentual dos Custos Operacionais, por Tipo de Veículo ...................... 70

Figura 45: Comparação Entre os Benefícios Observados e os Multiplicadores Tarifários, por

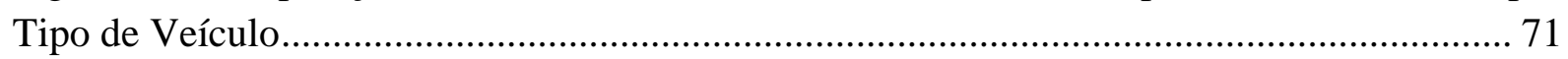

Figura 46: Variação dos Custos e Benefícios na Rodovia Dom Pedro, em função das TDs... 74

Figura 47: Variação dos Custos e Benefícios na Rodovia Dutra, em função das TDs ........... 74

Figura 48: Variação dos Custos e Benefícios na Rodovia Fernão Dias, em função das TDs.. 75

Figura 49: Aumento dos Custos dos Usuários em Decorrência do Aumento da Irregularidade

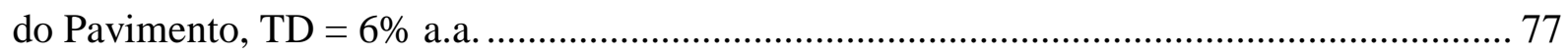

Figura 50: Aumento dos Custos dos Usuários em Decorrência do Aumento da Irregularidade

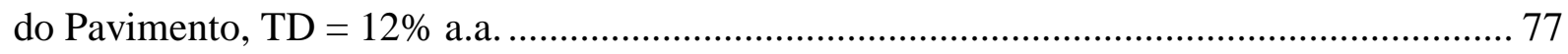

Figura 51: Aumento dos Custos dos Usuários em Decorrência do Aumento da Irregularidade do Pavimento, TD = $12 \%$ a.a. .................................................................................... 78

Figura 52: Benefícios Totais dos Usuários pela redução de custos operacionais, Condição Base

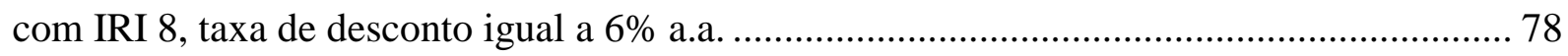

Figura 53: Benefícios Totais dos Usuários pela redução de custos operacionais, Condição Base

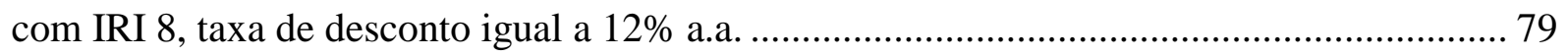

Figura 54: Benefícios Totais dos Usuários pela redução de custos operacionais, Condição Base

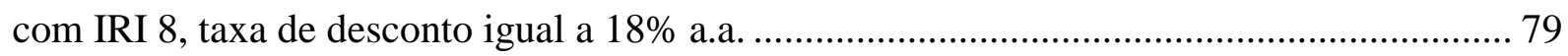
Figura 55: VPL das Estratégias Empregadas, Condição Base com IRI 8, taxa de desconto de

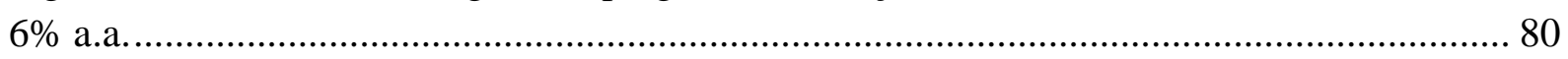

Figura 56: VPL das Estratégias Empregadas, Condição Base com IRI 8, taxa de desconto de $12 \%$ a.a...

Figura 57: VPL das Estratégias Empregadas, Condição Base com IRI 8, taxa de desconto de

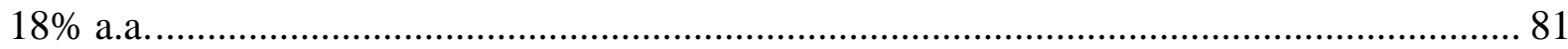

Figura 58: Tarifas de Equilíbrio, Taxa de Desconto de 6\% a.a. .......................................... 82

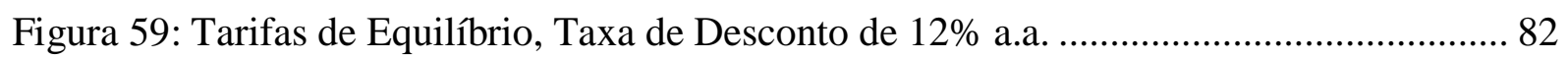

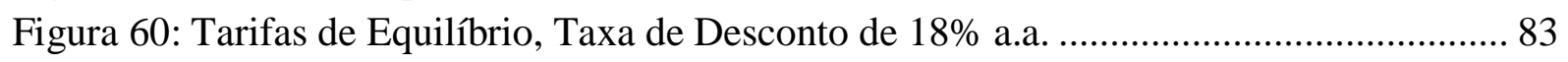

Figura 61: Tarifas de Equilíbrio com Percentuais Somente do Pavimento ............................. 85 


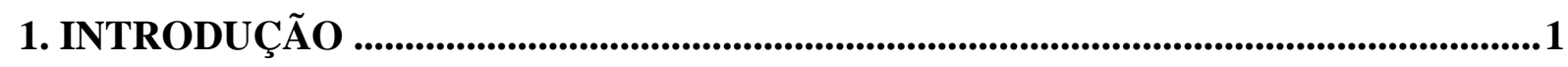

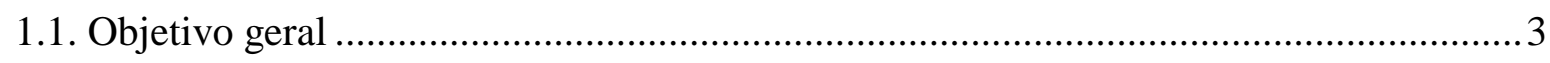

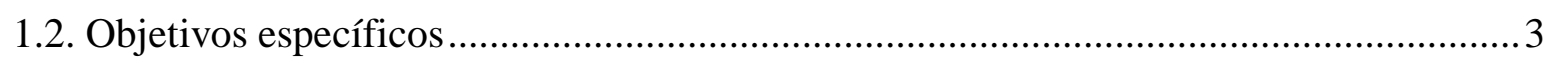

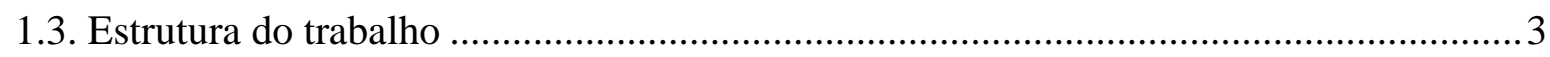

2. REVISÃO BIBLIOGRÁFICA ................................................................................... 4

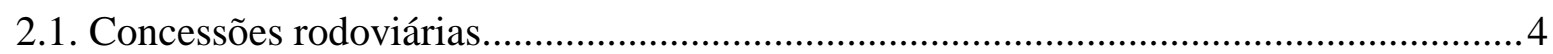

2.2. Avaliação econômica de projetos rodoviários .......................................................... 12

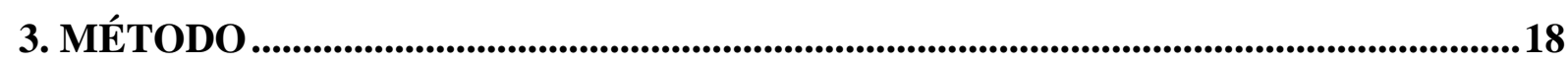

3.1. Aquisição dos dados e seleção dos segmentos rodoviários para estudo........................18

3.2. Descrição e histórico dos locais selecionados ...........................................................26

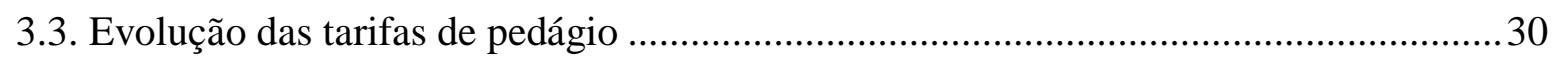

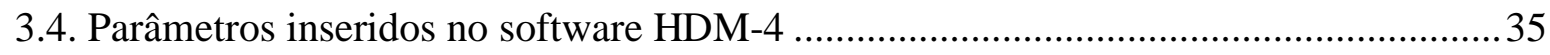

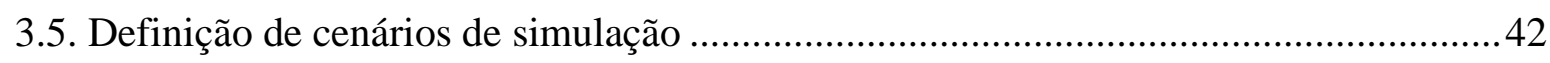

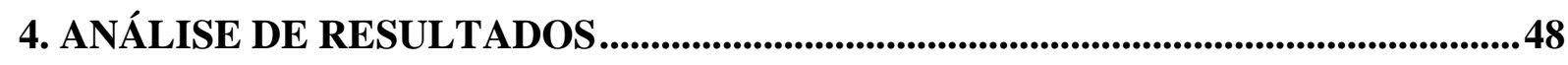

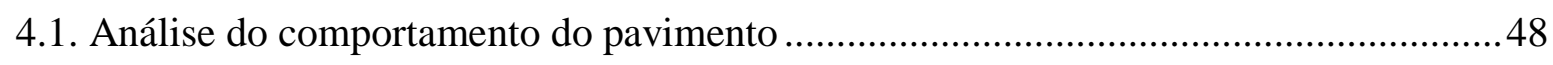

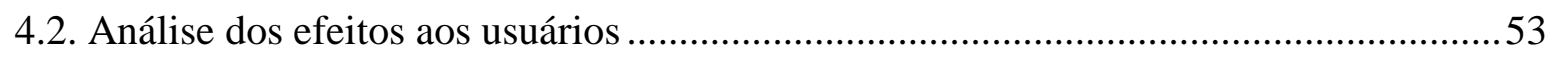

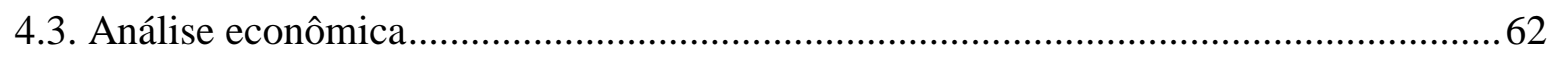

5. CONCLUSÕES E SUGESTÕES PARA TRABALHOS FUTUROS .........................86

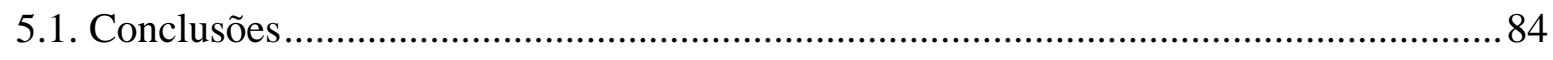

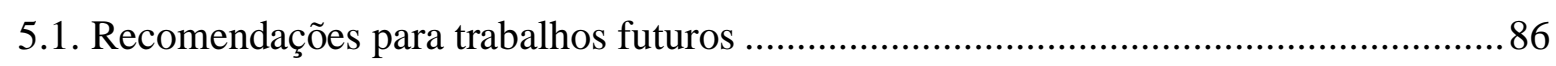

REFERÊNCIAS BIBLIOGRÁFICAS ....................................................................89

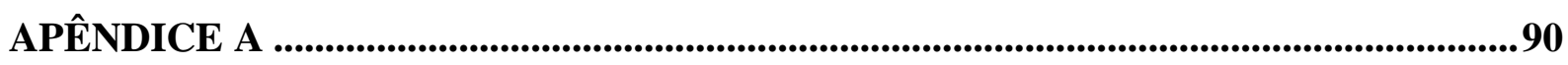

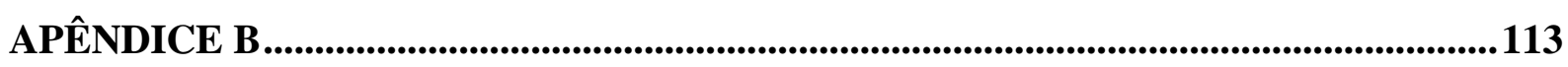

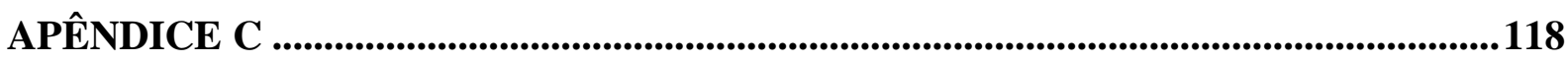

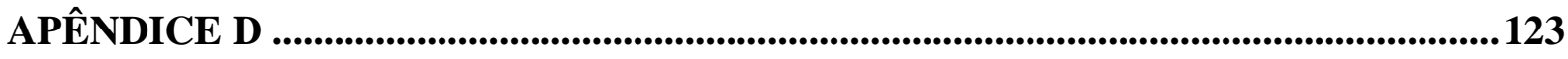





\section{INTRODUÇÃO}

Desde o início dos programas de concessão rodoviária no país, o ato de se delegar a uma empresa privada a responsabilidade pela operação, manutenção e pelas melhorias de uma rodovia passou a ser frequente, tanto pelo governo federal, quanto pelos governos estaduais. As concessões rodoviárias, que tiveram início com a Ponte Rio-Niterói no ano de 1995, vem crescendo continuamente, e hoje acumulam no Brasil um total de 59 concessionárias, responsáveis por $19.804 \mathrm{~km}$, ou 9,3\% do total de nossa malha rodoviária pavimentada (CNT, 2015).

Somente o estado de São Paulo possui praticamente um terço das concessionárias - 19 - num total de $5428 \mathrm{~km}$, ou 27,4\% do total concedido no país (ABCR, 2016), considerando-se apenas as concessões do governo estadual, reguladas pela ARTESP. Além disso, outras 4 concessões federais estão localizadas no estado, sendo essas reguladas pela ANTT.

As concessões da ARTESP foram realizadas em duas etapas distintas: a primeira iniciada em 1998, onde foram licitados 12 lotes, e a segunda iniciada em 2008, com a concessão de outros 7 lotes. As concessões da ANTT existentes no estado de São Paulo também foram realizadas em duas etapas distintas: a primeira etapa em 1996, contemplando a Rodovia Presidente Dutra (BR-116), e a segunda etapa em 2008, contemplando as rodovias Régis Bittencourt (BR-116), Fernão Dias (BR-381), e Transbrasiliana (BR-153).

Em cada uma dessas etapas, e para cada um dos poderes concedentes, os contratos de concessão apresentam diferenças significativas entre eles. As diferenças vão desde o critério de escolha da concessionária, o prazo de concessão, as melhorias previstas, até a taxa de retorno do investimento, dentre outros fatores que influenciam diretamente na tarifa de pedágio.

Dois são os principais motivos apontados pelos poderes concedentes do país para o aumento substancial das concessões nos últimos anos. O primeiro diz respeito à carência de investimentos do governo federal na infraestrutura de transportes que, conforme exposto pela CNT (2015), entre os anos de 1975 e 1995, apresentou uma queda substancial, saindo de uma proporção de $1,84 \%$ do PIB para apenas $0,14 \%$. A ARTESP (2016) justifica que "as concessões têm como finalidade suprir as necessidades de investimentos na infraestrutura de transportes, 
fundamentais ao desenvolvimento do Estado, bem como ao conforto e à segurança dos usuários".

O segundo motivo é a dificuldade alegada pelo poder público em conservar e operar as rodovias de forma eficaz, sendo dessa forma mais adequado entregar as atividades de operação e manutenção das rodovias a uma empresa privada. Estudos feitos pela NTC Logística (apud CNT, 2014) indicam que, no Brasil, rodovias com péssimo estado de conservação do pavimento podem aumentar os custos operacionais de veículos pesados em até 91,5\%. A CNT (2015) conclui que "a gestão privada de rodovias tem proporcionado ganhos significativos de qualidade nos trechos concessionados indicando, assim, que essa alternativa deve ser mais empregada em território nacional”.

Contudo, os vários modelos de concessão existentes acabam proporcionando diferenças no que tange especialmente aos valores pagos pelos usuários, e os benefício que os mesmo desfrutam, ou quanto tempo após o início da concessão esses benefícios são percebidos. Nesse sentido, sobre o programa de concessões no Brasil, a CNT (2015) destaca:

\footnotetext{
Ainda que o programa seja um instrumento estratégico para dar continuidade ao desenvolvimento de uma infraestrutura de transporte e logística integrada no Brasil e, portanto, importante para estimular o crescimento da economia nacional, são necessários ajustes. [...] Para a nova fase do programa, é relevante que os ajustes permitam que as obras previstas sejam efetivamente executadas dentro do prazo estabelecido. Ao mesmo tempo, o novo modelo deve permitir que as tarifas continuem garantindo o menor custo aos usuários.
}

Deve-se observar também que, apesar da aparente melhora na qualidade das rodovias concedidas, as mesmas ainda não se encontram em perfeito estado. A CNT (2015) informa que, durante a sua pesquisa, classificou $21,7 \%$ da extensão das rodovias concedidas como regular ou ruim, no estado geral das mesmas, enquanto que ao avaliar apenas o estado do pavimento, 20,5\% da extensão das rodovias concedidas foi classificada como Regular, Ruim ou Péssimo.

Ou seja, se considerarmos apenas a condição do pavimento, existem concessionárias que, apesar das exigências contratuais, entregam rodovias em condições insatisfatórias aos seus usuários, que além de pagar as tarifas de pedágio, arcam com os custos operacionais oriundos das deficiências no pavimento. Essa reflexão conduz à seguinte pergunta:

Como se comportam economicamente, do ponto de vista do usuário, os diversos modelos de contrato de concessão rodoviária no estado de São Paulo, ao considerar a condição do pavimento das rodovias? 


\subsection{OBJETIVO GERAL}

Avaliar o comportamento e as relações entre as tarifas (custos) e os benefícios dos usuários decorrentes da condição do pavimento, em diferentes modelos de concessão existentes no estado de São Paulo.

\subsection{OBJETIVOS ESPECÍFICOS}

a) Definir, através da análise de cluster, os locais selecionados para estudo;

b) Realizar a coleta de dados, pela internet, para realização das simulações;

c) Definir as hipóteses dos cenários de análise, dos quais derivam as estratégias de manutenção baseadas em parâmetros reais, para realização das análises econômicas;

d) Calcular os efeitos e os custos totais decorrentes, para os usuários, em cada estratégia de manutenção do pavimento, através do software HDM-4;

e) Identificar a evolução das tarifas de pedágio nos trechos selecionados;

f) Calcular os parâmetros utilizados para análise econômica (VPL, TIR e B/C);

g) Realizar uma avaliação econômica comparativa entre os diferentes modelos de concessão dos trechos selecionados

\subsection{ESTRUTURA DO TRABALHO}

O Capítulo 1 deste trabalho apresenta uma introdução ao tema proposto, contextualizando os motivos que justificam o desenvolvimento dessa pesquisa, e definindo os objetivos gerais e específicos desse trabalho.

O Capítulo 2 traz uma revisão com o histórico e características das concessões rodoviárias no mundo, no Brasil e no estado de São Paulo, bem como dos principais métodos para a análise econômica de projetos rodoviários.

O Capítulo 3 descreve o método utilizado para o desenvolvimento deste trabalho, destacandose: a seleção dos locais de estudo utilizando a análise de cluster; a aquisição de dados para realização de simulações no HDM-4; a definição dos cenários a serem avaliados na análise econômica; o cálculo dos efeitos dos usuários e seus respectivos custos; o cálculo das variáveis econômicas estabelecidas;

O Capítulo 4 faz uma análise crítica dos resultados obtidos, comparando os resultados com as diferenças básicas identificadas nos contratos de concessão, especialmente no que tange às obras de melhorias físicas e estruturais da rodovia, que geram grande impacto aos usuários.

O Capítulo 5, por fim, traz as conclusões obtidas através das análises dos resultados e de outras evidências apresentadas na revisão bibliográfica sobre as concessões rodoviárias. 


\section{REVISÃO BIBLIOGRÁFICA}

Embora existam pesquisas sobre concessões rodoviárias no país, a maioria se concentra em aspectos unicamente contratuais, estando presentes principalmente nos trabalhos de cursos como direito e economia. Este trabalho, portanto, buscou incorporar informações das mais variadas áreas do conhecimento, que pudessem de alguma forma contribuir para que o resultado dessa pesquisa tenha abrangência significativa, e traga discussões pertinentes tanto nos aspectos contratuais e econômicos, como também nos aspectos técnicos que envolvem a infraestrutura de rodovias concedidas. A revisão bibliográfica contida nesse capítulo traz informações que, primeiramente, contextualizam as concessões rodoviárias no Brasil, e então é destacada a importância da condição dos pavimentos rodoviários na análise dessas concessões, bem como a sua influência direta nos custos percebidos pelos usuários dessas rodovias.

\subsection{CONCESSÕES RODOVIÁRIAS}

A discussão sobre concessões rodoviárias é realizada a seguir, separando-se pelas concessões no mundo, no Brasil e no estado de São Paulo.

\section{a) Concessões Rodoviárias no Mundo}

$\mathrm{O}$ ato de se cobrar pedágios de pessoas que utilizam um determinado modo de transporte acompanha a humanidade já há bastante tempo, e as motivações da cobrança do mesmo variam consideravelmente ao longo da história. Andrews (2014) afirma que, através dos mais de 88 mil quilômetros de estradas construídas durante a existência do império romano, era possível encontrar tropas (conhecidas como stationarii e beneficiarii) que ofereciam segurança aos viajantes no patrulhamento das estradas. Por conta desse patrulhamento, essas tropas cobravam pedágios principalmente na travessia de pontes, passagens por montanhas ou nas fronteiras das províncias romanas.

Já na idade média, com a grande segmentação dos países em reinos menores, era comum a cobrança de pedágio apenas para que se realizasse a travessia das terras entre um reino e outro, ou mesmo a cobrança de pedágios em importantes rios, que permitiam o acesso a cidades com atividade comercial intensa. Um exemplo disso é o castelo de Loevestein, na Holanda, 
construído em 1361 no encontro dos rios Meuse e Waal, em posição estratégica para a cobrança de pedágios de navios.

No Estados Unidos, conforme exposto pelo FHWA (2016), após a Primeira Guerra Mundial e com a explosão econômica da década de 1920, onde metade das famílias do país dispunha de um automóvel, a cobrança de pedágio foi utilizada para auxiliar nos custos de construção das novas rodovias, pontes e túneis, necessários para atender a demanda crescente, sendo alguns exemplos o "Túnel Holland”, em Nova Iorque, e a "Ponte Golden Gate”, em São Francisco.

Contudo, a utilização de pedágios para recolher recursos para a construção de novas estruturas de transporte não foi repetida durante a renovação e ampliação da malha rodoviária dos EUA, nas décadas de 1950 e 1980, sendo em ambos os casos utilizados os recursos oriundos de impostos do governo federal.

Recentemente, o uso de rodovias com cobrança de pedágio foi intensificado nos Estados Unidos, porém principalmente no intuito de desestimular as viagens de automóveis realizadas em rodovias de intenso tráfego urbano, e sempre em rodovias de responsabilidade dos estados, como descrito pelo FHWA (2016).

Percebe-se atitude semelhante na Europa, onde o pedágio é utilizado muitas vezes como um instrumento de redução no tráfego. Um exemplo disso é o London Congestion Charge (Tarifa de Congestionamento de Londres). Em 2003, Londres adotou uma espécie de pedágio para a circulação de veículos automotores em sua área urbana, e conseguiu reduzir, até o ano de 2007, em $16 \%$ o tráfego dos veículos na área sujeita à tarifação, conforme exposto por Almeida e Oliveira (2013).

Em outros lugares pelo mundo, existem semelhanças e diferenças entre os modelos de concessão, especialmente no que se refere aos principais objetivos da concessão, e na participação do governo em todo o processo. No Japão, de acordo com Matsuda, Tsukada e Kikuchi (2005), o principal objetivo do governo durante o processo de concessões, realizado em 2003, foi promover o uso efetivo de rodovias, incentivando a mudança do tráfego de rodovias de uso geral para rodovias com pedágio, buscando dessa forma a redução do congestionamento e a melhoria na segurança viária do país. Buscou-se, portanto, melhorar a estrutura de algumas rodovias através do dinheiro obtido com o pedágio para realizar uma melhor distribuição do tráfego entre as diversas rodovias. 
Na Malásia, Ward e Sussman (2006) apontam vantagens e desvantagens no programa de concessões rodoviárias do país. As principais vantagens apontadas são o grande desenvolvimento da infraestrutura através das concessões, e a possibilidade de as empresas realizarem propostas para concessões de rodovias sem necessitarem da iniciativa do governo, o que permite uma maior agilidade no processo de concessão. Contudo, isso traz algumas desvantagens, sendo a principal delas a falta de transparência do governo, e a baixa participação popular nas tomadas de decisão.

Na América Latina, a experiência de concessões na Argentina começou no ano de 1990, com 13 concessões, de forma acelerada, por conta de erros de gestão e da hiper-inflação, que fizeram com que não houvessem verbas para o setor de infraestrutura do país. Dessa forma, segundo Nicolini (2002), de maneira simplificada, corredores que apresentassem Volume Diário Médio Anual (VDMA) superiores a 2000 veículos, foram concedidos. O critério para seleção das concessionárias foi o maior valor de outorga, os prazos de concessão iguais a 12 anos, e tiveram por objetivo minimizar os riscos comerciais, atrelando os reajustes das tarifas ao índice LIBOR (London InterBank Offered Rate).

Através dos diversos casos que foram descritos, percebe-se que há uma grande variação de todos os aspectos que envolvem as concessões rodoviárias no mundo todo. Nota-se, por exemplo, que os países com menor desenvolvimento econômico tendem a utilizar as concessões quando a situação econômica exige maiores investimentos, ou quando o próprio governo não consegue manter e operar as rodovias. Já em alguns países mais desenvolvidos, especialmente os EUA e países europeus, a cobrança de pedágio nas rodovias está diretamente relacionada ao controle de congestionamentos, na redução do tráfego em rodovias urbanas, e a captação de recursos para obras é mais frequente naquelas que demandam muito dinheiro, como pontes, túneis e viadutos.

Sendo assim, é importante questionar qual dessas realidades mais se adequa à realidade brasileira, quais modelos o Brasil vem seguindo ao longo dos anos, e quais as vantagens e desvantagens de se utilizar esses modelos. Para tanto, na sequência serão apresentadas as concessões rodoviárias existentes no Brasil. 


\section{b) Concessões Rodoviárias no Brasil}

O Programa de Concessão de Rodovias Federais (PROCROFE) do Brasil foi criado em 1993. $\mathrm{Na}$ época, o Brasil apresentava recentes mudanças políticas que impactaram significativamente nas ações adotadas pelo governo, como a constituição federal de 1988 e o primeiro presidente eleito - em 1989 - após o regime militar. Além disso, o país passava por uma crise econômica profunda, que só começou a ser controlada com o advento do plano Real, em 1994. A estabilidade gerada com a nova moeda, aliada à falta de recursos financeiros e as mudanças provocadas pela nova constituição, foram suficientes para que o governo federal implantasse o seu programa de concessões, com os primeiros contratos assinados em 1994.

O primeiro contrato de concessão assinado pelo governo federal, segundo a ABCR (2016) foi o da Ponte Rio-Niterói, em 29/12/1994. No mesmo ano, foram concedidas a Linha Amarela, no Rio de Janeiro, em parceria com esse município, e a Linha Azul, em Florianópolis, pelo governo do estado de Santa Catarina. No ano seguinte (1995), foi assinado o primeiro contrato de concessão de uma rodovia federal (Rodovia Presidente Dutra, BR-116). Os contratos assinados nesse período foram definidos como concessões da primeira etapa, e apresentaram grandes semelhanças entre si.

Ainda em 1995, a sanção da Lei n ${ }^{\circ} 9.277$ permitiu que a União delegasse a responsabilidade de algumas rodovias federais aos Estados, permitindo inclusive que esses estados realizassem a concessão dessas rodovias. As cobranças dos primeiros pedágios foram realizadas em $1^{\circ} \mathrm{de}$ agosto de 1996. Alguns meses antes, era criada a Associação Brasileira de Concessionárias de Rodovias - ABCR. Na sua criação, já contava com 7 concessionárias associadas.

Após alguns estados assumirem rodovias federais, em 1997 o Rio Grande do Sul e o Paraná realizaram concessões dessas rodovias. No Rio Grande do Sul, foi criada a AGERGS - Agência Estadual de Regulação dos Serviços Públicos Delegados do Rio Grande do Sul - responsável pela regulação e fiscalização das concessões no estado. No Paraná, essa responsabilidade permaneceu com o Departamento Estadual de Estradas de Rodagem (DER-PR) durante alguns anos, até a criação da AGEPAR - Agência Reguladora de Serviços Públicos Delegados de Infraestrutura do Paraná - em 2002, que passou a atuar somente em 2012.

O Estado de São Paulo implantou o seu programa de concessões de rodovias estaduais em 1998. Para essas concessões, o próximo item desse capítulo irá fornecer maiores detalhes. Após isso, em 2001, foi criada a ANTT - Agência Nacional de Transportes Terrestres - que passou a ser 
a responsável direta tanto pela regulação dos contratos existentes, como pela concessão de novos contratos, agindo como um braço do ministério dos transportes. A ARTESP - Agência Reguladora de Serviços Públicos Delegados de Transporte do Estado de São Paulo - foi criada em 2002, sendo a responsável pelas concessões rodoviárias do estado de São Paulo.

Após a criação da ANTT, o governo federal retomou as concessões rodoviárias somente em 2007, na segunda etapa de concessões. Nessa etapa foram concedidos 7 lotes, e os contratos já apresentavam diferenças significativas em relação aos da primeira etapa, principalmente em relação aos valores das tarifas de pedágio (com deságio das tarifas variando entre $27 \%$ e $65 \%$ ) e às sanções impostas pela ANTT em caso de descumprimento do contrato por parte das concessionárias. Destaca-se que dos 7 lotes concedidos, 5 foram adquiridos pelo grupo OHL (atualmente Arteris), configurando uma concentração do setor em uma única empresa.

O Estado de São Paulo retomou as suas concessões pouco tempo depois, em 2008, sendo delegados à iniciativa privada 6 lotes na segunda etapa do programa de concessões do estado. Novamente os lotes apresentaram algumas diferenças em relação à primeira etapa, embora menos significativas do que o que se apresentou nas concessões federais.

Em 2012, o governo federal lançou o PIL - Programa de Investimento em Logística - buscando investir em todos os modos de transporte, no objetivo de aumentar a competitividade da economia, escoar com eficiência a produção agrícola crescente, ampliar as exportações, dentre outros. Nesse sentido, em 2013, foi lançada a terceira etapa de concessões rodoviárias federais, novamente com diferenças substanciais em relação aos contratos das etapas anteriores.

As concessões federais vigentes no presente momento no estado de São Paulo são apresentadas na Tabela 1:

Tabela 1: Resumo das concessões federais no estado de São Paulo

\begin{tabular}{cccccc}
\hline Concessionária & Rodovia & $\begin{array}{c}\text { Assinatura do } \\
\text { contrato }\end{array}$ & $\begin{array}{c}\text { Prazo de } \\
\text { concessão }\end{array}$ & Etapa & Fase \\
\hline NovaDutra & BR-116 RJ/SP & $31 / 10 / 1995$ & 25 anos & $1^{\text {a }}$ & - \\
\hline Autopista Régis Bittencourt & BR-116 SP/PR & $14 / 02 / 2008$ & 25 anos & $2^{\text {a }}$ & 1 \\
\hline Autopista Fernão Dias & BR-381 MG/SP & $14 / 02 / 2008$ & 25 anos & $2^{\text {a }}$ & 1 \\
\hline Rodovia Transbrasiliana & BR-153 SP & $14 / 02 / 2008$ & 25 anos & $2^{\text {a }}$ & 1 \\
\hline & & \multicolumn{4}{c}{ Fonte: ANTT (2016) }
\end{tabular}

As diferenças entre os contratos de concessão existentes no governo federal foram abordadas por Caldeira e Rocha (2015), onde os contratos de cada etapa e cada fase foram analisados 
segundo algumas características (Tabela 2, somente com os modelos vigentes no estado de São Paulo). As características avaliadas foram: premissas (igual em todas as etapas); assunção de riscos (igual em todas as etapas); modelo de regulação; requisitos para início da cobrança de pedágio; revisão da tarifa básica de pedágio; reajuste da tarifa básica de pedágio; fontes de receitas; parâmetros de desempenho; desconto de reequilíbrio; obras condicionadas ao tráfego; fluxo de caixa marginal.

Tabela 2: Resumo das características dos contratos de concessão federal

\begin{tabular}{|c|c|c|}
\hline & Primeira Etapa & Segunda Etapa Fase 1 \\
\hline Premissas & $\begin{array}{l}\text { Equilíbrio econômico- } \\
\text { financeiro do contrato }\end{array}$ & $\begin{array}{l}\text { Equilíbrio econômico- } \\
\text { financeiro do contrato }\end{array}$ \\
\hline Assunção de Riscos & $\begin{array}{l}\text { Concessionária assume } \\
\text { integralmente riscos } \\
\text { inerentes à concessão }\end{array}$ & $\begin{array}{l}\text { Concessionária assume } \\
\text { integralmente riscos } \\
\text { inerentes à concessão }\end{array}$ \\
\hline Modelo de Regulação & Regulação pela TIR & Regulação pela TIR \\
\hline $\begin{array}{l}\text { Requisitos para início da cobrança } \\
\text { de pedágio }\end{array}$ & $\begin{array}{l}\text { Conclusão e aprovação } \\
\text { dos Trabalhos Iniciais }\end{array}$ & $\begin{array}{l}\text { Implantação de todas as } \\
\text { praças de pedágio; } \\
\text { conclusão dos trabalhos } \\
\text { iniciais; conclusão do } \\
\text { cadastro do passivo } \\
\text { ambiental }\end{array}$ \\
\hline Revisão da tarifa básica de pedágio & $\begin{array}{l}\text { Revisões anuais ou em } \\
\text { situações expressas em } \\
\text { contrato que impactem } \\
\text { na manutenção do } \\
\text { equilíbrio econômico- } \\
\text { financeiro do contrato }\end{array}$ & $\begin{array}{lr}\text { Revisão } & \text { ordinária } \\
\text { (anual); } & \text { revisão } \\
\text { extraordinária; } & \text { revisão } \\
\text { quinquenal } & \end{array}$ \\
\hline $\begin{array}{l}\text { Reajuste da Tarifa Básica de } \\
\text { Pedágio }\end{array}$ & $\begin{array}{l}\text { Índices de reajuste } \\
\text { relativos aos principais } \\
\text { componentes de custo } \\
\text { (terraplenagem, } \\
\text { pavimentação, obras- } \\
\text { de-arte especiais e } \\
\text { serviços de consultoria }\end{array}$ & $\begin{array}{l}\text { Reajuste pelo IRT } \\
\text { (IPCA) }\end{array}$ \\
\hline Fontes de Receitas & $\begin{array}{l}\text { Tarifas de Pedágio e } \\
\text { Fontes Extraordinárias }\end{array}$ & $\begin{array}{l}\text { Tarifas de Pedágio e } \\
\text { Fontes Extraordinárias }\end{array}$ \\
\hline Parâmetros de Desempenho & Não existem & $\begin{array}{l}\text { Sanções devido ao não } \\
\text { atingimento dos } \\
\text { parâmetros de } \\
\text { desempenho constantes } \\
\text { no PER }\end{array}$ \\
\hline
\end{tabular}

Fonte: adaptado de Caldeira e Rocha (2015) 
Deve-se destacar que uma característica importante ao se comparar contratos de concessão não foi abordada: o critério de escolha da concessionária, podendo ser o maior valor de outorga, ou a menor tarifa básica oferecida. Analisando as informações dessa tabela, é possível identificar uma maior ação regulatória nos contratos da segunda etapa de concessões, uma vez que existem requisitos mais elaborados para o início da cobrança de pedágio, as revisões das tarifas são bem definidas, e existe a cobrança de parâmetros de desempenho, determinados no PER (Programa de Exploração da Rodovia), que a concessionária deve atingir para não sofrer sanções por parte da ANTT.

Embora não apresentado nessa tabela, os contratos da terceira etapa de concessões trazem, dentre outras diferenças, a existência de fatores de produtividade, que ponderam as revisões das tarifas com a eficiência da concessionária na prestação de serviços, o que denota uma ação regulatória ainda maior.

\section{c) Concessões Rodoviárias no Estado de São Paulo}

Como já informado anteriormente, o programa de concessões do Estado de São Paulo teve início no ano de 1998, com a concessão de 12 lotes de rodovias estaduais. A Primeira Etapa, segundo a ARTESP (2016), totalizou 3600km de rodovias concedidas, em 170 municípios diferentes, e para uma população de 20 milhões de pessoas, cerca de metade da população do estado. O prazo das concessões era igual a 20 anos, e o critério de escolha das empresas vencedoras das licitações era o de maior outorga, ou seja, do maior valor pago, em 240 parcelas, ao poder concedente.

Já a Segunda Etapa de concessões trouxe algumas características diferentes em seus contratos. O prazo das concessões passou a ser de 30 anos, e o critério de escolha passou a ser a menor tarifa básica de pedágio ofertada, havendo também um valor fixo de outorga, que com os 6 lotes concedidos, arrecadou cerca de 5,5 bilhões de reais ao poder concedente. Além disso, ainda de acordo com a ARTESP (2016), as concessionárias seriam responsáveis pela manutenção de mais de $900 \mathrm{~km}$ de rodovias vicinais sem, contudo, cobrar pedágio nas mesmas.

Se considerarmos tanto as concessões estaduais como as concessões federais, o Estado de São Paulo hoje apresenta 287 municípios com acesso a pelo menos uma rodovia concedida, do total de 645 no estado. Esses municípios com acesso a rodovias concedidas acumulam um PIB total de mais de 1,5 trilhão de reais (PIB a preços correntes, para o ano de 2013), o que corresponde a $90 \%$ do PIB do estado, e a 30\% do PIB do Brasil, conforme valores consultados no IBGE 
(2016). Dessa forma, entende-se que as ações tomadas nessas rodovias têm um grande impacto em toda a economia, não somente do estado de São Paulo, como de todo o Brasil.

d) Cenário Atual e Perspectivas

Atualmente, no Brasil, existe uma forte tendência a se conceder a maior parte da responsabilidade pela infraestrutura dos diversos modos de transporte no país. Somente a segunda etapa do PIL prevê investimentos da ordem de 66 bilhões de reais em rodovias. A previsão para o ano de 2016 é que o governo federal conceda 11 lotes, num total de 7 mil km, abrangendo todas as 5 grandes regiões do Brasil. A evolução da malha rodoviária federal concedida desde o início do programa de concessões no Brasil pode ser vista na Tabela 3 a seguir:

Tabela 3: Percentual de rodovias concedidas pela União em relação ao total da malha pavimentada federal

\begin{tabular}{cccc}
\hline Etapa & Ano Base & \% & \% acumulado \\
\hline $1^{\text {a }}$ & 1997 & $2,6 \%$ & $2,6 \%$ \\
\hline $2^{\text {a }}$ & 2009 & $5,3 \%$ & $7,9 \%$ \\
\hline $3^{\text {a }}$ & 2013 & $8,1 \%$ & $16,0 \%$ \\
\hline
\end{tabular}

Fonte: adaptado de Zymler (2015)

No estado de São Paulo, de acordo com o DER (2016), esse percentual de rodovias concedidas hoje chega a aproximadamente $32 \%$ da malha estadual pavimentada (considerando o eixo das rodovias, os acessos e os dispositivos). A CNT (2015) aponta, contudo, que 19,7\% da extensão avaliada em sua pesquisa no estado de São Paulo apresentou alguma deficiência em relação ao pavimento. No Brasil, a classificação do Pavimento de acordo com a CNT é apresentada no gráfico da Figura 1:

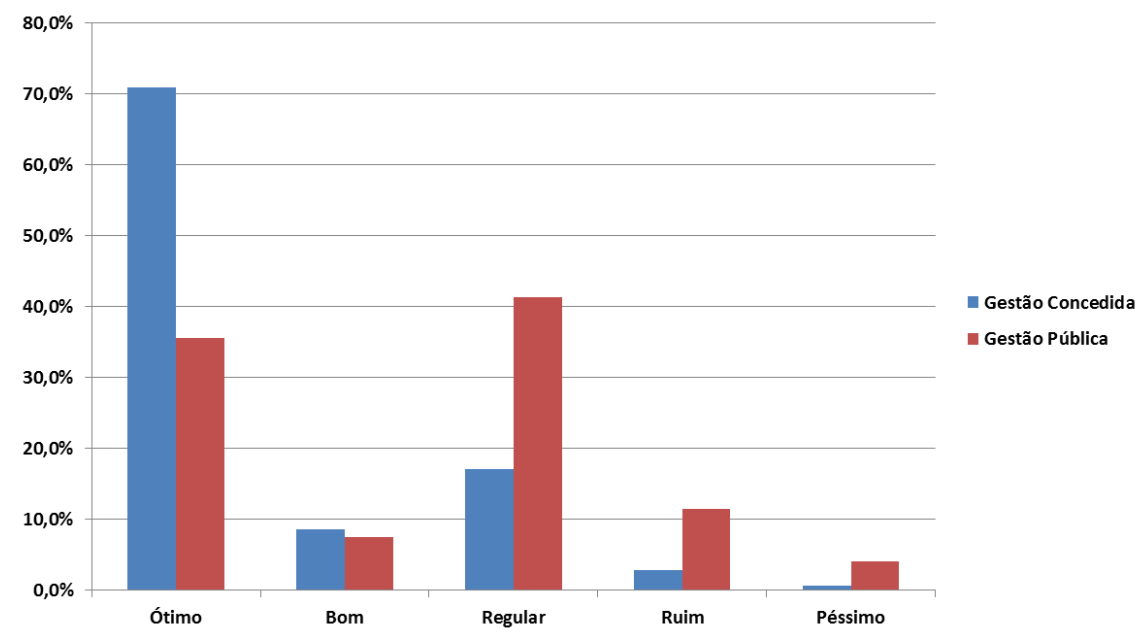

Figura 1: Classificação do pavimento das rodovias brasileiras, na extensão avaliada pela CNT (2014) 
Através dessa figura, é possível supor que, apesar das rodovias sob gestão concedida apresentarem resultados melhores do que as rodovias sob gestão pública, ainda existem problemas no pavimento de rodovias concedidas atualmente, o que permite que seja questionada a ação regulatória sobre essas concessões, e sobre o real benefício que elas proporcionam aos usuários. Como tudo indica que a tendência para os próximos anos seja a concessão ainda maior de trechos rodoviários, é necessário observar o comportamento das concessões, regidas sob diversos contratos distintos, a fim de se otimizar os contratos de concessão futuros.

\subsection{AVALIAÇÃO ECONÔMICA DE PROJETOS RODOVIÁRIOS}

a) Custos de Transporte

A avaliação dos custos de transporte de várias alternativas apresenta-se como uma importante ferramenta de tomada de decisão. Sinha e Labi (2007) definem que cada fase do processo de desenvolvimento de projetos de transporte envolve custos e benefícios ao operador, aos usuários e à comunidade como um todo. Na aplicação em pavimentos rodoviários, conforme explicam Haas, Hudson e Zaniewski (1994), esses custos podem se dividir da seguinte forma:

i. Custos do operador: custos de construção, manutenção e reabilitação; custos ou valores residuais ao final do período de projeto; engenharia e administração; custos de investimentos.

ii. Custos do usuário: tempo de viagem, operação dos veículos; acidentes; desconforto; atrasos e custos de operação extras em decorrência de recapeamento ou outras atividades de manutenção;

iii. Custos da comunidade: poluição do ar; poluição sonora; impactos de vizinhança.

Os mesmos autores indicam que os principais benefícios experimentados pela melhoria na condição dos pavimentos estão diretamente relacionados à redução dos custos de transporte ao usuário, e para se determinar esses benefícios, primeiramente é necessário definir quais características influenciam nos custos previamente listados (operação dos veículos, tempo de viagem, acidentes e desconforto). As medidas com maior influência para a determinação dos benefícios aos usuários são a estratégia de manutenção e a aderência do pavimento. A Figura 2 ilustra o impacto de diferentes estratégias de manutenção do pavimento no custo do usuário. 


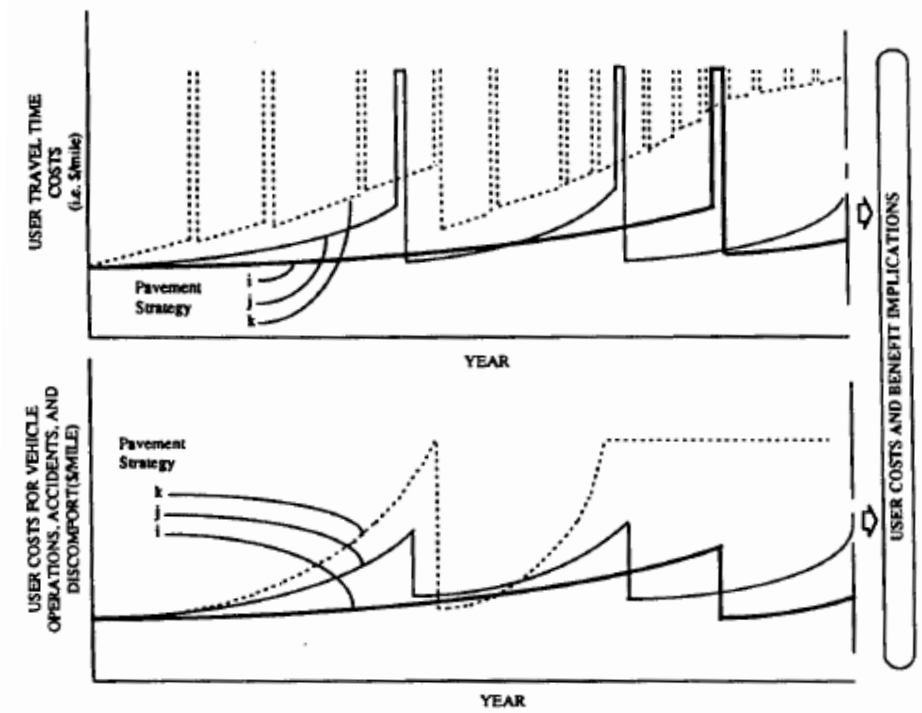

Figura 2: Efeitos das estratégias de manutenção dos pavimentos nos custos dos usuários (Haas, Hudson e Zaniewsky, 1994)

Essa figura exibe dois aspectos importantes em relação aos custos dos usuários. O primeiro diz respeito às intervenções no pavimento, onde uma frequência de intervenções muito alta gera maiores custos aos usuários devido ao tempo de viagem. O segundo se refere aos custos elevados das intervenções quando se excede os limites de serviço mínimos dos pavimentos. De forma resumida, a figura indica que as condições que minimizam os custos dos usuários são um pavimento projetado para uma grande durabilidade, que necessite de poucas intervenções ao longo de sua vida útil, e cujas intervenções ocorram em momentos onde os níveis de serviço mínimo não tenham sido atingidos.

Complementarmente, Sinha e Labi (2007) indicam também fatores que afetam o custo operacional dos veículos, sendo listados:

- Tipo de veículo;

- Tipo de combustível;

- Rampa;

- Velocidade do veículo;

- Atrasos;

- Mudanças de velocidade;

- Curvatura horizontal;

- Condição da superfície da rodovia.

b) Métodos de Avaliação Econômica de Projetos

Considerando o exposto por Haas, Hudson e Zaniewsky (1994) e por Hirschfeld (2007), temse os métodos mais empregados para a avaliação econômica de projetos, listados a seguir. 
i. $\quad$ Valor Presente Líquido (VPL)

O VPL consiste num método onde todas as receitas (por convenção, com sinal positivo) e despesas (sinal negativo) em um determinado fluxo de caixa são trazidas a um valor no presente, considerando determinada taxa de desconto (ou taxa mínima de atratividade). Se o VPL for negativo, o projeto analisado é inviável, pois os custos (ou as despesas) superam os benefícios (ou as receitas). Se o VPL for igual a 0 , todas as receitas irão somente anular as despesas, e nesse caso identifica-se a Taxa Interna de Retorno (TIR), explanada posteriormente. Se o VPL for maior do que 0 , tem-se um projeto economicamente viável, e no caso de vários projetos com VPLs positivos, seleciona-se aquele que apresentar o maior valor.

Entre os projetos, podem existir diferentes períodos de duração. Como, de acordo com Hirschfeld (2007), a Engenharia Econômica compara sempre alternativas de durações iguais, nos casos com diferentes durações são apresentadas duas soluções. A primeira solução é a de cortar somente parte de uma alternativa (ou de todas) para análise. A segunda solução consiste em adotar como duração final comum das alternativas o mínimo múltiplo comum das durações originais.

ii. Taxa Interna de Retorno (TIR)

O conceito básico da TIR é expresso na seguinte fórmula:

$$
V P C=V P B
$$

Onde:

VPC $=$ Valor Presente dos Custos;

$\mathrm{VPB}=$ Valor Presente dos Benefícios.

Ou seja, a TIR é a taxa que, aplicada a um determinado fluxo de caixa, iguala os benefícios e os custos trazidos a um valor presente, sendo por consequência a taxa de desconto onde o VPL é igual a 0. A TIR não somente é comparada entre as diferentes alternativas, como também, em geral, deve ser comparada com outras taxas de juros de investimentos, como por exemplo, a Taxa Mínima de Atratividade (TMA). Se a TIR for superior a TMA, isso indica que, para o investidor, esse projeto é vantajoso, e com grandes chances de trazer benefícios econômicos maiores do que ele iria experimentar com a outra alternativa de investimento. 


\section{iii. Relação Benefício/Custo (B/C)}

O método da Relação B/C é, segundo Haas, Hudson e Zaniewsky (1994) o método de uso mais difundido dentro das avaliações de rodovias. A relação B/C pode ser tanto a razão do Valor Presente de todos os benefícios pelo valor presente de todos os custos, como também pode ser a razão de cada benefício anual pelo respectivo custo. De qualquer forma, embora seja possível calcular a relação $\mathrm{B} / \mathrm{C}$ isoladamente, o que se recomenda é que seja realizada uma análise incremental, ou seja, que os custos sejam ordenados de forma crescente (começando pela alternativa "não fazer nada", de custo 0 e benefício também 0 ), e o cálculo da relação B/C seja feito sempre entre as alternativas com os custos sucessivamente maiores, até que calcule para a alternativa com maior custo, e se determine a alternativa com a maior relação B/C. A Tabela 4 fornece um exemplo de cálculo da relação B/C pela análise incremental.

Tabela 4: Exemplo de cálculo da relação B/C pela análise incremental

\begin{tabular}{cccccc}
\hline Alternativa Benefício & Custo & $\Delta \mathbf{B}$ & $\Delta \mathbf{C}$ & $\Delta \mathbf{B} / \Delta \mathbf{C}$ \\
\hline A & 10 & 5 & $10-0=10$ & $5-0=5$ & 2 (por ser alternativa padrão, =1) \\
B & 12 & 8 & $12-10=2$ & $8-5=3$ & $2 / 3=0,67<1$ (prevalece A) \\
C & 20 & 12 & $20-12=8$ & $12-8=4$ & $8 / 4=2>1$ (maior que o padrão, \\
prevalece C)
\end{tabular}

Pelo exemplo dado na Tabela, nota-se que se fossem consideradas as relações B/C individuais, a solução seria a alternativa "A". Porém, pela análise incremental, a melhor alternativa é a "C", por apresentar relação B/C maior do que 1 (viável economicamente), e por oferecer a maior relação $\Delta \mathrm{B} / \Delta \mathrm{C}$ em comparação às outras alternativas isoladamente consideradas. Segundo Hirschfeld (2007), essa alternativa irá apresentar também a maior taxa de retorno, o maior VPL o qualquer outro resultado, independentemente do método que se escolha para análise.

c) Modelos de Determinação dos Custos Operacionais

Alguns dos modelos para a determinação dos custos operacionais dos usuários são descritos por Sinha e Labi (2007) a seguir. 


\section{i. $\quad$ Método da AASHTO}

O pacote da AASHTO intitulado AASHTO's User Benefits Analysis for Highways (AASHTO, 2003), ou em tradução livre “Análise de Benefícios dos Usuários para Rodovias” estima os impactos da segurança, tempo de viagem e dos custos operacionais dos veículos, separando os custos operacionais em duas categorias: combustível e outros. Os custos contidos em "outros" são valores médios de um estudo realizado anteriormente. Já os custos de combustível são determinados por uma função, também determinada em estudos anteriores, que depende do tipo de veículo e da velocidade do mesmo,

\section{ii. Método HERS}

O método HERS (FHWA, 2002) calcula os custos de operação dos veículos com base em 5 componentes: consumo de combustível, consumo de lubrificantes, desgaste de pneus, manutenção e depreciação. A determinação dos custos é dada em função de fatores tais como velocidade, mudança de velocidade, curvas horizontais e tipo de veículo. Da mesma forma que o Método da AASHTO, o HERS utilizou parâmetros estabelecidos por diversos estudos, especialmente os preços e taxas de consumo de combustível estabelecidos por Zaniewski (1982).

\section{iii. HDM-4}

Desenvolvido pelo Banco Mundial, o HDM (do inglês Highway Development and Management), de acordo com Klein (2005), baseou-se em informações de países em desenvolvimento, como o Quênia, a Índia e o Brasil. Os fatores utilizados para a determinação dos custos são a rampa, irregularidade do pavimento, textura superficial mudança de velocidade, congestionamento e velocidade.

Algumas das principais aplicações do HDM-4 apontadas por Klein (2005) são a comparação de estimativas de custos e avaliações entre diversas alternativas de construção, manutenção e estratégias de intervenção, na formação de sistemas de gerência de pavimentos (SGP). Além disso, o HDM permite também a análise de sensibilidade de resultados, em função de mudanças nos parâmetros mais importantes do modelo.

A Figura 3 mostra a estrutura básica do HDM-4, composta pelas Ferramentas de Análise, Gerenciador de Dados e pelos Modelos. Os três modelos apresentados na Figura são:

- RDWE: Efeitos da deterioração das rodovias e das intervenções;

- RUE: Efeitos sobre os usuários; 
- SEE: Efeitos Ambientais, Energéticos e na Segurança

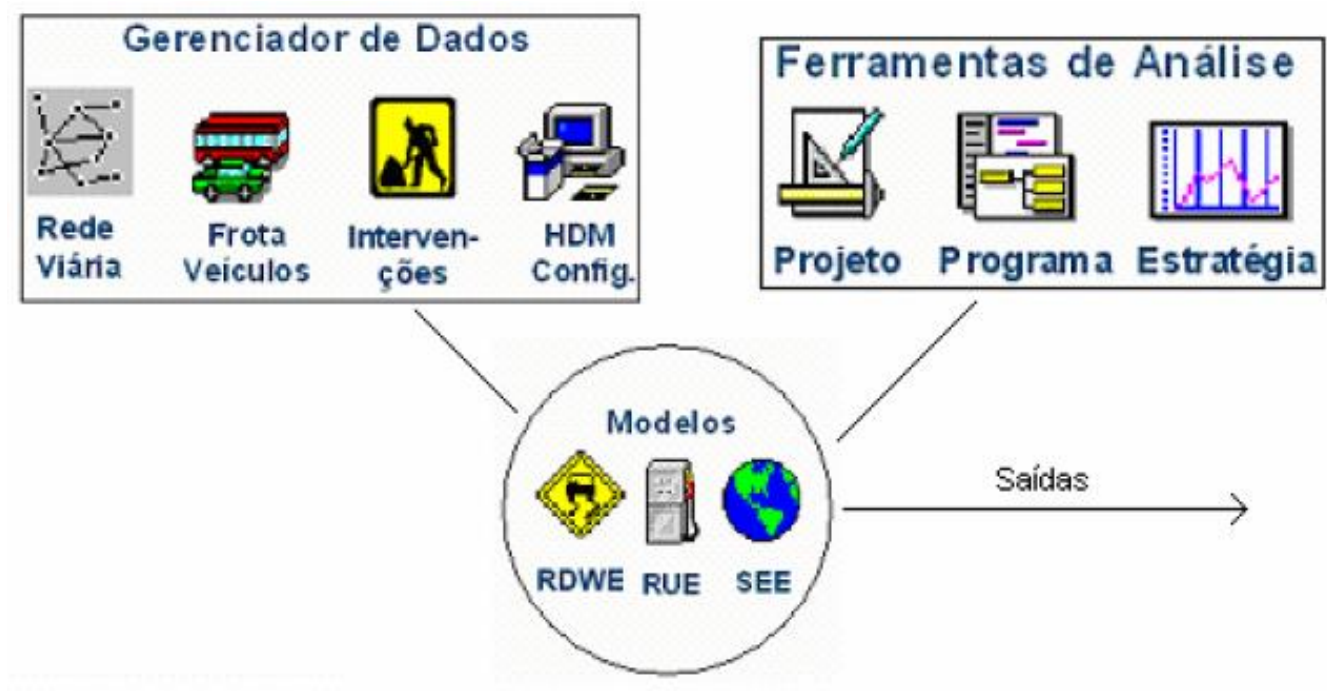

Figura 3: Estrutura do HDM-4 (Klein, 2005)

Dos modelos listados, o modelo que realiza o cálculo dos custos operacionais dos veículos é o RUE, compreendendo também os custos de tempo de viagem (tanto para passageiros, como para os veículos de carga), e os custos relacionados a acidentes. 


\section{MÉTODO}

\subsection{AQUISIÇÃO DOS DADOS E SELEÇÃO DOS SEGMENTOS RODOVIÁRIOS PARA ESTUDO}

Embora hoje, no Brasil, existam concessões rodoviárias em 12 dos 26 estados da federação, bem como uma concessão que abrange o território do Distrito Federal, para o desenvolvimento dessa pesquisa optou-se por trabalhar somente com as rodovias concedidas do estado de São Paulo, totalizando 23 concessões. Um dos principais motivos para se avaliar as concessões paulistas é que as mesmas apresentam os mais variados modelos possíveis, contribuindo dessa forma para que se atinjam os objetivos propostos.

Uma vez que, conforme já definido anteriormente, existem 3 modelos básicos de concessão das rodovias existentes em São Paulo - modelo da ARTESP e modelos da primeira e da segunda etapas da ANTT - torna-se necessário selecionar ao menos um segmento rodoviário de cada modelo. Para realizar isso, e por se tratar de um trabalho que visa estabelecer comparativos entre modelos distintos, é importante que sejam selecionados trechos com características parecidas.

Como a malha rodoviária concedida em São Paulo totaliza cerca de 6,5 mil km, e de modo a utilizar dados padronizados para toda essa malha, a seleção dos locais de estudo foi realizada através dos dados de tráfego nas praças de pedágio, disponível no endereço eletrônico do Departamento de Estradas de Rodagem de São Paulo (DER-SP), e complementado com as informações disponíveis nos relatórios anuais da ANTT.

Os dados constantes no site do DER-SP informam os Volumes Diários Médios (VDM) em cada praça de pedágio das concessões da ARTESP, entre os anos de 2012 e 2014, estando esses volumes divididos por "Veículos de Passeio" e "Veículos Comerciais". O VDM nas praças de pedágio também é disponibilizado nos relatórios anuais da ANTT, até o ano de 2013. Dessa forma, foi possível unir, em uma única planilha, informações tanto das concessões estaduais como das concessões federais. De posse dessas informações, foi possível classificar e formar grupos com todos os elementos do banco de dados, utilizando a Análise de Cluster, e com os grupos formados, selecionar os locais de estudo da pesquisa, usando como critério a semelhança das características físicas e operacionais. 
A Análise de Cluster é definida por Hair et al (2009) como um grupo de técnicas multivariadas que tem como principal objetivo agregar objetos, considerando as características que os mesmos possuem. O principal objetivo dessa técnica é a formação de grupos, onde os elementos de um mesmo grupo apresentem a máxima semelhança entre si, e que os diferentes grupos formados sejam heterogêneos. As Figuras 4 e 5 mostram a formação de clusters de dados aleatórios, representados em gráficos de dispersão, usando duas variáveis.

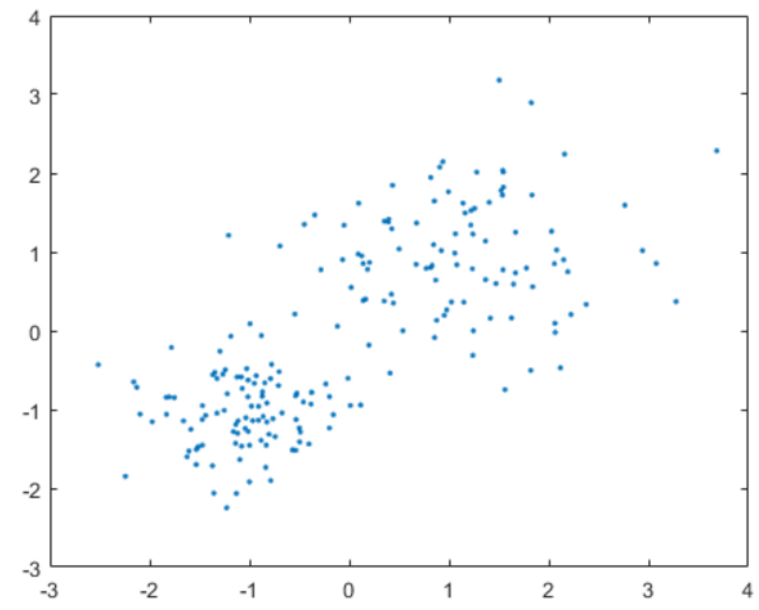

Figura 4: Gráfico de dispersão de dados aleatórios (Mathworks, 2016)

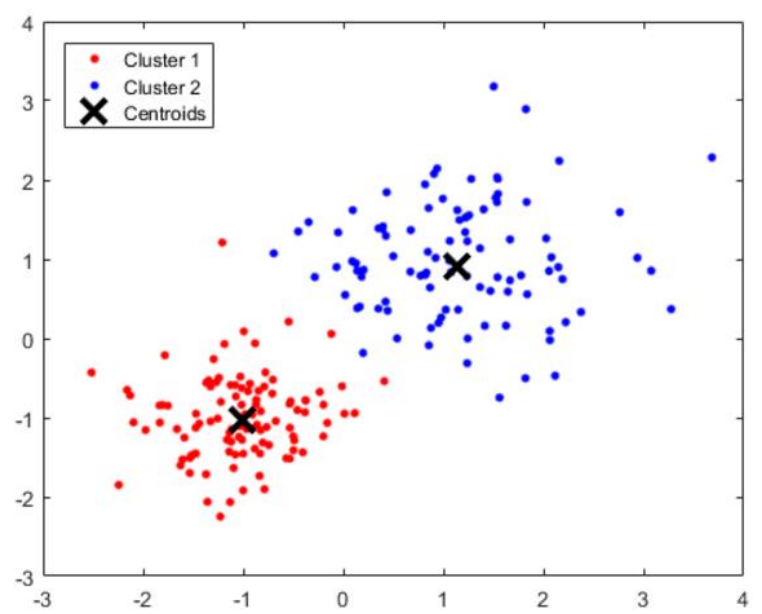

Figura 5: Gráfico indicativo dos clusters formados (Mathworks, 2016)

As etapas e as principais considerações de uma Análise de Cluster, definidas por Hair et al (2009), são descritas nos itens a seguir, onde também se indica quais valores e procedimentos foram assumidos no desenvolvimento dessa pesquisa. Foram utilizados dois softwares na elaboração dos clusters: para as análises utilizando o procedimento hierárquico, foi utilizado o SPSS; para as análises com o procedimento não-hierárquico, foi utilizado o software Matlab.

a) Seleção de variáveis e de medidas de distância

A correta seleção das variáveis a serem utilizadas no procedimento de agrupamento é de suma importância para o resultado da análise, uma vez que a técnica não permite identificar quais variáveis são relevantes ou não, e que variáveis incluídas de forma errônea podem gerar resultados que não são confiáveis.

Dessa forma, a seleção das variáveis deve ser criteriosa, e se basear tanto em conceitos teóricos como em resultados práticos avaliados. Além disso, a escala das variáveis selecionadas também deve ser avaliada, uma vez que variáveis com grandes dispersões (alto desvio-padrão) tendem a influenciar mais na formação dos grupos. Quando essa influência não é desejada, os valores 
das variáveis podem ser normalizados (convertendo cada score de dados iniciais em um valor padronizado, com média 0 e desvio-padrão 1), ou padronizados (ordenando todos os valores, onde o maior da série passa a ser 1 , e o menor passa a ser 0 ), assumindo dessa forma uma única escala.

Além da seleção das variáveis e da avaliação de suas escalas, outro aspecto importante a ser observado é a medida de distância entre os elementos. As três mais utilizadas são:

i) Distância euclidiana: distância em linha reta, entre dois pontos. Medida mais utilizada;

ii) Distância euclidiana quadrada: soma dos quadrados das diferenças dos valores das coordenadas de dois pontos. Medida de distância recomendada para métodos de agrupamento centroide e Ward;

iii) Distância city-block (de Manhattan): soma das diferenças absolutas entre dois pontos. Procedimento não recomendado para variáveis altamente correlacionadas;

Para a seleção dos trechos rodoviários que seriam avaliados nessa pesquisa, foram utilizadas duas variáveis, extraídas do site do DER-SP e dos Relatórios Anuais da ANTT: VDM Total (veículos de passeio e comerciais), e proporção de veículos comerciais (em \%), para os anos de 2012 e 2013, sendo ambas características operacionais de cada segmento rodoviário. Como não foram encontrados dados numéricos que descrevessem as características geométricas em todos os segmentos rodoviários, essa análise foi feita de forma subjetiva, após a formação dos clusters com as características operacionais.

As variáveis indicadas foram selecionadas por estarem disponíveis publicamente e incorporarem as rodovias concedidas de São Paulo quase na totalidade, além de serem importantes indicadores do comportamento operacional da rodovia, e também por sofrerem grandes variações entre os diversos segmentos rodoviários. Em relação à escala dessas variáveis, como não é possível afirmar qual é mais importante na análise que pretende ser realizada, optou-se por compatibilizar as escalas através da normalização das duas variáveis. Dentre as medidas de distância listadas, o Matlab utiliza como padrão a distância euclidiana quadrada, e optou-se por manter essa definição do software, uma vez que não se tem uma experiência prévia específica, para o conjunto de dados avaliado, da medida de distância ideal. 
b) Seleção do procedimento de agrupamento e validação dos clusters

A Análise de Cluster pode ser realizada através de dois procedimentos de agrupamento básicos: o procedimento hierárquico e o procedimento não-hierárquico. O procedimento hierárquico é uma forma de se realizar agrupamentos que visa formar uma estrutura de hierarquia, ou do tipo árvore, e pode ser dividido nos métodos divisivo ou aglomerativo. $\mathrm{O}$ método diviso parte de um único grupo, contendo todos os objetos de um banco de dados, e vai se dividindo até que cada objeto seja o seu próprio grupo. Já o método aglomerativo faz o oposto, saindo de um número de grupos igual ao número de objetos, e aglomerando esses grupos até que todos formem um único grupo com todas as observações.

O procedimento hierárquico é representado graficamente pelo "dendograma" (Figura 6), onde são apresentadas todas as observações, e em qual distância elas se juntaram ou se dividiram de um determinado agrupamento. As principais vantagens de se utilizar esse método são a sua rapidez e simplicidade, e o fato de apresentar todas as soluções em um único gráfico. Contudo, grandes amostras podem dificultar a interpretação de resultados, uma vez que o gráfico gerado ocupa um espaço muito grande, além de aumentar o espaço de processamento necessário.

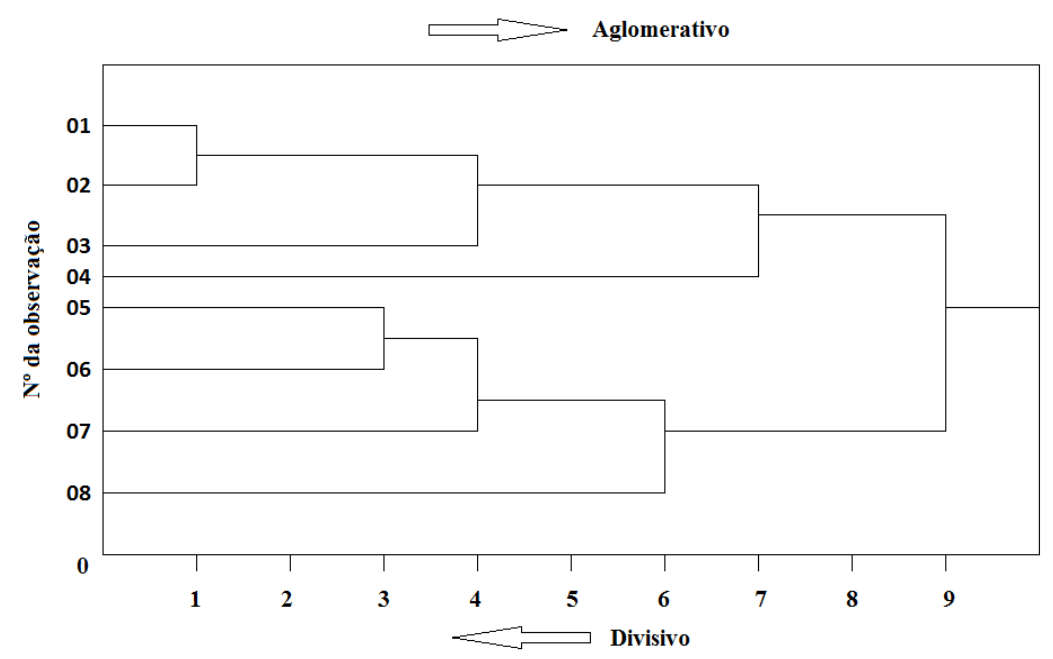

Figura 6: Exemplo de um dendograma, com a indicação dos métodos aglomerativo e divisivo (adaptado de Hair et al, 2009)

O procedimento não-hierárquico, por sua vez, caracteriza-se por ser um procedimento iterativo, onde após a determinação do número de clusters que devem ser formados definem-se, de forma aleatória ou com conhecimento prévio, sementes iniciais (centroides) para a atribuição dos elementos que apresentem maior similaridade aos respectivos clusters, sendo o centroide recalculado até que não existam mais observações re-atribuídas. 
De forma oposta ao procedimento hierárquico, o procedimento hierárquico pode ser utilizado em grandes bancos de dados, o que se apresenta como uma vantagem. Em contrapartida, esse procedimento não apresenta todas as soluções possíveis para o banco de dados, somente para o número de clusters e para as sementes iniciais pré-definidas.

Como pode ser observado, as diferenças entre os procedimentos não os tornam exclusivos, e sim complementares, podendo ser feitas análises em um mesmo banco de dados utilizando tanto o procedimento hierárquico como o não-hierárquico, como destaca Hair et al (2009). Sendo assim, ambos os procedimentos foram utilizados nessa pesquisa. Primeiramente, por se tratar de um banco de dados onde não se tinha um conhecimento de um padrão inicial do comportamento das variáveis, utilizou-se do procedimento hierárquico para avaliar todas as possíveis soluções.

Embora se trate de um banco de dados com um número elevado para esse procedimento, num total de 267 observações, foi possível extrair respostas quanto ao intervalo de grupos que poderiam ser gerados com esses dados. As Figuras 7 e 8 apresentam gráficos que mostram as distâncias e os agrupamentos gerados em cada dendograma, para os dados referentes aos anos de 2012 e 2013.

\section{Interpretação do Dendograma}

(Dados de 2012)

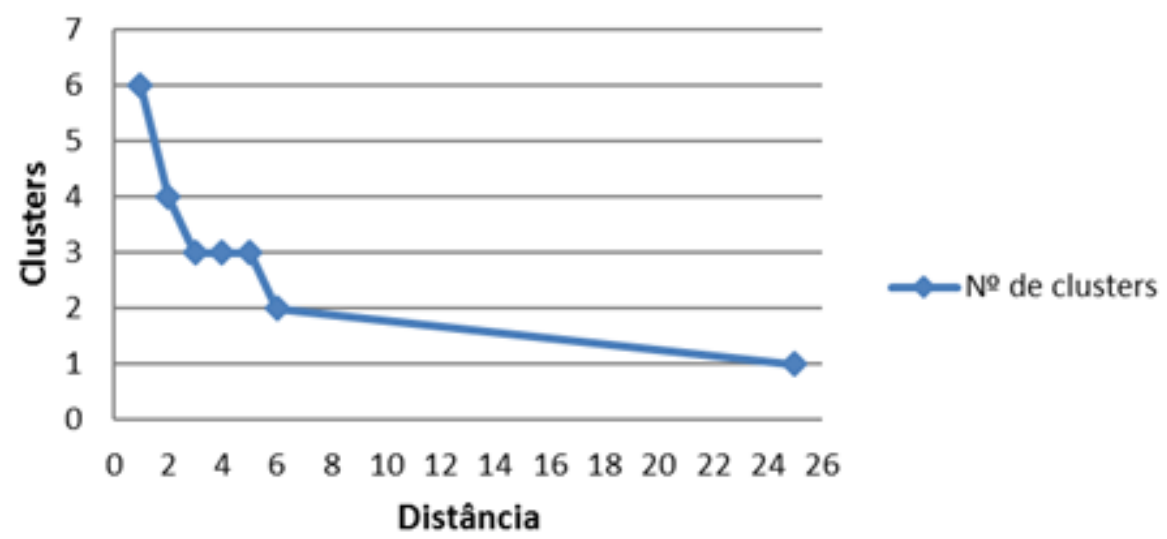

Figura 7: Gráfico interpretativo do dendograma gerado (dados de 2012) 
Interpretação do Dendograma

(Dados de 2013)

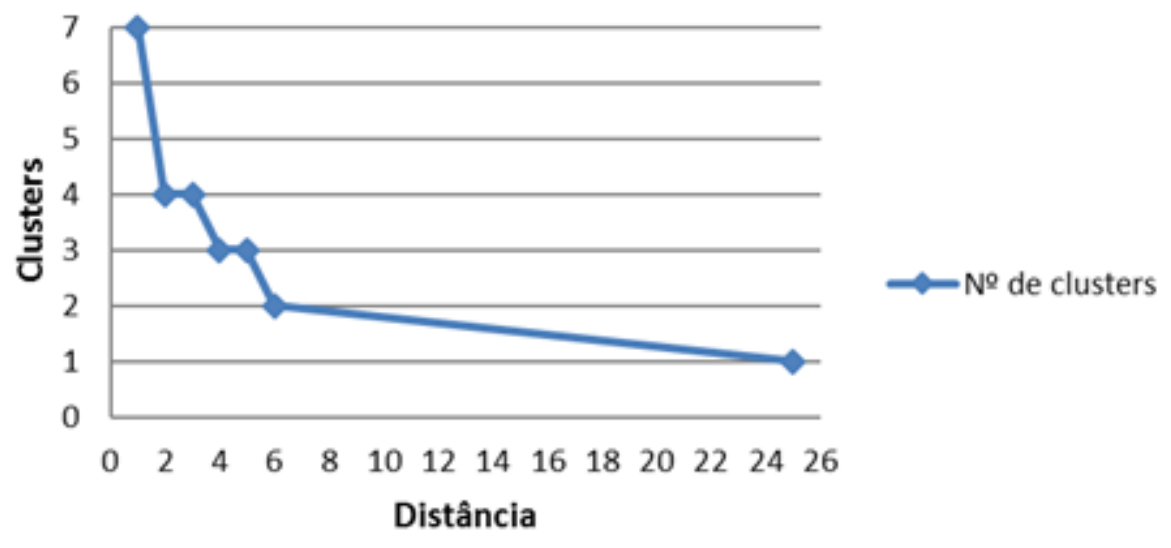

Figura 8: Gráfico interpretativo do dendograma gerado (dados de 2013)

Para o ano de 2012, o maior número de agrupamentos gerados foi 6, e o intervalo que apresentou maior "ganho" em relação à distância foi entre 6 e 4 clusters. Para o ano de 2013, o resultado foi semelhante: o número máximo de agrupamentos foi 7 , e o maior ganho ocorreu entre 7 e 4 clusters. Embora seja possível realizar simulações para um variado número de clusters, os resultados dos dendogramas indicam uma forte tendência dos melhores agrupamentos possuírem entre 4 e 7 grupos, delimitando dessa forma as análises feitas pelo procedimento não-hierárquico.

Para o procedimento não-hierárquico, foram realizadas simulações contendo entre 2 e 7 clusters, para os dados dos anos 2012 e 2013, e em todas as simulações, usando a ferramenta $k$ means do Matlab, a medida de distância definida foi a euclidiana quadrada (padrão do software), e as sementes iniciais foram aleatórios, realizando-se 1000 repetições das mesmas até que o software encontrasse o melhor agrupamento. Tendo essas definições, procedeu-se então com a geração dos clusters, onde além de agrupar cada elemento do banco de dados, foi determinada também a silhueta média de cada simulação realizada para a validação dos clusters.

A silhueta média é definida por Everitt, Landau e Leese (2001) como uma medida da qualidade de clusters, que varia entre - 1 e 1, onde valores próximos de 1 indicam que um elemento está no cluster apropriado, e valores próximos a -1 indicam que o elemento, em tese, deveria estar incluído em outro cluster. Dessa forma, o melhor agrupamento é aquele cuja silhueta média de todos os elementos de todos os clusters seja o mais próximo possível de 1. A Tabela 5 exibe os valores das silhuetas médias para cada simulação realizada. 
Tabela 5: Silhuetas médias das simulações realizadas

\begin{tabular}{ccccccccc}
\hline $\begin{array}{c}\text { Ano } \\
\text { base }\end{array}$ & $\mathbf{2}$ & $\mathbf{3}$ & $\mathbf{4}$ & $\mathbf{5}$ & $\mathbf{6}$ & $\mathbf{7}$ & Média \\
\hline 2012 & 0,640 & 0,605 & 0,625 & 0,582 & 0,607 & 0,626 & $\mathbf{0 , 6 1 4}$ \\
2013 & 0,649 & 0,616 & 0,627 & 0,602 & 0,606 & 0,624 & $\mathbf{0 , 6 2 1}$ \\
\hline
\end{tabular}

Percebe-se uma variação pouco significativa entre os resultados para os dois anos avaliados, resultado esperado uma vez que a variação de tráfego e da proporção de veículos comerciais entre esses dois anos foi pequena. O agrupamento para o ano de 2013, em média, foi superior, e por isso a seleção dos locais de estudo foi feita considerando os dados e os clusters desse ano.

A maior silhueta e que, portanto, indica o melhor agrupamento gerado para o ano de 2013, ocorreu quando foram gerados 2 grupos. Ao analisar os grupos formados, percebe-se contudo que somente 2 clusters são insuficientes para uma correta avaliação de segmentos comparáveis, uma vez que essa simulação agrupa elementos com características muito diferentes. A segunda maior silhueta média encontrada ocorre na formação de 4 grupos. Os clusters formados nesse caso são representados em um gráfico de dispersão, mostrado na Figura 9.

\section{GRÁFICO DE DISPERSÃO DOS DADOS, COM OS CLUSTERS FORMADOS}

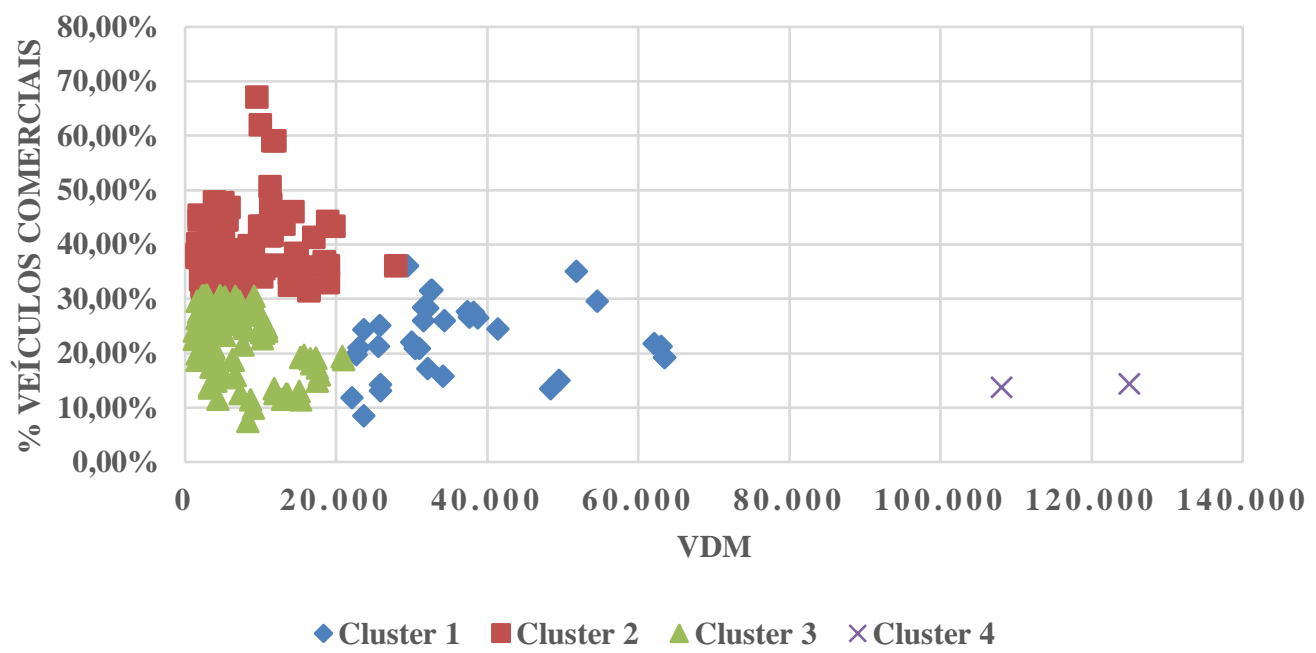

Figura 9: Gráfico de dispersão dos dados e clusters formados (4 clusters, dados de 2013) 
Quando formados 4 grupos, já se torna possível identificar padrões quanto às variáveis analisadas, podendo cada cluster ser descrito da seguinte forma:

- Cluster 1: VDM alto, proporção de veículos comerciais de baixa a moderada;

- Cluster 2: VDM de baixo a moderado, proporção de veículos comerciais alta;

- Cluster 3: VDM de baixo a moderado, proporção de veículos comerciais de baixa a moderada;

- Cluster 4: VDM muito alto, proporção de veículos comerciais de baixa a moderada.

Com exceção do Cluster 4, onde existem somente dois elementos com VDMs muito maiores do que os demais elementos do banco de dados (os dois elementos são referentes a um trecho da Rodovia Castelo Branco, em Osasco e Barueri, cidades da região metropolitana de São Paulo), os outros 3 clusters permitem realizar avaliações e definir locais com características semelhantes.

Além das características já apontadas, como o objetivo desse trabalho é a comparação entre diferentes modelos de contrato no estado de São Paulo, os clusters gerados deveriam conter pelo menos um trecho rodoviário de cada modelo existente. Isso ocorreu somente com os clusters 1 e 2, não sendo possível dessa forma usar os elementos constantes no cluster 3 .

Com os clusters definidos, foram selecionados elementos que apresentassem a maior similaridade entre as duas variáveis utilizadas no agrupamento (VDM e proporção de veículos comerciais), ou seja, cujas características operacionais fossem semelhantes e que permitissem análises comparativas. Além disso, verificou-se também se os trechos avaliados eram compatíveis em relação à geometria da via, fazendo uma análise subjetiva das imagens aéreas dos trechos, disponíveis no aplicativo Google Maps.

Considerando tanto as características operacionais, com os clusters formados, como o traçado das rodovias pela análise de imagens aéreas, foi possível chegar em dois conjuntos de possíveis trechos que podem ser estudados, sendo os mesmos apresentados nas Tabelas 6 e 7 .

Tabela 6: trechos pré-selecionados para estudo, cluster 1

\begin{tabular}{cccccccc}
\hline Concessionária & Contrato & Rodovia & Denominação & Km & Cidade & VDM & $\begin{array}{c}\text { \% } \\
\text { comerciais }\end{array}$ \\
\hline Viaoeste & ARTESP-1 & SP 075 & José Ermírio de Moraes & 12,5 & Sorocaba & 30.041 & $22 \%$ \\
Viaoeste & ARTESP-1 & SP 280 & Castelo Branco & 74 & Itu & 31.599 & $28 \%$ \\
NovaDutra & ANTT-1 & BR 116 & Dutra & 204 & Arujá & 31.589 & $26 \%$ \\
Autopista Fernão Dias & ANTT-2 & BR 381 & Fernão Dias & 65,7 & Mairiporã & 30.467 & $21 \%$ \\
\hline
\end{tabular}


Tabela 7: trechos pré-selecionados para estudo, cluster 2

\begin{tabular}{cccccccc}
\hline Concessionária & Contrato & Rodovia & Denominação & Km & Cidade & VDM & $\begin{array}{c}\text { \% } \\
\text { comerciais }\end{array}$ \\
\hline Rota das Bandeiras & ARTESP-2 & SP 065 & Dom Pedro I & 79,9 & Atibaia & 18.376 & $37 \%$ \\
Centrovias & ARTESP-1 & SP 310 & Washington Luiz & 181,35 & Rio Claro & 14.325 & $36 \%$ \\
Intervias & ARTESP-1 & SP 330 & Anhanguera & 181,76 & Leme & 14.811 & $38 \%$ \\
NovaDutra & ANTT-1 & BR 116 & Dutra & 182 & Guararema & 18.961 & $33 \%$ \\
Autopista Fernão Dias & ANTT-2 & BR 381 & Fernão Dias & 7,6 & Vargem & 15.543 & $36 \%$ \\
$\begin{array}{c}\text { Autopista Régis } \\
\text { Bittencourt }\end{array}$ & ANTT-2 & BR 116 & Régis Bittencourt & 298,8 & $\begin{array}{c}\text { Lourenço da } \\
\text { Serra }\end{array}$ & 14.240 & $46 \%$ \\
\hline
\end{tabular}

As concessões listadas na Tabela 6 contemplam locais com grande urbanização, estando as praças de pedágio localizadas, em sua maioria, dentro das áreas urbanas de municípios economicamente desenvolvidos. Isso faz com que essas rodovias tenham muitos acessos, muitos deles não controlados, o que poderia causar variações significativas em análises econômicas, especialmente no que se refere aos custos oriundos de congestionamentos. Sendo assim, optou-se pela seleção de 3 segmentos dos constantes na Tabela 7.

Dos trechos presentes na Tabela 7, foram selecionados os trechos da SP 065 (Dom Pedro), em Atibaia; da BR 381 (Fernão Dias), em Vargem; e da BR 116 (Dutra), em Guararema. Dessa forma, os três modelos de concessão existentes no estado de São Paulo são contemplados na análise, em rodovias com características de tráfego e geometria similares, podendo dessa forma se realizar um estudo comparativo entre as mesmas.

\subsection{DESCRIÇÃO E HISTÓRICO DOS LOCAIS SELECIONADOS}

Os três locais selecionados para estudo são trechos de importantes rodovias não somente no cenário paulista, mas também no cenário nacional, por estabelecerem as ligações Belo Horizonte - São Paulo (Fernão Dias), Rio de Janeiro - São Paulo (Dutra), e a ligação de Campinas com o Vale do Paraíba (Dom Pedro). Além disso, todas as praças de pedágio selecionadas estão contidas em um raio de aproximadamente 60 quilômetros.

Destaca-se que, uma vez definidos os locais de estudo, conforme descrito no item 3.1, foi necessário também estabelecer quais seriam as extremidades dos trechos para análise. Como os dados de volume e composição de tráfego eram coletados nas praças de pedágio, optou-se por delimitar os trechos de estudo pelas ligações rodoviárias existentes imediatamente antes e imediatamente depois das praças de pedágio, a fim de se minimizar os efeitos de acessos a 
outras rodovias. A seguir, é realizada uma breve descrição dos trechos selecionados, bem como apresentados seus históricos.

\section{a) Rodovia Presidente Dutra (BR-116)}

Inaugurada em 19 de janeiro de 1951, a antiga BR-2 surgiu no intuito de estabelecer a ligação viária entre as duas maiores cidades do Brasil: São Paulo e a então capital federal, Rio de Janeiro. Apesar das diversas críticas na época de sua construção pelos altos valores investidos, a rodovia mostrou-se um grande catalisador do desenvolvimento econômico da região do Vale do Paraíba, principalmente após a sua completa duplicação, no final da década de 60 .

Mesmo com toda a importância da rodovia, no início dos anos 90 a mesma se encontrava em um grande estado de deterioração do seu pavimento. A hiperinflação experimentada pelo Brasil na ocasião começou a ser controlada somente após o plano Real, em 1994, e essas dificuldades econômicas motivaram o país a iniciar o seu programa de concessões rodoviárias na mesma época, onde a Dutra foi uma das rodovias incluídas na primeira etapa das concessões federais, e a empresa responsável pela sua operação (NovaDutra) detém contrato válido até 2021.

A maior obra incluída no contrato de concessão da Dutra é a construção de uma nova pista de descida da Serra das Araras, embora essa obra não seja bem detalhada no PER, e esteja prevista para os últimos três anos de concessão. Além dessa obra, as de maior impacto são a construção de vias marginais, além da construção de faixas adicionais, com extensão de no máximo 20 $\mathrm{Km}$, não sendo possível fornecer valor mais preciso devido a forma vaga como essas obras são descritas no PER.

Uma característica que difere a Dutra da maioria das rodovias no país é a existência de uma rodovia com padrão semelhante operando paralelamente. Trata-se do sistema Ayrton Senna/Carvalho Pinto (SP-70), que liga São Paulo a Taubaté, cruzando praticamente os mesmos municípios da Dutra nesse trecho. Destaca-se essa característica pelo fato de, dentro desse trecho, os usuários possuírem duas alternativas de escolha para realizar a mesma viagem, muito embora ambas as alternativas possuam cobrança de pedágio.

O trecho da Dutra escolhido para análise situa-se entre o acesso à rodovia Ayrton Senna, no Km 178, e o trevo com a Rodovia Arthur Matheus (SP-56/60), acesso ao município de Santa Isabel, no Km 186. A praça de pedágio está localizada no Km 182, no município de Guararema, e possui cobrança bidirecional desde o ano de 2010. Antes, desde o início da concessão, essa 
praça era conhecida como "Parateí Sul", e realizava a cobrança somente para os usuários que trafegavam no sentido Rio-São Paulo.

Segundo a concessionária NovaDutra, os 402 quilômetros da Rodovia Presidente Dutra movimentam aproximadamente 50\% do PIB nacional, e cerca de 23 milhões de pessoas em 36 municípios habitam o entorno da rodovia. A Figura 10 mostra a Rodovia Presidente Dutra na região selecionada para a pesquisa.

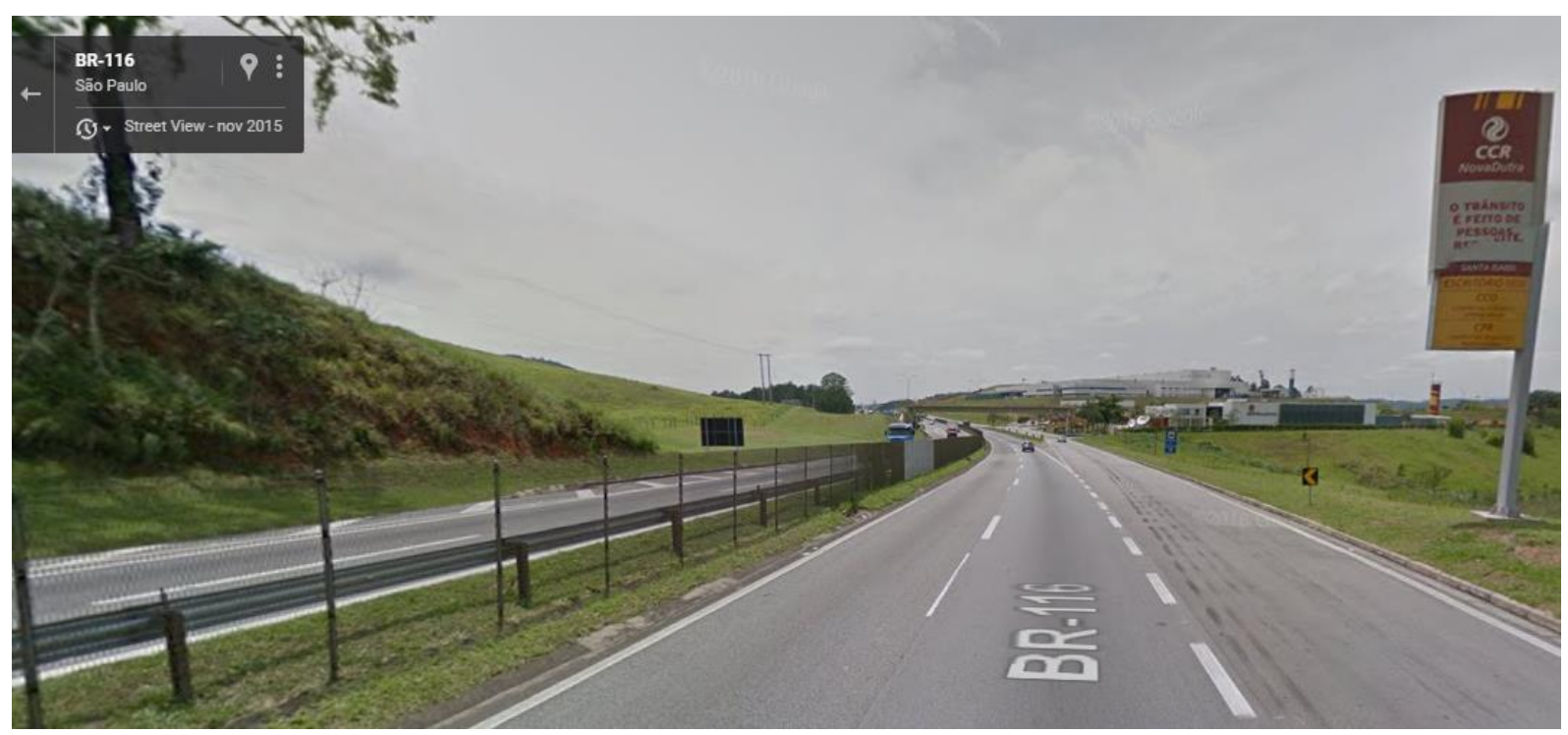

Figura 10: Rodovia Presidente Dutra, entre os Km 178 e 186 (Google, 2017)

b) Rodovia Fernão Dias (BR-381)

Outra importante ligação rodoviária do país, entre Belo Horizonte e São Paulo, a Rodovia Fernão Dias foi inaugurada como BR-55 no ano de 1959 pelo então presidente Juscelino Kubitschek, cujo governo teve o famoso plano de metas "50 anos em 5". Embora inaugurada em 1959, a ligação da capital mineira com a capital paulista só foi efetivada em 1961, com a conclusão das obras no trecho paulista. Em 2002, já como BR-381, foram concluídas as obras de duplicação em toda a extensão da rodovia.

Apesar da conclusão das obras de duplicação em 2002, a pesquisa CNT de 2006 já apontava trechos da rodovia com pavimento em condição regular, o que indica o estado de deterioração do mesmo. Como parte da segunda etapa de concessões federais, em 2007 a Rodovia Fernão Dias foi concedida para o grupo OHL (atualmente Arteris), num contrato de 25 anos. Segundo o Programa de Exploração da Rodovia - PER - da Fernão Dias, as obras de maior impacto a serem executadas pela concessionária são a implantação de ruas laterais em áreas urbanas da rodovia e a implantação de terceiras faixas em segmentos descontínuos, num total de $88 \mathrm{Km}$. 
O trecho selecionado para análise na Fernão Dias encontra-se entre o Km 2 (trevo com a SP036, acesso à Joanópolis) e Km 10 (trevo com a SPA-009/010, acesso à Bragança Paulista). A praça de pedágio está localizada no Km 7+600m, no município de Vargem, e possui cobrança bidirecional. A Figura 11 ilustra o trecho em estudo na Rodovia Fernão Dias.

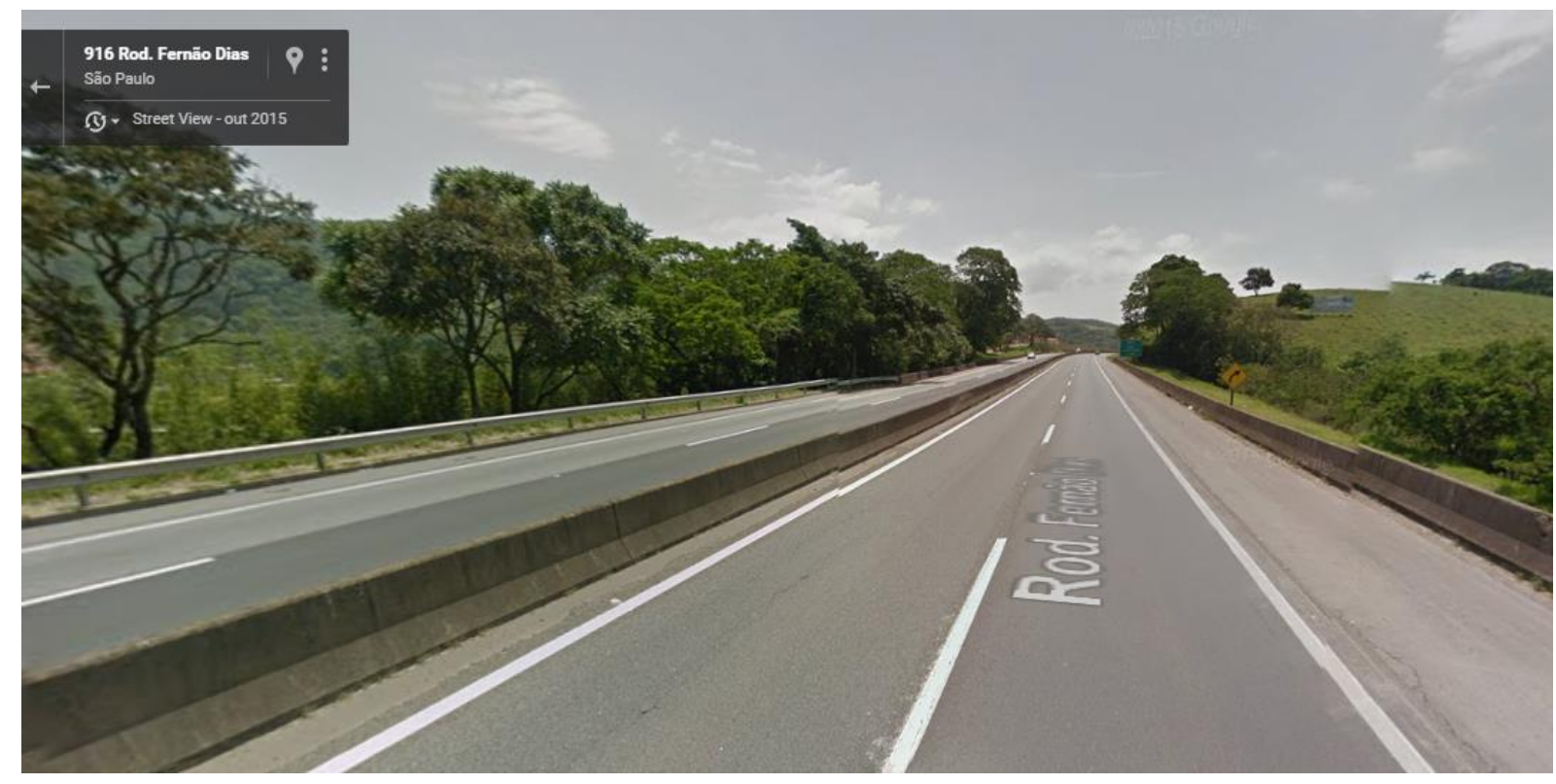

Figura 11: Rodovia Fernão Dias, entre os Km 2 e 10 (Google, 2017)

c) Rodovia Dom Pedro I (SP-065)

Dentre todas as rodovias selecionadas para essa pesquisa, a Rodovia Dom Pedro I é a que apresenta construção mais recente. Inaugurada em 1972, $150^{\circ}$ ano da independência do Brasil, foi planejada para realizar a ligação mais curta entre as rodovias Anhanguera (SP-330) e Dutra (BR-116), sem a necessidade de trafegar pelos municípios da região metropolitana de São Paulo. Após a inauguração do sistema Ayrton Senna/Carvalho Pinto, em meados dos anos 90, a Dom Pedro foi prolongada para ter ligação também com esse sistema rodoviário.

A Rodovia Dom Pedro I é de grande importância não somente para o estado de São Paulo, mas para alguns de seus estados vizinhos, uma vez que permite a ligação do interior com o litoral norte paulista e com o Rio de Janeiro, além de facilitar o acesso do interior à rodovia Fernão Dias, e por consequência com Belo Horizonte. Em 2009, a rodovia foi incluída da segunda etapa de concessões da ARTESP, sendo concedida ao grupo Odebrecht, através da concessionária "Rota das Bandeiras", por um período de 30 anos. A concessão abrange diversos segmentos rodoviários, incluindo o Anel Viário José Roberto Magalhães Teixeira (SP-083), e as rodovias SP-332, SP-360 e SP-063. Diferentemente das duas concessões da ANTT já 
descritas, a Rota das Bandeiras apresenta um plano de execução de obras mais robusto, incluindo a construção de $110 \mathrm{~km}$ de faixas adicionais na própria Rodovia Dom Pedro (abrangendo o trecho em estudo), e $40 \mathrm{Km}$ de duplicações em outras rodovias.

O trecho selecionado para análise na Dom Pedro encontra-se entre o Km 74 (trevo com a rodovia Fernão Dias - BR-381) e Km 83 (Estrada Municipal Shambala, acesso aos bairros Pedreira e Usina, em Atibaia). A praça de pedágio está localizada no Km 79+900m, no município de Atibaia, e possui cobrança bidirecional. A Figura 12 ilustra o trecho em estudo na Rodovia Dom Pedro I.

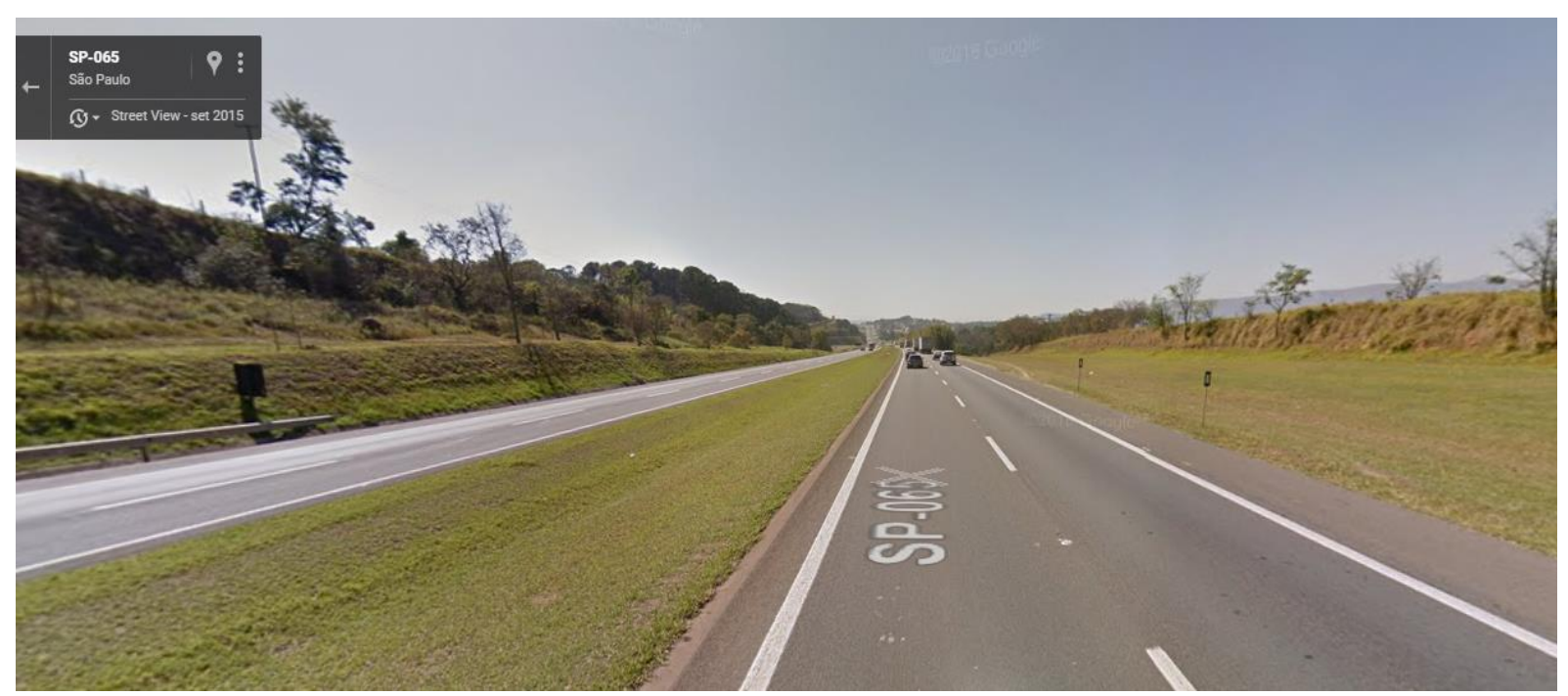

Figura 12: Rodovia Dom Pedro I, entre os Km 74 e 83 (Google, 2017)

\subsection{EVOLUÇÃO DAS TARIFAS DE PEDÁGIO}

As tarifas de pedágio cobradas em rodovias concedidas podem variar em função de diversos fatores. Alguns dos mais importante são o Trecho de Cobertura da Praça (TCP), que juntamente com a tarifa quilométrica define o valor cobrado em cada praça; os índices utilizados para reajuste da tarifa; o montante de recursos investido na concessão; e o volume e composição do tráfego pagante na rodovia ao longo da concessão. As tarifas praticadas no Brasil variam consideravelmente, podendo chegar a $\mathrm{R} \$ 0,18$ por quilômetro rodado no sistema Anchieta/Imigrantes (em cobrança unidirecional, cobrindo contudo ambos os sentidos das vias), e custando pouco mais de $\mathrm{R} \$ 0,02$ por quilômetro em algumas concessões da segunda etapa da ANTT (em ambos os casos, tendo como base as tarifas praticadas em 2015 para veículos da categoria 1$)$.

A menor tarifa praticada dentre os trechos selecionados nessa pesquisa é a da Fernão Dias, possuindo 8 praças de pedágio ao longo dos 562 quilômetros da concessão, e cuja tarifa 
praticada entre dezembro de 2015 e dezembro de 2016 era igual a $\mathrm{R} \$ 1,80$. Ou seja, para se percorrer toda a sua extensão, o usuário paga em média 2 centavos por quilômetro rodado. Em seu contrato de concessão (da segunda etapa da ANTT), é definido que os reajustes anuais da tarifa básica de pedágio ocorrem em função do IRT - Índice de Reajustamento de Tarifa representando a variação do IPCA (calculado pelo IBGE) entre o mês anterior à data de referência na apresentação da proposta de tarifa e o mês anterior à data-base de reajuste da tarifa.

Embora seja um contrato também regulado pela ANTT, a concessão da Rodovia Presidente Dutra (primeira etapa da ANTT) apresenta características muito diferentes no que diz respeito aos métodos de determinação e reajuste das tarifas. Em primeiro lugar, as praças apresentam valores distintos ao longo da rodovia, podendo variar de $\mathrm{R} \$ 3,10$ a $\mathrm{R} \$ 12,70$ na praça (no ano de 2015, para categoria 1). As tarifas quilométricas também variam na concessão, ficando entre 8 centavos, no trecho com cobertura da praça de pedágio de Arujá (Km 204) e 16 centavos no trecho coberto pela praça de Guararema, justamente o trecho em estudo. A tarifa quilométrica no trecho selecionado para estudo é $800 \%$ superior a tarifa cobrada na Rodovia Fernão Dias. Embora percentualmente essa diferença possa parecer maior do que os valores absolutos (diferença de 14 centavos na tarifa quilométrica), ainda assim é um valor significativo para o usuário, especialmente aqueles que trafegam longas extensões por essas rodovias. Os reajustes da tarifa da Dutra tomam como base índices de reajuste dos principais componentes de custo (Terraplenagem, Pavimentação, Obras de Artes Especiais e Serviços de Consultoria), fornecidos pela Fundação Getúlio Vargas.

A concessão da Rodovia Dom Pedro I, por sua vez, apresenta métodos de revisão das tarifas muito parecidos com as concessões da segunda etapa da ANTT, também tomando como base para o reajuste a variação do IPCA. As únicas diferenças estão no fato do cálculo ser realizado para a tarifa quilométrica, e posteriormente multiplicado pelo TCP, e na base corrente do reajuste, que é o segundo mês anterior ao mesmo, e não o mês anterior. O trecho em estudo apresentou em 2015 tarifa igual a R\$6,20, para um TCP de 41,8 quilômetros. A tarifa quilométrica é de aproximadamente 14 centavos, sendo um valor intermediário entre as concessões avaliadas.

Com o intuito de comparar a evolução tarifária, entre os anos de 1995 e 2015, nas três concessões selecionadas nessa pesquisa, são apresentados a seguir dois gráficos, um contendo a evolução das tarifas de pedágio cobradas nas três praças de pedágio selecionadas para o estudo 
ao longo dos anos (Figura 13), e outro contendo a evolução das tarifas quilométricas nos mesmos lugares (Figura 14).

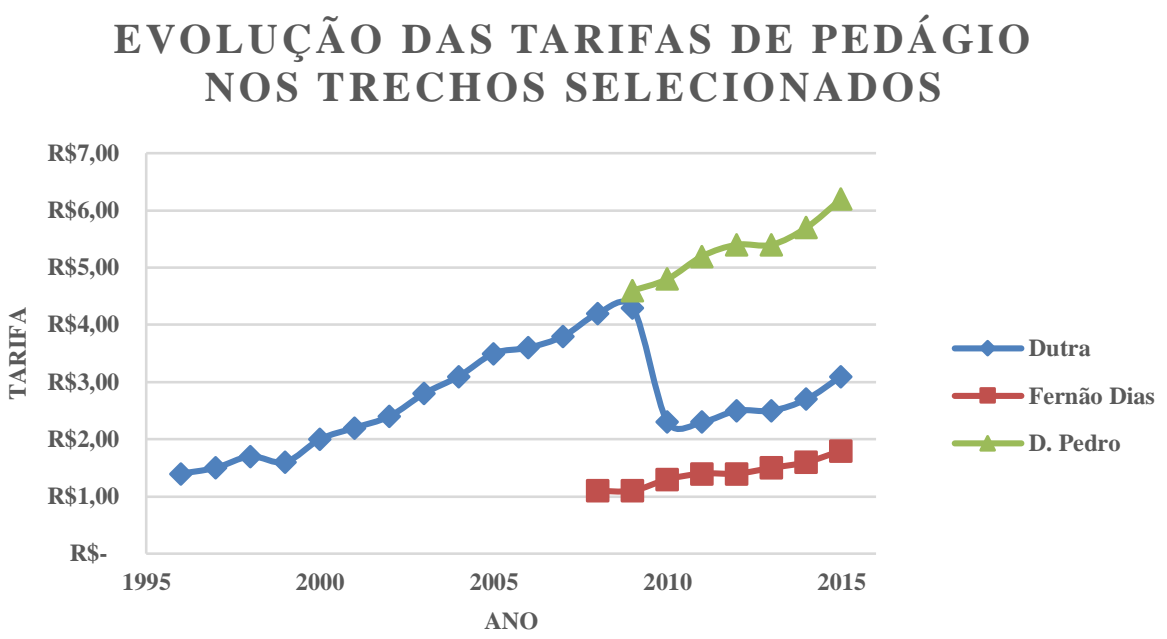

Figura 13: Evolução das tarifas de pedágio cobradas nas praças

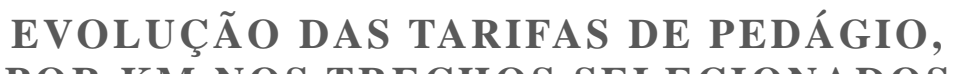

POR KM NOS TRECHOS SELECIONADOS

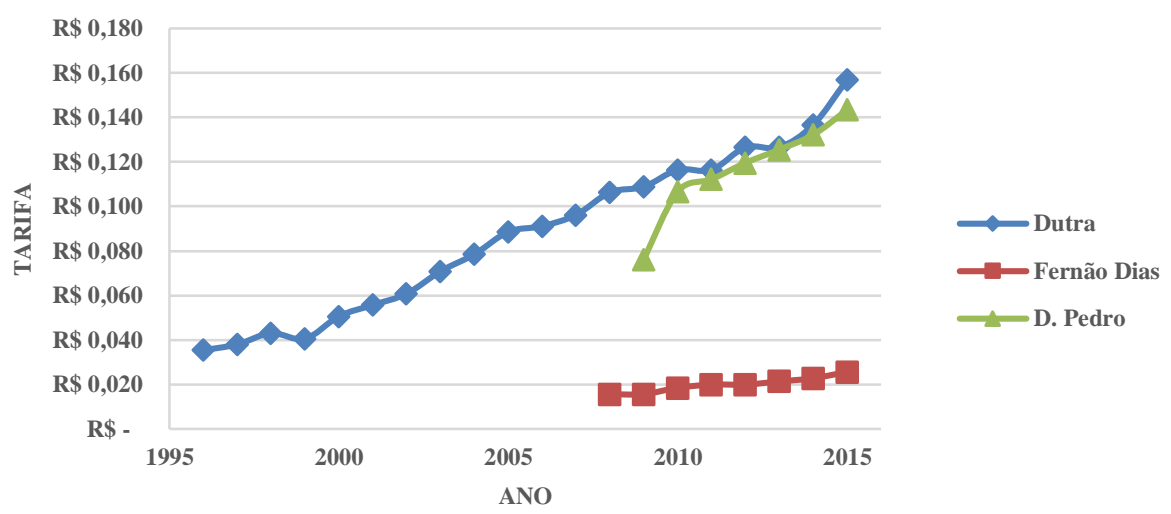

Figura 14: Evolução das tarifas cobradas por quilômetro, nos trechos selecionados

Em ambos os casos, percebe-se que há uma grande discrepância entre as tarifas praticadas nas concessões da ARTESP e ANTT da primeira etapa (Dom Pedro e Dutra, respectivamente), com a concessão da ANTT da segunda etapa (Fernão Dias). Essa discrepância ocorre, dentre outros fatores, pelas taxas de juros praticadas na época das concessões, a fonte de financiamento de recursos para as obras e o risco de se investir em concessões em cada período. Porém, essas variáveis não foram abordadas neste trabalho, uma vez que todas as análises buscaram avaliar somente a influência da condição do pavimento nos benefícios dos usuários. Não somente as tarifas praticadas nas praças são superiores, como a tarifa quilométrica também se apresenta 
muito maior nas duas primeiras. No ano de 2010, a Rodovia Dutra apresentou um forte decréscimo na tarifa cobrada na praça de pedágio pelo fato de que, até o ano anterior, a cobrança ter sido realizada somente em um dos sentidos da rodovia. Além disso, um aspecto importante que deve ser destacado também é a taxa de crescimento das tarifas, que pode ser facilmente observada pela inclinação das linhas de cada concessão no gráfico. Novamente, a Dutra e a Dom Pedro apresentaram crescimento da tarifa ao longo dos anos maior do que a Fernão Dias.

\section{TARIFAS DE PEDÁGIO PROPORCIONAIS NOS TRECHOS SELECIONADOS}

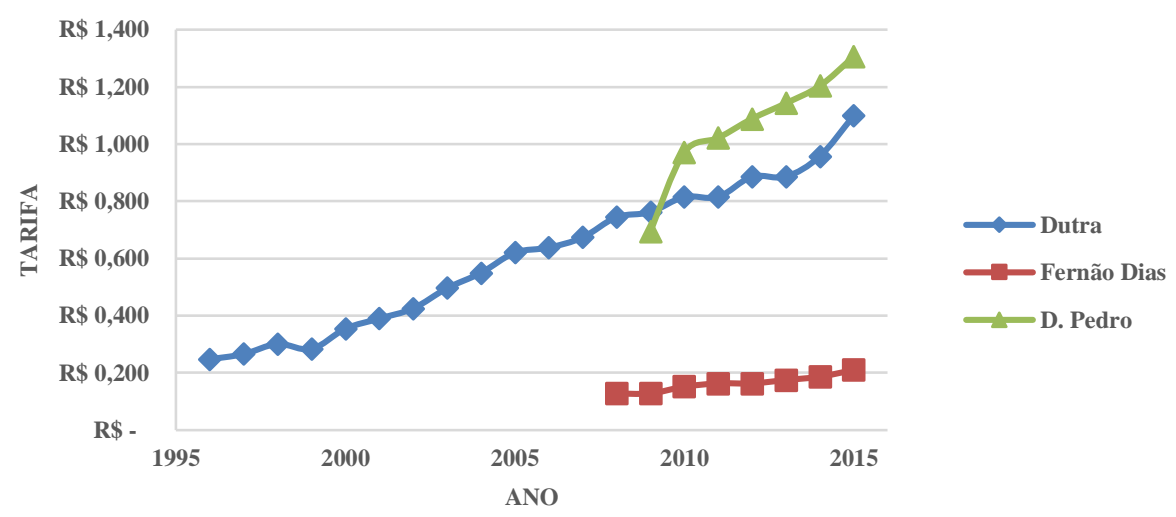

Figura 15:Evolução das tarifas pagas pelos usuários, proporcionalmente aos trechos percorridos

Como os trechos selecionados possuem extensões diferentes, a Figura 15 apresenta os valores calculados com base nas tarifas quilométricas para cada trecho, ou seja, o valor pago para se percorrer somente a extensão dos trechos em estudo. A única diferença perceptível em relação ao comportamento observado nos outros gráficos é que o trecho selecionado na rodovia Dom Pedro é o que apresenta o maior valor para ser percorrido, desde 2010.

Quando os reajustes nas tarifas quilométricas são comparados com a inflação do país (Figura 16), medida pelo IPCA - Índice Nacional de Preços ao Consumidor Amplo - percebe-se que todas as concessões do estudo, mesmo as que utilizam o IPCA para basear seus reajustes, apresentaram variações percentuais acumuladas maiores nas tarifas do que a inflação medida no mesmo período, ou seja, os preços dos pedágios para os usuários dessas rodovias aumentaram mais do que a inflação em um mesmo período. 


\section{Variação Percentual Acumulada das Tarifas Quilométricas e do IPCA}

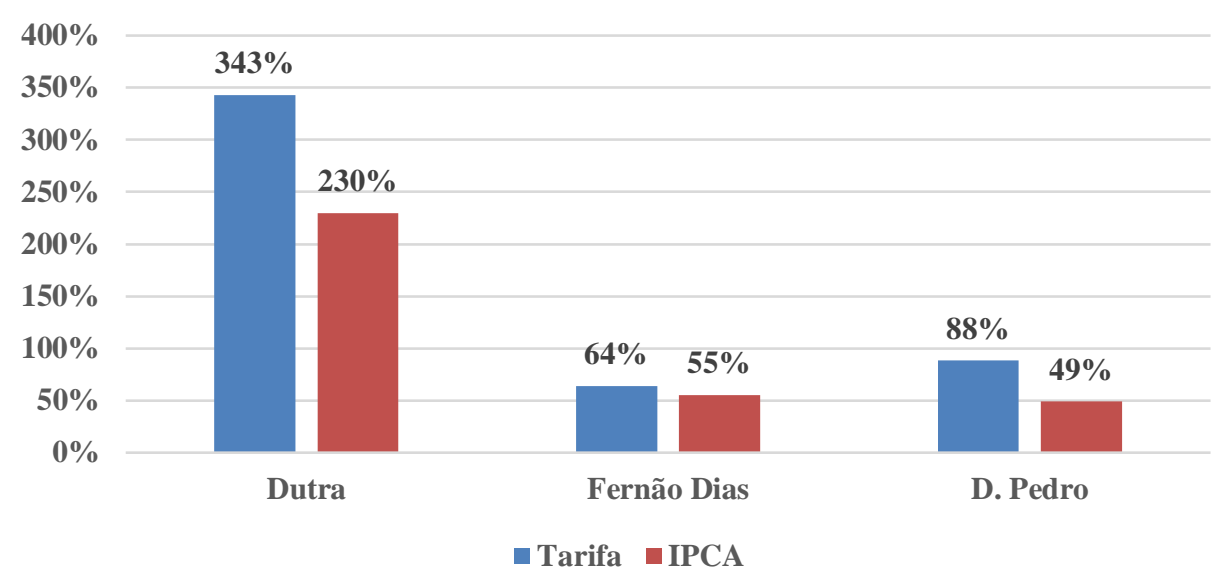

Figura 16:Evolução das tarifas pagas pelos usuários, proporcionalmente aos trechos percorridos

Sobre os valores apresentados, algumas considerações devem ser feitas. Para o caso da Rodovia Dom Pedro I, os valores históricos das tarifas foram facilmente encontrados, uma vez que a ARTESP disponibiliza em seu endereço eletrônico todo o histórico das tarifas de todas as concessões já realizadas, incluindo os TCPs e as datas de reajuste, até os dias atuais. No caso da Rodovia Fernão Dias, os relatórios anuais da ANTT também fornecem o histórico com todos os valores já praticados nas tarifas de pedágio, contudo os relatórios encontram-se desatualizados, uma vez que, na data da última consulta (08/02/2017), o último relatório disponível é referente ao ano de 2013. As tarifas após o ano de 2013 foram encontradas em documentos oficiais, como notas técnicas, que autorizavam e indicavam os reajustes nas tarifas. A Rodovia Presidente Dutra foi a que apresentou maiores dificuldades na obtenção dos valores históricos das tarifas de pedágio. Por se tratar de uma concessão realizadas em 1995, portanto 6 anos antes da criação da ANTT, os únicos documentos oficiais apresentados datam a partir de 2002. Os relatórios anuais apresentam valores históricos, porém os mesmos são válidos somente para as praças de pedágio de Viúva Graça, Itatiaia e Moreira César, que apresentam os maiores valores na concessão, não sendo apresentados os valores para as praças de Arujá, Guararema e Jacareí. O contrato de concessão, no item 47, indica que:

A tarifa a ser efetivamente cobrada dos usuários da RODOVIA corresponderá ao valor da TARIFA BÁSICA DE PEDÁGIO em cada uma das categorias previstas no item 45 fixada para cada um dos Postos de Pedágio nos respectivos sentidos, conforme estabelecido no item 23 do Edital da Fase III da Concorrência da qual se originou esse CONTRATO. 
Contudo, o edital não é disponibilizado no site da ANTT, e ao buscar o edital (de nº 0291/9300) em sites de pesquisa, não se encontra o mesmo em nenhuma das ocorrências. Dessa forma, para se estimar as tarifas cobradas entre os anos de 1996 e 2002, na praça de pedágio de Guararema, observou-se apenas a proporção mantida ao longo dos anos entre as tarifas dessa praça com as praças que se conhecem os valores históricos, citadas anteriormente, e aplicou-se essa proporção para os anos com dados ausentes.

\subsection{PARÂMETROS INSERIDOS NO SOFTWARE HDM-4}

Para a realização das simulações no HDM-4, são necessárias diversas variáveis de entrada. Essas variáveis são relacionadas a vários aspectos, como clima, caracterização do tráfego, estrutura do pavimento, projeto geométrico, dentre outros. Além disso, são necessários também os custos de alguns insumos, além de variáveis econômicas como taxa de desconto e período de análise do projeto. Devido ao grande número de variáveis a serem inseridas, e pela incerteza dos valores exatos de boa parte dessas variáveis, a maioria das considerações adotadas nessa pesquisa seguiram as recomendações de Nunes (2012), especialmente no que se refere à seleção das variáveis com maior influência nos resultados, as quais tiveram um cuidado ainda maior na sua determinação. As variáveis utilizadas, portanto, são descritas a seguir, separadas por cada tipo existente no ambiente de trabalho do HDM-4 (Figura 17):

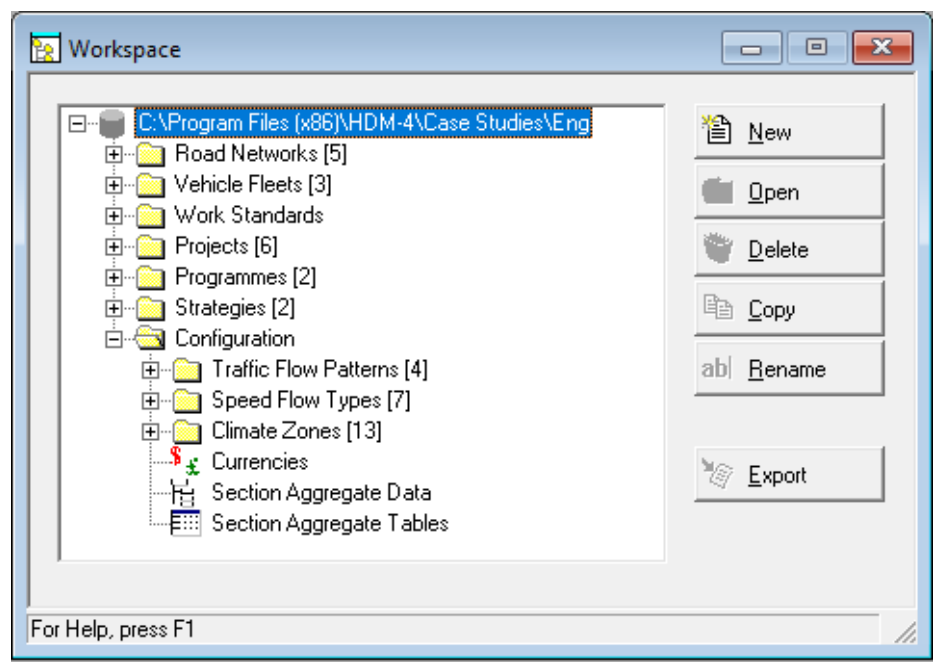

Figura 17:Ambiente de Trabalho do HDM-4

3.4.1 Características do Clima (Climate Zones): Dentro da pasta Configuration do ambiente de trabalho do HDM-4, estão contidos os parâmetros relacionados ao clima e ao tráfego. Os parâmetros relacionados ao clima são inseridos em uma janela como a que é mostrada na Figura 18: 


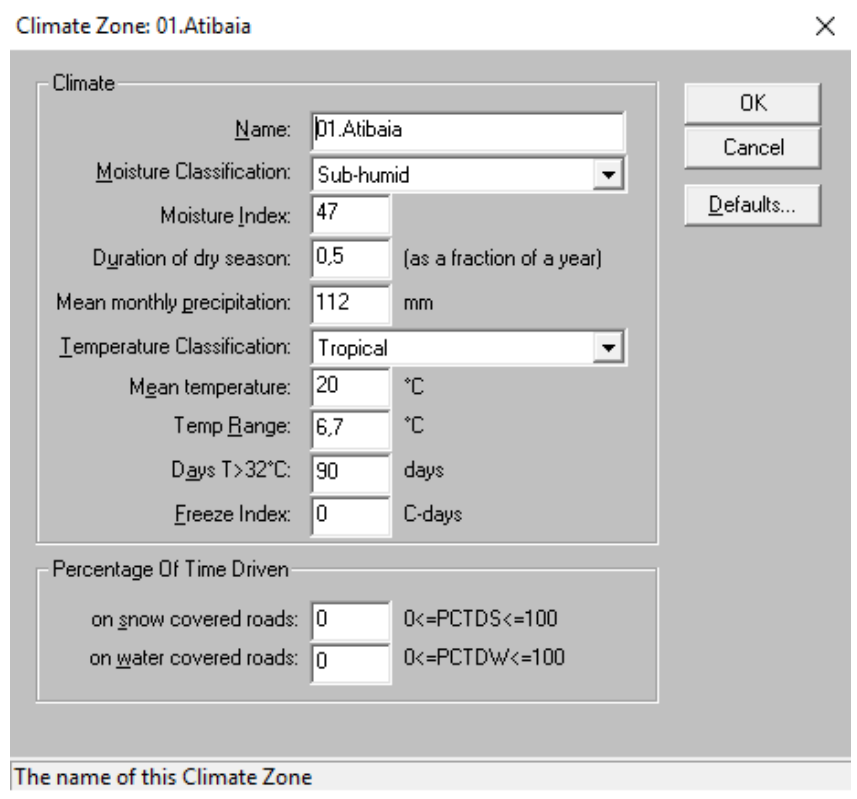

Figura 18: Configurações de clima no HDM-4

Para configurar os parâmetros climáticos, foram criadas 3 zonas climáticas, uma para cada município dos trechos em estudo. Os dados de cada município foram obtidos digitalmente, nos sites da EMBRAPA (2016) e do Cepagri da UNICAMP (2016). O resumo das variáveis inseridas, com seus respectivos valores para cada trecho em estudo, se encontra na Tabela 8.

Tabela 8: Valores utilizados nas variáveis climáticas

\begin{tabular}{cccc}
\hline Variável & Dutra & $\begin{array}{c}\text { RODOVIA } \\
\text { Dom Pedro }\end{array}$ & Fernão Dias \\
\hline Nome & 02. Guararema & 01. Atibaia & 03. Vargem \\
Classificação de umidade & Úmido & Úmido & Úmido \\
Índice de Umidade & 26 & 47 & 60 \\
Duração da estação seca (fração do ano) & 0,5 & 0,5 & 0,5 \\
Precipitação Média Mensal & $105 \mathrm{~mm}$ & $112 \mathrm{~mm}$ & $122 \mathrm{~mm}$ \\
Classificação de Temperatura & Tropical & Tropical & Tropical \\
Temperatura Média & $21^{\circ} \mathrm{C}$ & $20^{\circ} \mathrm{C}$ & $20^{\circ} \mathrm{C}$ \\
Variação de Temperatura & $7,0^{\circ} \mathrm{C}$ & $6,7^{\circ} \mathrm{C}$ & $6,6^{\circ} \mathrm{C}$ \\
Dias com Temperatura $>32$ graus & 90 dias & 90 dias & 90 dias \\
\hline
\end{tabular}

3.4.2 Características de Capacidade de Tráfego (Speed Flow Types e Traffic Flow Patterns): A caracterização da capacidade de tráfego dos locais em estudo tomou como base o modelo Four Lane Road, com o padrão de tráfego Free-Flow, já existentes no software. Essas definições são compatíveis com os valores reais para as rodovias em estudo, segundo dados de agências reguladoras ${ }^{1}$ e de estudos de tráfego nas rodovias paulistas ${ }^{2}$. 
3.4.3 Características da Frota (Vehicle Fleet): Por se tratar de uma análise econômica de rodovias com cobrança de pedágio, a caracterização dos veículos tomou como base a classificação dos veículos para cobrança de pedágio das rodovias paulistas, totalizando 10 categorias ( 9 categorias regulares - entre 2 e 6 eixos - mais uma categoria para veículos com mais de 6 eixos), sendo 4 categorias para veículos de passeio e 6 categorias para veículos comerciais. Para os veículos comerciais de dois eixos, foi criada uma categoria extra, contemplando os ônibus, considerando assim também o transporte de passageiros. Os veículos utilizados são apresentados na Tabela 9.

Tabela 9: Categorias e Veículos Utilizados

\begin{tabular}{|c|c|c|c|}
\hline & Eixos & Código & Multip. Tarifa \\
\hline 1 & 2 & $\mathrm{P}$ & 1 \\
\hline 2 & 2 & $2 \mathrm{C}$ & 2 \\
\hline 2 & 2 & $\mathrm{O}$ & 2 \\
\hline 3 & 3 & $3 \mathrm{C}$ & 3 \\
\hline 4 & 4 & $2 \mathrm{~S} 2$ & 4 \\
\hline 5 & 5 & $2 \mathrm{~S} 3$ & 5 \\
\hline 6 & 6 & $3 \mathrm{~S} 3$ & 6 \\
\hline 7 & 3 & P3 & 1,5 \\
\hline 8 & 4 & $\mathrm{P} 4$ & 2 \\
\hline 9 & 2 & M & 0,5 \\
\hline 10 & 7 & $3 \mathrm{~T} 4$ & 7 \\
\hline
\end{tabular}

Para a avaliação dos efeitos nos usuários, foi utilizado o modelo de Ciclo de Vida Ótimo para os veículos de carga, e o modelo de Ciclo de Vida Constante para os veículos de passeio, definidos como padrão pelo programa. As demais variáveis foram determinadas da seguinte forma (todos os valores são apresentados na Tabela 11 ou na descrição a seguir): 
- Fator de equivalência dos veículos (FEV): devido às diferenças entre os veículos que trafegam nos Estados Unidos e no Brasil, optou-se por não utilizar os fatores existentes no Highway Capacity Manual 2010 (HCM), elaborado dentro do contexto estadunidense, e sim utilizar os fatores pré-estabelecidos no HDM-4 para os veículos cadastrados.

- Tipo de pneu: radial (Radial-ply) para os veículos de passeio; diagonal (Bias-ply) para os veículos comerciais;

- ESALF (Equivalent Standart Axle Load Factor): calculado com base nas equações fornecidas pelo Manual de Estudo de Tráfego do DNIT (2006), estando os valores para cada tipo de eixo apresentados na Tabela 10. Os valores para cada composição são o somatório dos valores de ESALF para cada tipo de eixo existente no veículo.

Tabela 10: ESALF por tipo de eixo

\begin{tabular}{lll}
\hline Tipo de Eixo & Carga máxima & ESALF \\
\hline Simples & $6 \mathrm{t}$ & 0,683 \\
& $10 \mathrm{t}$ & 2,255 \\
Tandem Duplo & $17 \mathrm{t}$ & 3,213 \\
Tandem Triplo & $25,5 \mathrm{t}$ & 4,621 \\
\hline
\end{tabular}

- Carga de operação: foram utilizados os limites legais máximos para cada tipo de eixo: 6 toneladas para eixos simples de rodas simples; 10 toneladas para eixos simples de rodas duplas; 17 toneladas para eixos tandem duplo; 25,5 toneladas para eixos tandem triplo. A carga de operação foi o somatório desses limites para cada composição;

- Custo de veículo novo: foram adotados valores praticados no mercado, com base na pesquisa em sites especializados e aos dados da Fundação Instituto de Pesquisas Econômicas (FIPE), principal tabela de referência para o preço de veículos. Os valores são apresentados na Tabela 11, na coluna "Preço Veículo";

- Custo de pneus: valores obtidos através de consulta em lojas e oficinas;

- Custo do combustível: média anual (base 2015) no estado de São Paulo para Diesel e Gasolina, segundo a ANP (2017);

- Custo de lubrificantes: $\mathrm{R} \$ 20,00$ por litro (valor obtido através de consulta ao mercado);

- Taxa de juros anual na compra de um novo veículo: 12\% a.a (pré-definido pelo HDM).

- Número de passageiros: 20 passageiros (ônibus); 1 passageiro (veículos de passeio); 0 para os demais veículos; 
- Custo da hora de trabalho de passageiros: $\mathrm{R} \$ 10,00$ por hora (salário médio do brasileiro - aproximadamente $\mathrm{R} \$ 2200,00$ - dividido por 220 horas de trabalho mensais);

- Custo de atraso de carga: $\mathrm{R} \$ 25,00$ por hora de atraso para veículos não articulados; $\mathrm{R} \$ 45,00$ por hora de atraso para veículos articulados. Valores informados pela NTC\&Logística (2015);

- A utilização anual dos veículos tomou os valores previamente definidos pelo HDM-4;

- Demais custos mantiveram proporções de valores utilizados previamente no software;

Tabela 11: Parâmetros Gerais dos Veículos Cadastrados

\begin{tabular}{ccccccccccc}
\hline Código & $\begin{array}{c}\mathbf{N}^{\mathbf{o}} \\
\text { Eixos }\end{array}$ & $\mathbf{N}^{\mathbf{0}}$ Pneus & FEV ESALF & $\begin{array}{c}\text { Carga de } \\
\text { Operação }\end{array}$ & Preço Veículo & Preço Pneu & \multicolumn{2}{c}{$\begin{array}{c}\text { Preço } \\
\text { Combustível }\end{array}$} \\
\hline $\mathrm{P}$ & 2 & 4 & 1 & - & $1,0 \mathrm{t}$ & $\mathrm{R} \$ 40.000,00$ & $\mathrm{R} \$ 250,00$ & $\mathrm{R} \$$ & 3,14 \\
$2 \mathrm{C}$ & 2 & 6 & 1,4 & 2,938 & $16,0 \mathrm{t}$ & $\mathrm{R} \$ 150.000,00$ & $\mathrm{R} \$ 1.200,00$ & $\mathrm{R} \$$ & 2,74 \\
$\mathrm{O}$ & 2 & 6 & 1,5 & 2,938 & $16,0 \mathrm{t}$ & $\mathrm{R} \$ 200.000,00$ & $\mathrm{R} \$ 1.500,00$ & $\mathrm{R} \$$ & 2,74 \\
$3 \mathrm{C}$ & 3 & 10 & 1,4 & 3,896 & $23,0 \mathrm{t}$ & $\mathrm{R} \$ 150.000,00$ & $\mathrm{R} \$ 1.200,00$ & $\mathrm{R} \$$ & 2,74 \\
$2 \mathrm{~S} 2$ & 4 & 14 & 1,6 & 6,151 & $33,0 \mathrm{t}$ & $\mathrm{R} \$ 200.000,00$ & $\mathrm{R} \$ 1.500,00$ & $\mathrm{R} \$$ & 2,74 \\
$2 \mathrm{~S} 3$ & 5 & 18 & 1,6 & 7,559 & $41,5 \mathrm{t}$ & $\mathrm{R} \$ 350.000,00$ & $\mathrm{R} \$ 1.500,00$ & $\mathrm{R} \$$ & 2,74 \\
$3 \mathrm{~S} 3$ & 6 & 22 & 1,6 & 8,517 & $48,5 \mathrm{t}$ & $\mathrm{R} \$ 450.000,00$ & $\mathrm{R} \$ 1.500,00$ & $\mathrm{R} \$$ & 2,74 \\
$\mathrm{P} 3$ & 3 & 6 & 1 & - & $1,2 \mathrm{t}$ & $\mathrm{R} \$ 40.000,00$ & $\mathrm{R} \$ 250,00$ & $\mathrm{R} \$$ & 3,14 \\
$\mathrm{P} 4$ & 4 & 8 & 1 & - & $1,4 \mathrm{t}$ & $\mathrm{R} \$ 40.000,00$ & $\mathrm{R} \$ 250,00$ & $\mathrm{R} \$$ & 3,14 \\
$\mathrm{M}$ & 2 & 2 & 0,5 & - & $0,2 \mathrm{t}$ & $\mathrm{R} \$ 7.000,00$ & $\mathrm{R} \$ 150,00$ & $\mathrm{R} \$$ & 3,14 \\
$3 \mathrm{~T} 4$ & 7 & 26 & 1,8 & 10,322 & $57,0 \mathrm{t}$ & $\mathrm{R} \$ 500.000,00$ & $\mathrm{R} \$ 1.500,00$ & $\mathrm{R} \$$ & 2,74 \\
\hline
\end{tabular}

3.4.4 Caracterização da Rede Rodoviária (Road Network): Nessa etapa, foram inseridas as três seções selecionadas para estudo, nas rodovias Dutra (BR-116), Fernão Dias (BR-381) e Dom Pedro (SP-065). Os parâmetros para cada segmento foram definidos segundo a divisão do próprio software, pelas seguintes características:

a) Definição:

As definições básicas para cada seção seguiram alguns dos parâmetros previamente estabelecidos, como Zonas Climáticas e Padrão de Fluxo de Tráfego. Alguns parâmetros são comuns a todos, como a Classe de Superfície (Betuminosa), a Classe de Rodovia (Primária), o Tipo de Pavimento (Mistura Asfáltica sobre Base Granular), e a direção do Fluxo (Two-way, fluxo bidirecional). As extensões dos trechos são apresentadas na Tabela 12, juntamente com os parâmetros geométricos. O Volume de Tráfego (AADT), definido em todos os casos para o ano de 1995, é igual o VDM do ano de 1995, de cada trecho, multiplicado por 2 (para transformar em volume bidirecional). As demais variáveis, relacionadas a caraterísticas físicas da rodovia e comuns a todos os casos, recebem os seguintes valores (considerando uma rodovia 
de pista dupla, com faixa de tráfego de 3,5 metros de largura, acostamento de 2,8 metros, e duas faixas de tráfego por sentido):

- Largura da pista: 14 metros

- Largura do acostamento: 5,6 metros

- Número de faixas de tráfego: 4

A Figura 19 ilustra a tela do software na aba de Definição da Rede Rodoviária.

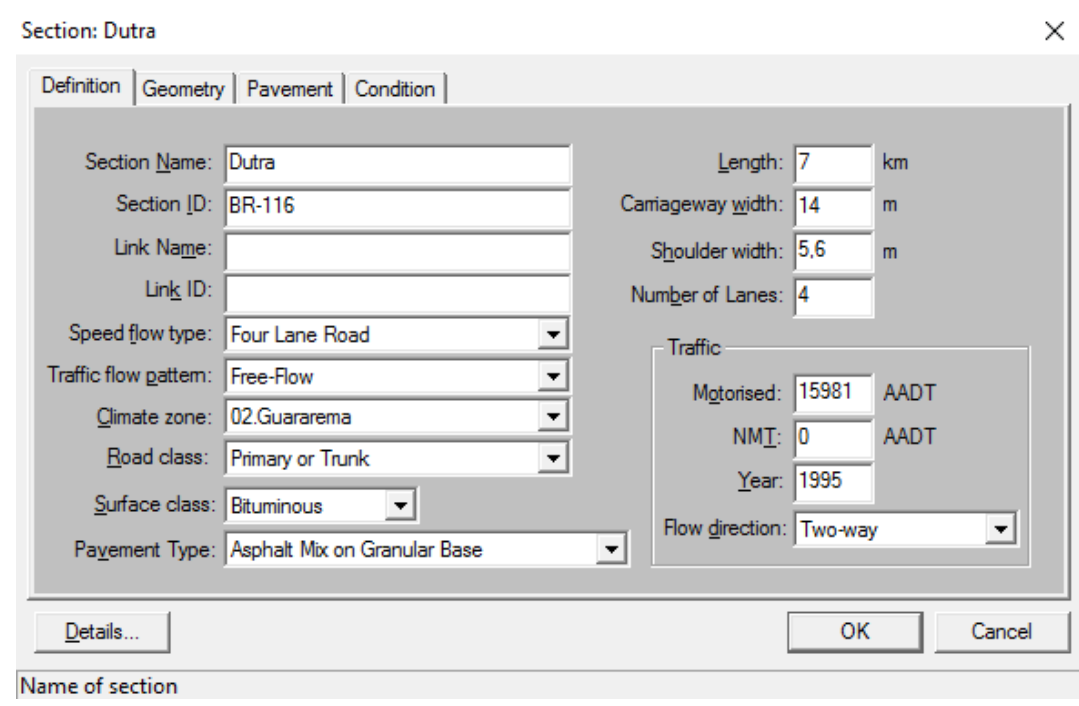

Figura 19: Configuração da Rede Rodoviária no HDM-4

b) Geometria:

Os parâmetros geométricos foram obtidos através dos softwares Google Earth ${ }^{\circ}$ e Autocad Civil 3D 2014®. As imagens disponibilizadas pelo Google Earth foram importadas no Autocad, e tratadas de modo a reproduzir as condições geométricas dos locais em estudo, respeitando o Raio Mínimo de Curva e a Rampa Máxima de cada trecho, e através das ferramentas de desenho foi possível determinar os parâmetros apresentados na Tabela 12. Não foram considerados os efeitos de drenagem nas simulações.

Tabela 12: Parâmetros Geométricos Utilizados

\begin{tabular}{cccc}
\hline Variável & Dutra & $\begin{array}{c}\text { Rodovia } \\
\text { Dom Pedro }\end{array}$ & Fernão Dias \\
\hline Subidas + Descidas $(\mathrm{m} / \mathrm{km})$ & 15,1 & 22,0 & 22,2 \\
Curvatura Horizontal Média $($ graus/km) & 6,3 & 7,0 & 22,9 \\
Limite de Velocidade $(\mathrm{km} / \mathrm{h})$ & 110 & 110 & 100 \\
Extensão do Trecho $(\mathrm{km})$ & 7,0 & 8,2 & 9,1 \\
Altitude $(\mathrm{m})$ & 634 & 772 & 845 \\
\hline
\end{tabular}

c) Pavimento:

Apesar da escassez de informações disponibilizadas publicamente sobre as estruturas dos pavimentos nos trechos selecionados, foi possível identificar nas concessões federais, através 
de relatórios de pesquisa das concessionárias, algumas informações que foram utilizadas na definição dos parâmetros do pavimento. Em todos os casos, foi definido que a espessura do revestimento seria igual a $200 \mathrm{~mm}$, sendo $100 \mathrm{~mm}$ da camada mais antiga, e $100 \mathrm{~mm}$ da camada mais nova. Também em todos os casos, foi definido que todos os trabalhos executados anteriormente ocorreram no ano de 1994 (ano anterior ao início da análise). Os demais parâmetros, definidos para a estação seca (Dry Season) constam na Tabela 13.

Tabela 13: Parâmetros Relacionados ao Pavimento

\begin{tabular}{|c|c|c|c|}
\hline \multirow{2}{*}{ Variável } & \multicolumn{3}{|c|}{ Rodovia } \\
\hline & Dutra & Dom Pedro & Fernão Dias \\
\hline Número Estrutural & 6,0 & 5,5 & 5,0 \\
\hline CBR Subleito (\%) & 12 & 10 & 8 \\
\hline SNP & 7,37 & 6,73 & 6,05 \\
\hline Deflexão (mm) & 0,27 & 0,31 & 0,37 \\
\hline
\end{tabular}

Cabe destacar que os valores adotados, ainda que não sejam reais, buscaram representar as condições reais das rodovias selecionadas, tendo a Dutra um pavimento com melhor suporte no subleito e estrutura mais resistente, a Fernão Dias uma pior condição de suporte no subleito e também uma estrutura menos resistente, e a Dom Pedro apresentando uma condição intermediária entre as duas primeiras.
d) Condição:

A condição definida em todos os trechos avaliados levou em consideração os valores tabelados pelo HDM-4, para um pavimento em condição regular. $\mathrm{O}$ ano dessa condição foi definido como 1994, o ano anterior ao início da análise econômica. Os valores utilizados são apresentados na Tabela 14.

Tabela 14: Valores de Condição Inicial do Pavimento

\begin{tabular}{cc}
\hline Variável & Valor \\
\hline Irregularidade - IRI $(\mathrm{m} / \mathrm{km})$ & 4 \\
Área total de trincas $(\%)$ & 5 \\
Área com Desgaste $(\%)$ & 10 \\
Número de Panelas $(\mathrm{qtde} / \mathrm{km})$ & 0 \\
Quebra de Bordo $\left(\mathrm{m}^{2} / \mathrm{km}\right)$ & 10 \\
Trilha de Roda média $(\mathrm{mm})$ & 5 \\
Profundidade de Textura $(\mathrm{mm})$ & 0,7 \\
Resistência ao deslizamento $(\mathrm{SCRIM}$ a $50 \mathrm{Km} / \mathrm{h})$ & 0,45 \\
Drenagem & Regular \\
\hline
\end{tabular}




\subsection{DEFINIÇÃO DE CENÁRIOS DE SIMULAÇÃO}

Definidos os parâmetros que caracterizam os locais de estudo, é possível prosseguir com a avaliação de projetos do HDM-4. Nessa etapa, além de selecionar os parâmetros previamente cadastrados (vide Figura 20), são necessárias ainda algumas informações complementares.

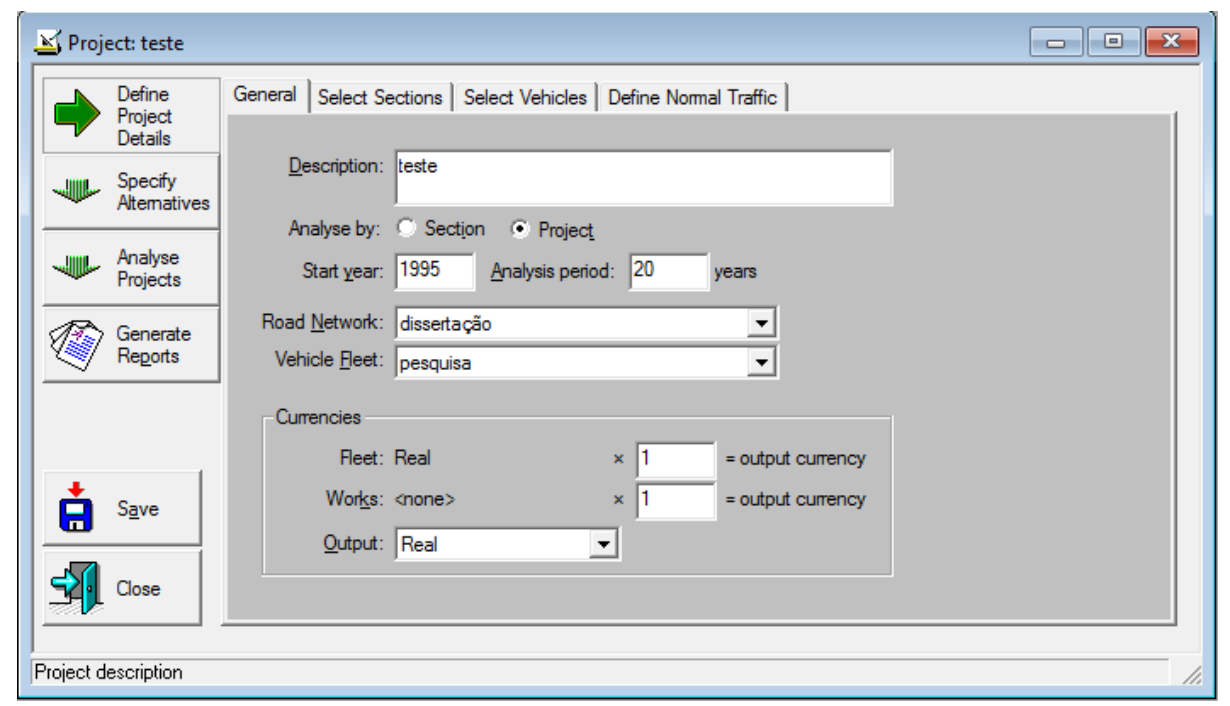

Figura 20: Configuração da Análise de Projeto no HDM-4

Além do ano de início e do período das análises, outro dado importante que deve ser inserido nessa etapa é a caracterização do tráfego durante esse período (última aba da janela ilustrada na Figura 20). É necessário informar o tráfego no ano de início da análise, a composição inicial de cada veículo e a taxa de crescimento de tráfego anual, a partir do ano inicial (Figura 21).

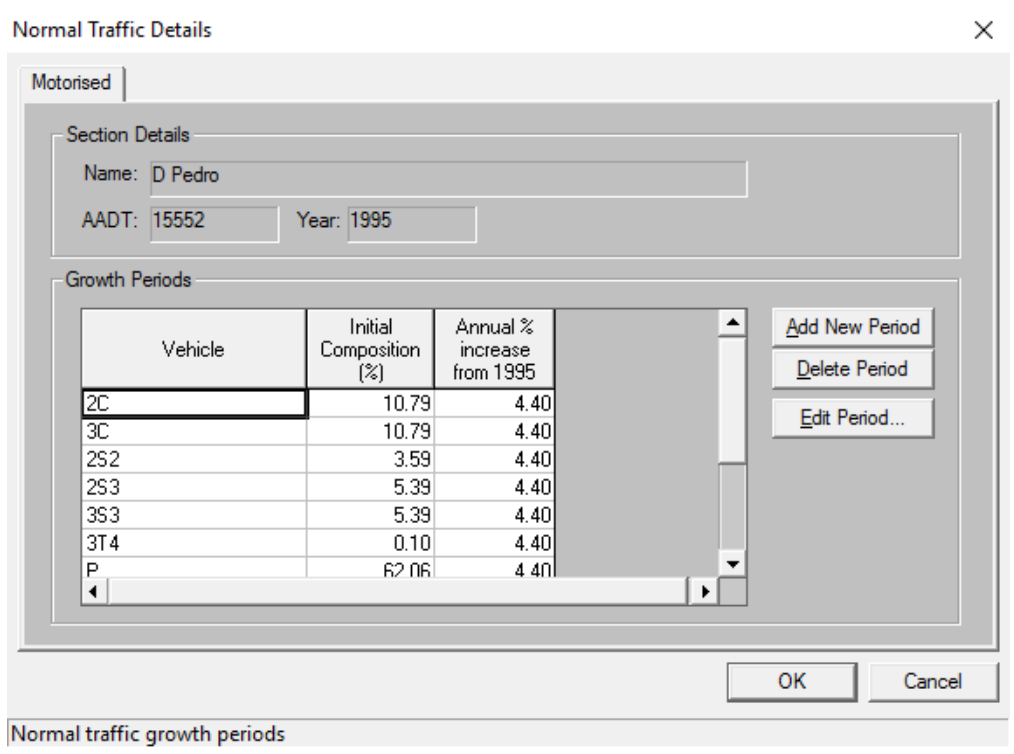

Figura 21: Caracterização do Tráfego Durante o Período de Análise 
Como já mencionado anteriormente, durante a aquisição dos dados para seleção dos locais de estudo dessa pesquisa, os volumes de tráfego encontrados foram apenas entre os anos de 2012 a 2015. Sendo assim, e pela necessidade de se conhecer os dados referentes aos anos anteriores, foi necessário realizar uma estimativa do tráfego entre os anos de 1995 e 2011. Para tanto, foram aplicados dois índices.

Desde o ano de 1999, a ABCR - Associação Brasileira de Concessionárias de Rodovias - mede o tráfego nas praças de pedágio das rodovias de suas associadas. O número índice tem como base média o valor de 100, para o ano de 1999, refletindo assim as variações no volume de tráfego nos anos subsequentes com base no volume médio medido em 1999. Sendo assim, definiu-se o VDM entre os anos de 1999 e 2012 para as rodovias em estudo pela simples aplicação da média anual do Índice ABCR ao tráfego verificado no ano de 2013. O mesmo ocorreu para os anos de 2014 e 2015, uma vez que não se dispunha do tráfego nesses anos para as rodovias Dutra e Fernão Dias.

Entre os anos de 1995 e 1999, como não existia o índice ABCR, o tráfego foi determinado através do conceito de elasticidade VDM x PIB, relacionando a variação percentual do Produto Interno Bruto paulista com a variação percentual de tráfego nas rodovias paulistas. A elasticidade VDM x PIB adotada foi igual a 1,0, ou seja, para cada $1 \%$ de variação no PIB do estado de São Paulo, o VDM nas rodovias paulistas também variava 1\%, sendo esse valor o limite mínimo do intervalo comumente citado por vários autores no Brasil (entre 1\% e 1,5\%).

Com os volumes de tráfego de veículos de passeio e veículos comerciais definidos para o intervalo de análise dessa pesquisa, foi possível calcular a taxa de crescimento médio anual do tráfego para os veículos de passeio e comerciais, através da fórmula:

$$
i_{a}=\left[\left(\frac{V D M_{n}}{V D M_{0}}\right)^{\frac{1}{n}}\right]-1
$$

Onde:

$\mathrm{i}_{\mathrm{a}}=$ taxa média de crescimento anual;

$\mathrm{VDM}_{\mathrm{n}}=$ Volume Diário Médio no último ano da análise

$\mathrm{VDM}_{0}=$ Volume Diário Médio no primeiro ano da análise

$\mathrm{n}=$ período de análise (anos)

O crescimento médio anual calculado foi de $4,33 \%$ a.a. para os veículos de passeio, e de 4,53\% a.a. para os veículos comerciais. 
Com esses valores, a última etapa é a divisão do tráfego entre os veículos cadastrados (conforme Tabela 9, apresentada anteriormente). Como os dados de tráfego disponibilizados pelas agências reguladoras e pelas concessionárias não são divididos por categoria, para essa pesquisa foram utilizados valores tipicamente encontrados em rodovias paulistas, além de experiências anteriores do autor e do orientador dessa pesquisa. A divisão do tráfego, por tipo de veículo, ocorreu de forma igual em todos os anos da análise, mantendo dessa forma a mesma configuração durante 20 anos. Essa decisão não reflete a realidade, uma vez que pode existir variação na configuração dos veículos que transitam pelas rodovias, contudo, principalmente devido à escassez de informações, optou-se por manter esse padrão. A divisão de tráfego, em cada rodovia analisada, por tipo de veículo, é apresentada na Tabela 15.

\begin{tabular}{cccc}
\multicolumn{4}{c}{ Tabela 15: Distribuição do Tráfego por Tipo de Veículo } \\
\hline Código & Dutra & Dom Pedro & Fernão \\
\hline P & $64,97 \%$ & $62,06 \%$ & $62,06 \%$ \\
2C & $4,89 \%$ & $9,79 \%$ & $7,79 \%$ \\
O & $5,00 \%$ & $1,00 \%$ & $3,00 \%$ \\
3C & $9,89 \%$ & $10,79 \%$ & $10,79 \%$ \\
2S2 & $3,29 \%$ & $3,59 \%$ & $3,59 \%$ \\
2S3 & $4,94 \%$ & $5,39 \%$ & $5,39 \%$ \\
3S3 & $4,94 \%$ & $5,39 \%$ & $5,39 \%$ \\
P3 & $0,46 \%$ & $0,44 \%$ & $0,44 \%$ \\
P4 & $0,19 \%$ & $0,18 \%$ & $0,18 \%$ \\
M & $1,33 \%$ & $1,27 \%$ & $1,27 \%$ \\
3T4 & $0,10 \%$ & $0,10 \%$ & $0,10 \%$ \\
\hline
\end{tabular}

Após a caracterização do tráfego durante o período de análise, é possível dar sequência nas simulações. Por se tratar de uma análise econômica, são necessárias ao menos duas alternativas, para que se estabeleçam os comparativos entre essas alternativas. No caso desse trabalho, as alternativas são diferentes estratégias de manutenção, adotadas tanto por concessionárias, como por órgãos públicos. As alternativas foram criadas, de tal forma a seguir as seguintes hipóteses:

- Hipótese 1: O pavimento irá sofrer intervenção somente quando sua superfície estiver em condição impraticável, com alta irregularidade;

- Hipótese 2: O pavimento receberá intervenções preventivas, porém somente quando os níveis de irregularidade forem maiores do que os definidos para uma condição "Boa";

- Hipótese 3: O pavimento, após um período de recuperação até que se atinjam níveis de irregularidade "Excelente", recebe intervenções de modo a permitir que esse nível seja mantido sempre; 
- Hipótese 4: O pavimento, após um período de recuperação até que se atinjam níveis de irregularidade "Excelente", recebe intervenções de reforço, programadas em um intervalo de 5 anos.

A Hipótese 1 é a Condição Base de comparação para as análises, uma vez que ela representa estratégias de manutenção presentes em grande parte das rodovias sob administração do poder público, e o pior cenário, em termos de irregularidade e conforto, para o usuário. A Hipótese 2 traz uma alternativa empregada pelo poder público, na figura do DNIT, em contratos do CREMA - Contrato de Restauração e Manutenção - programa do governo federal que, em sua segunda etapa, prevê obras de recuperação funcional e estrutural de pavimentos, considerando uma vida útil de 10 anos, em um contrato de 5 anos.

As Hipóteses 3 e 4 referem-se a rodovias concedidas. Tomando como base as exigências constantes no PER das concessões da segunda etapa da ANTT, em ambas as hipóteses, as concessionárias devem, num período máximo de 5 anos, recuperar o pavimento até um limite mínimo exigido (IRI igual a 2,7 m/km), e após isso, mantê-lo sempre na mesma condição. Ao mesmo tempo, o PER estabelece que as soluções técnicas de manutenção devem garantir vida de serviço superior a 5 anos, mantendo o bom estado do pavimento até a próxima intervenção programada. Em cima dessas duas exigências do PER, foram definidas as Hipóteses 3 e 4, sendo o diferencial de ambas o fato de, em uma, haver sempre intervenção antes de se atingir IRI de $2,7 \mathrm{~m} / \mathrm{km}$ (Hipótese 3), enquanto que em outra, a intervenção é programada, e ocorre a cada 5 anos (Hipótese 4). O gráfico da Figura 22 mostra, em um exemplo hipotético, as diferenças entre os tipos de intervenção utilizados nas simulações.

\section{ESTRATÉGIAS DE MANUTENÇÃO ADOTADAS}

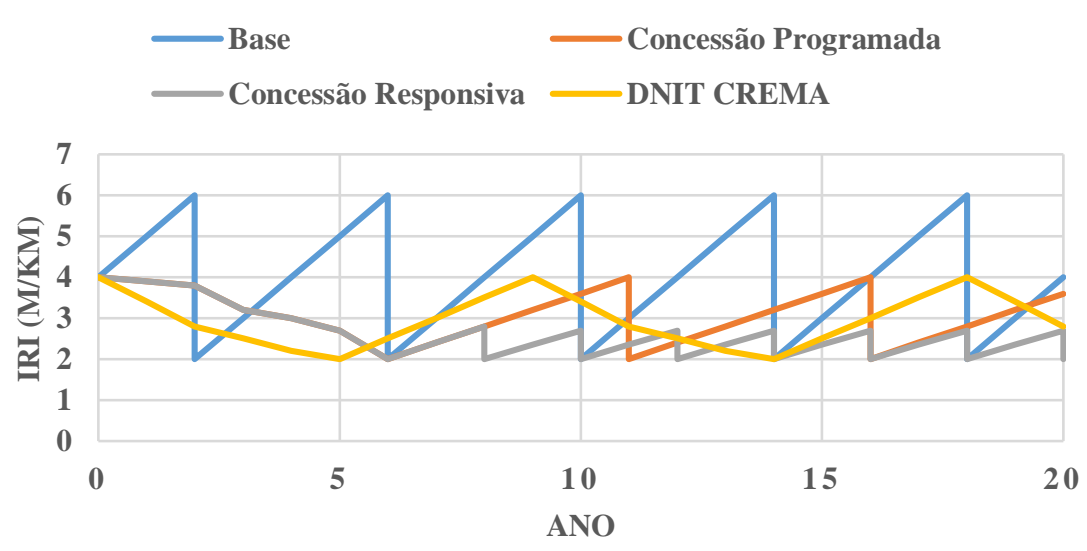

Figura 22: Estratégias de Manutenção Utilizadas nas Simulações 
Para criar as estratégias supracitadas, foram cadastradas duas atividades básicas de manutenção: Microrrevestimento asfáltico (Thin Overlay) para as atividades de manutenção rotineira, ou aquelas que visam reduzir gradativamente a irregularidade do pavimento; e Reforço (Overlay dense-graded Asphalt), para as atividades programadas que visam recuperar o pavimento. Em todos os casos, o Microrrevestimento foi projetado com espessura de $25 \mathrm{~mm}$, Coeficiente de Força igual a 0,2 e indicador de defeito de construção igual a 1 (representando condição de construção regular). O Reforço, por sua vez, foi projetado com espessura de 50mm, Coeficiente de Força igual a 0,4 e indicador de defeito de construção igual a 0,5 (representando um pavimento bem construído).

Por se tratar de uma análise econômica do ponto de vista do usuário de rodovias, não foram incluídos os custos dos serviços executados, uma vez que para o usuário de rodovias concedidas, mais importante do que o valor gasto na execução de obras é a qualidade e durabilidade do serviço executado, exercendo esses fatores influência direta no conforto, segurança e satisfação dos usuários. As atividades de manutenção de cada estratégia citada anteriormente são descritas, com seus respectivos valores limite, na Tabela 16.

Tabela 16: Descrição das Estratégias de Manutenção Adotadas

$\begin{array}{cc}\text { Estratégia } & \text { Descrição e Valores Limite } \\ \begin{array}{c}\text { Condição } \\ \text { Base }\end{array} & \text { intervenção responsiva, com REFORÇO, sempre que IRI atingir valor igual a 6; IRI } \\ \text { após intervenção igual a 2; }\end{array}$

CREMA

DNIT

Concessão

Responsiva

Concessão

Programada intervenção programada, com MICRORREVESTIMENTO, reduzindo o IRI para 3,4 ao final do primeiro ano; 2,8 ao final do segundo ano; 2,5 ao final do terceiro ano; 2,2 ao final do quarto ano; 2 ao final do quinto ano; após o quinto ano, ciclo reinicia no décimo ano;

intervenção programada, com MICRORREVESTIMENTO, reduzindo o IRI para 3,9 ao final do primeiro ano; 3,8 ao final do segundo ano; 3,2 ao final do terceiro ano; 3,0 ao final do quarto ano; 2,7 ao final do quinto ano; 2 ao final do sexto ano; após o sexto ano, intervenção com MICRORREVESTIMENTO sempre que IRI atingir 2,7; IRI após intervenção igual a 2

intervenção programada, com MICRORREVESTIMENTO, reduzindo o IRI para 3,9 ao final do primeiro ano; 3,8 ao final do segundo ano; 3,2 ao final do terceiro ano; 3,0 ao final do quarto ano; 2,7 ao final do quinto ano; 2 ao final do sexto ano; após o sexto ano, intervenção com REFORÇO a cada 5 anos; IRI após intervenção igual a 2 
Tendo as 4 alternativas listadas, é possível realizar as simulações, porém devem ser feitas algumas considerações. Primeiramente, como os preços das peças e combustível são inseridos somente para o ano de 2015, efeitos como inflação ou grandes variações nos preços dos insumos não são considerados nas análises do HDM-4. Portanto, apesar de possuir os valores das tarifas cobradas ao longo de todo o período de análise, optou-se por utilizar somente as tarifas cobradas no ano de 2015, aplicando diretamente sobre essas as taxas de desconto utilizadas, excluindo também os efeitos de inflação e outras possíveis variações nas tarifas de pedágio.

Nessa pesquisa, as análises econômicas foram realizadas utilizando o VPL, a relação B/C e a TIR. Por se tratarem de diferentes ferramentas de análise, as abordagens e os usos das mesmas foram diferentes. Para o VPL, foram realizadas duas suposições: de forma hipotética, considerou-se que as concessões ocorreram sempre juntas, durante todo o período de análise, avaliando dessa forma os efeitos das diferenças existentes entre as tarifas de cada modelo de concessão. A segunda suposição é a que mais se aproxima da realidade, pois apesar de avaliar todas as rodovias em todo o período de análise, considera os períodos onde não houve cobrança de pedágio. Em ambas as suposições para o VPL, realizaram-se simulações com taxa de desconto igual a $6 \%, 12 \%$ e $18 \%$.

A Relação B/C utilizou os valores calculados na análise do VPL, determinando pela análise incremental qual estratégia apresentou a maior relação de benefícios pelos custos dos usuários. A TIR, por sua vez, foi calculada pelas duas suposições do VPL, e posteriormente comparada com a rentabilidade de empresas do setor de transportes, e também com investimentos no mercado de ações que apresentam baixo risco ao investidor. De forma resumida, procura-se na análise da TIR perguntar: “Qual foi a melhor opção de investimento para um investidor entre os ano de 1995 e 2015 ? Investir em uma empresa de transportes ou realizar outros investimentos de menor risco de mercado?". Além disso, observou-se se as tarifas de pedágio podem ou não ser um impeditivo do crescimento e da saúde econômica dos usuários, quer eles estejam em uma transportadora, quer sejam usuários com veículos de passeio.

Destaca-se que os cenários simulados foram hipotéticos, considerando que todos os trechos foram concedidos exatamente ao mesmo tempo, seguindo sempre as mesmas estratégias de manutenção. Embora essa não seja a condição real, nem mesmo a ideal, isso permite que as análises econômicas tenham sempre um mesmo período, de modo a permitir um comparativo tanto entre as alternativas de manutenção, como entre as rodovias. 


\section{ANÁLISE DE RESULTADOS}

A seguir serão apresentados os resultados obtidos através das simulações com o software HDM4, sendo observados três aspectos: o comportamento do pavimento nas diferentes estratégias de manutenção adotados; os efeitos aos usuários decorrentes da condição do pavimento, em cada estratégia de manutenção; e a análise econômica das alternativas, considerando as diferenças nos custos operacionais entre os diferentes estratégias de manutenção, e os custos pelo pagamento de pedágio nas rodovias.

\subsection{ANÁLISE DO COMPORTAMENTO DO PAVIMENTO}

A avaliação do comportamento do pavimento deu-se de acordo com as variáveis que caracterizam a sua condição. Foram analisadas as seguintes variáveis de saída do HDM-4: Área total de trincas (percentual em relação à área total do pavimento), Afundamento de trilha de roda médio $(\mathrm{mm})$ e IRI $(\mathrm{m} / \mathrm{km})$. Em avaliação preliminar, foi possível identificar que não há variação significativa nos valores das variáveis entre as rodovias, sendo mais perceptíveis as diferenças entre as estratégias de manutenção. Em relação às rodovias, percebe-se apenas que o trecho selecionado na Rodovia Presidente Dutra, de maneira geral, apresentou degradação mais acelerada no pavimento e em maiores níveis, fato que pode ser explicado principalmente pelo maior número de eixos equivalentes trafegando no trecho da Dutra em comparação com os outros dois trechos (Fernão Dias e Dom Pedro), como pode ser observado na Figura 23:

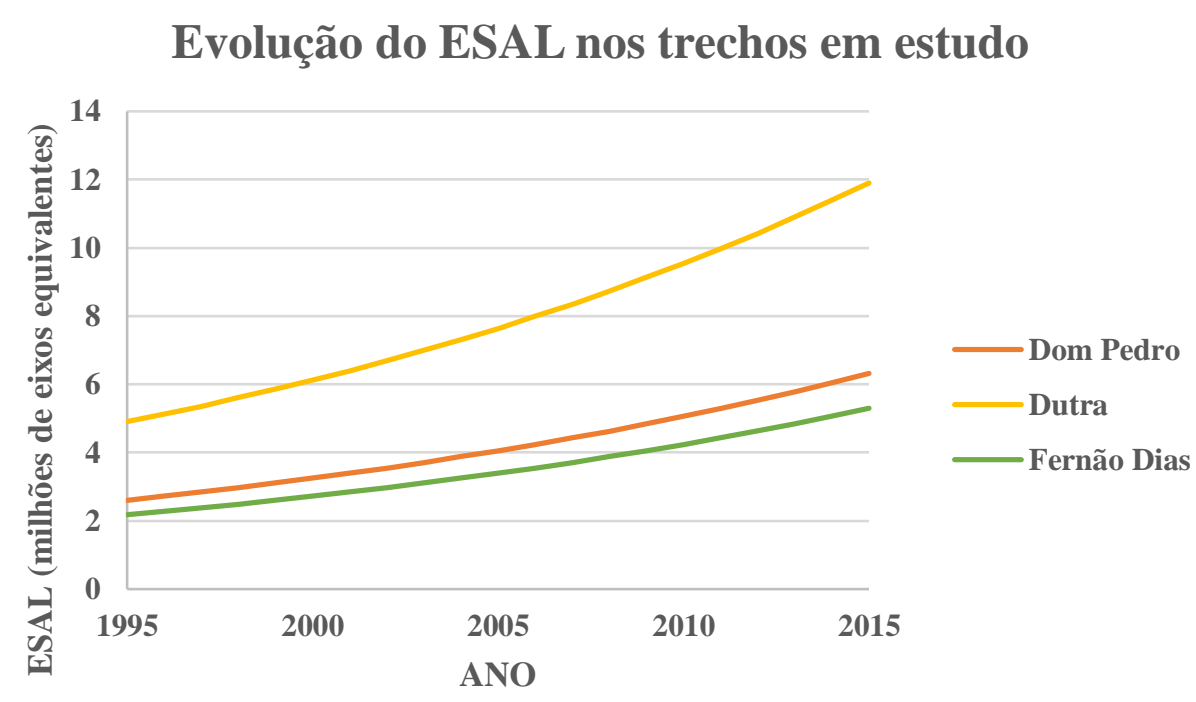

Figura 23: Evolução do $n^{\circ}$ de eixos equivalentes nos trechos em estudo 
Sendo assim, para avaliar as diferenças entre as alternativas, serão apresentados os resultados de um único trecho, uma vez que os comportamentos são semelhantes nos demais.
a) Área total de trincas $(\%)$

A área total de trincas no pavimento representa, dentro da extensão avaliada, qual o percentual da área total do pavimento que se encontra com trincas, independente da causa das mesmas. Em todas as estratégias, o percentual inicial da área de trincas definido foi igual a 5\% (conforme já exposto anteriormente, na Tabela 14). A evolução dessa área de trincas ao longo dos anos, em cada estratégia adotada para o trecho selecionado da Rodovia Dom Pedro I, pode ser observada no gráfico da Figura 24.

\section{EVOLUÇÃO DA ÁREA TOTAL DE TRINCAS - DOM PEDRO}

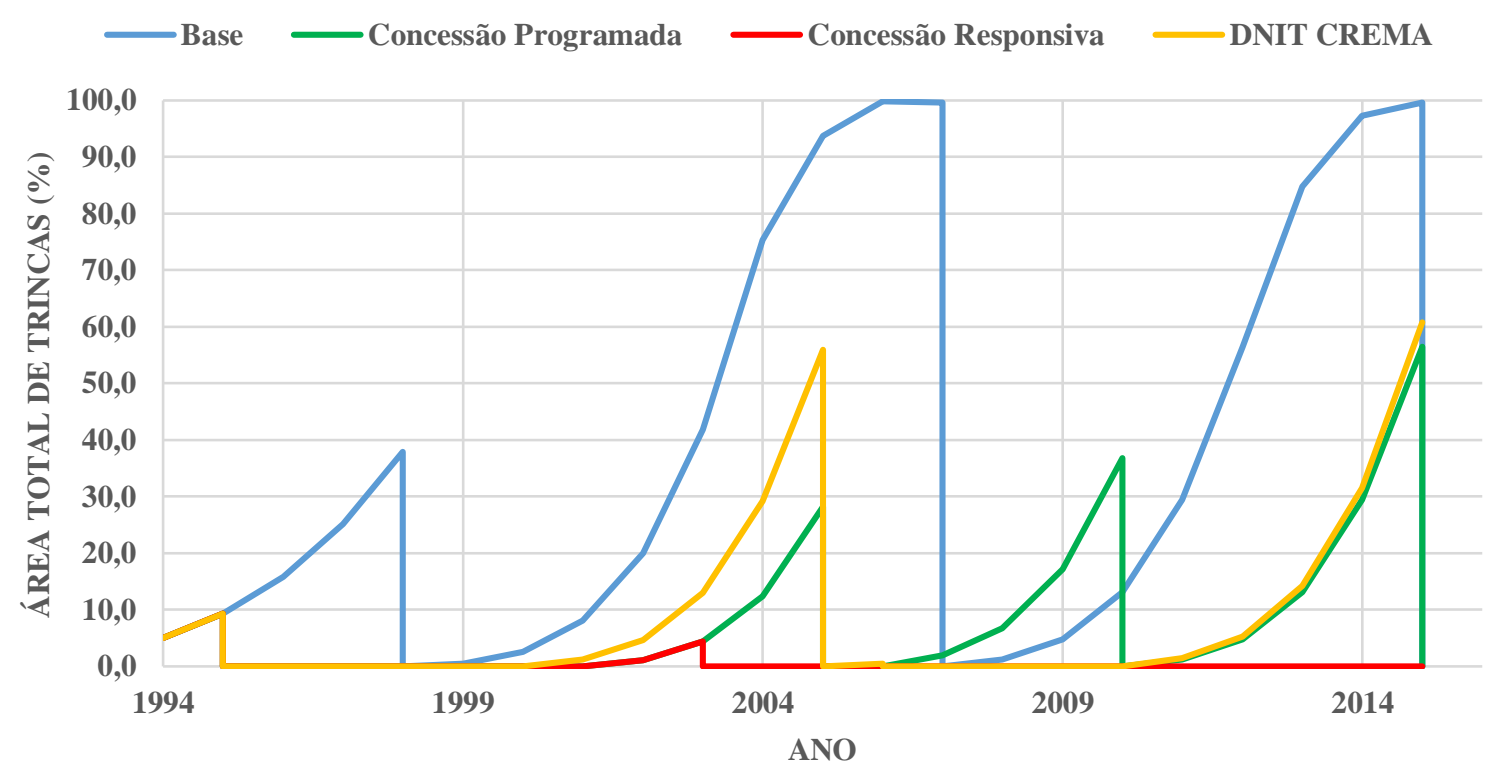

Figura 24: Evolução da área total de trincas no trecho da rodovia Dom Pedro I

Como esperado, a condição base é a que apresentou o maior nível de degradação do pavimento, ao se considerar as trincas. As intervenções nessa estratégia ocorreram quase sempre quando o pavimento já apresentava $100 \%$ de sua área trincada. A estratégia "Concessão Responsiva" foi a que apresentou os menores percentuais de área com trincas, o que também era esperado, uma vez que dentre as estratégias existentes, era a que possuía a maior frequência de intervenções. Nas demais estratégias, o comportamento foi semelhante, embora a estratégia do CREMA tenha atingido maiores picos no total de área trincada, porém com um menor número de intervenções. 
b) Trilha de roda média $(\mathrm{mm})$

O afundamento médio de trilha de roda, medido em milímetros, é um importante parâmetro na avaliação do comportamento do pavimento, por ser também um indicativo da condição estrutural do mesmo, uma vez que a trilha de roda é um indicador de deformação permanente do pavimento, ou seja, um indicativo de falha ou redução da sua condição estrutural. A evolução da trilha de roda no trecho da rodovia Dom Pedro I é indicada na Figura 25.

\section{EVOLUÇÃO DA TRILHA DE RODA - DOM PEDRO}

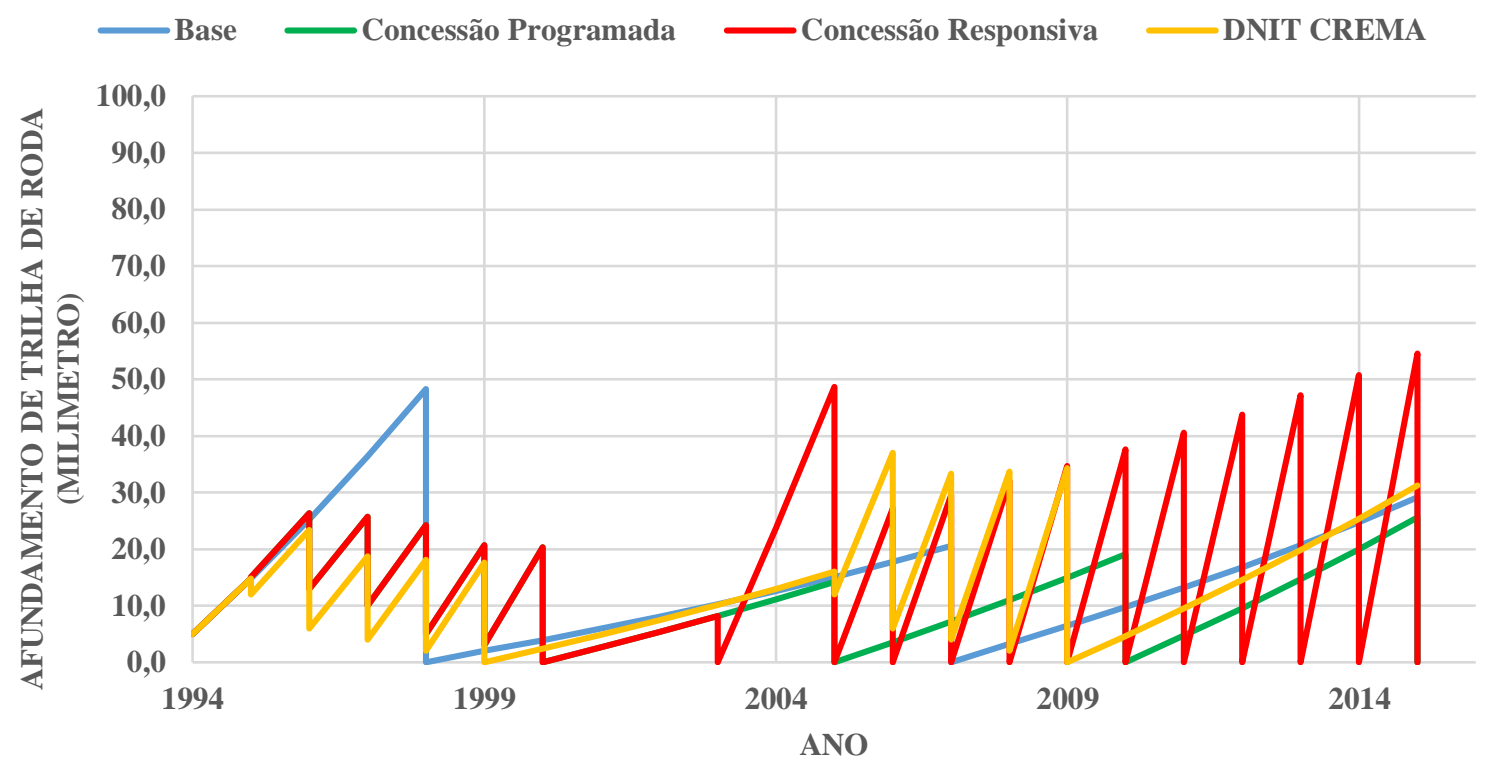

Figura 25: Evolução do afundamento médio da trilha de roda, trecho da Dom Pedro I

Diferentemente da evolução da área total de trincas no pavimento, percebe-se que os maiores valores de afundamento médio de trilha de roda ocorreram na estratégia de "Concessão Responsiva”. Isso indica que, apesar de manter os níveis de IRI sempre abaixo de um valor estabelecido, as intervenções frequentes com microrrevestimento não atuam na correção estrutural do pavimento, o que permite a ocorrência de afundamentos maiores na trilha de roda com essa estratégia.

Outro indicativo dessa suposição é que, apesar da condição base aplicar intervenções no pavimento somente quando o mesmo encontra-se com alto nível de degradação e com baixa serventia, o fato das intervenções nessa estratégia serem sempre de "Reforço" no pavimento permite uma menor ocorrência de trilhas de roda. Destaca-se que, muito embora as trilhas de roda não exerçam influência direta na irregularidade do pavimento, a sua existência prejudica 
a segurança dos usuários, por ser um ponto de acúmulo de água das chuvas, possibilitando a ocorrência de aquaplanagem.

c) $\operatorname{IRI}(\mathrm{m} / \mathrm{km})$

Para os propósitos da pesquisa desenvolvida, o IRI é a variável com maior relevância, na medida em que grandes irregularidades aumentam o consumo de combustíveis, lubrificantes, pneus e peças, e aumentam os tempos de viagem, elevando o custo de transporte. A evolução da irregularidade longitudinal, medida através do IRI em metros por quilômetro, é apresentada no gráfico ilustrado na Figura 26.

\section{EVOLUÇÃO DO IRI - DOM PEDRO}

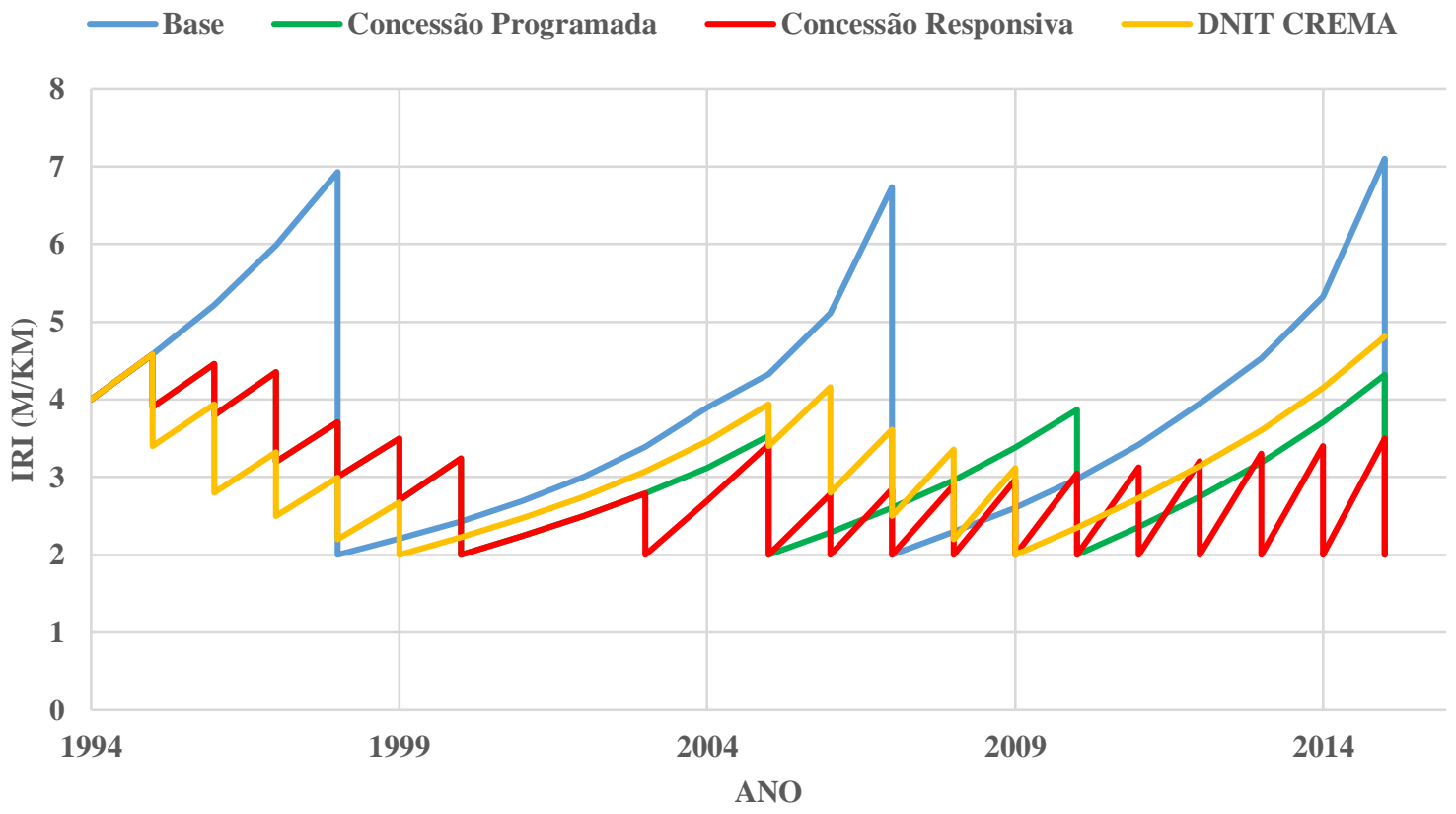

Figura 26: Evolução do afundamento médio da trilha de roda, trecho da Dom Pedro I

A primeira informação importante que pode ser extraída desse gráfico é que a definição da condição Base foi coerente, uma vez que a mesma, mesmo após intervenções, apresenta sempre os maiores valores de IRI, sendo dessa forma a estratégia que, economicamente, é a mais desfavorável para os usuários de uma rodovia. As intervenções ocorrem em condições tão extremas que, embora as mesmas fossem programadas sempre que o IRI atingisse valor igual a $6 \mathrm{~m} / \mathrm{km}$, a irregularidade chega a atingir $7 \mathrm{~m} / \mathrm{km}$, ou mesmo superar esse valor (como ocorre no ano de 2015), o que reflete uma rápida deterioração do pavimento quanto maior a irregularidade do mesmo. 
As demais estratégias de manutenção apresentam irregularidades significativamente menores em relação à condição Base, mas possuem comportamentos distintos. A estratégia do CREMA, devido aos parâmetros de contrato, apresentou menor IRI médio nos primeiros anos de análise, quando comparada às estratégias atribuídas às concessões. Após o quinto ano de análise, a ausência de qualquer atividade de manutenção ou reabilitação permite que o IRI cresça e se mantenha quase sempre maior que o IRI nas estratégias com concessão, com exceção de um período de 2 anos, entre 2008 e 2010, onde a estratégia "Concessão Programada" possui IRI superior ao da condição do CREMA.

A evolução do IRI no período de 5 anos sem intervenções (entre 2000 e 2005), saindo de 2 $\mathrm{m} / \mathrm{km}$ para $4 \mathrm{~m} / \mathrm{km}$ no caso da Rodovia Dom Pedro, é superior ao desejado, uma vez que durante o período sem intervenções, o pavimento deveria atender o limite máximo de irregularidade nos contratos do CREMA - 2,8 m/km. Contudo, destaca-se que em muitos casos, o HDM-4 superestima as previsões do IRI, levando a valores maiores do que os reais. Além disso, a adoção do valor de IRI após as intervenções de "Reforço" igual a $2 \mathrm{~m} / \mathrm{km}$ teve como base evidências empíricas de rodovias no estado de São Paulo com pavimento em boas condições, podendo esse valor após as intervenções ser menor, o que por consequência diminuiria o IRI nos períodos sem intervenções.

Ainda que exista a possibilidade do IRI determinado pelo HDM-4 ser superestimado, os mesmos tipos de intervenção foram aplicados em todas as estratégias, o que faz com que esse comportamento se repita nas análises com as concessões. Os 6 primeiros anos de análise nas opções "Concessão Responsiva" e "Concessão Programada" são exatamente iguais, uma vez que seguem as exigências da fase de "Trabalhos Iniciais" do PER. Após o sexto ano de análise, é possível observar o comportamento do pavimento quando submetido a duas estratégias distintas: uma com intervenções frequentes, mantendo os limites máximos de irregularidade permitidos, mas de menor qualidade construtiva (Concessão Responsiva), e outra com intervenção de maior qualidade construtiva, que visa também melhorar a condição estrutural do pavimento, pautada pelo intervalo mínimo exigido no PER entre intervenções desse tipo, mas que acaba excedendo o limite máximo imposto (Concessão Programada).

O que se percebe é que, no caso da estratégia responsiva, as intervenções ocorrem praticamente todo ano, uma vez que a intervenção com microrrevestimento tem menor durabilidade do que o reforço do pavimento. A estratégia programada, por sua vez, embora apresente valores finais de IRI mais elevados, permanece dentro do limite máximo na maior parte do tempo, em cada ciclo de 5 anos entre as intervenções. Na prática, ambas as estratégias podem ser aplicadas 
simultaneamente nas concessões, contudo a separação de ambas serve para avaliar melhor o impacto da decisão de se adotar uma ou outra estratégia, na medida em que ambas apresentam vantagens e desvantagens.

\subsection{ANÁLISE DOS EFEITOS AOS USUÁRIOS}

A análise dos efeitos aos usuários, nas diferentes estratégias de manutenção, foi realizada considerando-se 5 componentes básicos: redução no consumo de combustível, lubrificante, pneus, peças e redução no tempo de viagem. Optou-se por realizar essa análise somente com a Rodovia Dom Pedro, uma vez que, novamente, os comportamentos em função das estratégias foram semelhantes em todos os trechos. De uma forma geral, a diferença mais observada foi que na Dutra, o consumo apresentava-se ligeiramente superior ao consumo das demais rodovias. A análise por componente é realizada a seguir. Todos os valores apresentados são na unidade de medida por 1000 veículos x km.

a) Redução no consumo de combustível

O consumo de combustível variou anualmente para cada estratégia adotada. Dessa forma, para fins comparativos, optou-se por comparar os resultados com as médias de todo o período de análise, para cada tipo de veículo e para cada estratégia de intervenção adotada. Os valores para a Rodovia Dom Pedro são apresentados na Tabela 17, juntamente com os valores de desviopadrão $(\mu)$ identificados.

Tabela 17: Consumo médio de combustível e desvio-padrão das simulações realizadas

\begin{tabular}{|c|c|c|c|c|c|c|c|c|}
\hline \multirow{2}{*}{ Veículo } & \multicolumn{2}{|l|}{ Base } & \multicolumn{2}{|l|}{ Cprog } & \multicolumn{2}{|l|}{ CREMA } & \multicolumn{2}{|l|}{ Cresp } \\
\hline & Consumo ( 1 ) & $\mu$ & Consumo ( 1 ) & $\mu$ & Consumo ( 1 ) & $\mu$ & Consumo ( 1 ) & $\mu$ \\
\hline $\mathbf{P}$ & 84,5 & 1,6 & 85,4 & 0,2 & 85,4 & 0,2 & 85,3 & 0,1 \\
\hline 2C & 239,3 & 1,5 & 238,8 & 1,4 & 238,8 & 1,4 & 238,3 & 1,3 \\
\hline $\mathbf{O}$ & 226,8 & 2,5 & 225,3 & 1,2 & 225,3 & 1,1 & 224,9 & 1,1 \\
\hline $3 \mathrm{C}$ & 472,5 & 9,8 & 477,2 & 2,1 & 477,2 & 1,9 & 476,5 & 1,8 \\
\hline 2S2 & 560,1 & 12,9 & 568,2 & 2,1 & 568,2 & 2,3 & 567,5 & 1,6 \\
\hline $2 \mathrm{S3}$ & 619,6 & 4,3 & 622,1 & 2,9 & 622,1 & 2,7 & 621,0 & 2,4 \\
\hline $3 \mathrm{S3}$ & 680,0 & 6,7 & 676,8 & 3,9 & 676,8 & 3,6 & 675,4 & 3,3 \\
\hline $\mathbf{P 3}$ & 103,5 & 1,9 & 104,5 & 0,2 & 104,5 & 0,2 & 104,4 & 0,2 \\
\hline P4 & 123,4 & 1,9 & 124,4 & 0,3 & 124,4 & 0,3 & 124,3 & 0,2 \\
\hline $\mathbf{M}$ & 40,5 & 1,2 & 41,1 & 0,1 & 41,1 & 0,1 & 41,1 & 0,0 \\
\hline $3 \mathrm{~T} 4$ & 770,8 & 10,5 & 764,5 & 4,4 & 764,5 & 4,3 & 763,1 & 4,1 \\
\hline
\end{tabular}


Diferentemente do que se esperava, os maiores consumos médios identificados nem sempre foram encontrados na alternativa "Base". Em veículos como P, 3C, 2S2, dentre outros, a condição Base foi, inclusive, a que apresentou o menor consumo médio entre todas as alternativas consideradas. Contudo, observa-se que a alternativa Base foi a que apresentou os maiores valores de desvio-padrão em todos os veículos, com valores muito superiores aos encontrados nas demais estratégias de manutenção. Dessa forma, o gráfico a seguir (Figura 27) ilustra a redução do consumo de combustível, nas diferentes estratégias de manutenção, para cada veículo, quando comparados com o máximo valor de consumo encontrado na condição Base, que reflete a pior condição do pavimento.

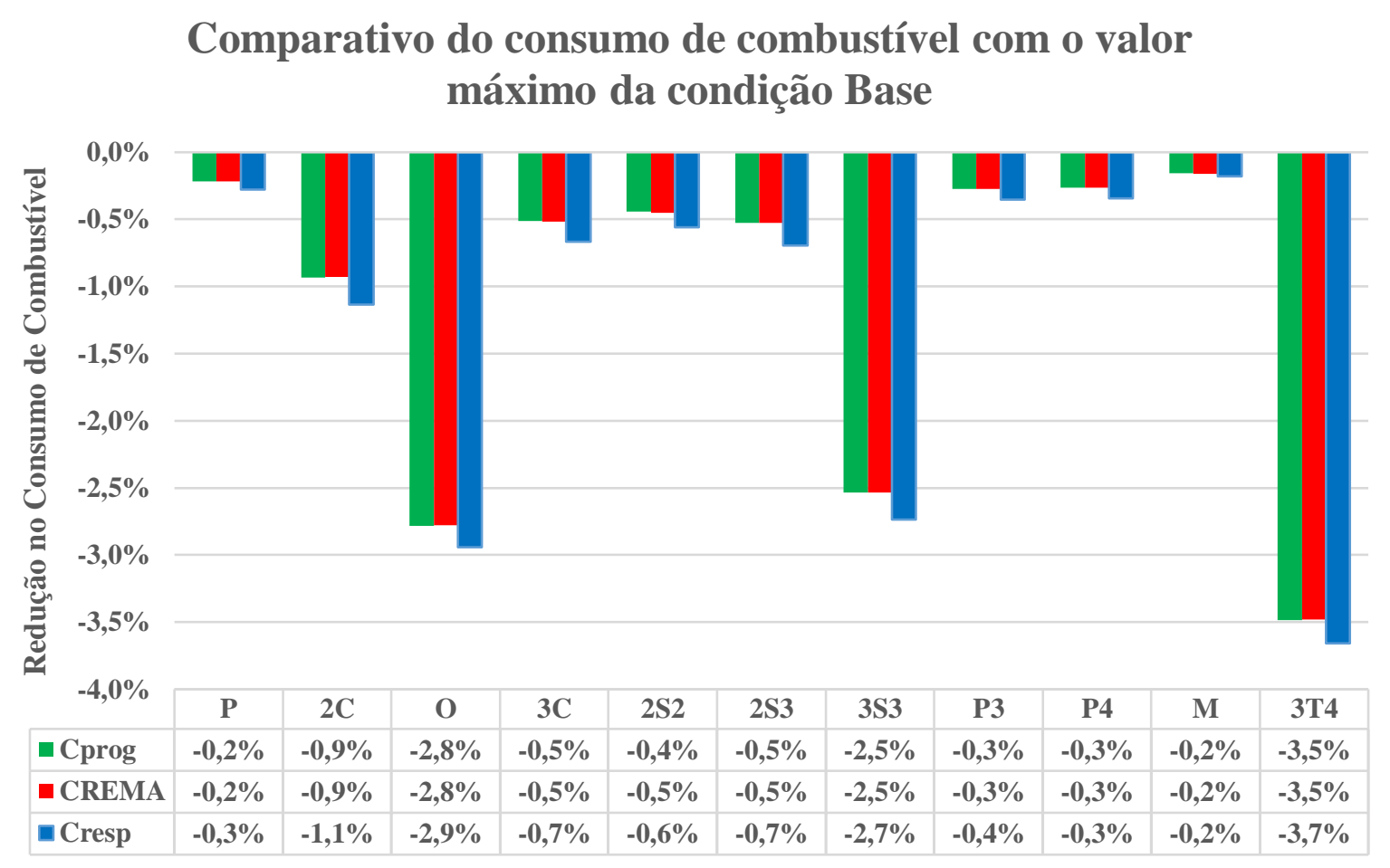

Figura 27: Redução do consumo de combustível em relação aos valores máximos da condição

\section{Base}

Por esse gráfico, percebe-se que o maior impacto da melhor condição do pavimento ocorre nos veículos 3S3 e 3T4 (caminhões com 6 e 7 eixos, respectivamente), bem como nos Ônibus (O), o que era esperado. A redução foi pouco significativa para os veículos de passeio (M, P, P3 e P4), e um pouco maior nos demais veículos. Dentre as estratégias de manutenção, a que possibilitou maior redução no consumo foi a Concessão Responsiva. A maior redução de consumo no combustível identificada, de 3,7\%, é compatível com os valores fornecidos pela CNT (2016), que aponta redução média de 5\% no combustível quando os veículos trafegam em rodovias com pavimento em boas condições. 
b) Redução no consumo de lubrificantes

Para avaliar a redução do consumo de lubrificantes, foi adotada a mesma abordagem dos combustíveis. Contudo, a redução de consumo de lubrificantes foi praticamente nula, uma vez que os valores de consumo foram quase idênticos entre as diferentes estratégias adotadas, como pode ser constatado avaliando os valores constantes na Tabela 18.

Tabela 18: Consumo médio de lubrificantes

\begin{tabular}{ccccc}
\hline Veículo & Base & Cprog & CREMA & Cresp \\
& & & & \\
\hline P & 0,64 & 0,64 & 0,64 & 0,64 \\
$\mathbf{2 C}$ & 2,06 & 2,06 & 2,06 & 2,06 \\
$\mathbf{O}$ & 2,23 & 2,22 & 2,22 & 2,22 \\
$\mathbf{3 C}$ & 4,09 & 4,10 & 4,10 & 4,10 \\
$\mathbf{2 S 2}$ & 4,28 & 4,29 & 4,29 & 4,29 \\
$\mathbf{2 S 3}$ & 4,40 & 4,41 & 4,41 & 4,40 \\
$\mathbf{3 S 3}$ & 4,53 & 4,52 & 4,52 & 4,52 \\
$\mathbf{P 3}$ & 0,69 & 0,69 & 0,69 & 0,69 \\
$\mathbf{P 4}$ & 0,75 & 0,75 & 0,75 & 0,75 \\
$\mathbf{M}$ & 0,46 & 0,46 & 0,46 & 0,46 \\
$\mathbf{3 T 4}$ & 4,72 & 4,71 & 4,70 & 4,70 \\
\hline
\end{tabular}

Os desvios-padrões em todos os casos foram muito próximos de zero, o que demonstra pouca influência do estado do pavimento ao longo do tempo no modelo para determinação do consumo de lubrificantes do HDM-4. Em nenhum caso, a variação no consumo médio de lubrificantes da condição Base para as demais ultrapassou 0,5\%. As pequenas variações ocorreram tanto na redução como no aumento do consumo, dependendo do tipo de veículo.

c) Redução no consumo de pneus

Foi realizado o mesmo procedimento aplicado aos demais componentes na avaliação da redução do consumo de pneus. A Tabela 19 apresenta os valores médios de consumo e os respectivos desvios-padrões. Como pode ser observado, do mesmo modo como ocorreu com o consumo de lubrificantes, os valores médios foram praticamente os mesmos entre as estratégias de manutenção, na maioria dos tipos de veículos. Do mesmo modo, os desvios-padrões foram na sua maioria iguais a zero ou muito próximos disso. Porém, deve ser destacado que apesar dos valores baixos, a escala da variável analisada também é bem próxima de zero, o que motiva a realização de um comparativo com os valores máximos da condição base, como fora realizado na análise da redução de combustível. 
Tabela 19: Consumo médio de pneus e desvios-padrões

\begin{tabular}{ccccccccc}
\hline Veículo & $\begin{array}{c}\text { Base } \\
\text { Consumo } \\
\left(\mathbf{n}^{\mathbf{0}}\right)\end{array}$ & $\boldsymbol{\mu}$ & $\begin{array}{c}\text { Cprog } \\
\text { Consumo } \\
\left(\mathbf{n}^{\mathbf{0}}\right)\end{array}$ & $\boldsymbol{\mu}$ & $\begin{array}{c}\text { CREMA } \\
\text { Consumo } \\
\left(\mathbf{n}^{\mathbf{0}}\right)\end{array}$ & $\boldsymbol{\mu}$ & $\begin{array}{c}\text { Cresp } \\
\text { Consumo } \\
\left(\mathbf{n}^{\mathbf{0}}\right)\end{array}$ & $\boldsymbol{\mu}$ \\
\hline $\mathbf{P}$ & 0,060 & 0 & 0,060 & 0 & 0,060 & 0 & 0,060 & 0 \\
$\mathbf{2 C}$ & 0,070 & 0 & 0,070 & 0 & 0,070 & 0 & 0,070 & 0 \\
$\mathbf{O}$ & 0,070 & 0 & 0,070 & 0 & 0,070 & 0 & 0,070 & 0 \\
$\mathbf{3 C}$ & 0,140 & 0 & 0,140 & 0 & 0,140 & 0 & 0,140 & 0 \\
$\mathbf{2 S 2}$ & 0,194 & 0 & 0,191 & 0,0030 & 0,191 & 0,0030 & 0,191 & 0,0030 \\
$\mathbf{2 S 3}$ & 0,235 & 0,0051 & 0,231 & 0,0030 & 0,231 & 0,0030 & 0,231 & 0,0030 \\
$\mathbf{3 S 3}$ & 0,276 & 0,0051 & 0,273 & 0,0048 & 0,273 & 0,0046 & 0,272 & 0,0040 \\
$\mathbf{P 3}$ & 0,087 & 0,0046 & 0,090 & 0 & 0,090 & 0 & 0,090 & 0 \\
$\mathbf{P 4}$ & 0,108 & 0,0040 & 0,110 & 0 & 0,110 & 0 & 0,110 & 0 \\
$\mathbf{M}$ & 0,070 & 0,0022 & 0,070 & 0 & 0,070 & 0 & 0,070 & 0 \\
$\mathbf{3 T 4}$ & 0,322 & 0,0040 & 0,320 & 0 & 0,320 & 0 & 0,320 & 0 \\
\hline
\end{tabular}

As reduções no consumo de pneus, quando comparando os valores médios das três estratégias de manutenção alternativas à condição base com os valores máximos da mesma, são apresentadas no gráfico da Figura 28.

\section{Comparativo do consumo de pneus com o valor máximo da condição Base}

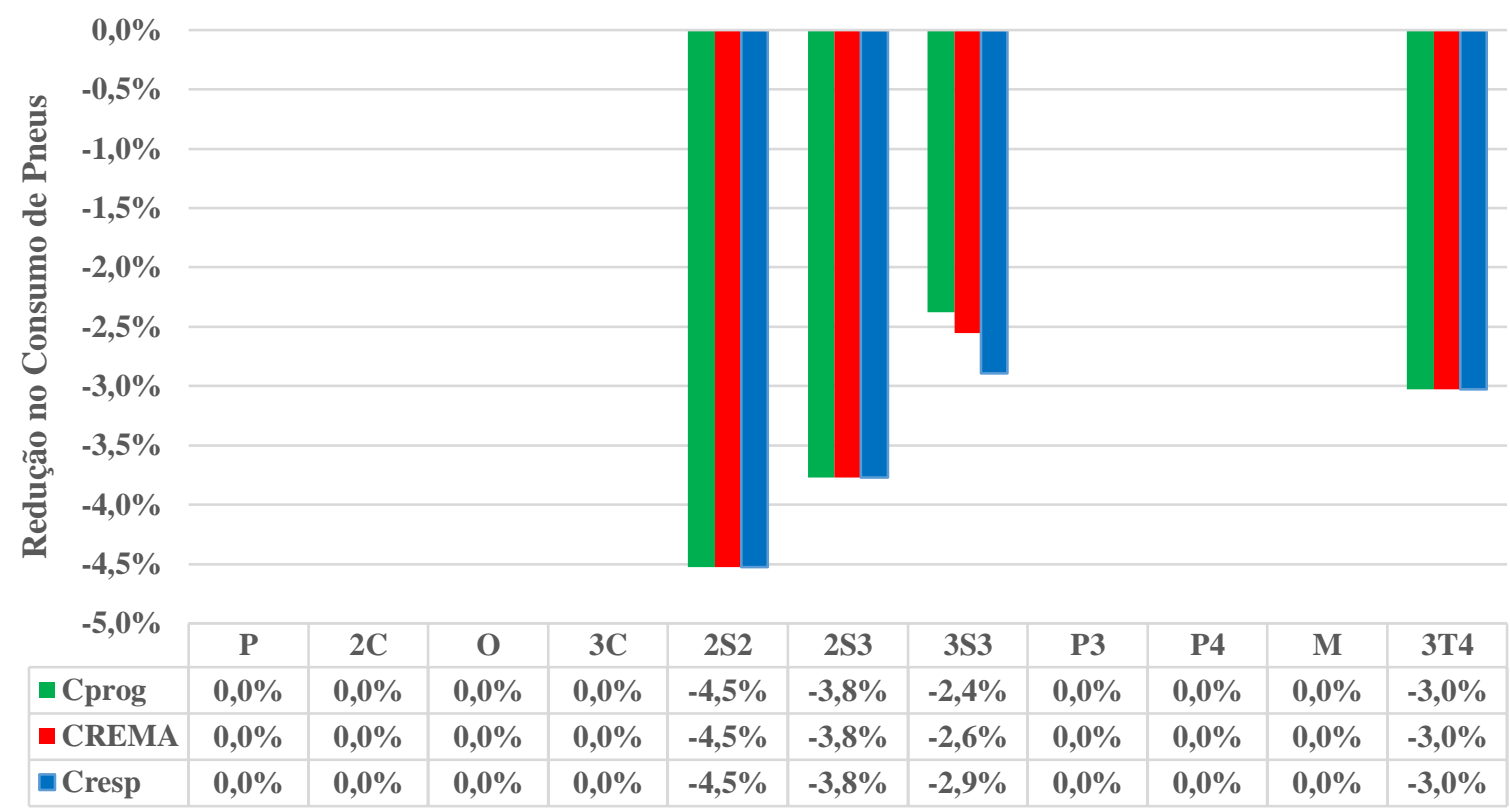

Figura 28: Redução do consumo de pneus em relação aos valores máximos da condição Base 
Percebe-se que somente caminhões articulados, entre 4 e 7 eixos, sofreram impacto com o melhor desempenho do pavimento ao longo dos anos, no que se refere à economia de pneus. A maior redução de consumo foi identificada nos veículos do tipo $2 \mathrm{~S} 2$, ou seja, nos caminhões articulados com 4 eixos, quando a redução no consumo de pneus chegou a 4,5\%, superior inclusive à redução no consumo de combustível. Entre as estratégias de manutenção, somente nos veículos do tipo $3 \mathrm{~S} 3$ foi possível perceber diferença na redução de consumo, estando os valores praticamente idênticos nos demais veículos.

d) Redução no consumo de peças

O HDM-4 calcula o consumo de peças dos veículos como uma relação do seu custo com o preço de um veículo novo, podendo ser expressa em porcentagem. A Tabela 20 expressa esses valores.

Tabela 20: Consumo médio de peças, como proporção do preço de um veículo novo

\begin{tabular}{|c|c|c|c|c|}
\hline & Base & Cprog & CREMA & Cresp \\
\hline Veículo & $\begin{array}{c}\text { Consumo (\% preço } \\
\text { veic novo) }\end{array}$ & $\begin{array}{c}\text { Consumo (\% preço } \\
\text { veic novo) }\end{array}$ & $\begin{array}{c}\text { Consumo (\% preço } \\
\text { veic novo) }\end{array}$ & $\begin{array}{c}\text { Consumo (\% preço } \\
\text { veic novo) }\end{array}$ \\
\hline $\mathbf{P}$ & $22,59 \%$ & $20,87 \%$ & $20,86 \%$ & $20,59 \%$ \\
\hline $2 \mathrm{C}$ & $23,20 \%$ & $21,24 \%$ & $21,23 \%$ & $20,89 \%$ \\
\hline $\mathbf{O}$ & $10,15 \%$ & $8,83 \%$ & $8,82 \%$ & $8,59 \%$ \\
\hline $3 \mathrm{C}$ & $23,20 \%$ & $21,24 \%$ & $21,23 \%$ & $20,89 \%$ \\
\hline $2 \mathrm{~S} 2$ & $25,16 \%$ & $23,22 \%$ & $23,21 \%$ & $22,87 \%$ \\
\hline $2 \mathrm{S3}$ & $35,39 \%$ & $32,67 \%$ & $32,64 \%$ & $32,17 \%$ \\
\hline $3 S 3$ & $35,39 \%$ & $32,67 \%$ & $32,64 \%$ & $32,17 \%$ \\
\hline P3 & $22,59 \%$ & $20,87 \%$ & $20,86 \%$ & $20,59 \%$ \\
\hline P4 & $22,59 \%$ & $20,87 \%$ & $20,86 \%$ & $20,59 \%$ \\
\hline $\mathbf{M}$ & $9,60 \%$ & $8,38 \%$ & $8,37 \%$ & $8,17 \%$ \\
\hline $3 T 4$ & $35,39 \%$ & $32,67 \%$ & $32,64 \%$ & $32,17 \%$ \\
\hline
\end{tabular}

Pelos valores apresentados, é possível verificar que o custo das peças gera um maior impacto nos veículos comerciais, como era esperado. Também se observa que a Concessão Responsiva é a estratégia que traz a maior redução no consumo de peças dos veículos, estando as demais alternativas (CREMA e Concessão Programada) com valores muito próximos. A Figura 29 apresenta um gráfico, com a redução proporcional do consumo de peças quando comparadas à condição base. 


\section{Comparativo do consumo de peças com a média da condição Base}

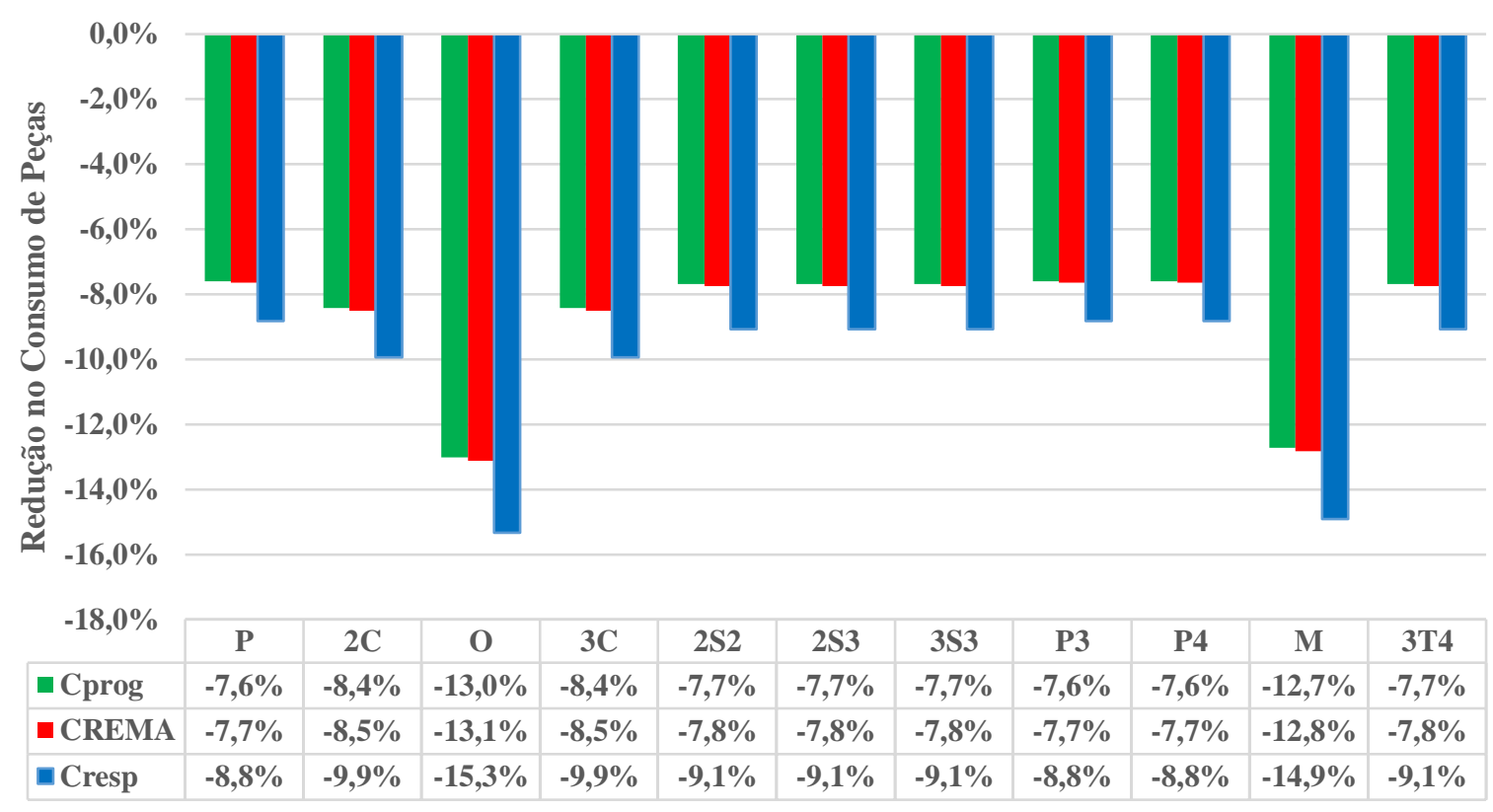

Figura 29: Redução do consumo de peças em relação aos valores médios da condição Base

Os veículos com a maior redução no consumo de peças, proporcionalmente aos valores da condição base, foram os ônibus e as motocicletas. O consumo para esses veículos foi reduzido em cerca de $15 \%$ para a estratégia Concessão Responsiva, ficando próxima dos $13 \%$ para as demais estratégias. Os demais veículos apresentaram reduções na ordem de $10 \%$ para a estratégia Concessão Responsiva, e de aproximadamente 8\% para as demais estratégias. Destaca-se que entre os componentes avaliados, o consumo de peças foi o que apresentou maior sensibilidade às melhores condições do pavimento.

e) Redução no tempo de viagem

As análises relacionadas ao tempo de viagem contemplaram duas variáveis distintas. Para os veículos de carga, foi avaliada a redução no tempo de retenção de carga. Já para os veículos com passageiros, foi avaliada a redução nas horas de trabalho equivalentes dos mesmos, considerando que os atrasos contam como tempo em que os mesmos poderiam ser produtivos, sendo esse tempo posteriormente relacionado com o custo da hora de trabalho. Antes de proceder com essas análises, porém, a Figura 30 apresenta a evolução das velocidades médias no trecho da rodovia Dom Pedro, para as 4 estratégias de manutenção adotadas. 
Velocidades Médias Anuais, Trecho da Rodovia Dom Pedro I

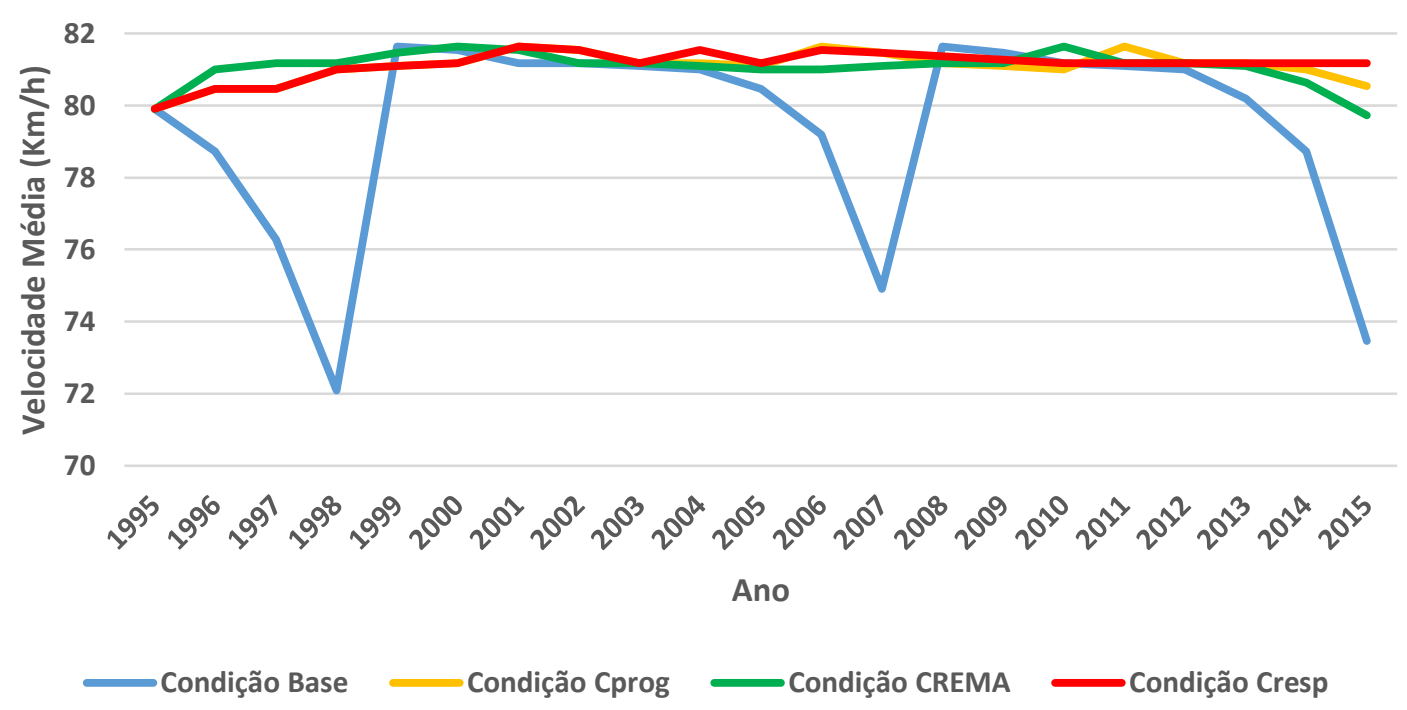

Figura 30: Variação da Velocidade Média Anual do Fluxo de Tráfego

Como se observa nesse gráfico, a velocidade média do fluxo se mantém praticamente a mesma entre as alternativas, sempre próxima de $80 \mathrm{~km} / \mathrm{h}$. É possível afirmar também que a pior condição do pavimento, num geral, para a estratégia de manutenção base, refletiu na redução de velocidade para um mínimo de $72 \mathrm{~km} / \mathrm{h}$ no ano de 1998. Embora compatível com valores sugeridos por alguns órgãos para os valores de IRI adotados, essa velocidade é superior a observada na prática, muitas vezes, em rodovias com pavimento em péssimo estado. Tendo isso exposto, a Tabela 21 apresenta os atrasos médios para veículos de carga, nas estratégias definidas, para cada 1000 veículos x km.

Tabela 21: Atraso médio dos veículos de carga

\begin{tabular}{ccccc}
\hline \multirow{2}{*}{ Veículo } & Base & Cprog & CREMA & Cresp \\
& Atraso (h) & Atraso (h) & Atraso (h) & Atraso (h) \\
\hline 2C & 14,0 & 13,8 & 13,8 & 13,7 \\
3C & 11,0 & 10,8 & 10,8 & 10,8 \\
$\mathbf{2 S 2}$ & 12,7 & 12,3 & 12,3 & 12,3 \\
$\mathbf{2 S 3}$ & 14,0 & 13,6 & 13,6 & 13,6 \\
$\mathbf{3 S 3}$ & 15,2 & 14,8 & 14,8 & 14,8 \\
$\mathbf{3 T 4}$ & 16,7 & 16,3 & 16,3 & 16,2 \\
\hline
\end{tabular}

A redução do atraso médio, percentualmente, é apresentada no gráfico da Figura 31. 


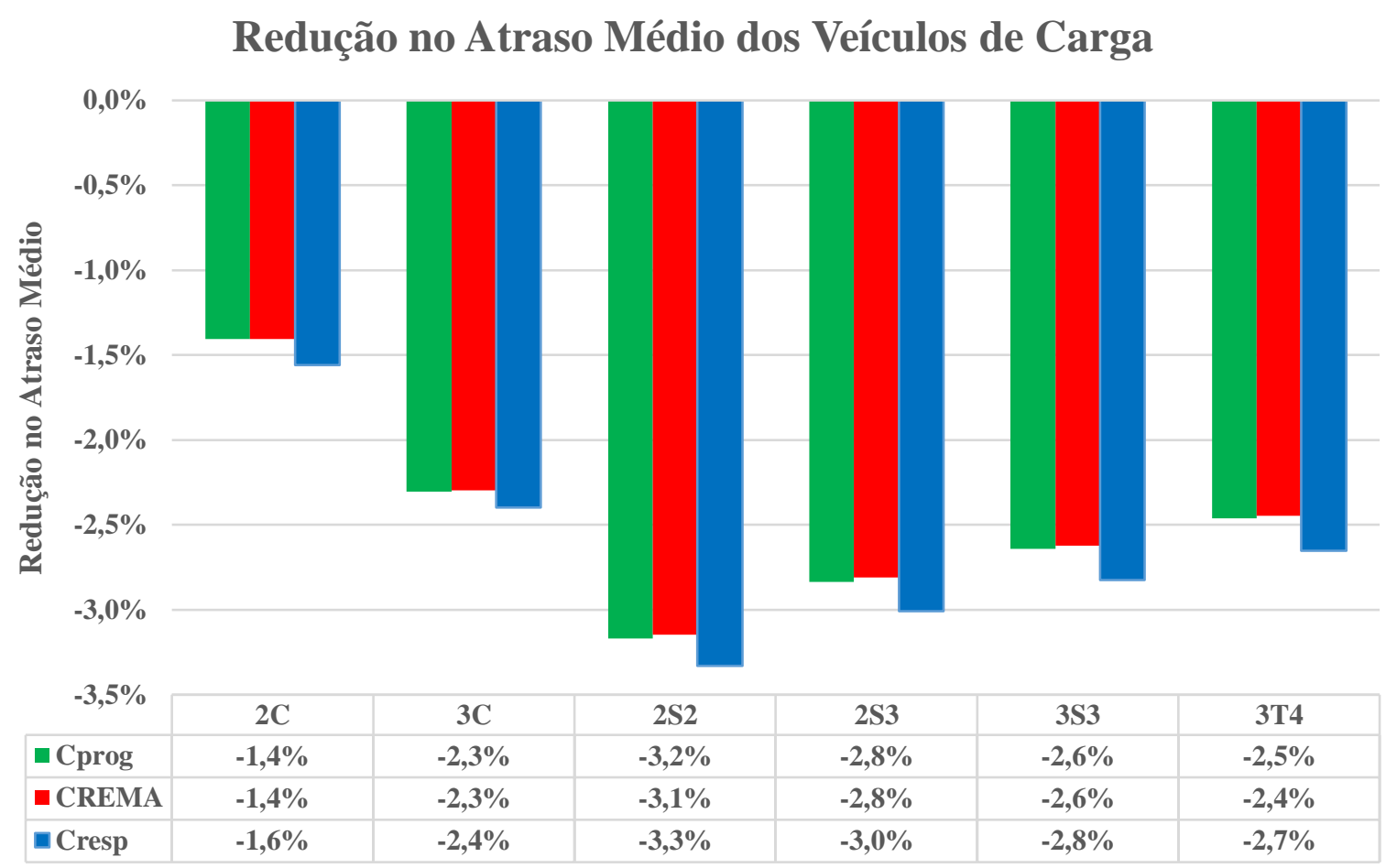

Figura 31: Redução do atraso médio em veículos de carga

Em termos percentuais, a redução no atraso médio é semelhante aos demais elementos avaliados anteriormente, indicando também o impacto positivo das melhorias na condição do pavimento. Em valores absolutos, a redução de 0,5 hora para cada 1000 veículos-km nos veículos do tipo 3T4 na estratégia Concessão Responsiva, corresponde a uma economia média de 0,0005 hora para cada veículo-km, ou seja, uma redução de 1,8 segundos para cada quilômetro que um veículo trafegue. Embora não pareça uma economia de tempo significativa, como muitas vezes traz uma obra de ampliação de capacidade ou de correção de traçado das vias, para esse tipo de veículo, que anualmente trafega 86000 quilômetros, isso representa uma redução anual de 43 horas, ou seja, quase dois dias poupados no período de um ano para cada veículo.

A análise para veículos de passageiros parte do pressuposto de que os atrasos são contabilizados como horas de trabalho desperdiçadas, ou seja, horas onde os passageiros poderiam ser produtivos em seu trabalho, mas acabaram desperdiçando pelo atraso na viagem. No caso do HDM-4, como já mencionado anteriormente, são contabilizados os custos com horas de trabalho e também com horas não trabalhadas. Os valores calculados pelo HDM são apresentados na Tabela 22. 
Tabela 22: Atraso médio dos veículos de passageiros

\begin{tabular}{ccccc}
\hline Veículo & Base & Cprog & CREMA & Cresp \\
& Atraso (h) & Atraso (h) & Atraso (h) & Atraso (h) \\
\hline P & 7,79 & 7,63 & 7,63 & 7,62 \\
O & 250,50 & 247,26 & 247,28 & 246,84 \\
$\mathbf{P 3}$ & 7,74 & 7,57 & 7,57 & 7,57 \\
$\mathbf{P 4}$ & 7,82 & 7,66 & 7,66 & 7,65 \\
$\mathbf{M}$ & 8,23 & 8,11 & 8,11 & 8,10 \\
\hline
\end{tabular}

Faz-se importante mencionar que ocorrem grandes diferenças nos valores entre os ônibus e os demais veículos pelo maior número de passageiros que um ônibus comporta. As reduções nos atrasos são mostradas na Figura 32.

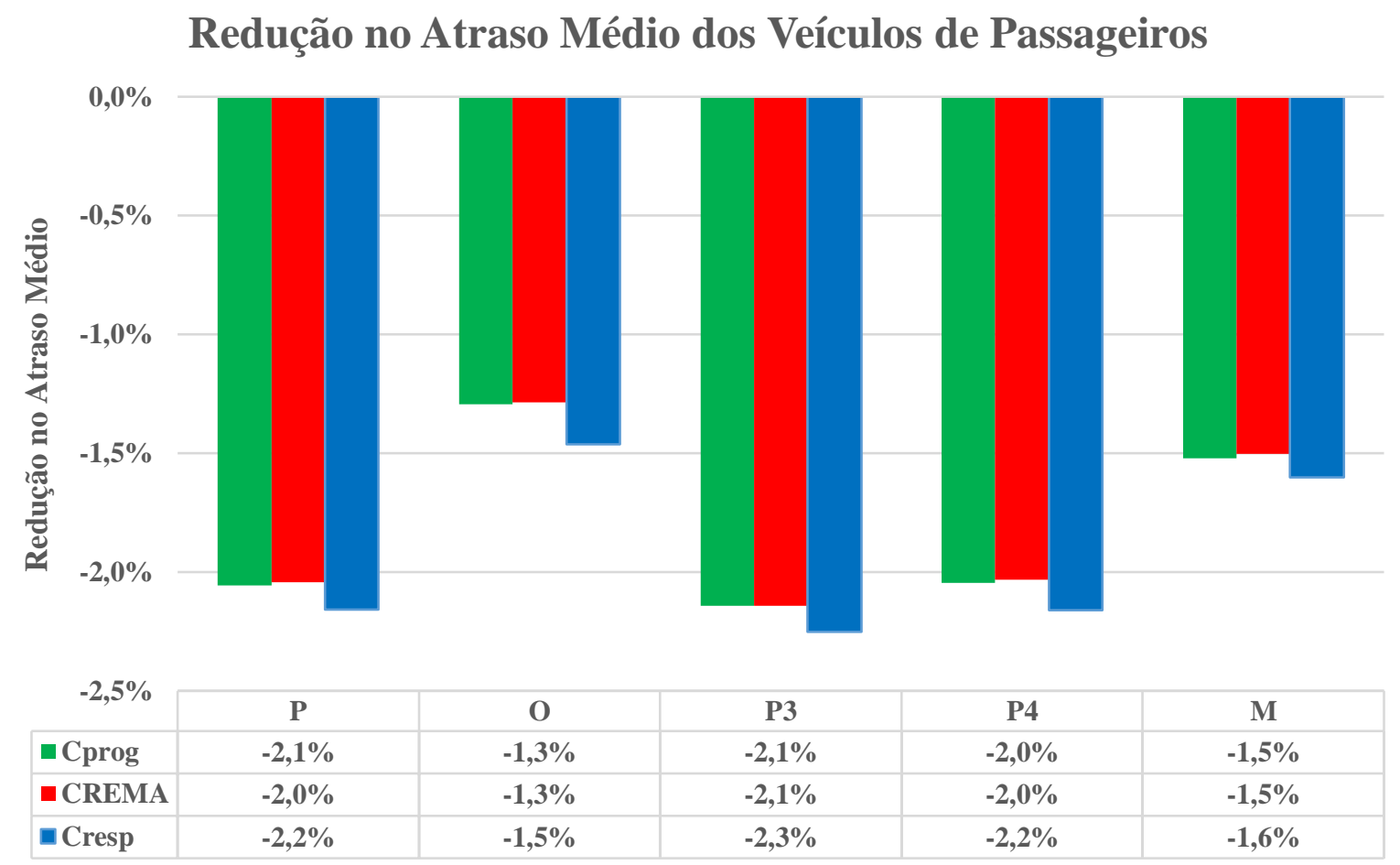

Figura 32: Redução do atraso médio em veículos de passageiros

Os veículos que tiveram maior redução no atraso médio das viagens foram os automóveis, com uma redução de aproximadamente $2 \%$ no atraso, enquanto os ônibus e as motocicletas apresentam redução próxima de 1,5\%. Como na maioria das avaliações já realizadas, a estratégia Concessão Responsiva apresentou maior impacto na redução dos atrasos quando comparada às demais estratégias. 


\subsection{ANÁLISE ECONÔMICA}

A análise econômica dos trechos selecionados foi realizada através dos três métodos citados anteriormente nesse trabalho: VPL, Relação B/C e TIR. Os benefícios considerados foram as reduções nos custos operacionais dos veículos nas três estratégias de manutenção definidas como alternativa à condição base. Os custos, por sua vez, foram uma relação direta do volume de tráfego, dividido por categoria, com a respectiva tarifa quilométrica de pedágio em seu valor integral. Destaca-se que foram adotadas as tarifas integrais pela ausência das composições tarifárias vencedoras dos leilões, não encontradas em nenhum dos endereços eletrônicos das agências reguladoras. A fim de estabelecer comparativos mais próximos das situações reais, ao final das análises econômicas foi incluída uma análise contendo aproximações dos percentuais das tarifas destinados exclusivamente à manutenção do pavimento.

A adoção desses percentuais tomou como base os relatórios financeiros das concessionárias, que incluem, até o ano de 2009, os valores investidos diretamente na recuperação e na manutenção do pavimento.

O VPL teve por objetivo principal avaliar a viabilidade econômica da concessão das rodovias, sob o ponto de vista do usuário. A relação B/C permite, além de avaliar a viabilidade econômica das concessões, estabelecer um comparativo ponderado entre as diferentes estratégias e rodovias selecionadas. A TIR permite estabelecer um comparativo dos resultados para as concessões com outros tipos de investimento possíveis no mercado, especialmente os de menor risco ao investidor.

Em todos os casos, foram utilizadas taxas de desconto (TD) de 6, 12 e 18\%, como forma de se realizar uma análise de sensibilidade dos resultados, estando esses valores próximos dos citados por Haas, Hudson e Zaniewsky (1994) para taxas de desconto utilizados pelos operadores em obras de pavimentação (entre 4 e 10\%). Como geralmente o HDM-4 é utilizado para avaliações de projetos futuros, os preços dos componentes inseridos no software têm uma única data de referência, e não consideram efeitos de inflação e demais variações nos preços. Dessa forma, para se evitar distorções pela ausência de informações dos preços dos componentes em anos anteriores, tanto os benefícios medidos na redução de custos dos componentes, como os custos com as tarifas de pedágio, foram medidos com os valores de referência para o ano de 2015, somente com a aplicação das taxas de desconto para se determinar os valores no presente. 
Embora, como explicado no item 3.5 desse trabalho, o HDM-4 tenha utilizado um único VDM, considerado de forma bidirecional, para o ano de 1995, e a determinação dos volumes de tráfego nos anos subsequentes tenha sido com taxas constantes, a análise tanto para os benefícios como para os custos tomou como base os volumes de tráfego unidirecionais calculados inicialmente, com base no índice ABCR e nos valores de elasticidade VDMxPIB. Para possibilitar a análise entre os diferentes tipos de veículo, foi utilizado o relatório "MT Road User Costs Summary by Vehicle", que apresenta os custos médios anuais (em reais) para cada veículo-km. A Figura 33 ilustra a tela do HDM-4 com esse relatório.

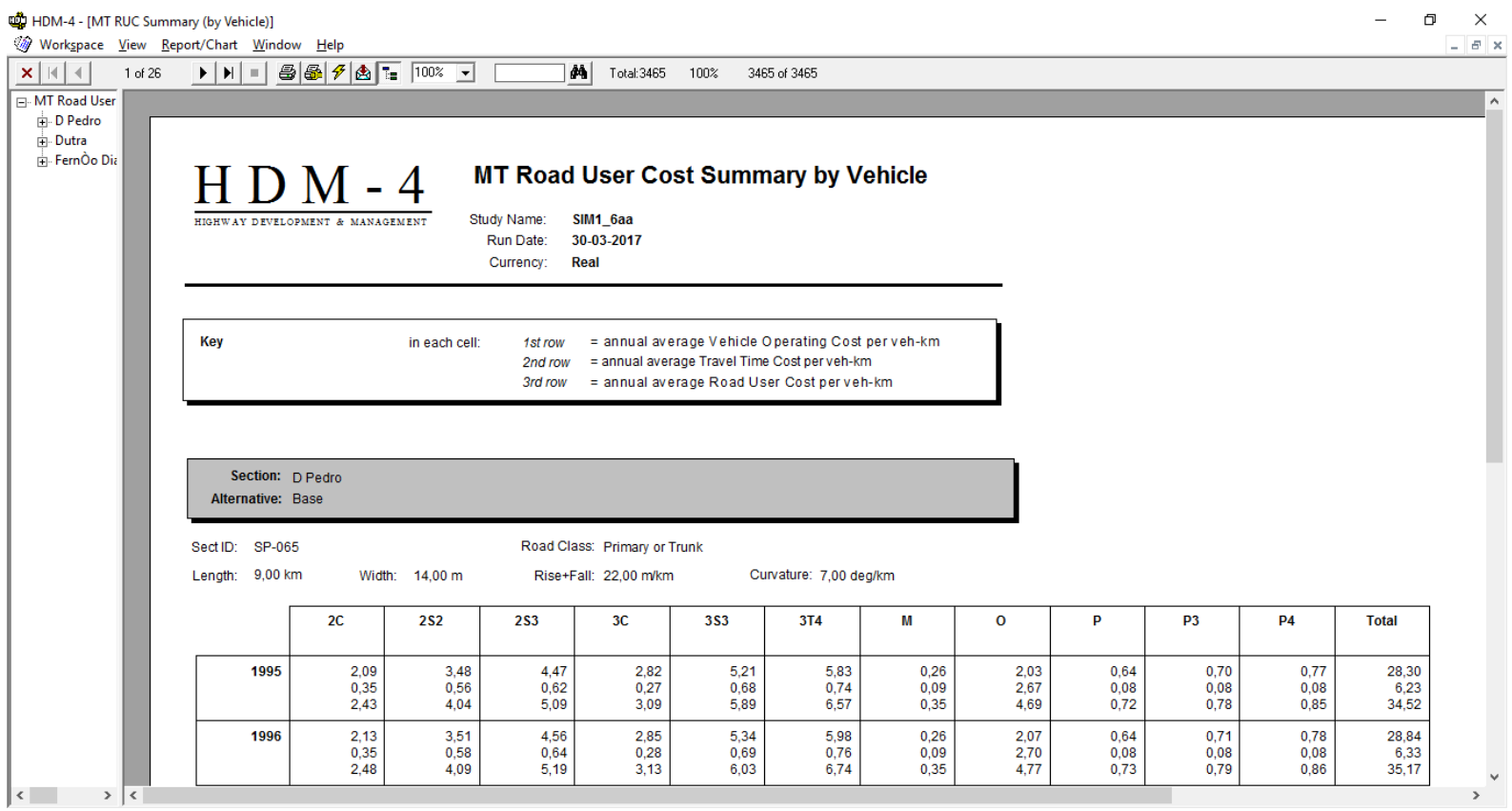

Figura 33: Tela do HDM-4 com o relatório de custos anuais médios dos usuários

4.3.1 Análise pelo Valor Presente Líquido (VPL): a análise pelo VPL teve duas abordagens distintas: a comparação dos VPLs para cada estratégia de manutenção, considerando os custos de forma absoluta, e o cálculo dos VPLs pela redução de custos operacionais, incorporando-se os custos com as tarifas de pedágio. Os custos totais dos usuários, em R $\$$ de 2015, para as diferentes TD adotadas, em cada estratégia de manutenção, são apresentados nas Figuras 34, 35 e 36. 
Valor Presente dos Custos Totais dos Usuários (TD=6\%

a.a.)

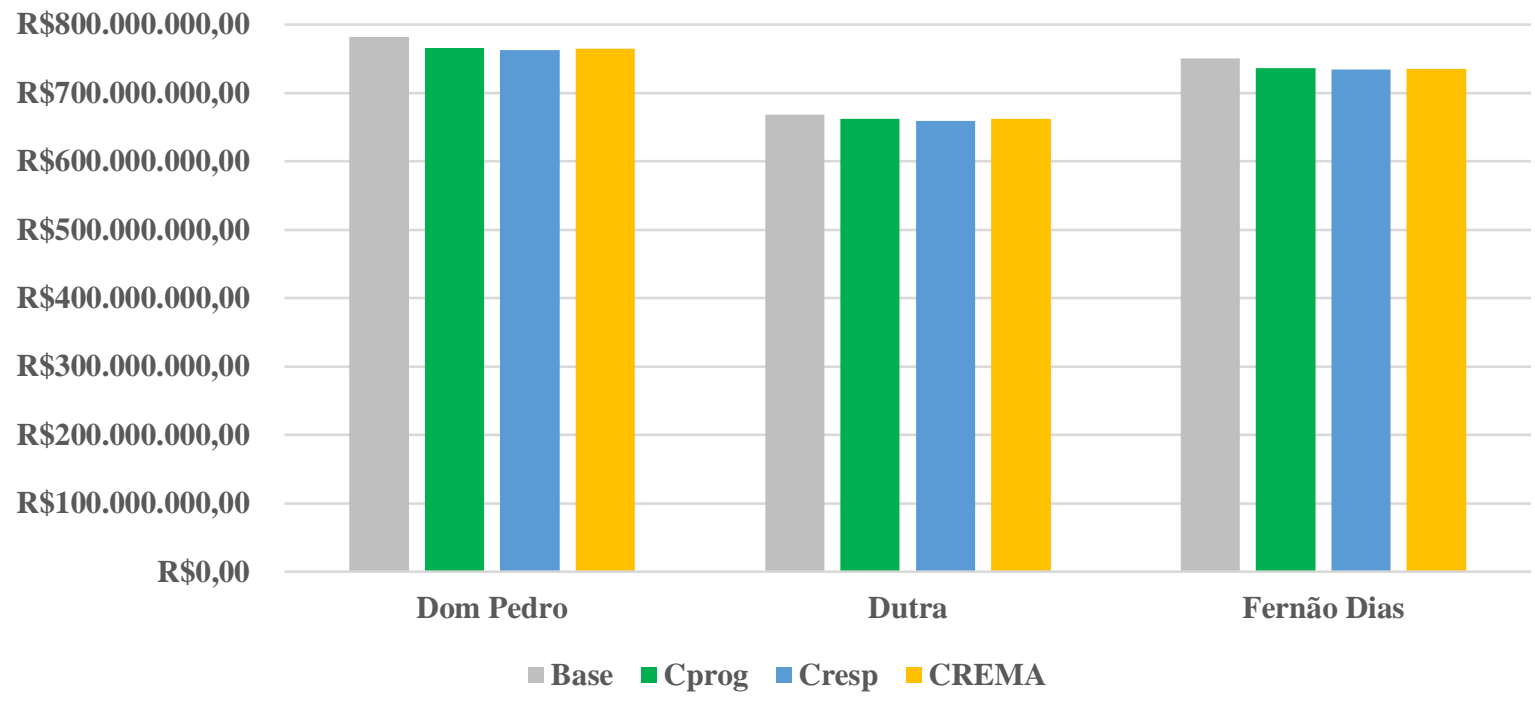

Figura 34: Custos Totais dos Usuários, com taxa de desconto igual a 6\% a.a.

Valor Presente dos Custos Totais dos Usuários (TD=12\%

a.a.)

$\mathbf{R} \$ 800.000 .000,00$

$\mathbf{R} \$ 700.000 .000,00$

$\mathbf{R} \$ 600.000 .000,00$

$\mathbf{R} \$ 500.000 .000,00$

$\mathbf{R} \$ 400.000 .000,00$

$\mathbf{R} \$ 300.000 .000,00$

$\mathbf{R} \$ 200.000 .000,00$

R\$100.000.000,00

$\mathbf{R} \$ \mathbf{0 , 0 0}$

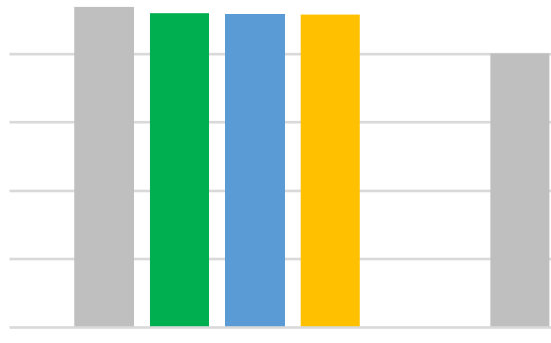

Dom Pedro

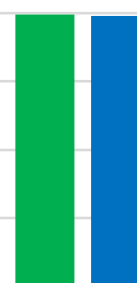

Dutra

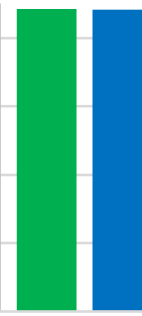

Fernão Dias

-Base $\backsim$ Cprog $\square$ Cresp $\square$ CREMA

Figura 35: Custos Totais dos Usuários, com taxa de desconto igual a 12\% a.a. 


\section{Valor Presente dos Custos Totais dos Usuários (TD=18\% \\ a.a.)}

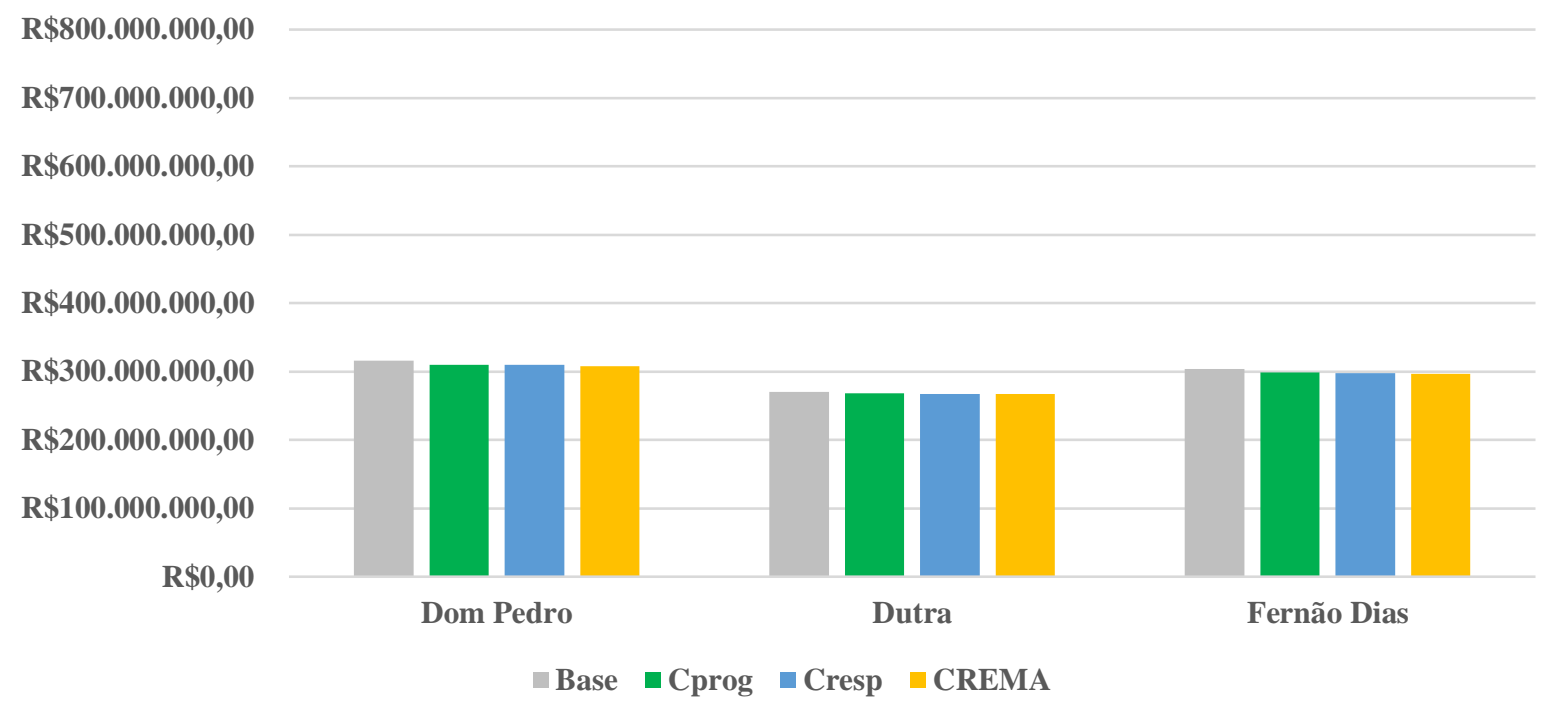

Figura 36: Custos Totais dos Usuários, com taxa de desconto igual a 18\% a.a.

Embora exista uma redução nos custos totais dos usuários, somente a avaliação pelos valores absolutos torna-se uma tarefa difícil, uma vez que a economia observada, dentro das escalas utilizadas, é pequena. Dessa forma, faz-se necessário também observar as reduções dos custos totais (que, na prática, se configuram como os benefícios dessa análise), quando se comparam as estratégias de manutenção com a condição base, ilustradas nas Figuras 37, 38 e 39.

\section{Redução nos Custos Totais (TD=6\% a.a.)}

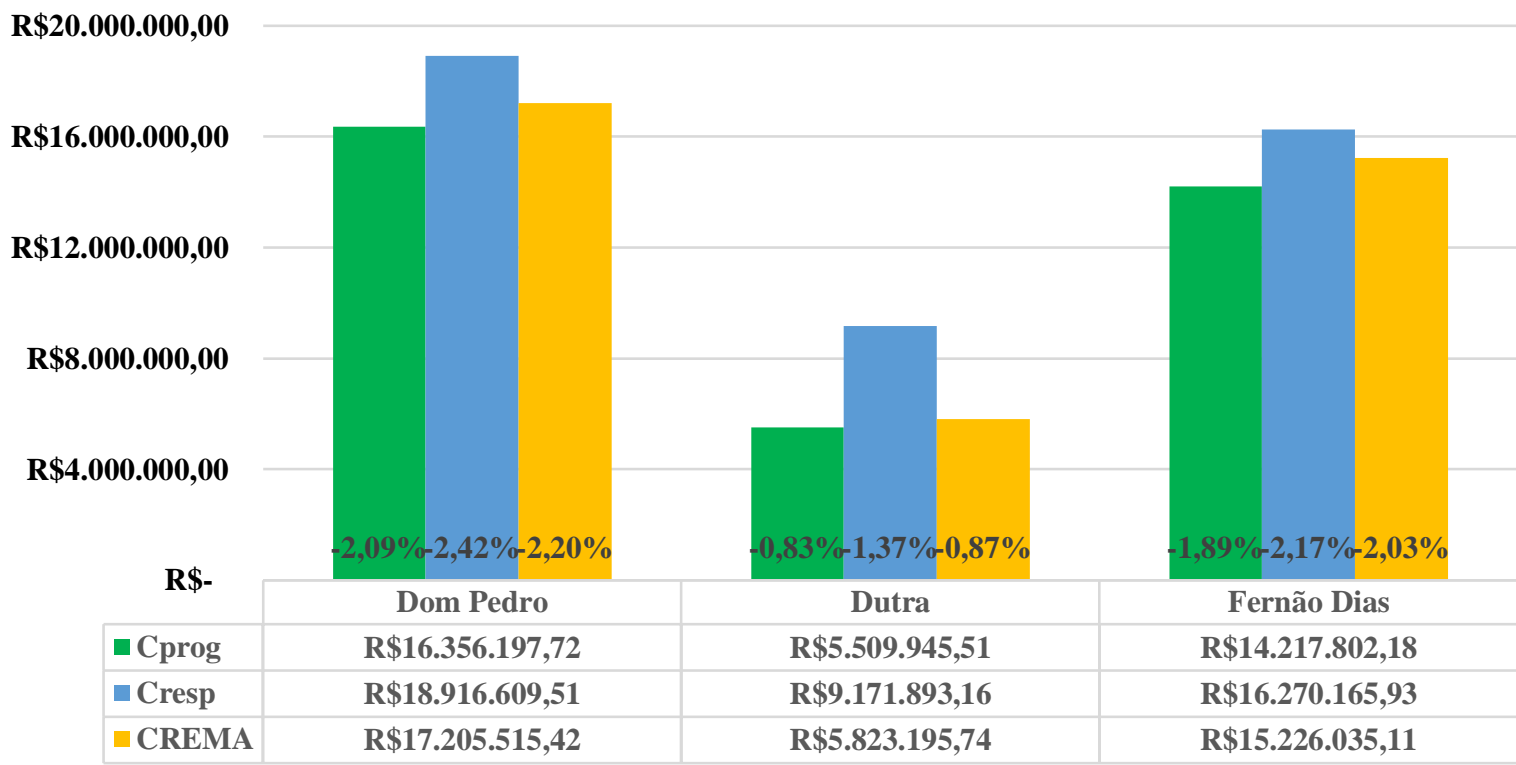

Figura 37: Benefícios Totais dos Usuários pela redução de custos operacionais, taxa de desconto igual a $6 \%$ a.a. 


\section{Redução nos Custos Totais (TD=12\% a.a.)}

$\mathbf{R} \$ 20.000 .000,00$

$\mathbf{R} \$ 16.000 .000,00$

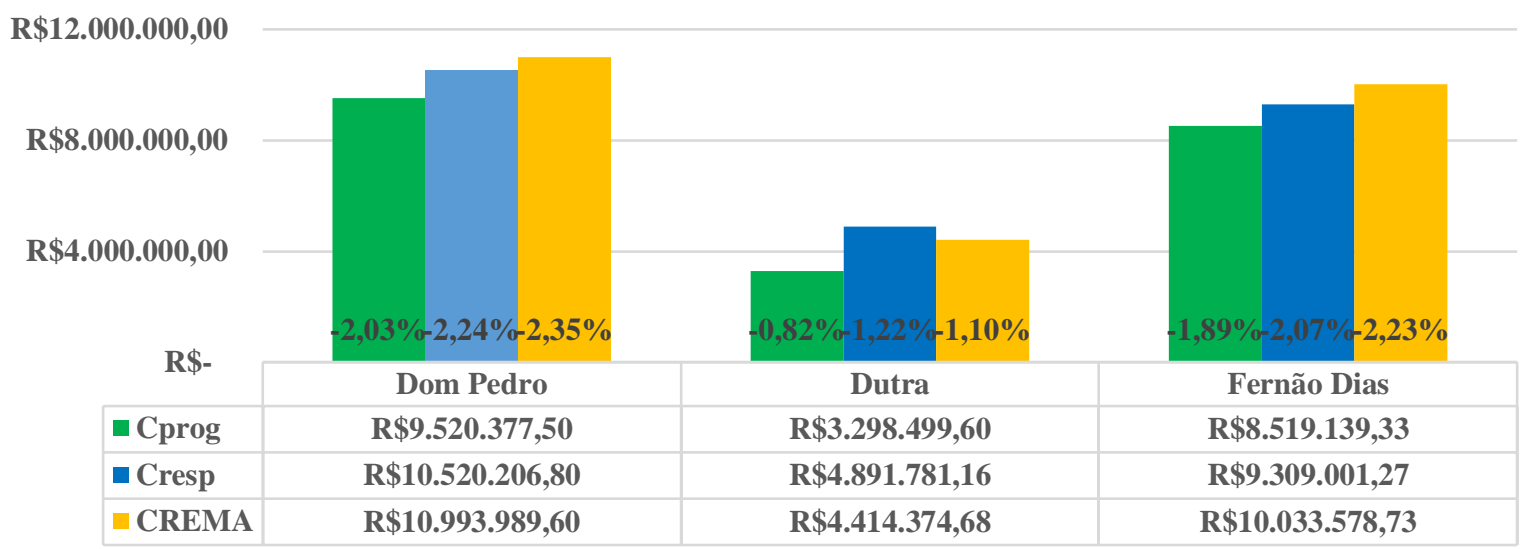

Figura 38: Benefícios Totais dos Usuários pela redução de custos operacionais, taxa de desconto igual a $12 \%$ a.a.

\section{Redução nos Custos Totais (TD=18\% a.a.)}

R $\$ 20.000 .000,00$

$\mathbf{R} \$ 16.000 .000,00$

$\mathbf{R} \$ 12.000 .000,00$

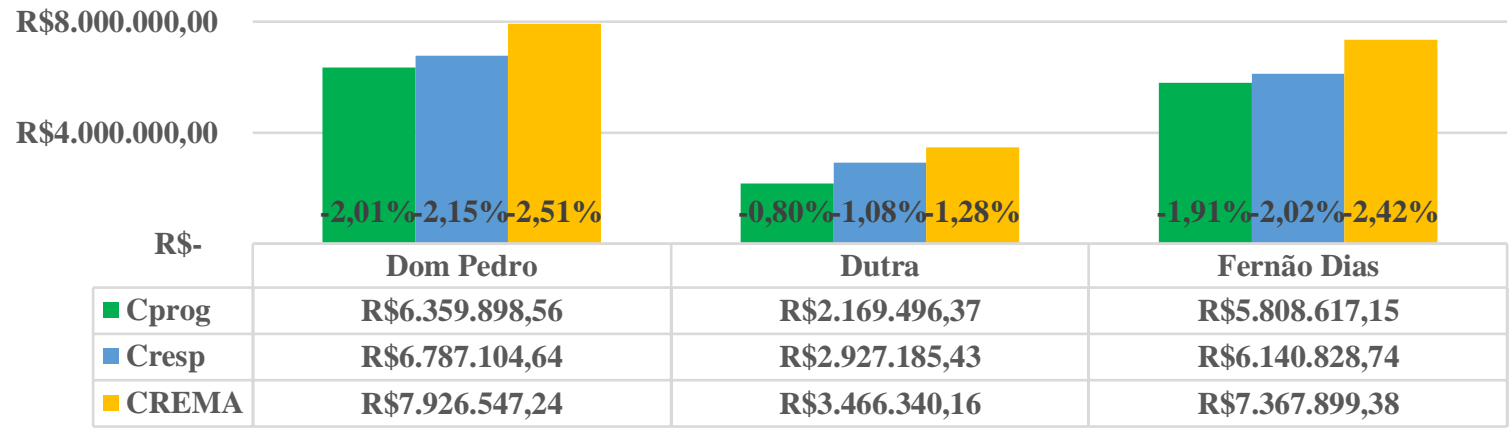

Figura 39: Benefícios Totais dos Usuários pela redução de custos operacionais, taxa de desconto igual a $18 \%$ a.a.

Dentre as estratégias de manutenção, a que apresentou menor sensibilidade à variação nas taxas de desconto foi a Concessão Programada. A Concessão Responsiva apresentou menores reduções nos custos operacionais na medida em que as taxas de desconto aumentaram. A 
estratégia do CREMA, por sua vez, aumentou proporcionalmente os benefícios econômicos com o aumento das taxas de desconto. Nesse sentido, a configuração dos fluxos de caixa exerce grande influência no modo como os custos variam em função da taxa de desconto, e os comportamentos distintos entre as estratégias, especialmente entre a Concessão Responsiva e o CREMA, pode ser explicado pelos diferentes fluxos de caixa observados em ambas, uma vez que a Concessão Responsiva apresenta intervenções no pavimento em frequências muito maiores do que as existentes no CREMA e, consequentemente, benefícios menores, mas em frequências maiores.

Porém é importante apontar também algumas importantes diferenças observadas nos parâmetros de desempenho iniciais dos contratos do CREMA e das Concessões. Ao se observar os valores indicados na Tabela 16 (capítulo 3.5), conclui-se que os parâmetros do CREMA são mais rigorosos do que os das concessões, exigindo menores índices de irregularidade em um menor espaço de tempo (vide Figura 22). Embora essa estratégia apresente limites de irregularidade maiores do que os praticados nas concessões, é importante o questionamento acerca da adequação desses parâmetros de desempenho aos valores que tragam os maiores benefícios aos usuários.

Após a determinação dos benefícios dos usuários, indicados nos gráficos das Figuras 37 a 39, a Figura 40 apresenta os custos totais decorrentes da cobrança de pedágio nos trechos em estudo, para as TDs definidas anteriormente.

\section{Custos Totais dos Usuários com Pagamento de Pedágio}

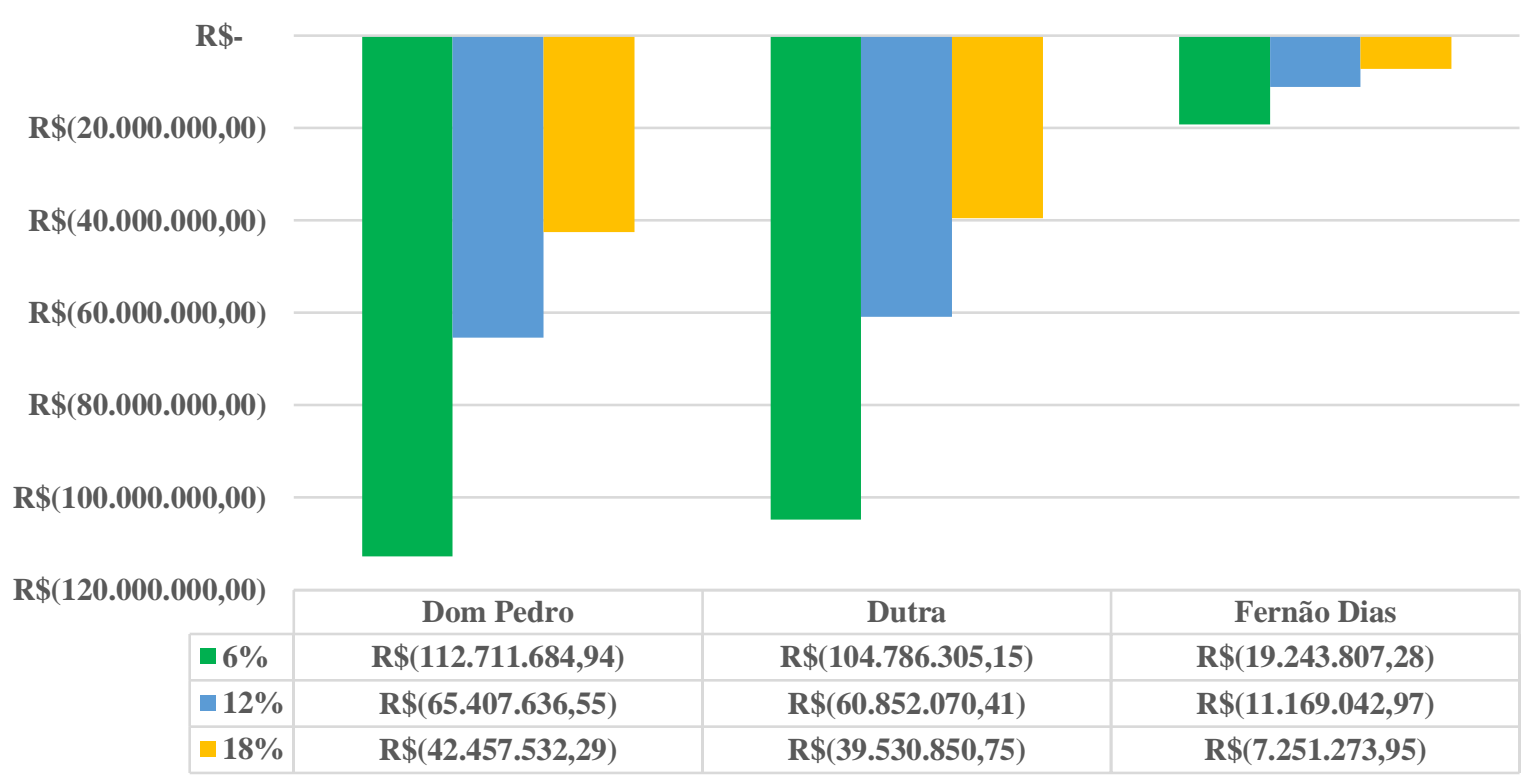

Figura 40: Custos Totais dos Usuários devido ao Pagamento de Pedágio 
Como esperado devido a discrepância das tarifas cobradas entre as concessões, as rodovias Dutra e Dom Pedro apresentaram custos bastante elevados em comparação com os valores da Fernão Dias. Porém, mesmo antes da determinação do VPL, já é possível observar que esses custos também são superiores aos benefícios que, mesmo na menor TD, sequer ultrapassaram os R\$20 millhões, enquanto os custos totais na Dutra e Dom Pedro são de cerca de R \$100 milhões para a mesma TD.

Ocorre dessa forma, em todos os casos, valores de VPL negativos (Figuras 41, 42 e 43), o que de forma direta indica que a concessão das rodovias em estudo, considerando somente os benefícios pela manutenção do pavimento das mesmas, não é viável economicamente para os seus usuários com as tarifas praticadas, principalmente se for considerada a existência de estratégias de manutenção empregadas comumente em rodovias brasileiras, que trazem também benefícios econômicos muito próximos dos existentes nas concessões (caso do CREMA).

\section{VPL das Estratégias $(\mathrm{TD}=6 \%$ a.a. $)$}

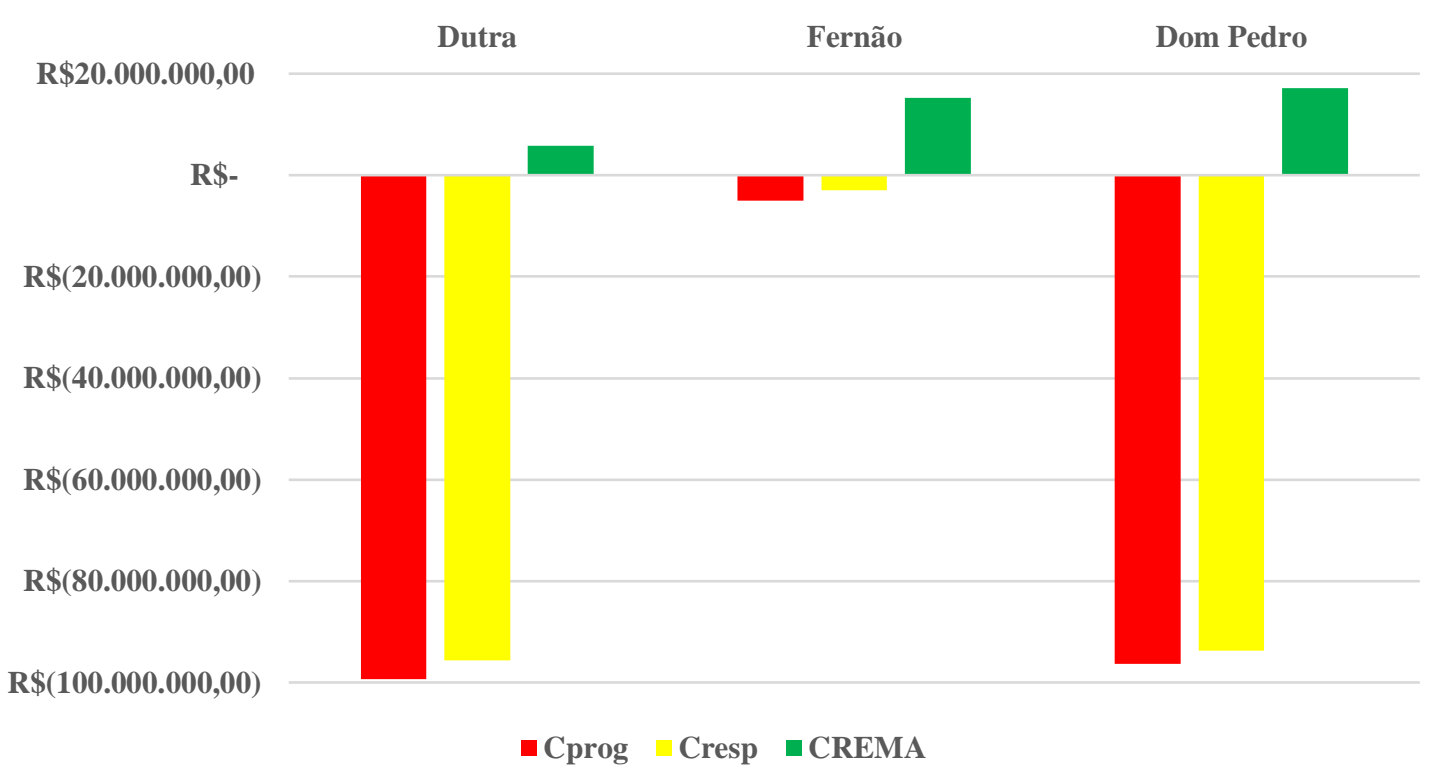

Figura 41: VPL das Estratégias Empregadas, com taxa de desconto de 6\% a.a. 


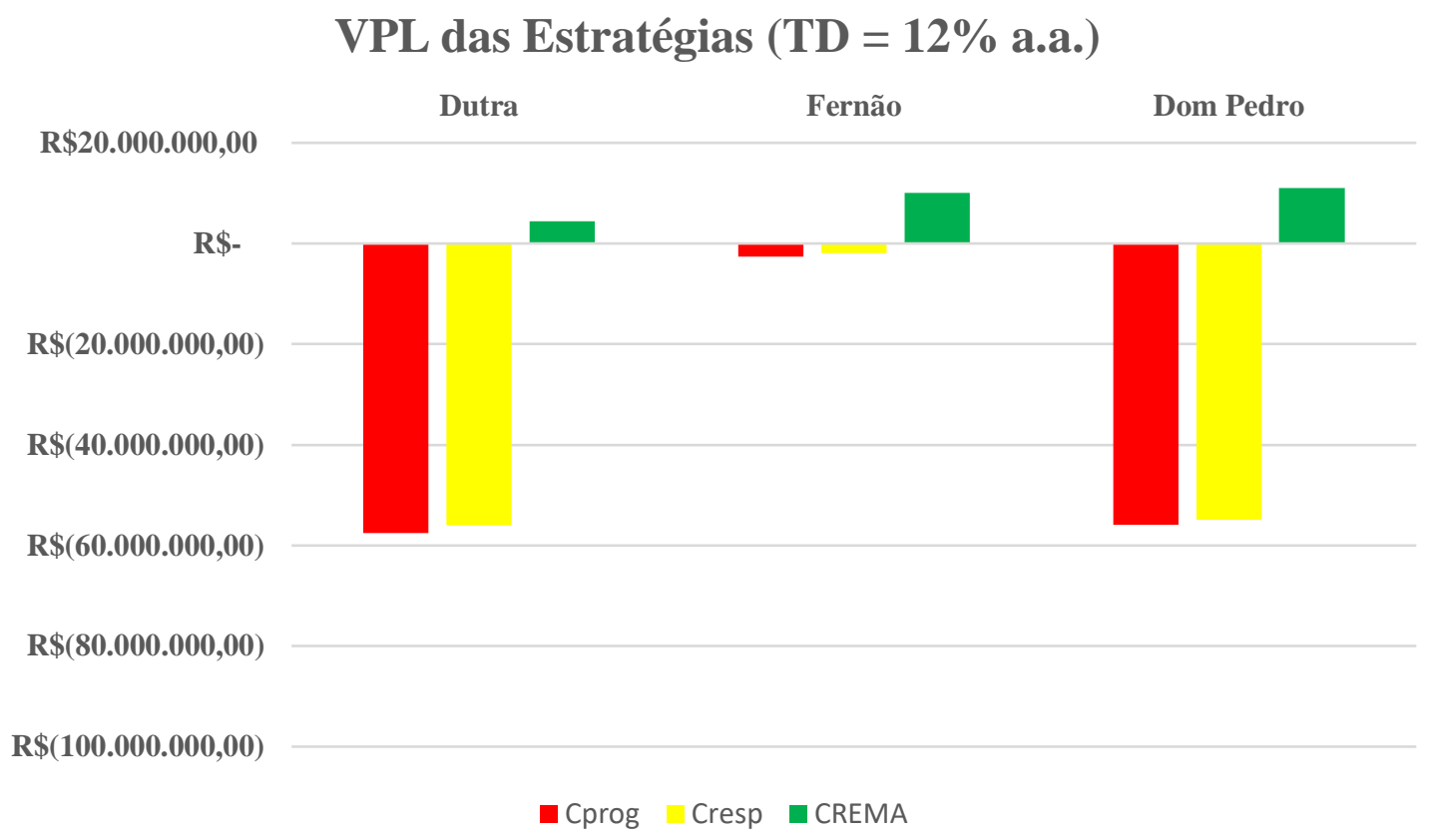

Figura 42: VPL das Estratégias Empregadas, com taxa de desconto de 12\% a.a.

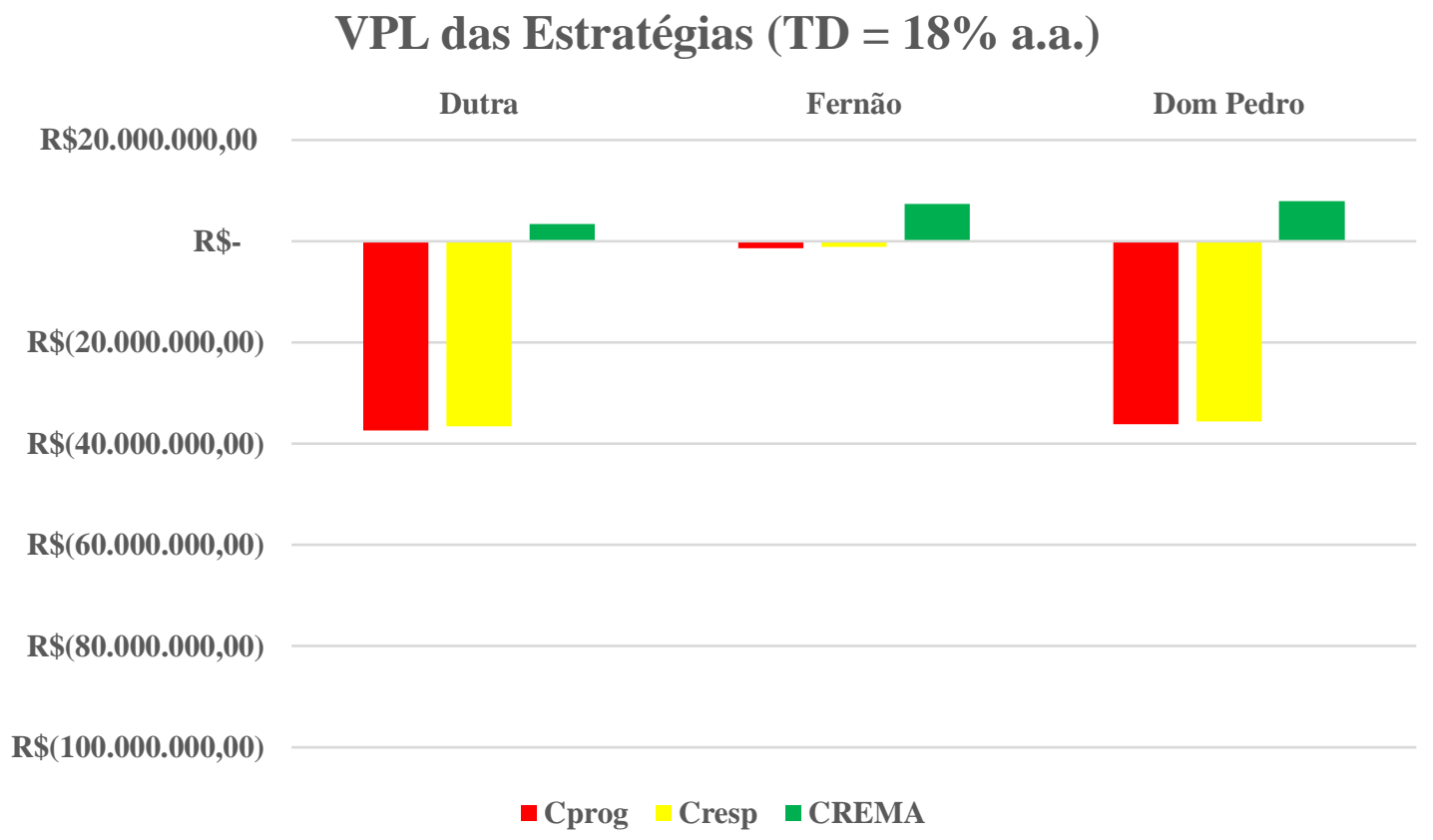

Figura 43: VPL das Estratégias Empregadas, com taxa de desconto de 18\% a.a.

Observa-se que em nenhuma estratégia associada às concessões o VPL foi positivo, o que indica que a cobrança de pedágio não é viável aos usuários, considerando o método e os valores assumidos nesse trabalho. Além disso, a estratégia do CREMA apresentou valores positivos em todas as rodovias, para todas as análises, pelo fato de não existir cobrança de pedágio nas 
rodovias submetidas a essa estratégia de manutenção. Mesmo a rodovia Fernão Dias, com as menores tarifas de pedágio entre as rodovias em estudo, não apresentou VPL positivo, nem com o aumento das taxas de desconto. Sendo assim, foi feita a determinação das tarifas quilométricas de equilíbrio, ou seja, as tarifas que igualam os custos do pedágio com os benefícios pela redução de custos operacionais, estando essas tarifas apresentadas na Tabela 23.

Tabela 23: Tarifas de Equilíbrio dos Trechos em Estudo

\begin{tabular}{cccc}
\hline \multirow{2}{*}{ Rodovia } & \multicolumn{3}{c}{ Taxa de Desconto } \\
& $\mathbf{6 \%}$ & $\mathbf{1 2 \%}$ & $\mathbf{1 8 \%}$ \\
\hline Dutra & $\mathrm{R} \$ 0,0137$ & $\mathrm{R} \$ 0,0126$ & $\mathrm{R} \$ 0,0116$ \\
Fernão Dias & $\mathrm{R} \$ 0,0219$ & $\mathrm{R} \$ 0,0216$ & $\mathrm{R} \$ 0,0220$ \\
Dom Pedro & $\mathrm{R} \$ 0,0239$ & $\mathrm{R} \$ 0,0230$ & $\mathrm{R} \$ 0,0228$ \\
\hline
\end{tabular}

Por se tratarem de rodovias com características semelhantes, as rodovias Fernão Dias e Dom Pedro apresentaram tarifas de equilíbrio muito próximas, embora a rodovia Fernão Dias tenha apresentado um comportamento diferente com a variação das taxas de desconto. As menores tarifas de equilíbrio na Dutra são decorrentes, possivelmente, dos menores benefícios encontrados na mesma.

Além da verificação da viabilidade da concessão das rodovias para os usuários, foi possível verificar o comportamento dos custos entre os diferentes tipos de veículos, para a estratégia de manutenção Concessão Responsiva (a que apresentou as maiores reduções de custos dentre as alternativas para rodovias concedidas). A Figura 44 apresenta os percentuais de redução de custos para esse caso, nos três trechos em estudo, para TD de 6\% a.a.

\section{Redução de Custos Operacionais, por tipo de Veículo (TD = $6 \%$ a.a.)}

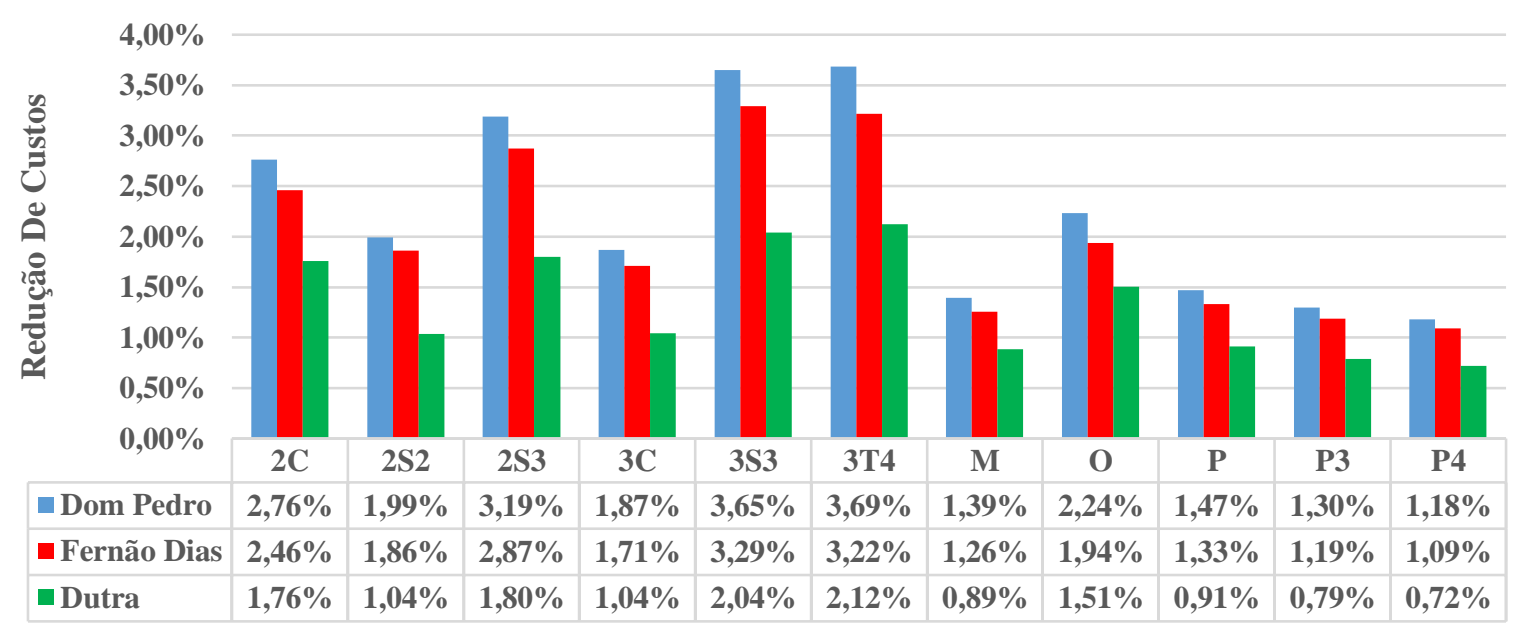

Figura 44: Redução Percentual dos Custos Operacionais, por Tipo de Veículo 
As maiores reduções de custos operacionais, da mesma forma como já havia ocorrido com o consumo dos componentes, foram identificadas nos veículos comerciais, ocorrendo com os veículos do tipo $3 \mathrm{~S} 3$ e $3 \mathrm{~T} 4$ - aproximadamente $3,5 \%$ a uma TD de $6 \%$ a.a. Como forma de comparar os benefícios com os custos entre os diferentes tipos de veículos, o gráfico na Figura 45 apresenta os valores médios da relação entre a redução dos custos operacionais de todos os veículos comparados com os veículos de passeio (P), que assumem valor igual a "1".

Embora as cobranças de pedágio sejam realizadas proporcionalmente ao impacto que cada veículo causa na rodovia (no caso do Brasil, função direta do número de eixos, para os veículos comerciais - vide Tabela 9), buscou-se apenas estabelecer um comparativo entre a proporção do que é pago nos pedágios com os benefícios observados. Essa proporção foi então comparada com os multiplicadores de tarifas praticados nas concessões em estudo, visando identificar quais veículos se aproximam mais do equilíbrio entre o multiplicador da tarifa e a relação dos benefícios com os veículos de passeio, e quais veículos estão mais distantes desse equilíbrio.

\section{Comparativo dos Multiplicadores Tarifários com as relações de benefícios de todos os veículos com veículos de passeio}

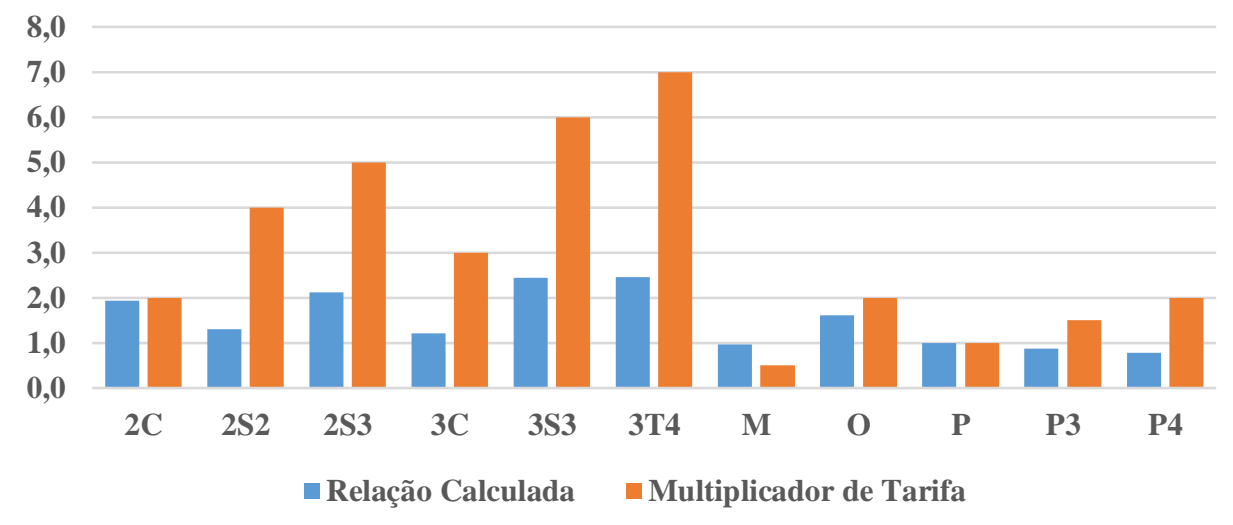

Figura 45: Comparação Entre os Benefícios Observados e os Multiplicadores Tarifários, por Tipo de Veículo

Desse gráfico, é possível extrair informações importantes, como um desequilíbrio facilmente percebido entre as tarifas cobradas e os benefícios dos veículos do tipo P3 e P4 (automóveis com reboque e semi-reboque), quando comparados aos veículos $\mathrm{P}$ (veículos de passeio). Outra importante constatação é o notado desequilíbrio entre os dois indicadores em veículos 
comerciais acima de 3 eixos, onde a cobrança aumenta proporcionalmente mais do que os benefícios para esses veículos.

As motocicletas apresentaram praticamente os mesmos benefícios, em termos percentuais, dos automóveis, embora a tarifa cobrada seja a metade da cobrada aos mesmos. Os veículos comerciais de 2 eixos (2C) tiveram praticamente a mesma proporção nos benefícios e custos, quando comparados aos veículos de passeio, enquanto os ônibus tiveram uma pequena diferença entre esses indicadores.

É necessário reforçar que esse comparativo teve por objetivo apenas levantar um questionamento acerca dos multiplicadores de tarifa vigentes. Sabe-se que o impacto de veículos com maior número de eixos na rodovia é maior, especialmente no pavimento, elemento de estudo dessa pesquisa, porém é necessário identificar se esses impactos são realmente observados na mesma proporção dos multiplicadores de tarifas aplicados, uma vez que os benefícios percebidos não respeitaram essa proporção.

\subsubsection{Análise pela Relação Benefício/Custo (B/C):}

A análise econômica pelo método da relação Benefício/Custo deu-se através de análise incremental, como já descrito anteriormente neste trabalho. Como a análise pelo VPL já indicou custos muitas vezes superiores aos benefícios medidos, optou-se por utilizar a relação B/C para avaliar somente as diferenças entre as estratégias de manutenção empregadas. Contudo, algumas observações devem ser realizadas.

Os custos, para as estratégias de rodovias concedidas (Cprog e Cresp) são os mesmos, uma vez que são oriundos apenas das tarifas de pedágio e dos VDMs. Já a estratégia do CREMA apresenta custos iguais a “zero", pois não há cobrança de pedágio nessa estratégia. Isso nos leva a conclusão de que a relação B/C no caso do CREMA tende ao infinito, por apresentar custo igual a zero, e essa seria sempre a melhor estratégia, independente dos benefícios e custos das outras estratégias, o que se configura como uma análise equivocada, uma vez que a condição Base utilizada apresenta uma situação extrema de má-gestão e descaso do poder público, permitindo assim que uma estratégia que deveria ser prática comum, com parâmetros mínimos de desempenho (CREMA) tenha benefícios comparáveis aos encontrados nas estratégias de rodovias concedidas, sem contudo haver uma cobrança pontual de pedágio aos usuários. 
Tendo isso posto, a estratégia do CREMA deve ser excluída da análise, restando apenas as estratégias Cprog e Cresp. Como ambas apresentam os mesmos custos em todas as situações, conclui-se também que em todos os casos a melhor estratégia, dentro das concedidas, é a Cresp, pois foi a que apresentou os maiores benefícios, em todas as rodovias, para todas as TDs. Pela análise incremental, como a variação dos custos ( $\Delta \mathrm{C}$ da tabela 4$)$ é igual a zero para os dois casos citados, a relação B/C também vai tender ao infinito, assumindo valor positivo quando os benefícios aumentam, ou valor negativo quando os benefícios diminuem.

Resumidamente, as únicas conclusões que podem ser tiradas nessa análise é que o método da relação B/C não é o mais adequado ao caso estudado, uma vez que os custos calculados para cada alternativa resultam em valores indeterminados, ao se realizar a análise incremental (valores divididos por zero, com resultado tendendo ao infinito). Isso se dá principalmente por não se avaliarem outros custos aos usuários além do pagamento de pedágios, ainda que mesmo em rodovias com gestão pública exista o pagamento de impostos, que podem ser revertidos de forma direta nas obras de manutenção do pavimento.

\subsubsection{Análise pela Taxa Interna de Retorno (TIR):}

Para fazer a análise pela TIR, calculada através da função de mesmo nome no Excel, primeiramente foi necessário ordenar todos os benefícios e custos anuais, sem aplicação da taxa de desconto, e subtraindo os custos dos benefícios, determinar o resultado anual. Esse procedimento foi realizado somente para a alternativa Cresp, por ser a alternativa que apresentou os maiores benefícios entre as estratégias vinculadas a rodovias concedidas. Com os resultados ordenados anualmente, procedeu-se o cálculo da TIR apenas aplicando a função aos resultados calculados.

Nessa etapa, o software só calculou a TIR do trecho da Rodovia Fernão Dias, retornando um valor de 47,94\%. Para os demais trechos, o software retornou um valor de erro (\#NÚM!). De forma a esclarecer o comportamento das taxas de desconto nos fluxos de caixa em estudo, foram elaborados gráficos, mostrados nas Figuras 46, 47 e 48, que indicam os valores dos custos e dos benefícios, nos três trechos em estudo, em função da variação das TDs. 


\section{Variação do VPC e VPB em função das Taxas de Desconto - Dom Pedro}

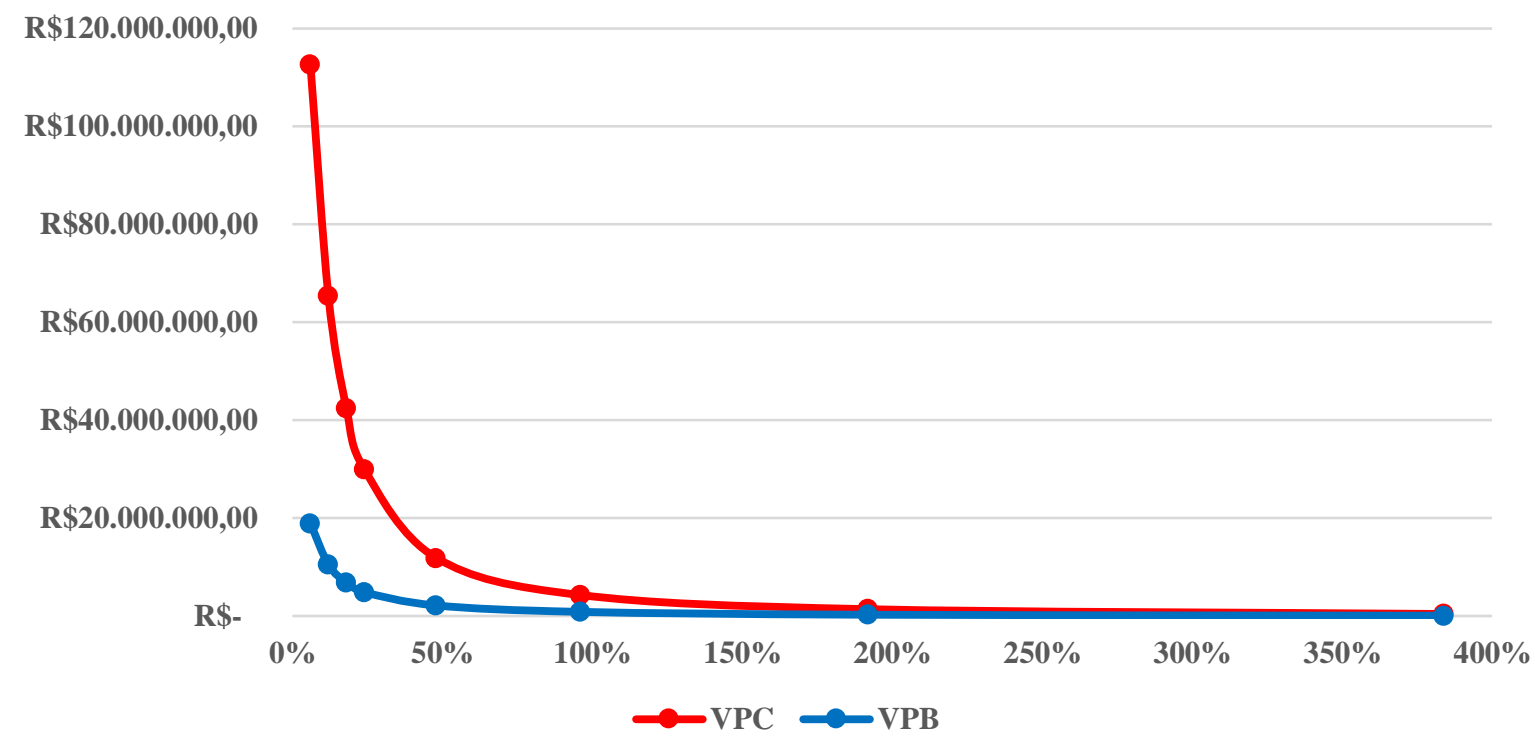

Figura 46: Variação dos Custos e Benefícios na Rodovia Dom Pedro, em função das TDs

\section{Variação do VPC e VPB em função das Taxas de Desconto - Dutra}

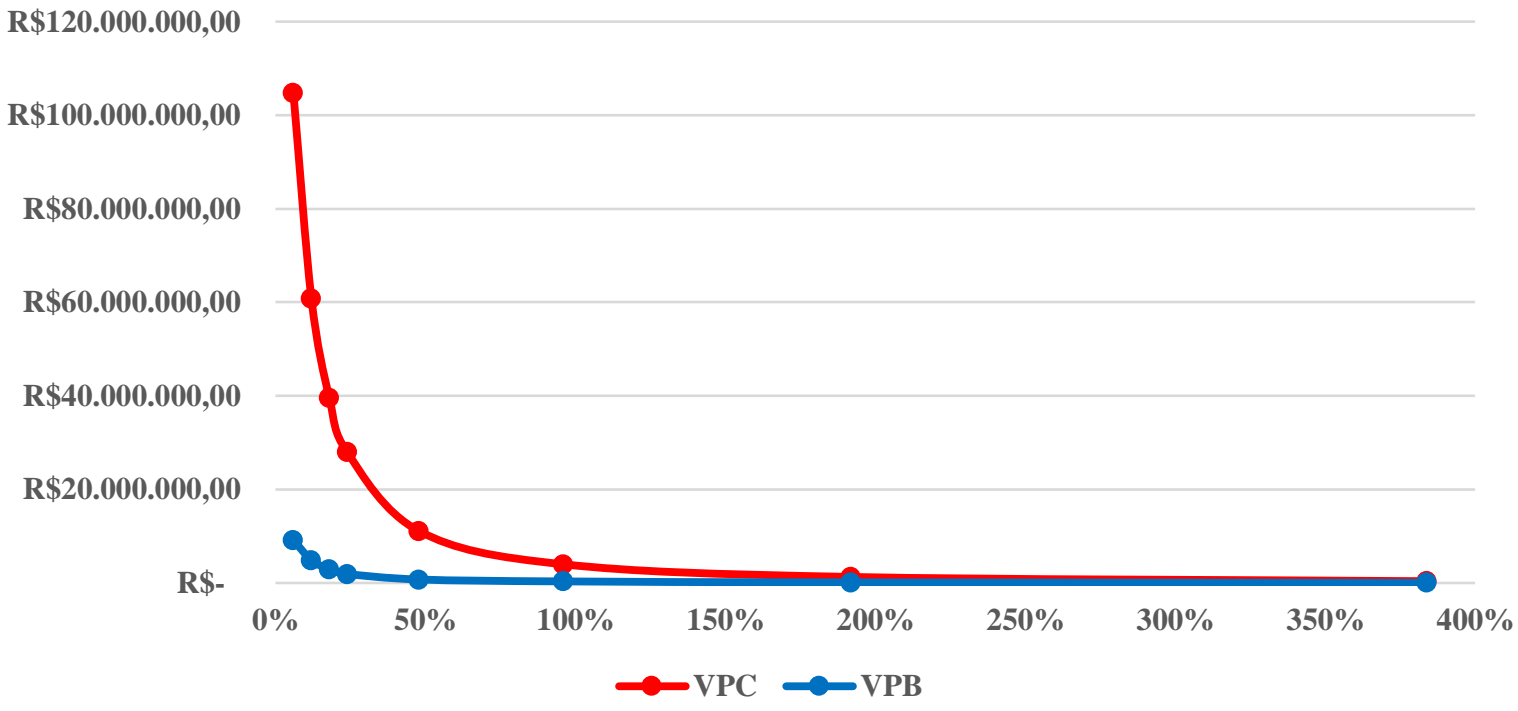

Figura 47: Variação dos Custos e Benefícios na Rodovia Dutra, em função das TDs 


\section{Variação do VPC e VPB em função das Taxas de Desconto - Fernão Dias}

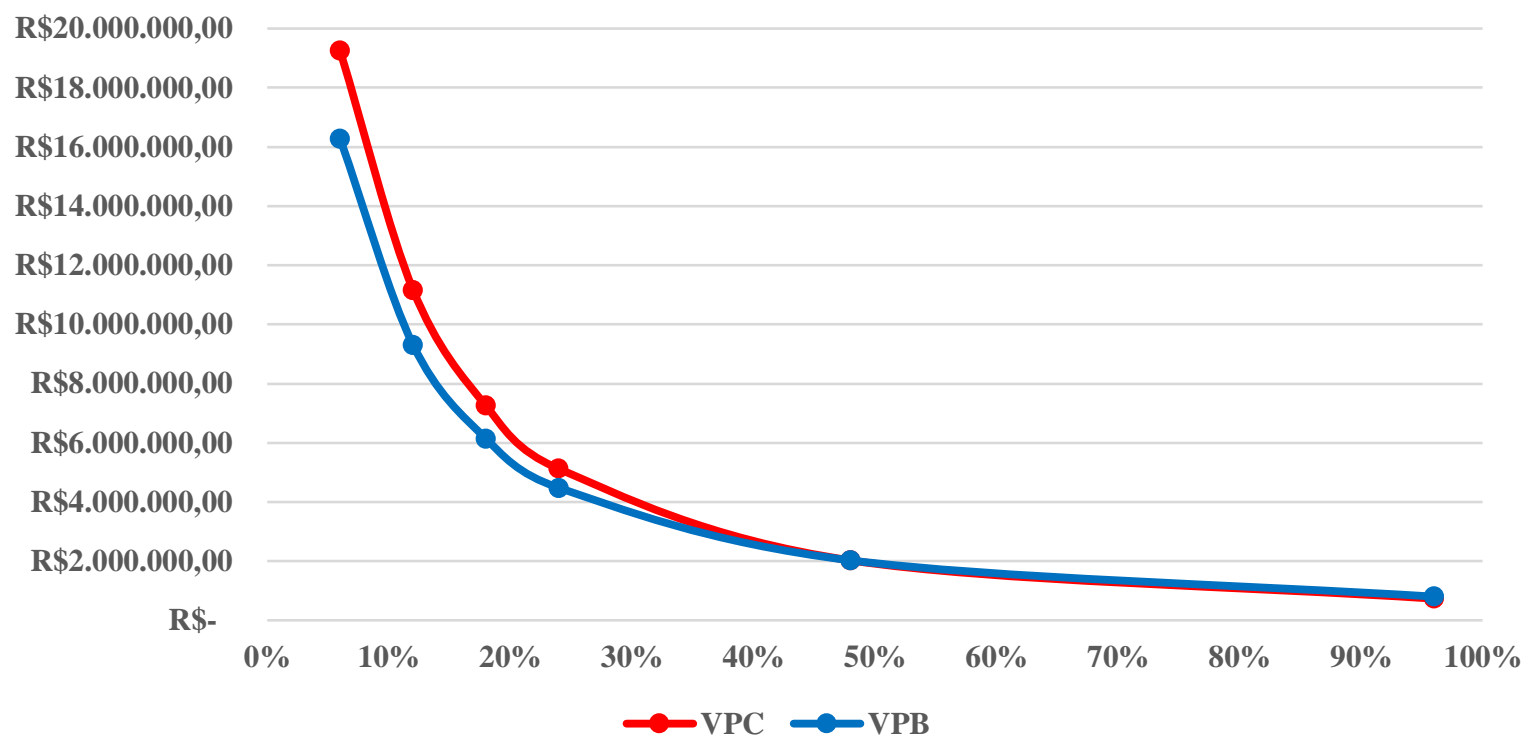

Figura 48: Variação dos Custos e Benefícios na Rodovia Fernão Dias, em função das TDs

O que se observa nesse caso é que, nas Rodovias Dutra e Dom Pedro, independente da taxa de desconto que se aplique, em nenhum momento os Benefício conseguem sequer igualar os Custos, não havendo, portanto, um ponto de VPL igual a "zero". Entende-se dessa forma a impossibilidade do software calcular a TIR em ambos os casos. Já para a Rodovia Fernão Dias, a TIR é facilmente identificada no gráfico da Figura 48 (aproximadamente 48\%), estando os custos, após esse ponto, mantidos sempre abaixo dos benefícios.

Conceitualmente e comparado a valores obtidos no mercado, uma TIR igual a $48 \%$ é muito alta, e indicaria um investimento por parte do usuário altamente rentável. Porém, mesmo no trecho da Rodovia Fernão Dias, o VPL calculado foi negativo, valor que por si só já indica que a concessão não é viável para os usuários. Dessa forma, como com TDs abaixo de $48 \%$ os custos são sempre maiores que os benefícios, a TIR calculada poderia indicar a máxima rentabilidade que o agente responsável pela manutenção da rodovia (concessionária) pode obter. De fato, ao se comparar com a rentabilidade que algumas concessionárias de rodovias tiveram no ano de 2016, segundo a EXAME (2017) - CCR Autoban teve rentabilidade igual 52,6\%; CCR NovaDutra igual a 32,8\% - percebe-se que essa suposição é válida.

Contudo, em nenhum momento os custos dos agentes foram levantados, tampouco incluídos na análise do HDM-4. Embora a análise econômica desta pesquisa tenha como foco o pavimento das rodovias, tanto as concessionárias como o poder público possuem diversos outros custos na 
operação das mesmas. Esses custos influenciam diretamente em qualquer análise que pudesse ser realizada também do ponto de vista da agência que opera a rodovia.

Por conta das dificuldades de se caracterizar os fluxos de caixa deste estudo, e pela complexidade dos agentes envolvidos em análises de projetos rodoviários, chega-se à conclusão que, tal qual a relação B/C, a TIR não é indicada para o caso em estudo. Para corroborar essa conclusão, a literatura expressa que em fluxos de caixa com variações constantes nos sinais, como no caso da Rodovia Fernão Dias, a TIR pode apresentar múltiplos resultados, sem que se possa afirmar categoricamente que um desses resultados é o correto.

\subsubsection{Análise Complementar, com IRI limite da Condição Base igual a $8 \mathrm{~m} / \mathrm{km}$ :}

Embora os resultados apresentados até este ponto já indiquem claramente um grande desequilíbrio entre os valores de pedágio pagos pelos usuários e os benefícios decorrentes da manutenção praticada pelas concessionárias nos pavimentos, optou-se por realizar uma análise complementar, onde a estratégia definida como "Base" apresentaria como limite para intervenção no pavimento um IRI igual a $8 \mathrm{~m} / \mathrm{km}$, em substituição ao IRI igual a $6 \mathrm{~m} / \mathrm{km}$ adotado até então. Para as definições do HDM-4, um pavimento de uma rodovia como as rodovias em estudo, com IRI igual a $8 \mathrm{~m} / \mathrm{km}$, apresenta condição muito ruim, não havendo nenhuma classificação inferior a essa. Dessa forma, limitando o IRI a $8 \mathrm{~m} / \mathrm{km}$, os benefícios observados nas demais estratégias de manutenção devem ser maiores, e assim pretende-se observar se mesmo com o pavimento em condições extremas, os trechos em estudo ainda apresentariam VPL negativo.

Como os custos totais não são alterados nas demais estratégias de manutenção, os gráficos das Figuras 49, 50 e 51 apresentam os Custos Totais da alternativa Base, para IRI igual a 6 e 8 $\mathrm{m} / \mathrm{km}$. Observa-se que o aumento na TD provocou um aumento proporcional dos custos totais, quando a alternativa Base teve como valor limite um IRI igual a 8. A exceção ocorreu no trecho da Rodovia Dutra, onde a maior diferença entre os custos totais ocorreu a uma TD de $12 \%$. O maior aumento nos custos foi identificado na Rodovia Fernão Dias, quando a TD foi igual a $18 \%$. 


\section{Aumento dos Custos Totais dos Usuários - IRI 8 (TD=6\%}

a.a.)

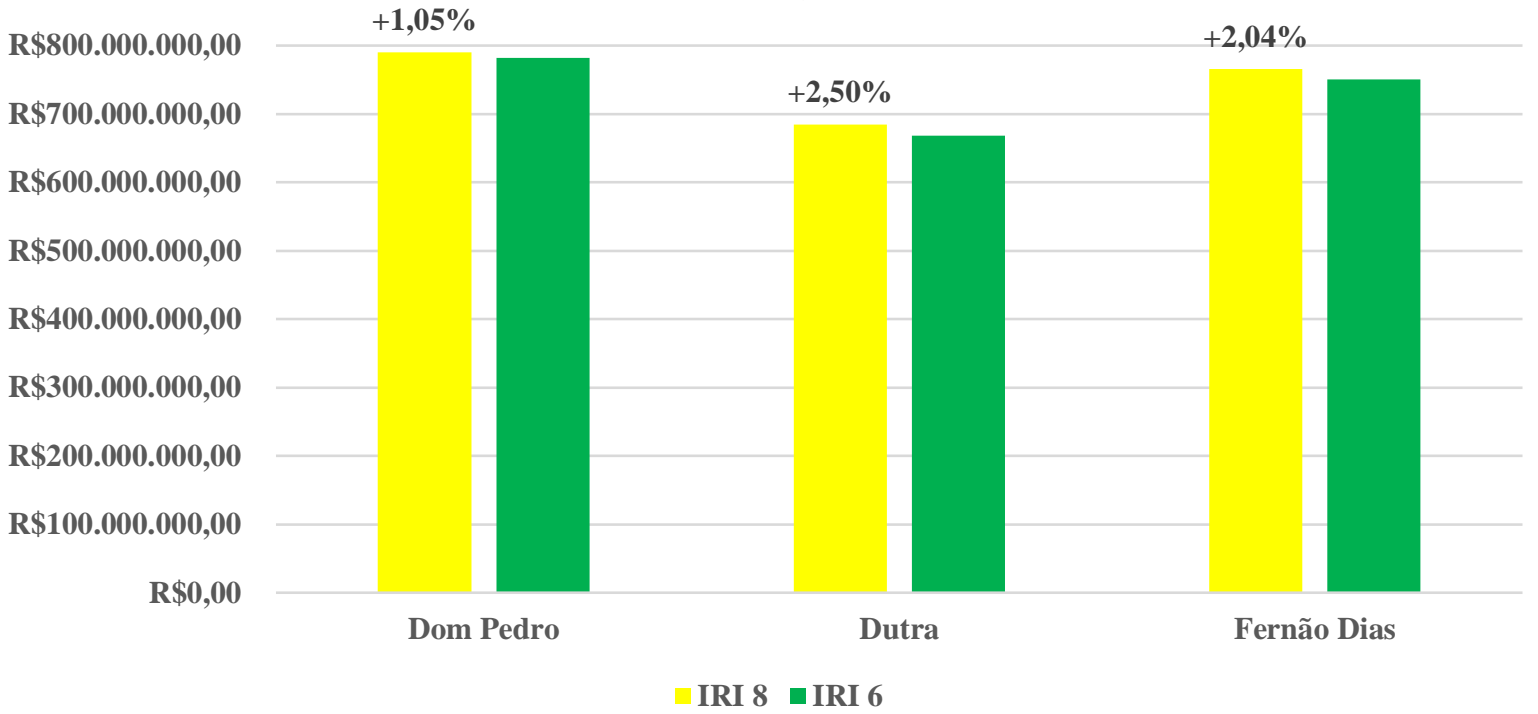

Figura 49: Aumento dos Custos dos Usuários em Decorrência do Aumento da Irregularidade do Pavimento, $\mathrm{TD}=6 \%$ a.a.

\section{Aumento dos Custos Totais dos Usuários - IRI 8 (TD=12\% \\ a.a.)}

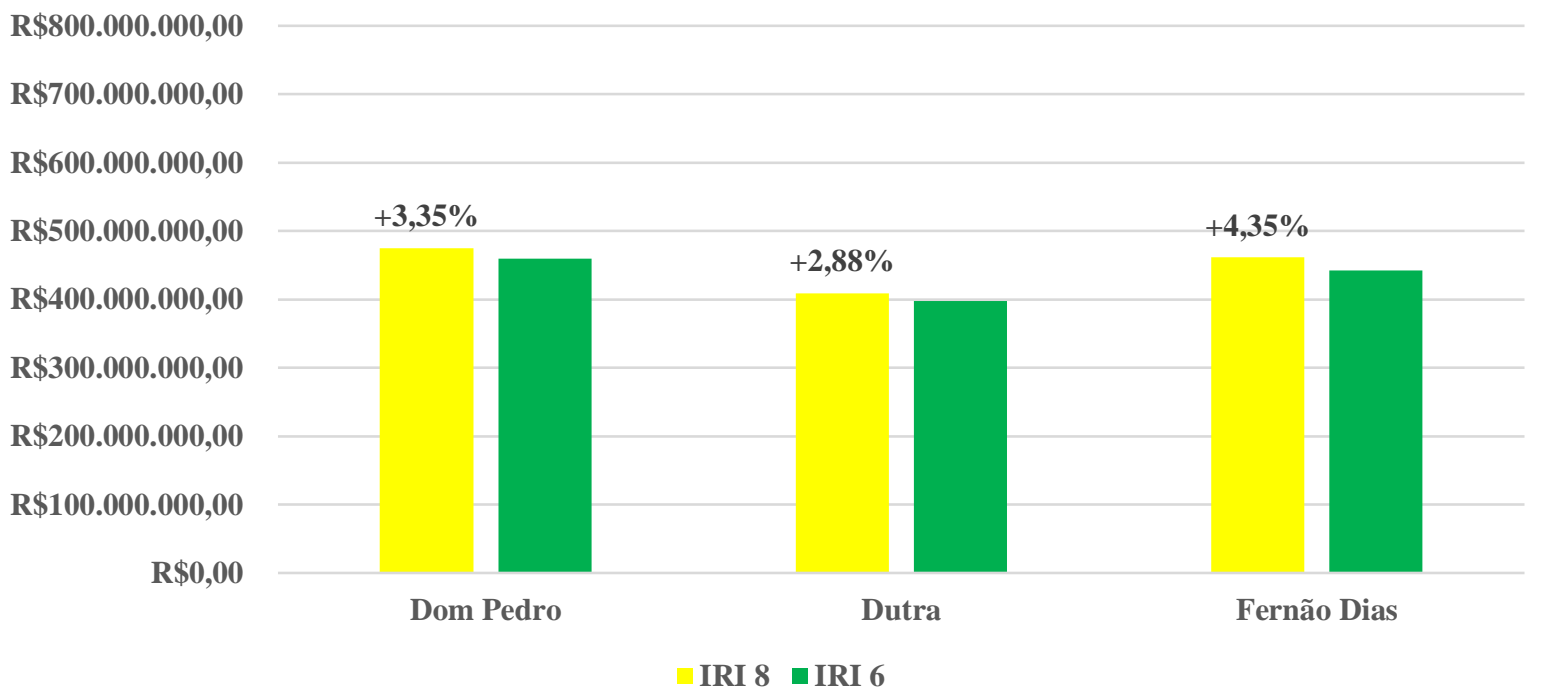

Figura 50: Aumento dos Custos dos Usuários em Decorrência do Aumento da Irregularidade do Pavimento, $\mathrm{TD}=12 \%$ a.a. 


\section{Aumento dos Custos Totais dos Usuários - IRI 8 (TD=18\% \\ a.a.)}

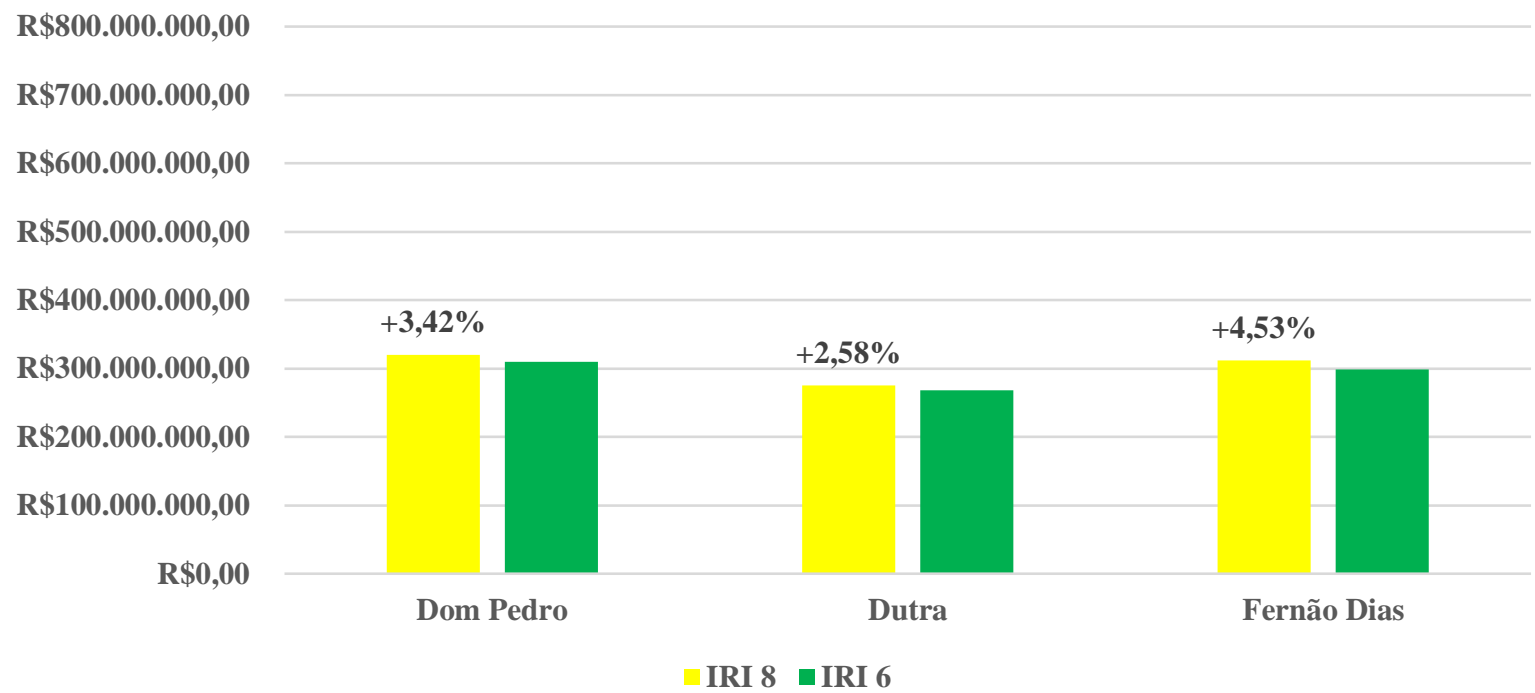

Figura 51: Aumento dos Custos dos Usuários em Decorrência do Aumento da Irregularidade do Pavimento, $\mathrm{TD}=12 \%$ a.a.

Os maiores custos totais na alternativa Base refletem em maiores benefícios nas outras alternativas. Os resultados são apresentados nas Figuras 52, 53 e 54.

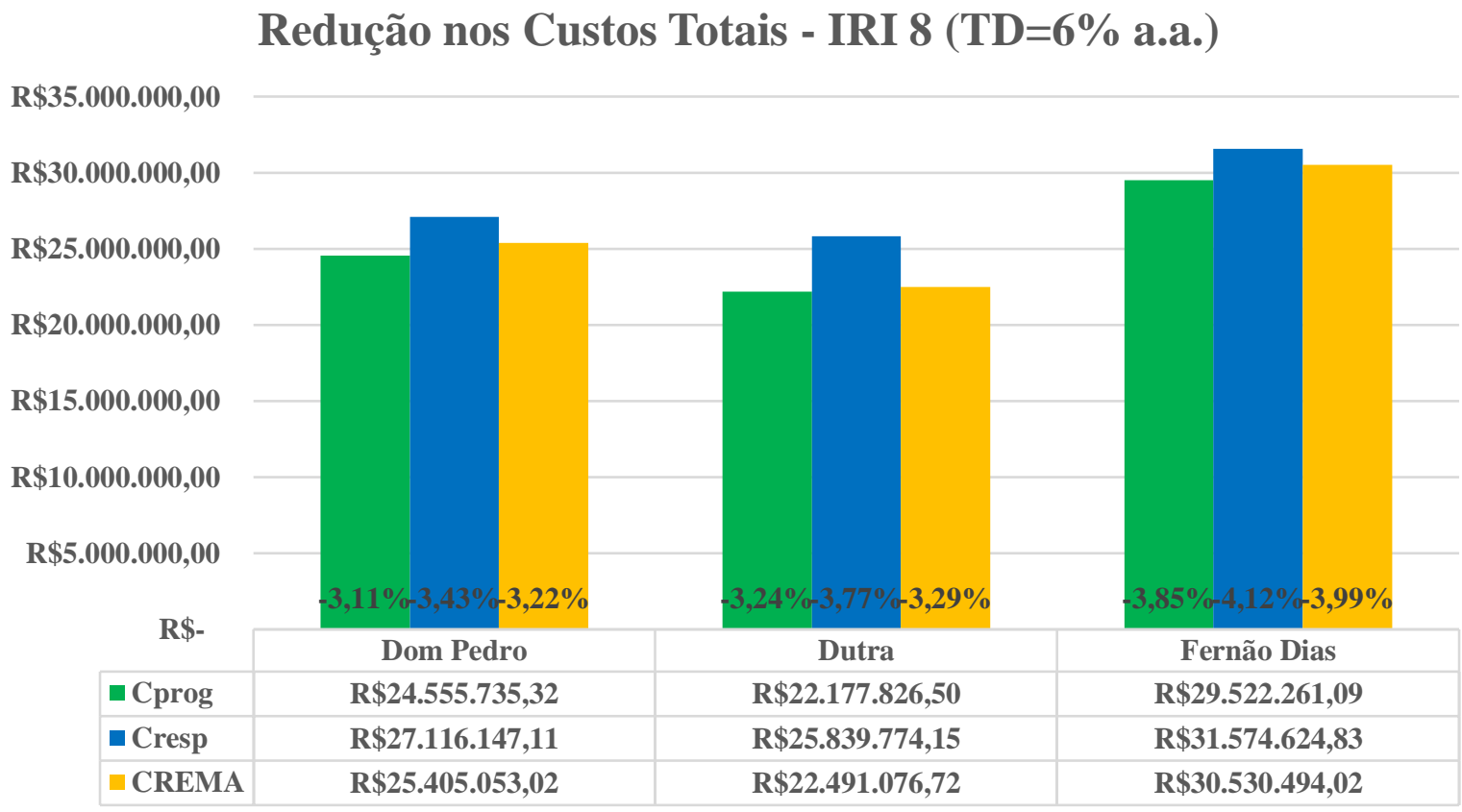

Figura 52: Benefícios Totais dos Usuários pela redução de custos operacionais, Condição Base com IRI 8, taxa de desconto igual a $6 \%$ a.a. 


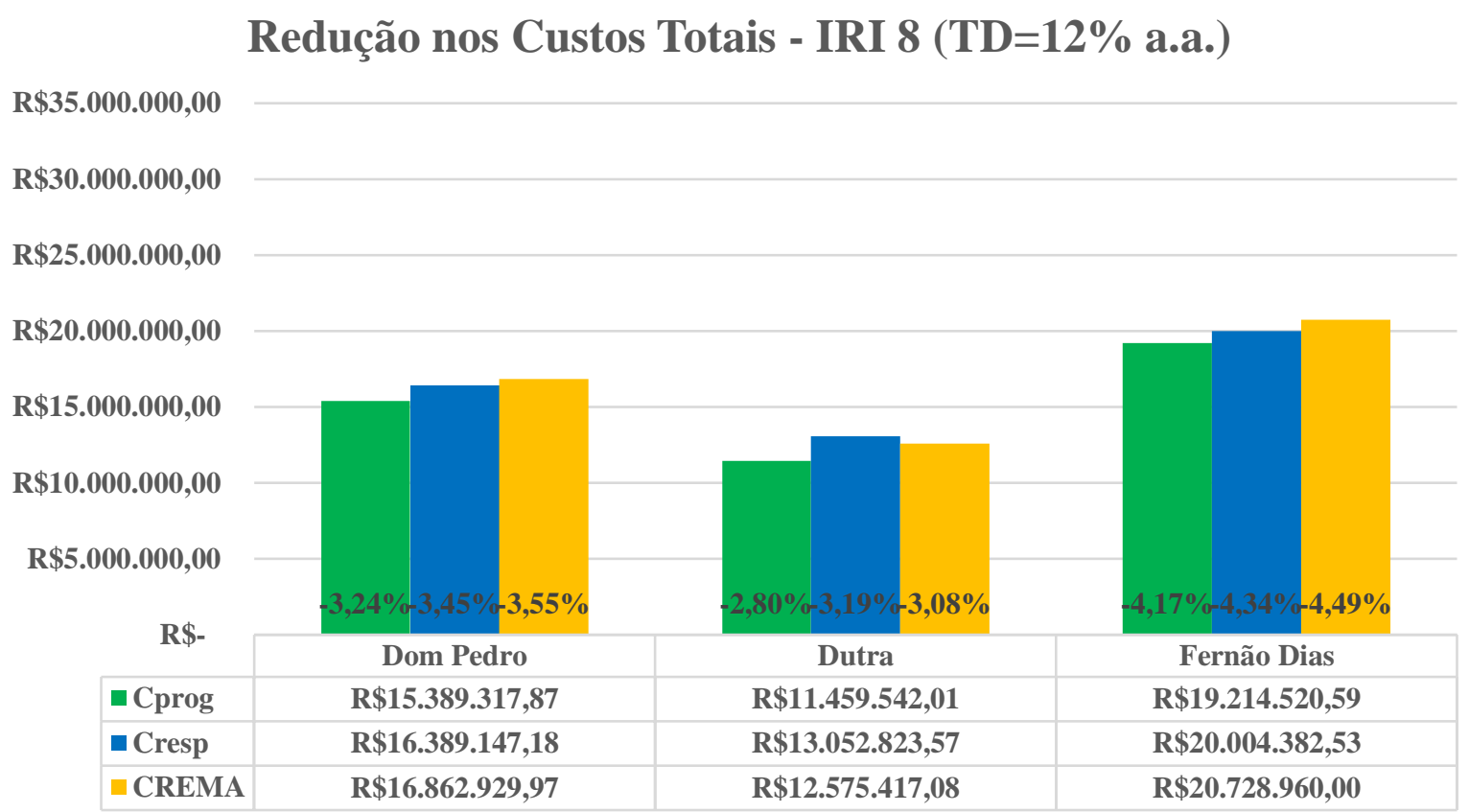

Figura 53: Benefícios Totais dos Usuários pela redução de custos operacionais, Condição Base com IRI 8, taxa de desconto igual a $12 \%$ a.a.

\section{Redução nos Custos Totais - IRI 8 (TD=18\% a.a.)}

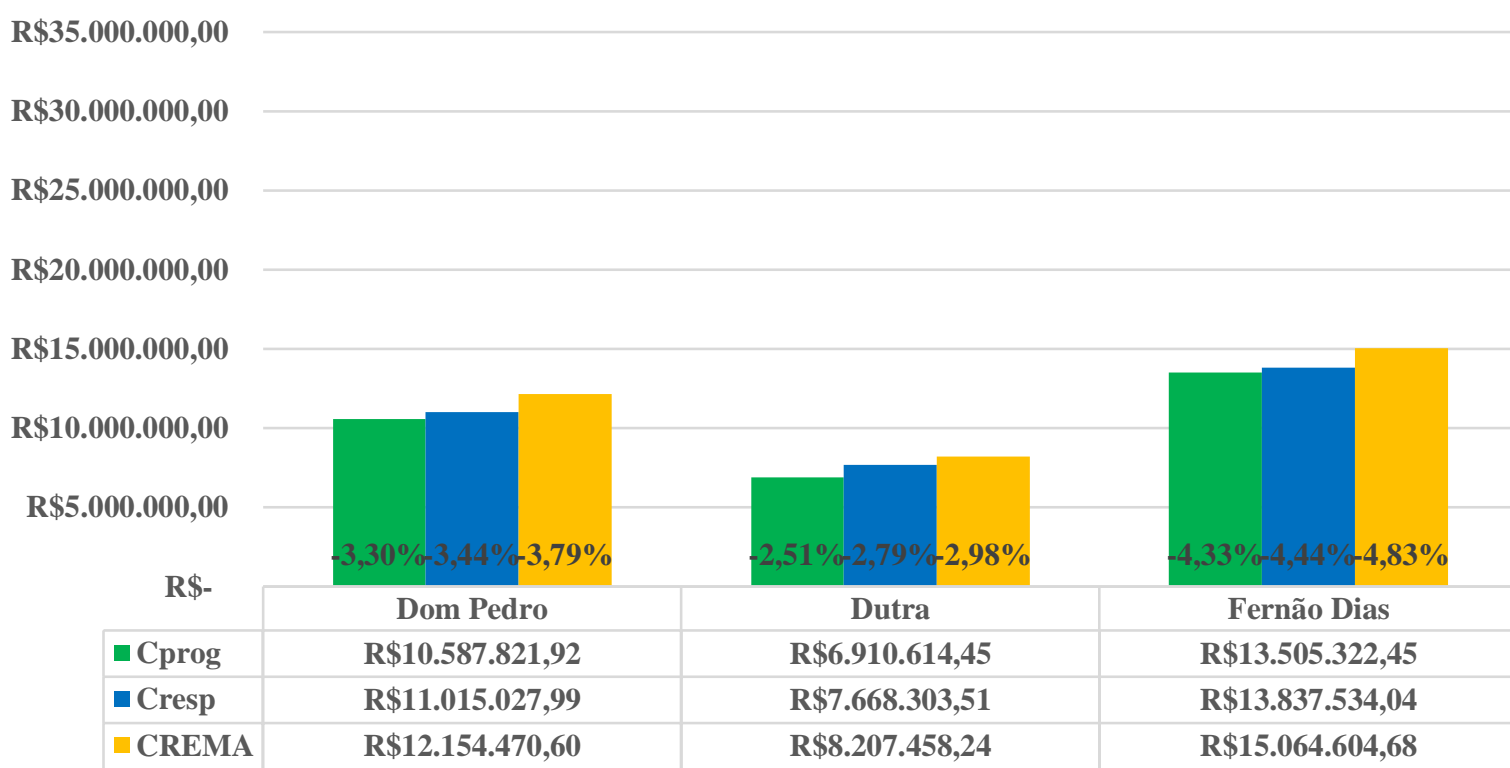

Figura 54: Benefícios Totais dos Usuários pela redução de custos operacionais, Condição Base com IRI 8, taxa de desconto igual a $18 \%$ a.a.

Como esperado, os benefícios observados foram superiores àqueles calculados para a condição Base com IRI limite igual a 8. No trecho da Rodovia Fernão Dias, que apresentou as maiores reduções nos custos totais, esse percentual chegou a quase 5\%. Diferentemente da análise 
quando o IRI limite da condição Base era igual a 6, nas novas simulações, todas as estratégias apresentaram maiores sensibilidades às variações na $\mathrm{TD}$, sendo os benefícios proporcionalmente maiores quanto maior a TD aplicada. A exceção, novamente, foi o trecho da Dutra, onde todas as estratégias de manutenção trouxeram benefícios proporcionalmente menores com o aumento da TD. Como também já havia ocorrido na simulação original, a estratégia do CREMA passa a apresentar benefícios maiores que as demais estratégias a partir da TD igual a $12 \%$ na maioria dos trechos avaliados.

Como os custos dos usuários com o pagamento de pedágio se mantém os mesmos, a subtração desses custos, em valor presente, dos benefícios calculados em relação a condição Base com IRI limite igual a 8, também em valor presente, fornece os VPLs, que são apresentados nas Figuras 55, 56 e 57. Com as simulações utilizando como IRI limite da condição base $8 \mathrm{~m} / \mathrm{km}$, o único trecho do estudo que passou a apresentar VPL positivo, ou seja, cuja concessão seria uma solução economicamente viável aos usuários, foi o trecho da Fernão Dias. Mesmo com o pavimento em condições de irregularidade extremas, as rodovias Dutra e Dom Pedro apresentam tarifas que oneram excessivamente os usuários, uma vez que os benefícios oriundos da manutenção do pavimento, para que este permaneça sempre em ótimas condições, não foram suficientes para igualar os custos com o pagamento de pedágios.

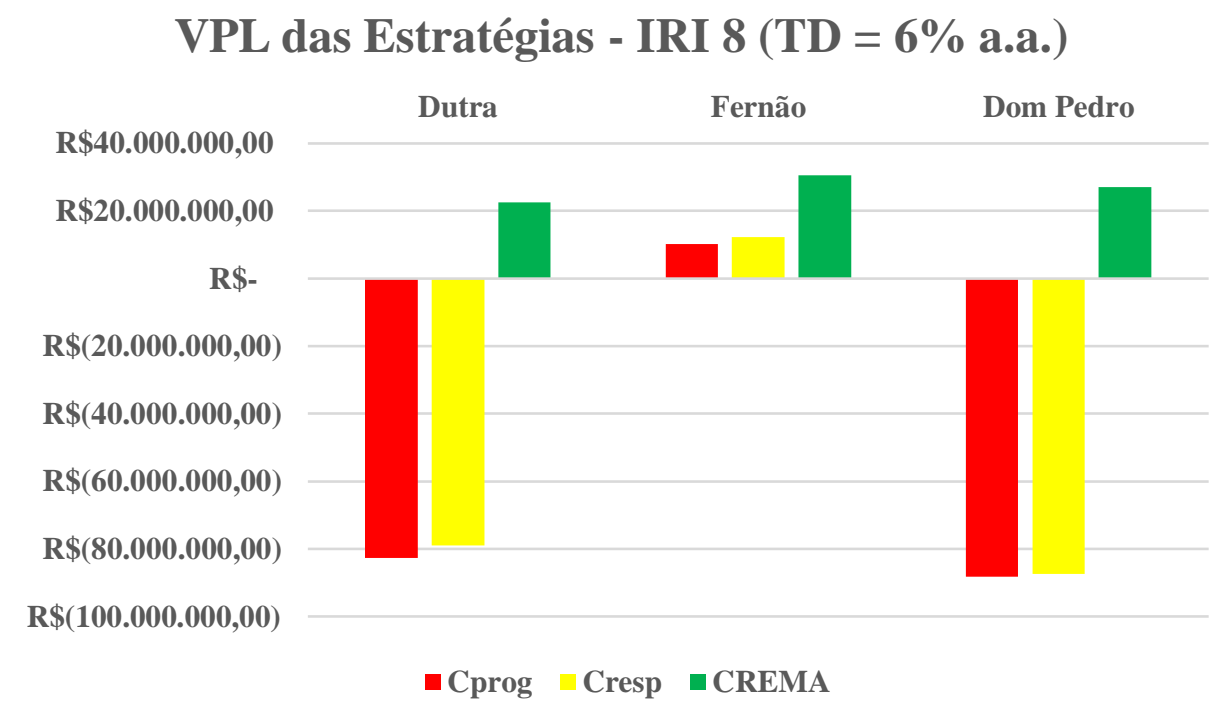

Figura 55: VPL das Estratégias Empregadas, Condição Base com IRI 8, taxa de desconto de $6 \%$ a.a. 


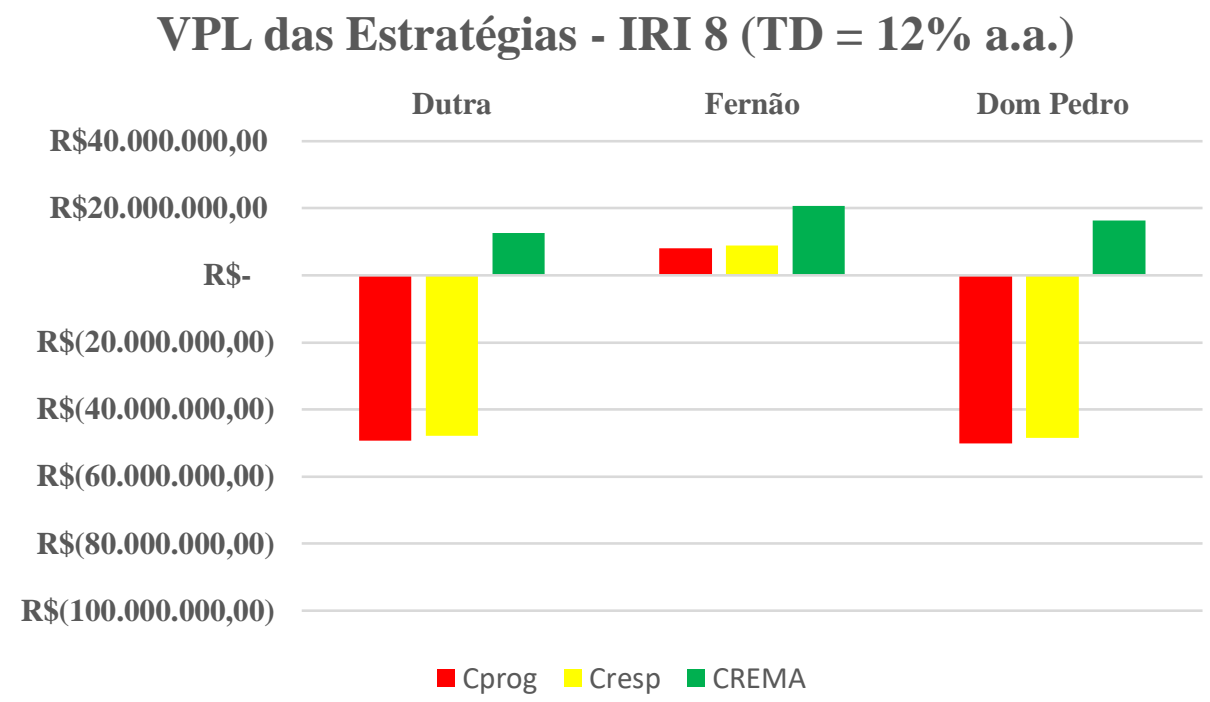

Figura 56: VPL das Estratégias Empregadas, Condição Base com IRI 8, taxa de desconto de $12 \%$ a.a.

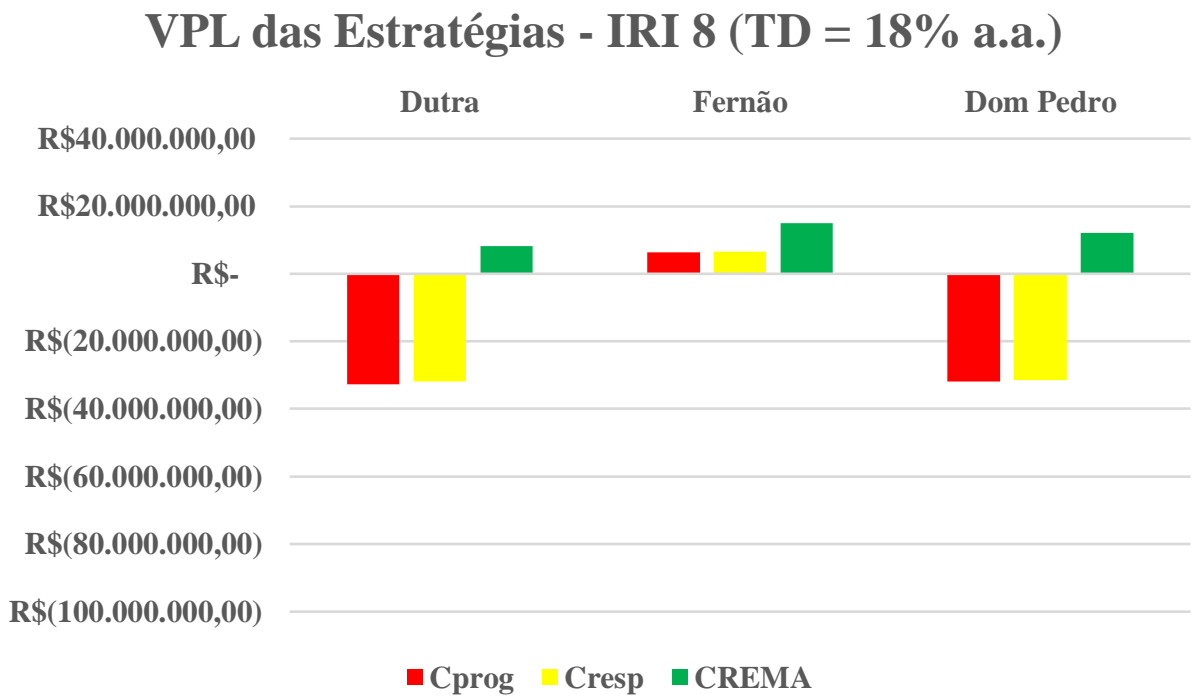

Figura 57: VPL das Estratégias Empregadas, Condição Base com IRI 8, taxa de desconto de $18 \%$ a.a.

Um comparativo entre as tarifas reais com as tarifas de equilíbrio nas rodovias é apresentado nas Figuras 58, 59 e 60. Os gráficos apresentados demonstram uma característica que deve ser destacada nessa nova simulação, com IRI limite igual a 8: enquanto nas simulações originais as tarifas de equilíbrio apresentaram baixa sensibilidade à variação na taxa de desconto, nas novas simulações ocorreu o contrário.

Nas rodovias Fernão Dias e Dom Pedro, as tarifas de equilíbrio tiveram relação diretamente proporcional com o aumento da taxa de desconto, enquanto na rodovia Dutra essa relação foi 
inversamente proporcional. Esse comportamento se mostra compatível com o comportamento observado anteriormente, na análise dos benefícios (Figuras 52 a 54), onde a rodovia Dutra apresentava benefícios proporcionalmente menores com o aumento das TDs, e as demais rodovias apresentavam o comportamento oposto.

\section{Tarifas de Equilíbrio (TD = $6 \%$ a.a.)}

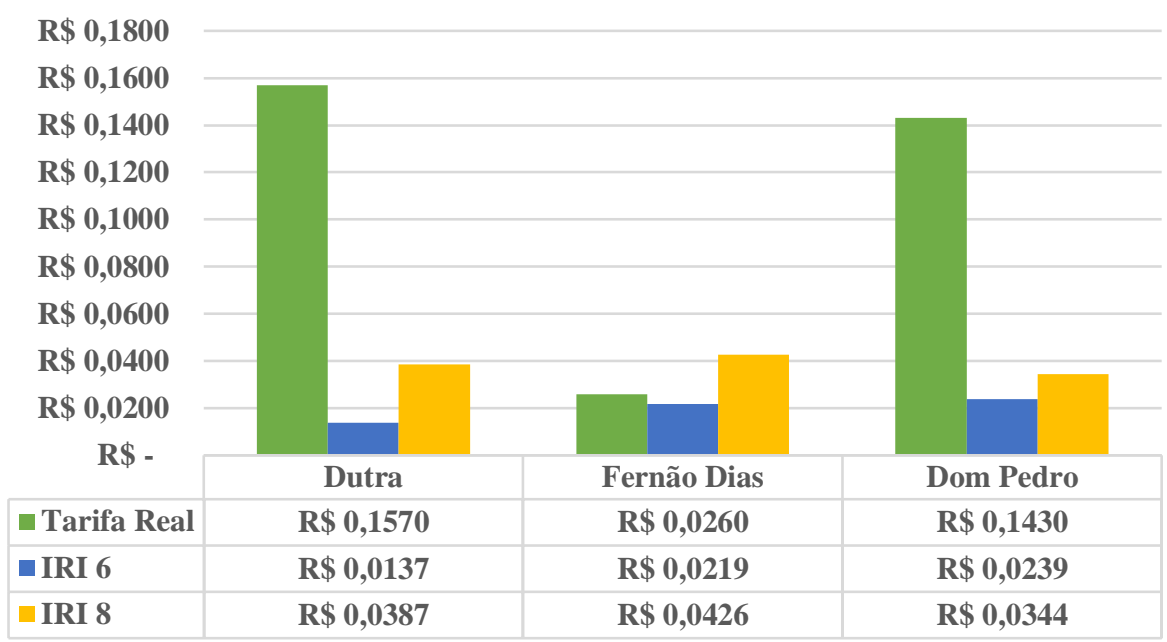

Figura 58: Tarifas de Equilíbrio, Taxa de Desconto de 6\% a.a.

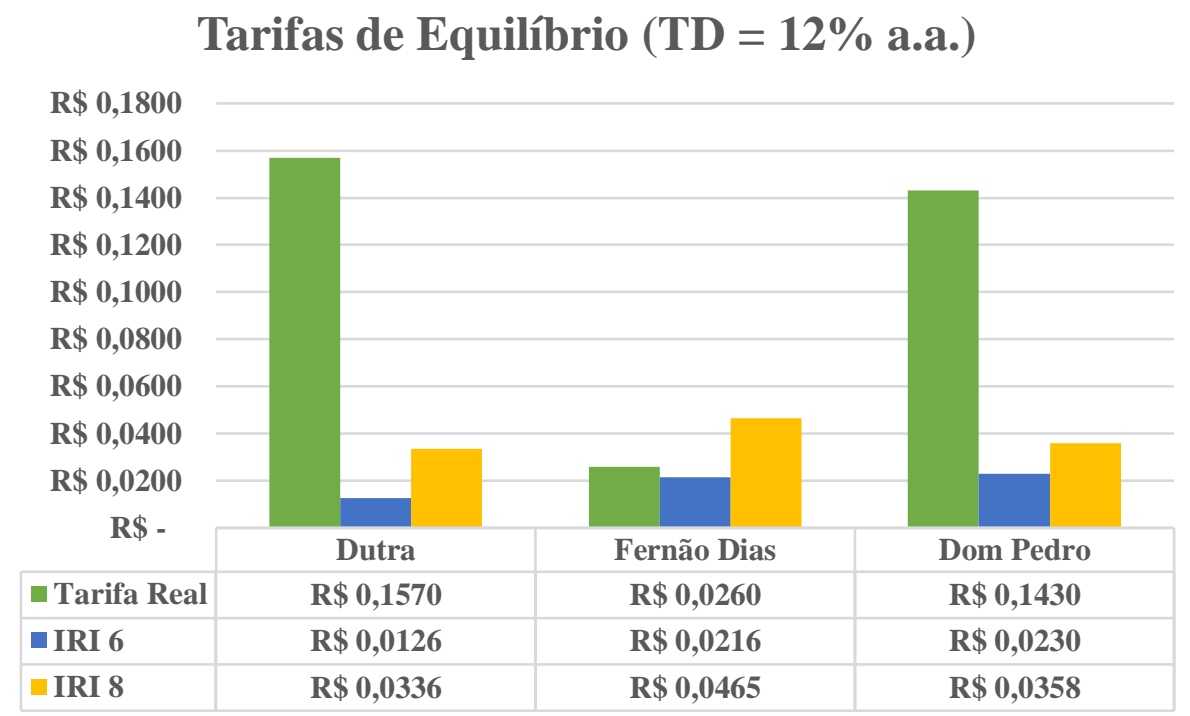

Figura 59: Tarifas de Equilíbrio, Taxa de Desconto de 12\% a.a. 


\section{Tarifas de Equilíbrio (TD = 18\% a.a.)}

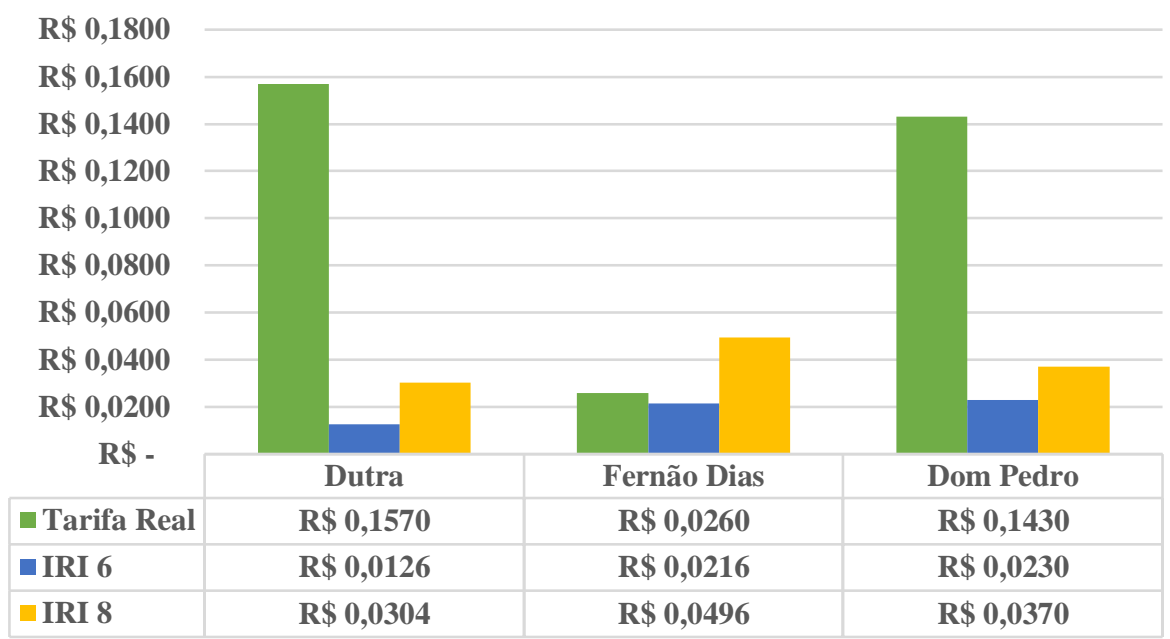

Figura 60: Tarifas de Equilíbrio, Taxa de Desconto de 18\% a.a.

Em uma análise crítica, com base nas melhorias previstas nos contratos das concessionárias, discutidas no item 3.2 deste trabalho, o que se percebe é que, embora apresente a maior tarifa de pedágio dentre os trechos avaliados, a rodovia Dutra foi a que apresentou não apenas os menores benefícios na redução de custos operacionais, como também foi uma das mais modestas em termos de obras com grande impacto na rodovia. A obra citada como a de maior importância na concessão (nova pista da Serra das Araras), teve sua execução repassada para a próxima concessionária (ainda indefinida) a assumir o trecho, não estando dessa forma incluída nas tarifas de pedágio cobradas até então. Como as demais obras não possuem impacto significativo em toda a rodovia - entenda-se, nesse caso, o aumento significativo de capacidade de tráfego em toda a sua extensão, ou a correção de traçado em grandes trechos, melhorando de forma significativa a segurança dos usuários - a suposição de que as tarifas cobradas oneram de forma significativa o usuário possui fortes indícios de ser válida.

Embora com um volume superior de obras de melhorias, a tarifa cobrada na concessão da Dom Pedro encontra-se muito próxima do valor da Dutra. Por conta do desequilíbrio entre benefícios e custos demonstrado, a suposição de cobrança excessiva aos usuários nessa rodovia também é aplicável, embora sejam necessários maiores estudos, trazendo maiores evidências sobre a redução de custos devido à redução de tempo de viagem com as obras de melhoria previstas, para que seja possível apontar conclusões sobre esse contrato.

Já a Rodovia Fernão Dias, que possui a menor tarifa de pedágio, também apresentou poucas obras de melhoria significativas, e ao se avaliar o pavimento, a mesma só foi justificada quando 
a condição Base apresentou pavimento em condições extremas de irregularidade. Porém, como dentre as rodovias avaliadas, essa esteve mais próxima do limite entre o "viável" e "inviável" economicamente para o usuário, também não é possível afirmar, considerando as melhorias previstas no contrato, que a concessão não foi viável para os usuários.

Deve-se destacar, contudo, que embora as simulações tenham sido realizadas considerando um pavimento em condições ruins, as pesquisas da CNT anteriores à concessão da Fernão Dias indicavam um pavimento em condições regulares. Ainda que a análise da CNT seja de modo subjetivo, esse pode ser um indicativo de que a rodovia, antes da concessão, não se encontrava em estado tão grave quanto o simulado, o que acarretaria em benefícios ainda menores do que os medidos após as simulações. A concessionária também não mantém a rodovia sempre dentro dos parâmetros estabelecidos em contrato. Como exemplo, no ano de 2013, a Autopista Fernão Dias teve 304 Termos de Registro de Ocorrência (TRO) de Buracos na pista ou acostamento, somente no estado de São Paulo, conforme consta no Relatório Anual da ANTT do ano de 2013. Se forem considerados outros defeitos encontrados no pavimento (escorregamento de massa asfáltica, abaulamento, depressão), esse número chega a 340 só no estado de São Paulo, e 624 ocorrências relacionadas ao pavimento em toda a extensão concedida. Em média, são quase duas ocorrências registradas por dia, no ano de 2013, de defeitos no pavimento.

Dessa forma, mesmo a concessão que apresentou as menores tarifas pode não trazer benefícios que "paguem" os custos de pedágio dos usuários, uma vez que os parâmetros definidos nas simulações possivelmente não são respeitados em todos os trechos. Para reforçar essa afirmação, os defeitos listados são somente os apontados pela ANTT em sua atividade de fiscalização rotineira, podendo a rodovia apresentar valores de irregularidade não oriundos de defeitos do pavimento, mas superiores aos estabelecidos no PER.

A fim de se observar melhor as suposições descritas nesse capítulo, foram aplicados percentuais (entre 15 e 30\%) que refletem somente o montante da tarifa destinado à manutenção dos pavimentos. Com base nos relatórios financeiros da ANTT entre 1998 e 2009, simularam-se os cenários com a tarifa destinada ao pavimento nas rodovias igual a 15\% no trecho da Dom Pedro I, 25\% na Fernão Dias e 30\% na Dutra, buscando refletir os diferentes níveis de investimento de cada contrato de concessão. Tem-se assim os seguintes resultados, indicados na Figura 61, para $\mathrm{TD}=6 \%$ a.a. 


\section{Tarifas de Equilíbrio (TD = 6\% a.a.)}

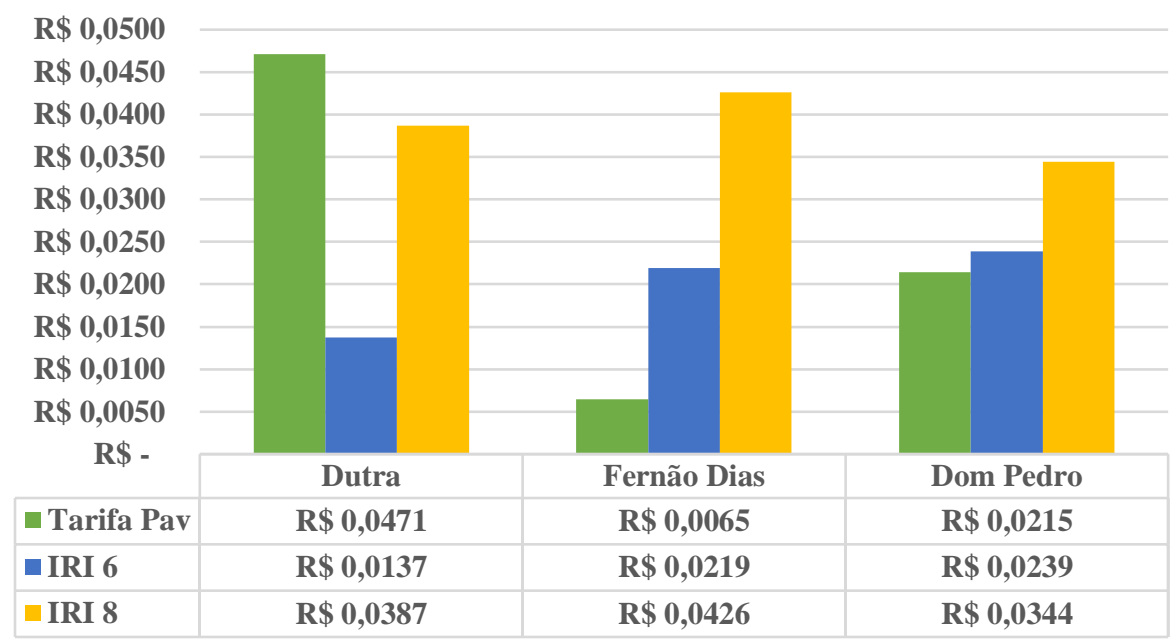

Figura 61: Tarifas de Equilíbrio com Percentuais Somente do Pavimento

Mesmo com a adoção de percentuais somente para a manutenção do pavimento nas tarifas de pedágio, o trecho da rodovia Dutra segue apresentando tarifas maiores do que as que trariam equilíbrio econômico para os usuários do trecho. Ao fazer a mesma consideração na Rodovia Fernão Dias, entretanto, a mesma apresenta tarifa menor do que a de equilíbrio, ou seja, provavelmente os benefícios percebidos pelos usuários foram maiores do que os custos que os mesmos tiveram nesse trecho. No trecho da Rodovia Dom Pedro, a tarifa do pavimento também foi menor do que as tarifas de equilíbrio, contudo com valores muito próximos, o que reforça a necessidade de maiores estudos que avaliem a viabilidade econômica da concessão nesse trecho para os usuários. 


\section{CONCLUSÕES E SUGESTÕES PARA TRABALHOS FUTUROS}

Este trabalho teve o intuito de questionar se as concessões rodoviárias no estado de São Paulo estão dando retorno econômico aos seus usuários, em razão da melhoria de qualidade do pavimento em que eles trafegam. Apesar das limitações inerentes à complexidade do objeto de estudo e da dificuldade na aquisição de dados, este trabalho tem conclusões importantes.

\subsection{CONCLUSÕES}

Esta pesquisa foi inteiramente desenvolvida com dados obtidos pela internet ou com variáveis cujos valores foram adotados a partir de evidências extraídas de relatórios também disponíveis em endereços eletrônicos. Muito embora a pesquisa tenha se completado e atingido o seu objetivo, a maior parte das limitações ocorreu devido à ausência de informações que poderiam ser disponibilizadas nos sites das agências reguladoras. Apesar do reconhecimento de que a disponibilização desses dados demanda esforço por parte das agências reguladoras, isso facilitaria e possibilitaria um maior número de pesquisas aplicadas às rodovias concedidas, trazendo análises técnicas úteis às agências e aplicáveis nas constantes revisões e melhorias do marco regulatório, tanto no estado de São Paulo, como no Brasil.

Mesmo com as limitações da pesquisa, os resultados obtidos foram considerados satisfatórios. O software HDM-4 mostrou-se adequado ao estudo proposto, ainda que o mesmo não inclua um módulo de avaliação específica para concessões rodoviárias, e que a forma como os dados são inseridos no software atenda bem avaliações de projetos futuros, mas limite muito as retroanálises. O VPL apresentou-se como o melhor método para se realizar análises econômicas sob o ponto de vista do usuário, pois os fluxos de caixa do estudo reduzem a aplicabilidade do método da Taxa Interna de Retorno e os custos iguais em diferentes estratégias de manutenção prejudicam a análise pela relação Benefício/Custo incremental.

Os benefícios medidos, em geral, não foram tão significativos quanto o esperado, em uma demonstração clara de que, ainda que o pavimento seja mantido sempre em níveis de irregularidade baixos, a tarifa cobrada por esse serviço não pode ser muito elevada, para que o usuário não seja onerado além dos benefícios que ele recebe com o pavimento em boas condições. As análises com percentuais da tarifa de pedágio destinados somente ao pavimento reforçaram essa hipótese, principalmente na Rodovia Dutra. 
Um indício de que os custos com o pedágio superam, na prática, os benefícios percebidos pelos usuários, é a inclusão das tarifas de pedágio no valor das passagens de ônibus ou no frete das transportadoras, o que reflete em aumento de preços dos insumos para toda a sociedade. Outro indício desse desequilíbrio são as rentabilidades medidas nas concessionárias de rodovias, com valores superiores às rentabilidades de grandes transportadoras de carga, podendo atingir o dobro em alguns casos.

Esses indícios levam a uma das conclusões mais importantes dessa pesquisa: embora a melhoria da condição do pavimento, na forma de redução de irregularidade longitudinal, visivelmente traga benefícios econômicos para os usuários, muitas vezes esses benefícios podem não ser suficientes para justificar a cobrança de pedágio. De forma resumida, realizar concessões somente com o objetivo de transferir os custos de manutenção dos pavimentos rodoviários a uma empresa privada, para que a mesma repasse aos usuários, não se configura como uma prática adequada quando se pretende reduzir os custos de transporte em todo o estado ou país. Em condições extremas, a redução de custos operacionais em uma estratégia de manutenção comumente utilizada em concessões sequer chegou a $5 \%$, não sendo suficiente para justificar a implantação de concessões na maioria dos casos.

Em um país cujo investimento mínimo necessário em infraestrutura de transportes é de quase 1 trilhão de reais (cerca de 15\% do PIB), segundo a CNT (2014), sendo aproximadamente 360 bilhões só em rodovias, as concessões rodoviárias podem desempenhar um papel importante nessa expansão, desde que tragam benefícios significativos para a sociedade. Nesse intuito, a remuneração das concessionárias existe e deve ser justa, porém sem onerar os usuários, permitindo que estes também sejam "remunerados" com os benefícios que uma concessão pode trazer. Portanto, entende-se como o ideal que os futuros contratos de concessão tragam um maior número de obras de aumento de capacidade e de correção de traçado das rodovias, trazendo reduções significativas nos tempos de viagem e no número de acidentes.

Quanto aos parâmetros de desempenho dos pavimentos nos contratos, identificou-se um maior rigor nos contratos do CREMA, em rodovias sob gestão pública, do que nos contratos da ANTT, uma vez que os parâmetros de irregularidade apresentados permitem a rodovia recuperada em um menor tempo na estratégia do CREMA. Se um contrato com um órgão rodoviário público apresenta maior rigor do que um contrato de concessão, deve-se no mínimo questionar se os parâmetros utilizados nas concessões são os mais adequados, até pelo fluxo de caixa decorrente da estratégia do CREMA ter apresentado maiores valores com o aumento das taxas de desconto. 


\subsection{RECOMENDAÇÕES PARA TRABALHOS FUTUROS}

Inicialmente, recomenda-se a todo o meio acadêmico na área de engenharia de transportes uma maior participação em conjunto, com o objetivo de identificar informações importantes para pesquisas que podem ser fornecidas pelas agências reguladoras de forma padronizada. Outro aspecto importante é que cada limitação do método proposto nessa pesquisa pode abrir caminho para um estudo específico, a fim de se avaliar os impactos dentro de uma rodovia concedida.

Nesse sentido, dá-se destaque para a distribuição do tráfego nas diferentes horas do ano, uma vez que na pesquisa foi adotado, de forma simplificada, o padrão Free Flow. A sazonalidade e os horários de pico podem trazer resultados consideravelmente diferentes na análise econômica, podendo ser um aspecto aprofundado em outras pesquisas.

A maior parte dos dados utilizados nessa pesquisa pode passar por ajustes, principalmente a fim de alimentar o software HDM-4 com dados reais, fornecidos pelas concessionárias ou pelas agências reguladoras, permitindo o aprimoramento e uma maior relevância dos resultados. Dentre essas informações, estão incluídos: volume de tráfego real dos trechos; composição de tráfego real; estrutura real dos pavimentos; projeto geométrico das rodovias; caracterização real dos veículos cadastrados. O conhecimento dessas informações pode trazer maior confiabilidade nos resultados obtidos, contribuindo dessa forma para a discussão sobre as concessões rodoviárias no país.

Recomenda-se também que o método descrito nesse trabalho seja aprimorado, a fim de incluir em sua análise não apenas os efeitos do pavimento nos custos dos usuários, mas também os efeitos de tráfego (nível de serviço, redução no tempo de viagem), a segurança (redução no número de acidentes através da melhoria do traçado ou da duplicação de vias com implantação de canteiros centrais) e também os aspectos ambientais (energia, emissões de poluentes e ruído).

Uma proposta viável é a inclusão dos elementos rodoviários constantes no PER, a fim de se avaliar os efeitos do atendimento integral dos parâmetros de desempenho de sinalização, drenagem, terraplenagem, elementos de proteção e segurança, dentre outros. 


\section{REFERÊNCIAS BIBLIOGRÁFICAS}

ABCR (2016). Associação Brasileira de Concessionárias de Rodovias. Disponível em <http://www.abcr.org.br>. Acesso em 10 mai. 2016.

ALMEIDA, R. A. e OLIVEIRA, A. V. M. (2013). Sistemas de Tarifação de Congestionamento: Estudo de Caso de Londres. Revista dos Transportes Públicos, São Paulo, n. 133, p. 83-100.

ANDRADE, G. R. (2012). Capacidade e relação fluxo-velocidade em autoestradas e rodovias de pista dupla paulistas. Dissertação (Mestrado) - Programa de Pós-Graduação em Engenharia de Transportes. Escola de Engenharia de São Carlos. Universidade de São Paulo, São Carlos, SP.

ANDREWS, E. (2014). 8 Ways Roads Helped Rome Rule the Ancient World. Disponível em: < http://www.history.com/news/history-lists/8-ways-roads-helped-rome-rule-the-ancientworld>. Acesso em: 17 mai. 2016..

ANP (2017). Série histórica do levantamento de preços e de margens de comercialização de combustíveis. Agência Nacional do Petróleo, Gás e Biocombustíveis. Disponível em <http://www.anp.gov.br >. Acesso em 21 fev. 2017.

ANTT (2012). Rodovias Federais Concedidas: Relatório 2012. Agência Nacional de Transportes Terrestres, Brasília, DF, 426 p.

ANTT (2013). Rodovias Federais Concedidas: Relatório 2013. Agência Nacional de Transportes Terrestres, Brasília, DF, 322 p.

ANTT (2016). Agência Nacional de Transportes Terrestres. Disponível em: <http://www.antt.gov.br>. Acesso em: 17 mai. 2016.

ARTESP (2008). Concorrência Pública Internacional - Edital no 002/2008. Agência de Transporte do Estado de São Paulo. Disponível em $<$ http://www.artesp.sp.gov.br/transparencia-editais-e-contratos-de-concessao.html>. Acesso em 21 nov. 2016.

ARTESP (2016). Agência de Transporte do Estado de São Paulo. Disponível em: <http://www.artesp.sp.gov.br>. Acesso em: 10 mai. 2016.

Autopista Fernão Dias (2016). Desenvolvimento do Modelo de Deterioração de Pavimentos Asfálticos com Uso de Instrumentação e Sistema Weight In Motion. Relatório Final. Autopista Fernão Dias, 323 p.

BRASIL (2016). Programa de Investimento em Logística. Disponível em: <http://www.logisticabrasil.gov.br >. Acesso em: 17 mai. 2016.

CALDEIRA, L. K. O.; ROCHA, C. H. (2015). Evolução do Marco Regulatório das Concessões Rodoviárias no Brasil. XXIX Congresso Nacional de Pesquisa e Ensino em Transportes - ANPET. Ouro Preto. p. 2306-2317. 
CCR (2007). CCR Day 3: pensando no futuro, agindo no presente. CCR. Disponível em: <http://ri.ccr.com.br>. Acesso em 19 dez. 2016.

CCR NovaDutra (2016). Concessionária NovaDutra - Institucional. Disponível em: <http://www.novadutra.com.br/institucional/ >. Acesso em: 30 nov. 2016.

CNT (2014a). Pesquisa Rodoviária 2014 - Relatório Gerencial. Confederação Nacional do Transporte, Brasília, 388 p.

CNT (2014b). Plano CNT de Transporte e Logística 2014. Confederação Nacional do Transporte, Brasília, 752 p.

CNT (2015). Pesquisa Rodoviária 2015 - Relatório Gerencial. Confederação Nacional do Transporte, Brasília, 420p.

DER-SP (2016). Departamento Estadual de Estradas de Rodagem. Disponível em: <http://www.der.sp.gov.br>. Acesso em: 17 mai. 2016.

DNER (1995). Contrato de Concessão de Serviço Público Precedida de Obra Pública Entre a União, Por Intermédio do Departamento Nacional de Estradas de Rodagem DNER e da Concessionária da Rodovia Presidente Dutra S.A. Disponível em: <http://www.antt.gov.br/rodovias/Nova_Dutra.html >.

DNIT (2006). Manual de Estudos de Tráfego: Publicação IPR -723. Instituto de Pesquisas Rodoviárias, Rio de Janeiro, 384 p.

EMBRAPA (2016). Banco de Dados Climáticos do Brasil. Empresa Brasileira de Pesquisa Agropecuária. Disponível em: <https://www.cnpm.embrapa.br/projetos/bdclima/balanco>. Acesso em 19 dez. 2016.

EVERITT, B.S.; LANDAU, S. e LEESE, M. (2001). Cluster Analysis. 4 ed. New York: Arnold Publishers, 2001, 237p.

EXAME (2016). Revista EXAME - Melhores e Maiores 2016. Disponível em: <http://mm.exame.abril.com.br>. Acesso em: 20 mar. 2017.

FHWA (2016). Toll Facilities in The United States: Bridges, Roads, Tunnels, Ferries. PL-16011, FHWA, USA.

FIPE (2017). Preço Médio de Veículos. Fundação Instituto de Pesquisas Econômicas. Disponível em < http://veiculos.fipe.org.br>. Acesso em 21 fev. 2017.

HAAS, R., HUDSON, W. R. e ZANIEWSKI, J. (1994) Modern Pavement Management. Krieger Publishing Company. Malabar, Florida.

HAIR Jr., J. F.; ANDERSON, R. E.; TATHAM, R. L.; BABIN, B. J. e BLACK, W. C. (2009). Análise Multivariada de Dados. 6 ed. Porto Alegre, RS: Bookman Companhia Editora, 2009, $688 \mathrm{p}$. 
HIRSCHFELD, H. (2007). Engeharia Econômica e Análise de Custos. 7 ed. São Paulo: Atlas, 2007.

IBGE (2016). Instituto Brasileiro de Geografia e Estatística. Disponível em <http://www.ibge.gov.br>. Acesso em 10 mai. 2016.

KLEIN, F. C. (2005). Análise da Influência de Características Geométricas de Rodovias nos Custos dos Usuários Utilizando o Programa HDM-4. Dissertação (Mestrado) - Programa de Pós-Graduação em Engenharia de Transportes. Escola de Engenharia de São Carlos. Universidade de São Paulo, São Carlos, SP.

LOEVESTEIN. (2016). Slot Loevestein. Disponível em: 〈https://www.slotloevestein.nl/en >. Acesso em: 17 mai. 2016.

MATHWORKS (2016). Matlab Documentation. Disponível em: <http://www.mathworks.com/help/matlab/index.html>. Acesso em: 20 mar.2016.

MATSUDA, W.; TSUKADA, Y.; KIKUCHI, M. (2005). Flexible Charge Measures Used on Toll Roads: An Analysis of Demonstration Projects in Japan. Transportation Research Record. Washington, n. 1932, p. 137-146.

NICOLINI-LLOSA, J. L. (2002). Toll Road Concessions in Argentina: What Can Be Learned. Transportation Research Record. Washington, n. 1812, p. 10-21.

NTC\&Logística (2015). Anuário 2014/2015. NTC\&Logística. 148 p.

NUNES, D. F. (2012). Procedimento para análise de sensibilidade do programa HDM-4. Dissertação (Mestrado) - Programa de Pós-Graduação em Engenharia de Transportes. Escola de Engenharia de São Carlos. Universidade de São Paulo, São Carlos, SP.

PEDRO, L. M. (2012). Análise dos diferentes contratos de concessão rodoviária e suas contabilizações. Dissertação (Mestrado) - Programa de Pós-Graduação em Controladoria e Contabilidade. Faculdade de Economia, Administração e Contabilidade de Ribeirão Preto. Universidade de São Paulo, Ribeirão Preto, SP.

SINHA, K. C. e LABI, S. (2007). Transportation Decision Making: Principles of Project Evaluation and Programming. Hoboken, NJ: Wiley

UNICAMP (2016). Clima dos Municípios Paulistas. Centro de Pesquisas Meteorológicas e Climáticas Aplicadas a Agricultura. Universidade de Campinas. Disponível em: <http://www.cpa.unicamp.br/outras-informacoes/clima-dos-municipios-paulistas.html>. Acesso em 19 dez. 2016.

WARD, J. L. e SUSSMAN, J. M. (2006). Malaysian Toll Road Public-Private Partnership Program: Analysis and Recommendations for Policy Improvements. Transportation Research Record. Washington, n. 1960, p. 119-127.

ZYMLER, B. (2015). O Controle das Concessões - O Caso das Rodovias. $9^{\circ}$ Congresso Brasileiro de Rodovias e Concessões. Brasília. 


\section{APÊNDICE A - Detalhamento das variáveis de entrada do software HDM-4}

Variáveis do item Climate Zones

- Trecho da Rodovia Dom Pedro I

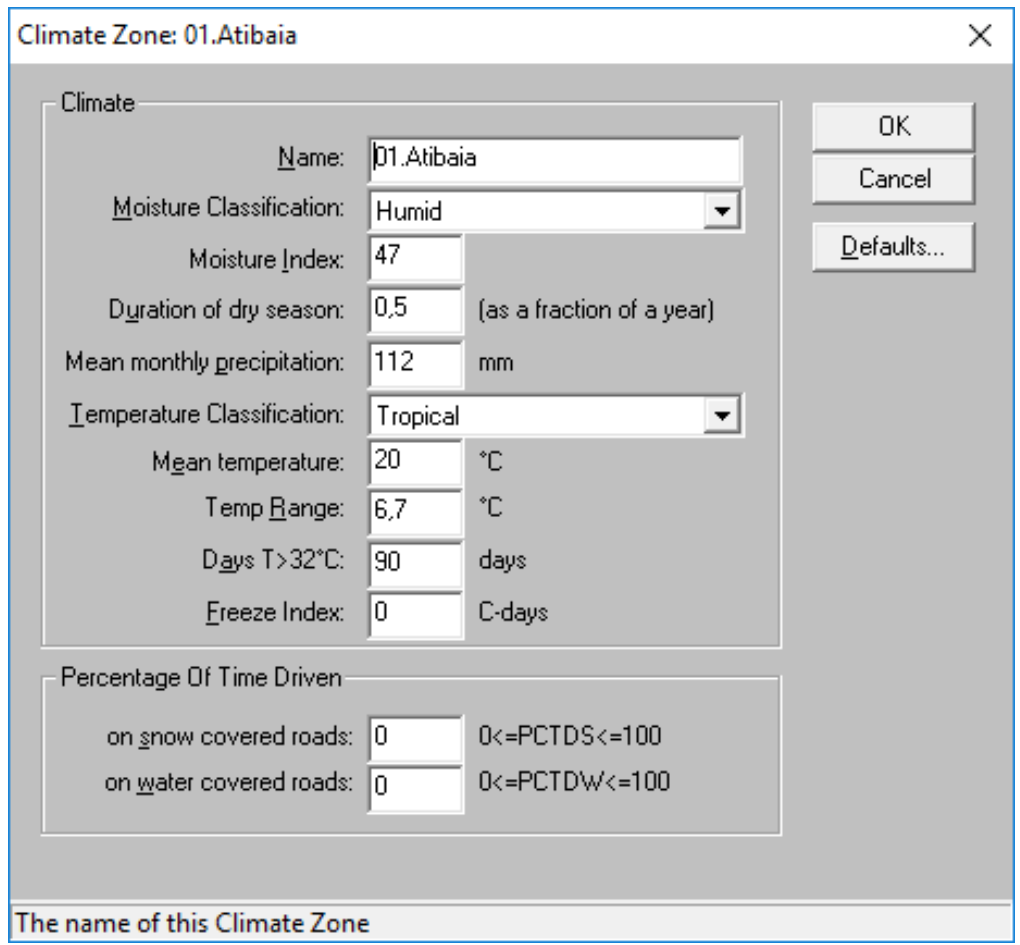

- Trecho da Rodovia Dutra

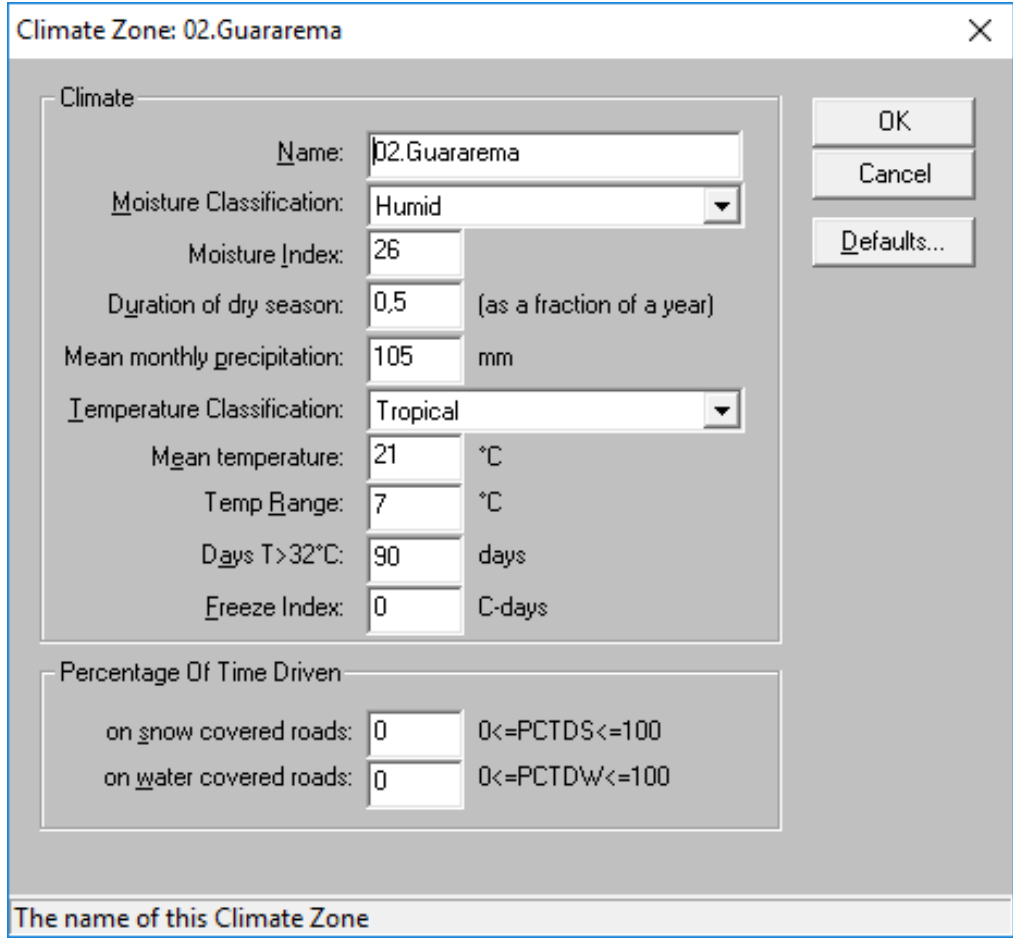


- Trecho da Rodovia Fernão Dias

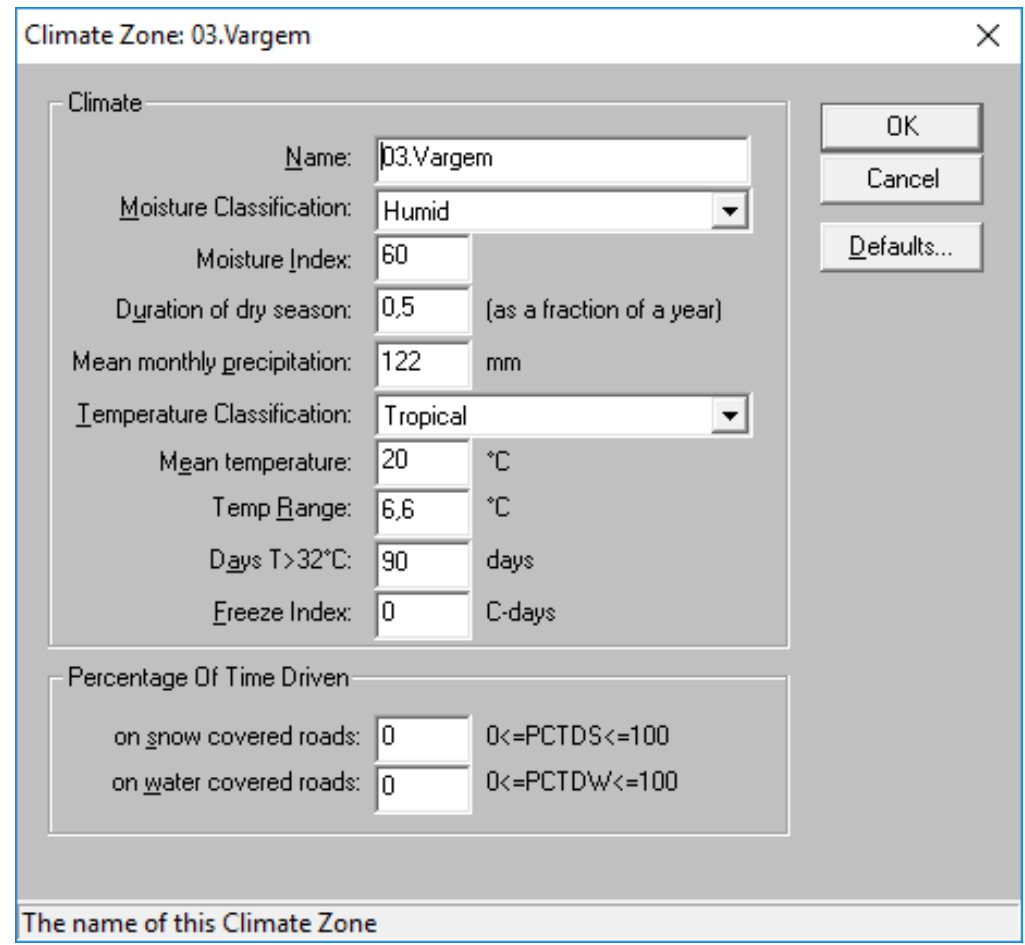

Variáveis do item Speed Flow Type (aplicado a todos os trechos)

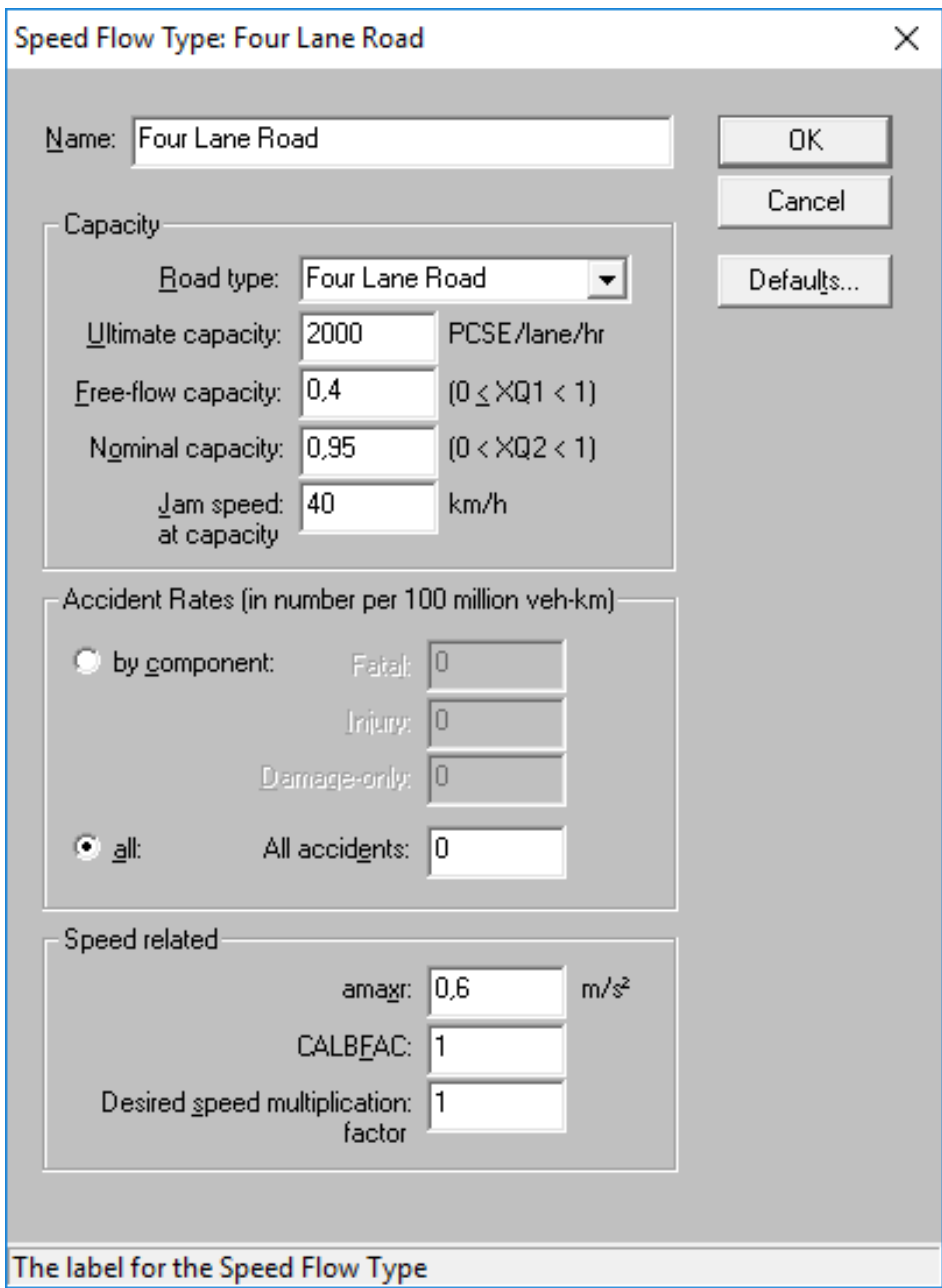


Quadro do item Traffic Flow Pattern (aplicado a todos os trechos)

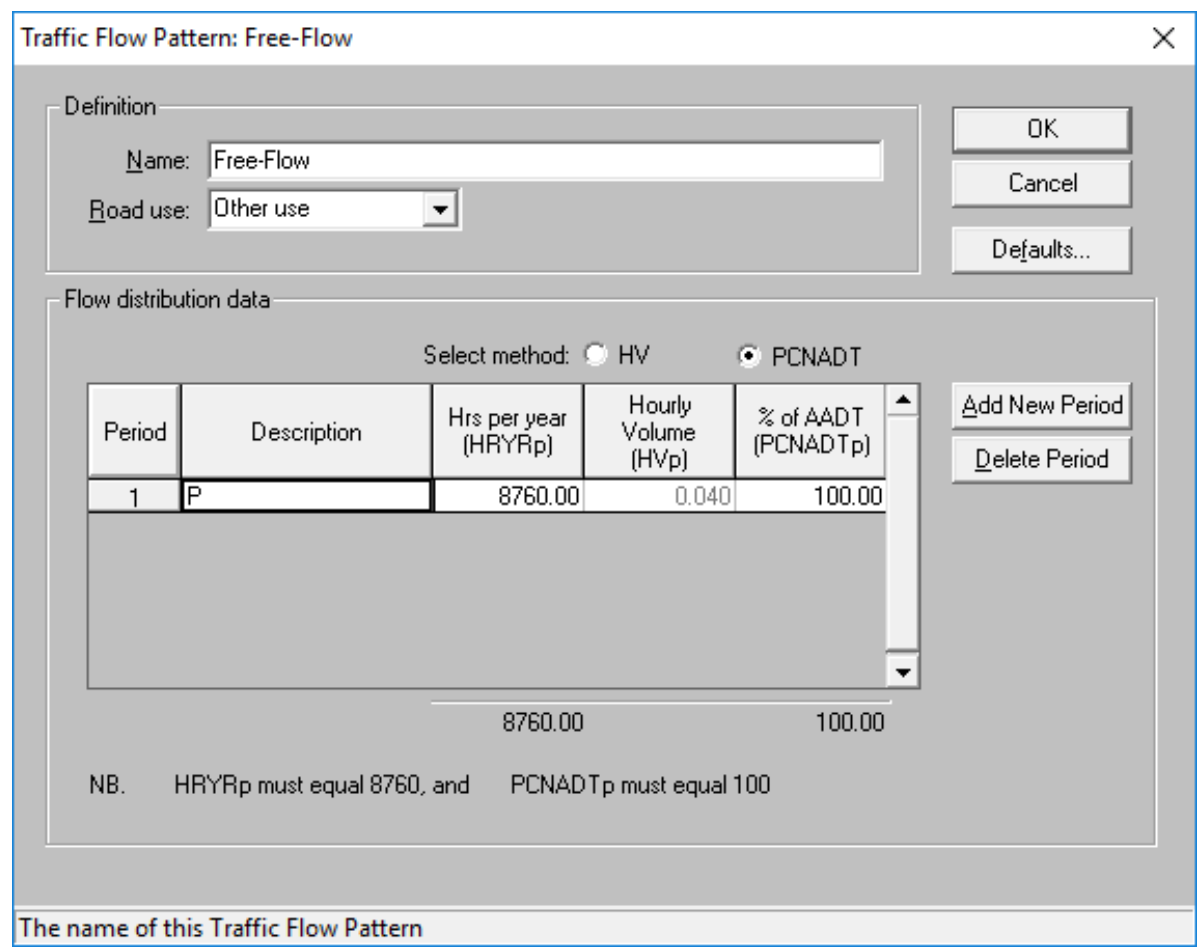

Caracterização dos Veículos (aplicado a todos os trechos)

- Veículos do tipo $2 \mathrm{C}$

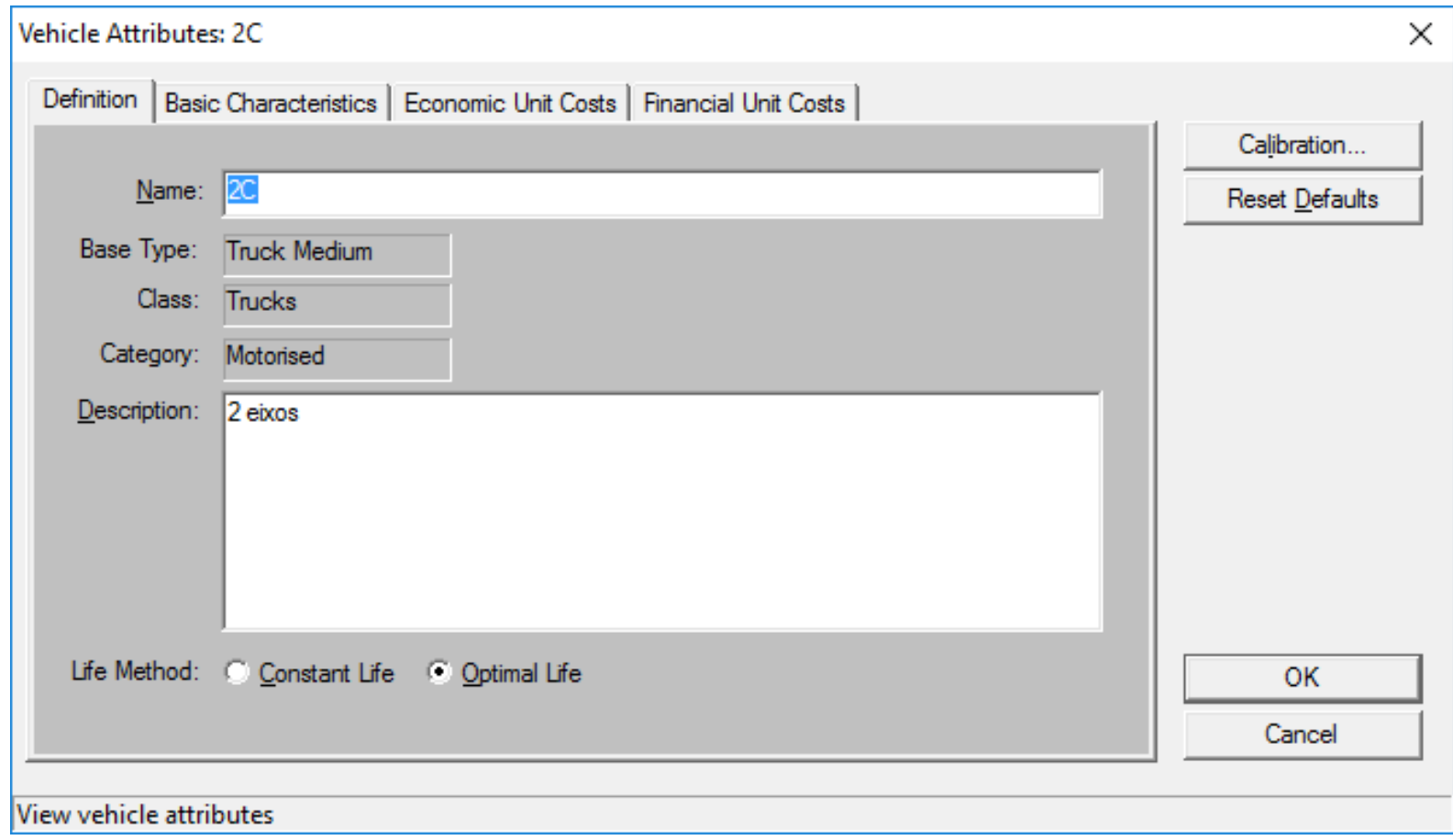




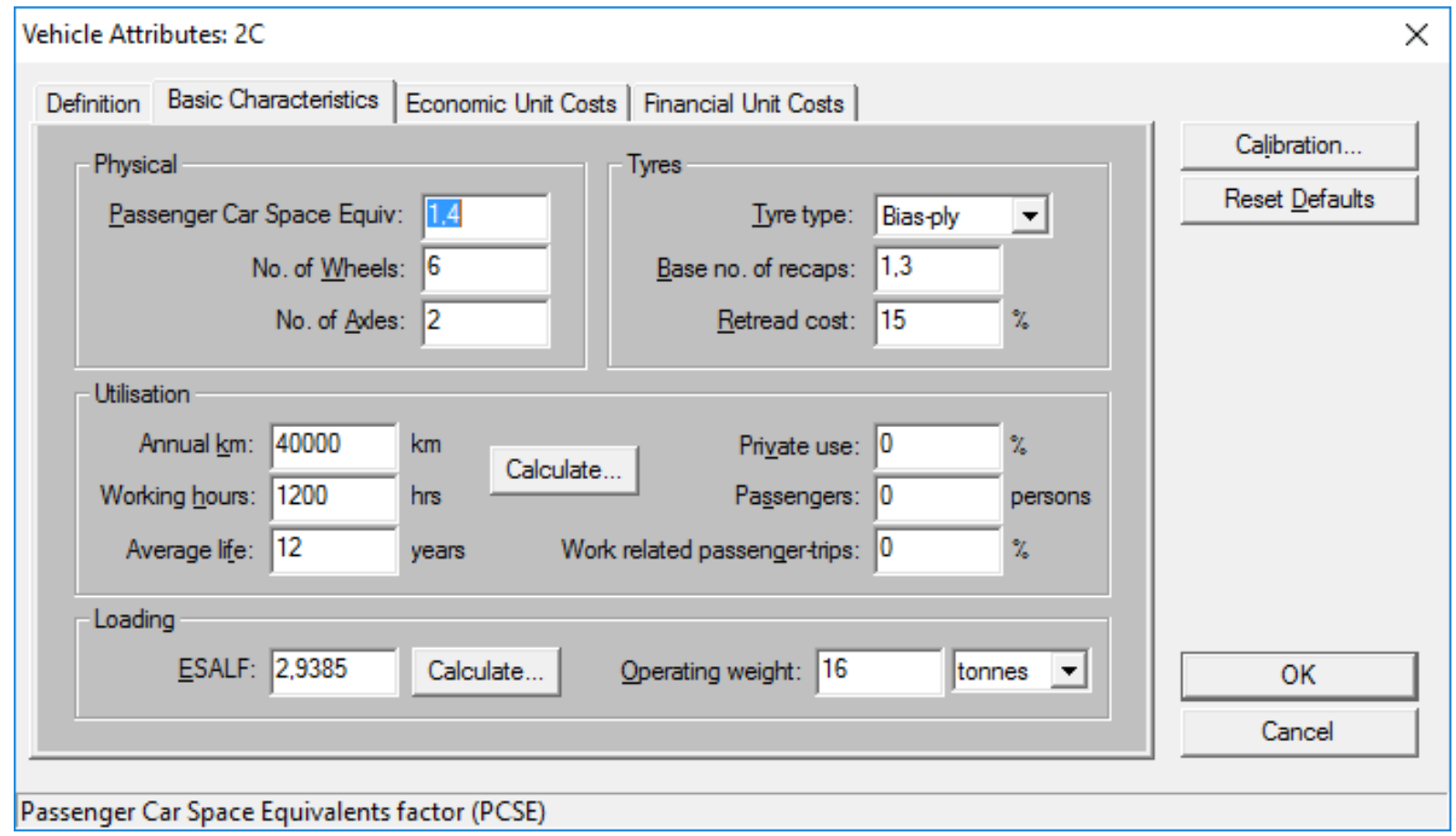

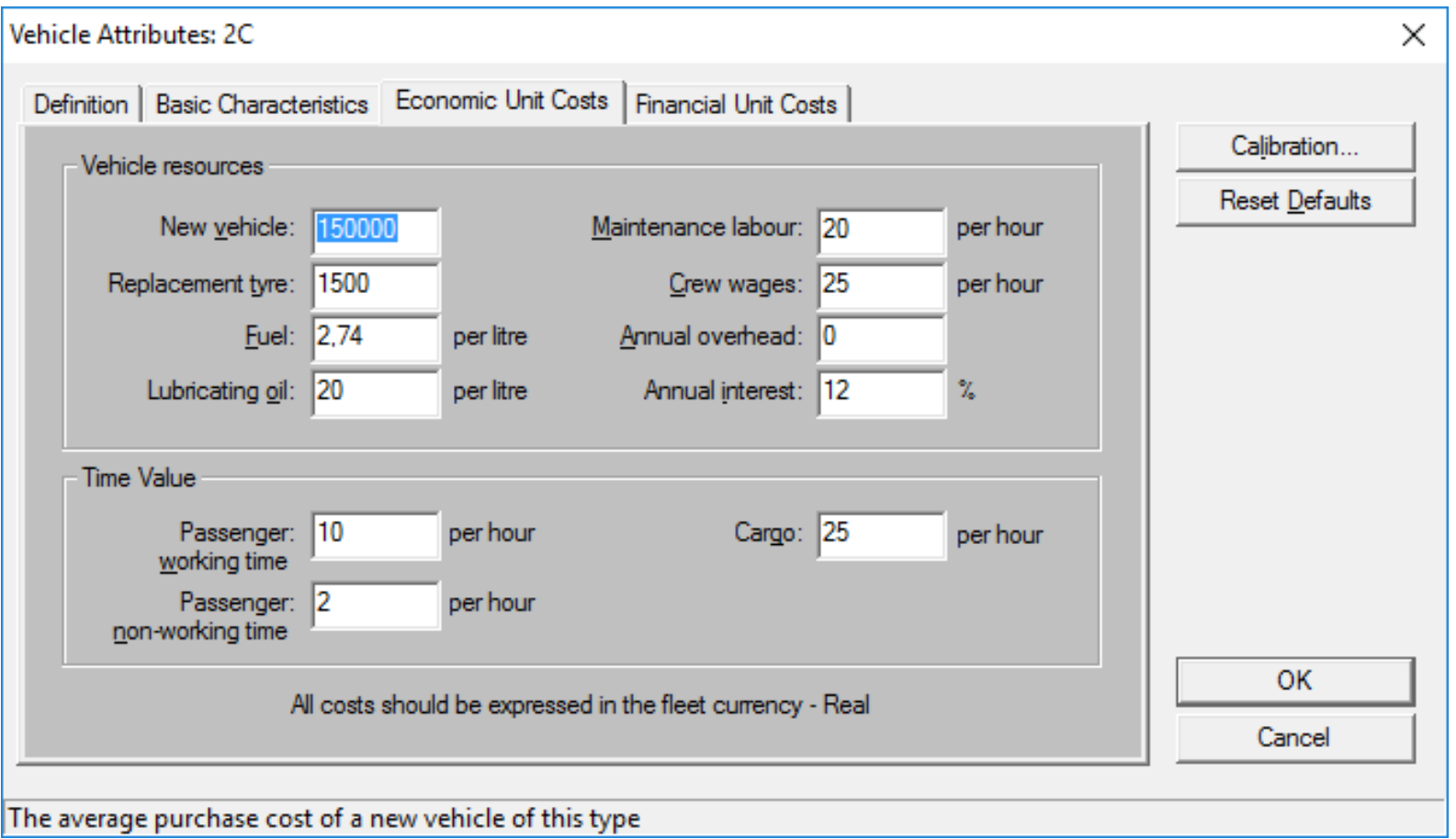


- Veículos do tipo 2S2

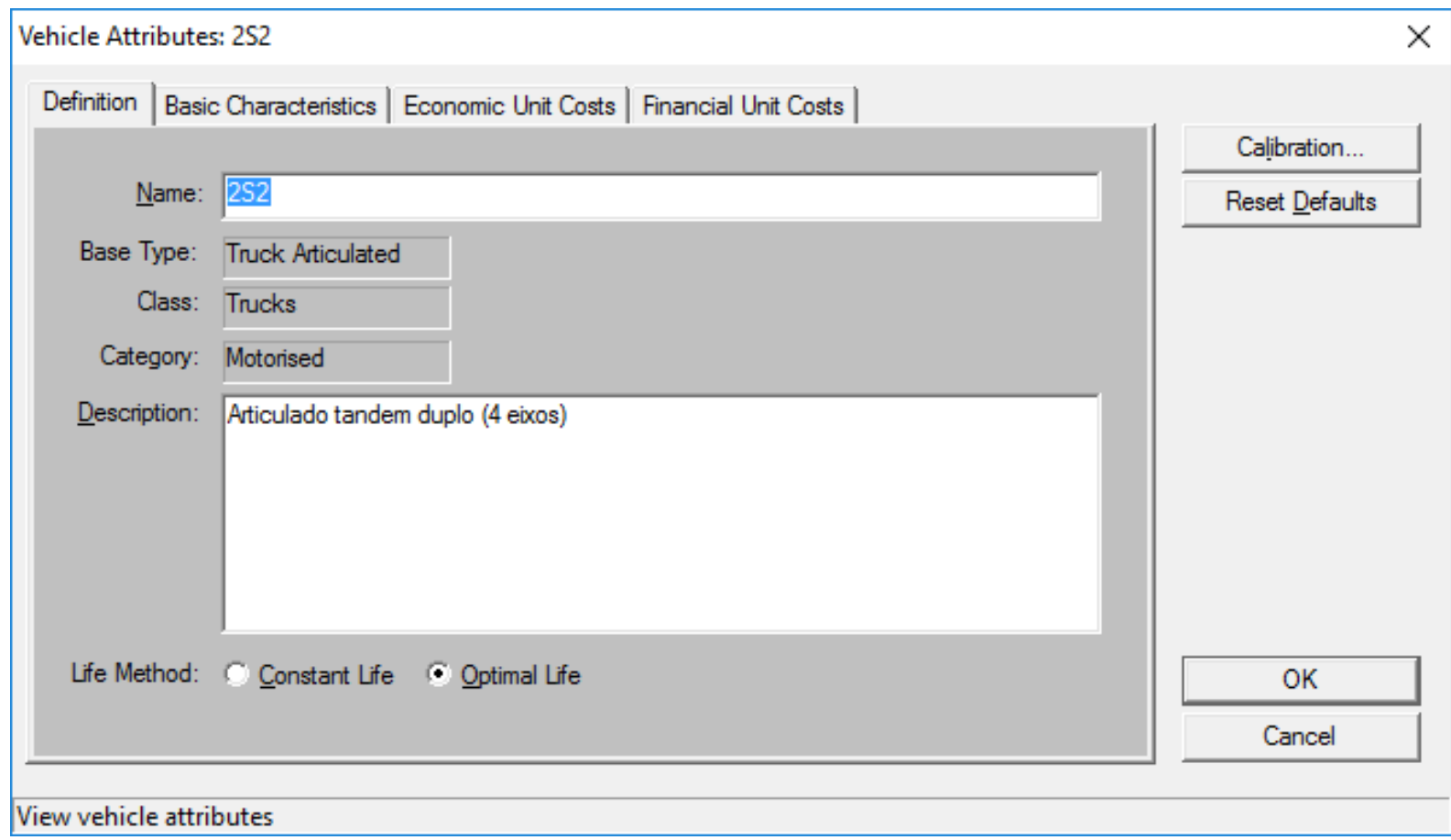

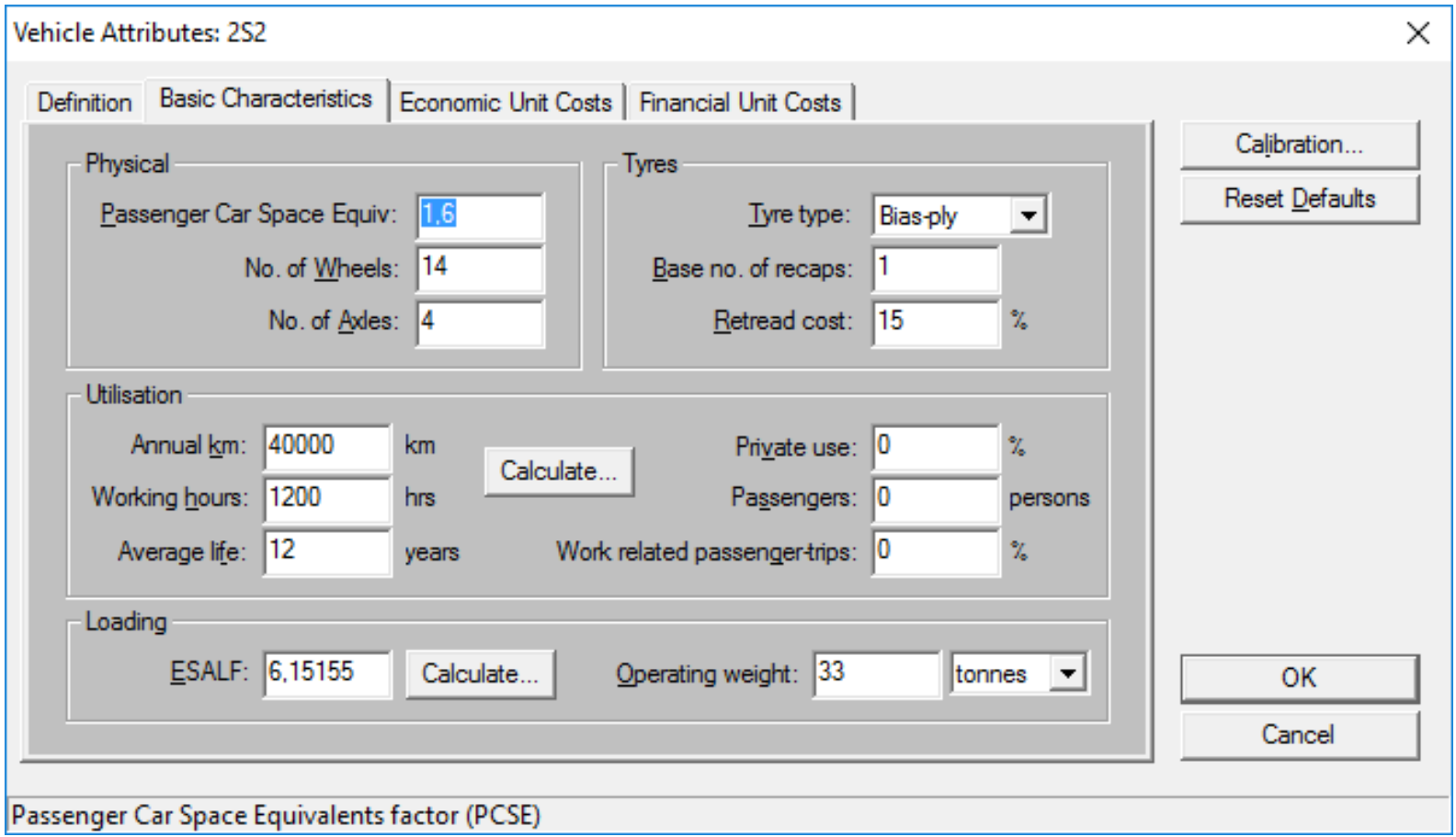




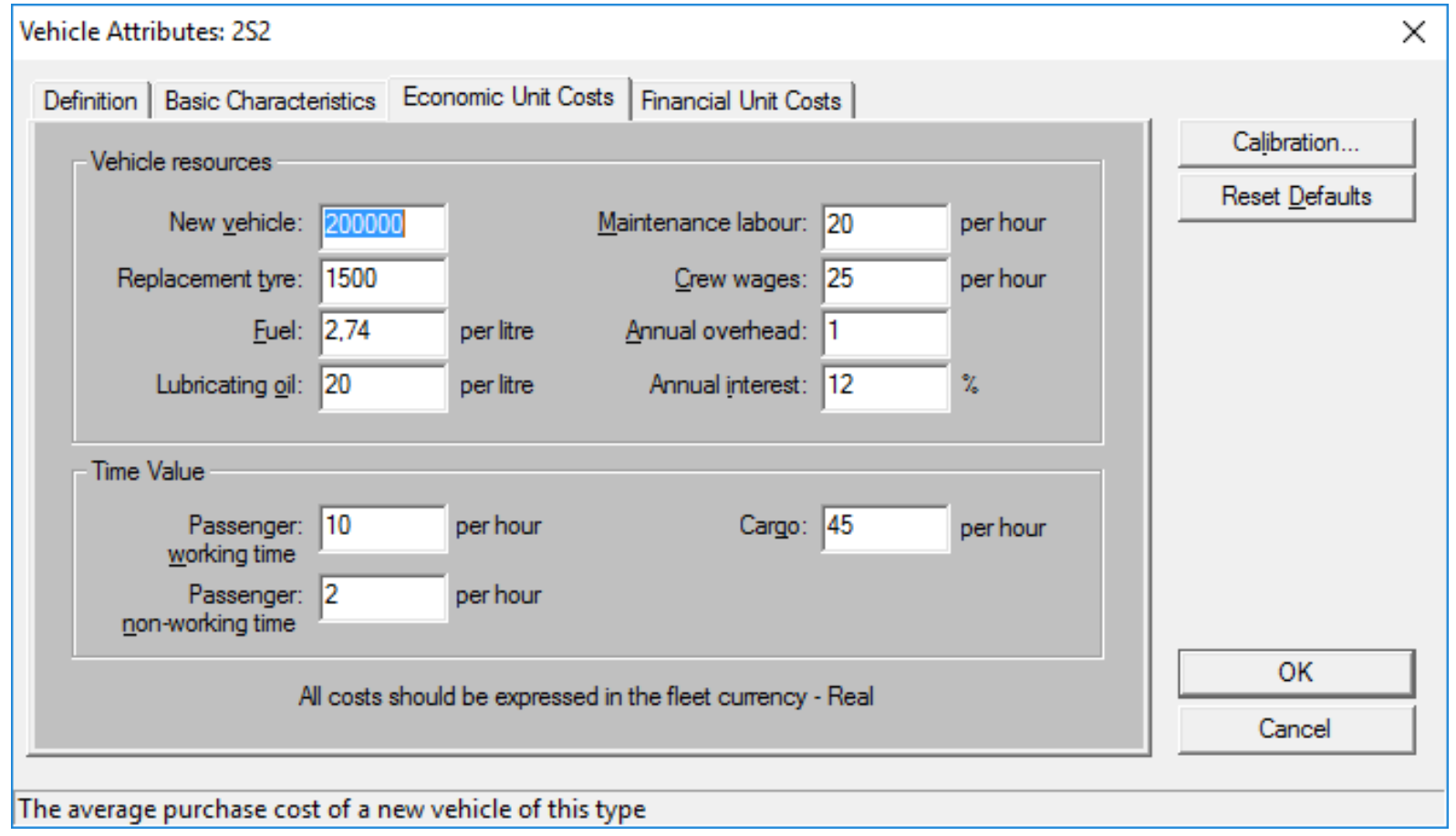

- Veículos do tipo 2S3

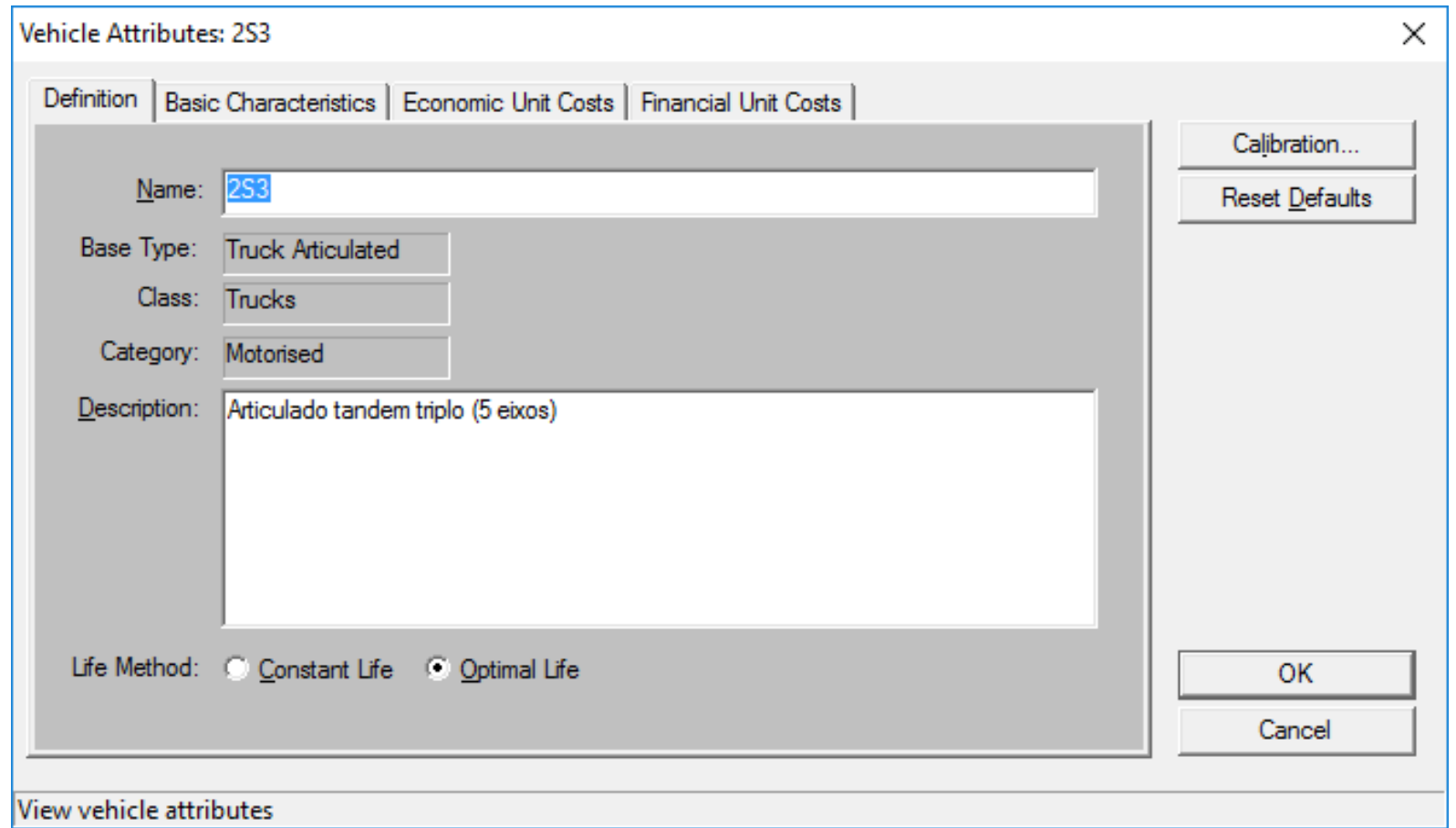




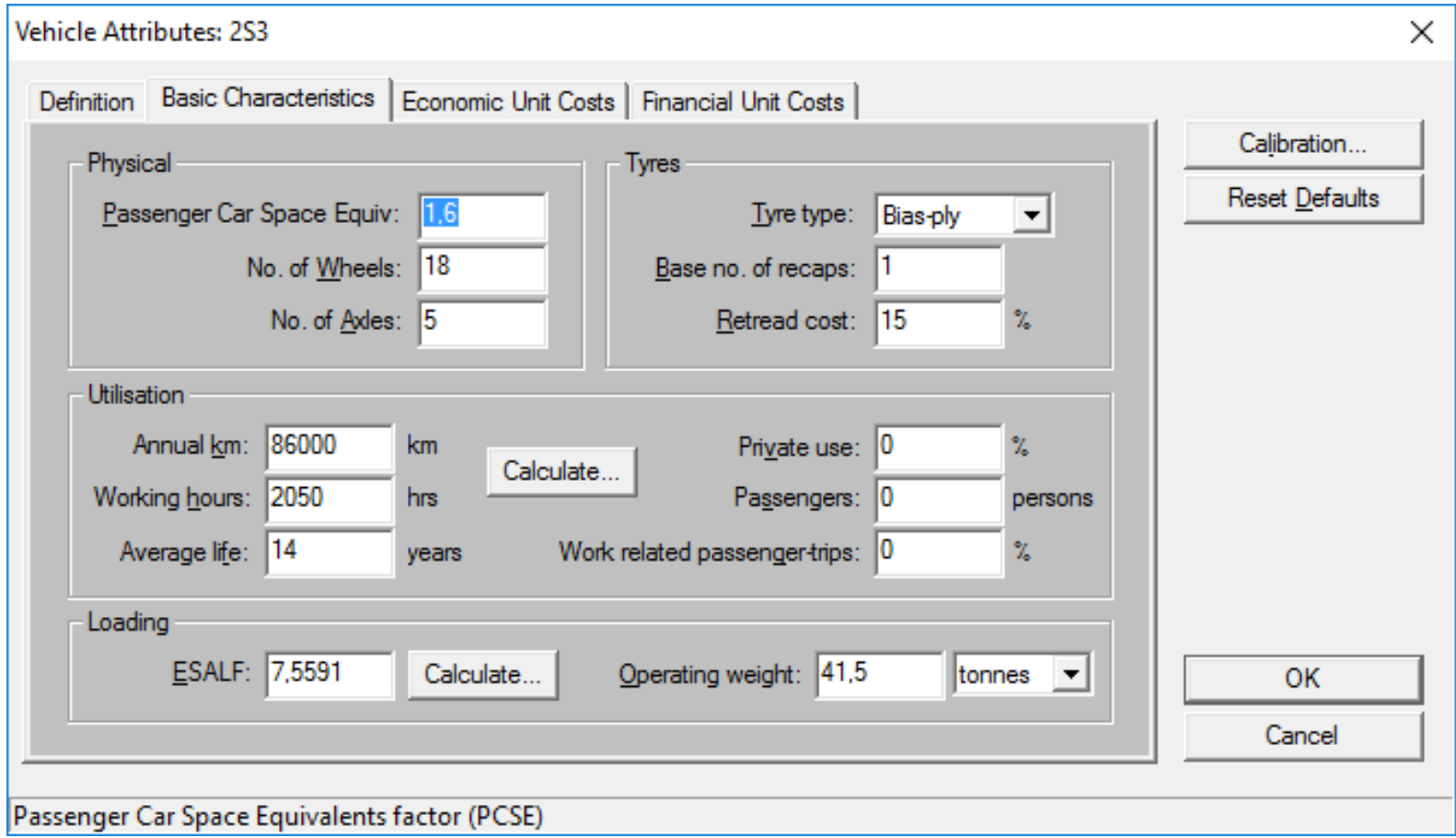

\begin{tabular}{|c|c|c|c|c|c|}
\hline \multicolumn{5}{|c|}{ Vehicle Attributes: 2S3 } & \\
\hline Definition & | Basic Characteristics & Economic Unit Costs & |Financial Unit Costs | & & \multirow[b]{2}{*}{ Calibration... } \\
\hline \multicolumn{5}{|c|}{ - Vehicle resources } & \\
\hline & & \multirow{2}{*}{\multicolumn{2}{|c|}{ Maintenance labour: 20}} & \multirow{5}{*}{$\begin{array}{l}\text { per hour } \\
\text { per hour }\end{array}$} & Reset Defaults \\
\hline & New vehicle: 35000 & & & & \\
\hline & placement tyre: 1500 & \multirow{3}{*}{$\begin{array}{l}\text { per litre } \\
\text { per litre }\end{array}$} & Crew wages: 25 & & \\
\hline & Fuel: 2,74 & & Annual overhead: 1 & & \\
\hline & Lubricating gil: 20 & & Annual ịterest: 12 & & \\
\hline \multicolumn{5}{|c|}{ Time Value - } & \\
\hline & $\begin{array}{l}\text { Passenger: } 10 \\
\text { working time }\end{array}$ & \multirow{2}{*}{\multicolumn{2}{|c|}{$\begin{array}{l}\text { per hour } \\
\text { per hour }\end{array}$}} & \multirow[t]{2}{*}{ per hour } & \\
\hline & $\begin{array}{l}\text { Passenger: } 2 \\
\text { n-working time }\end{array}$ & & & & \\
\hline \multirow{2}{*}{\multicolumn{5}{|c|}{ All costs should be expressed in the fleet currency - Real }} & OK \\
\hline & & & & & Cancel \\
\hline
\end{tabular}


- Veículos do tipo 3C

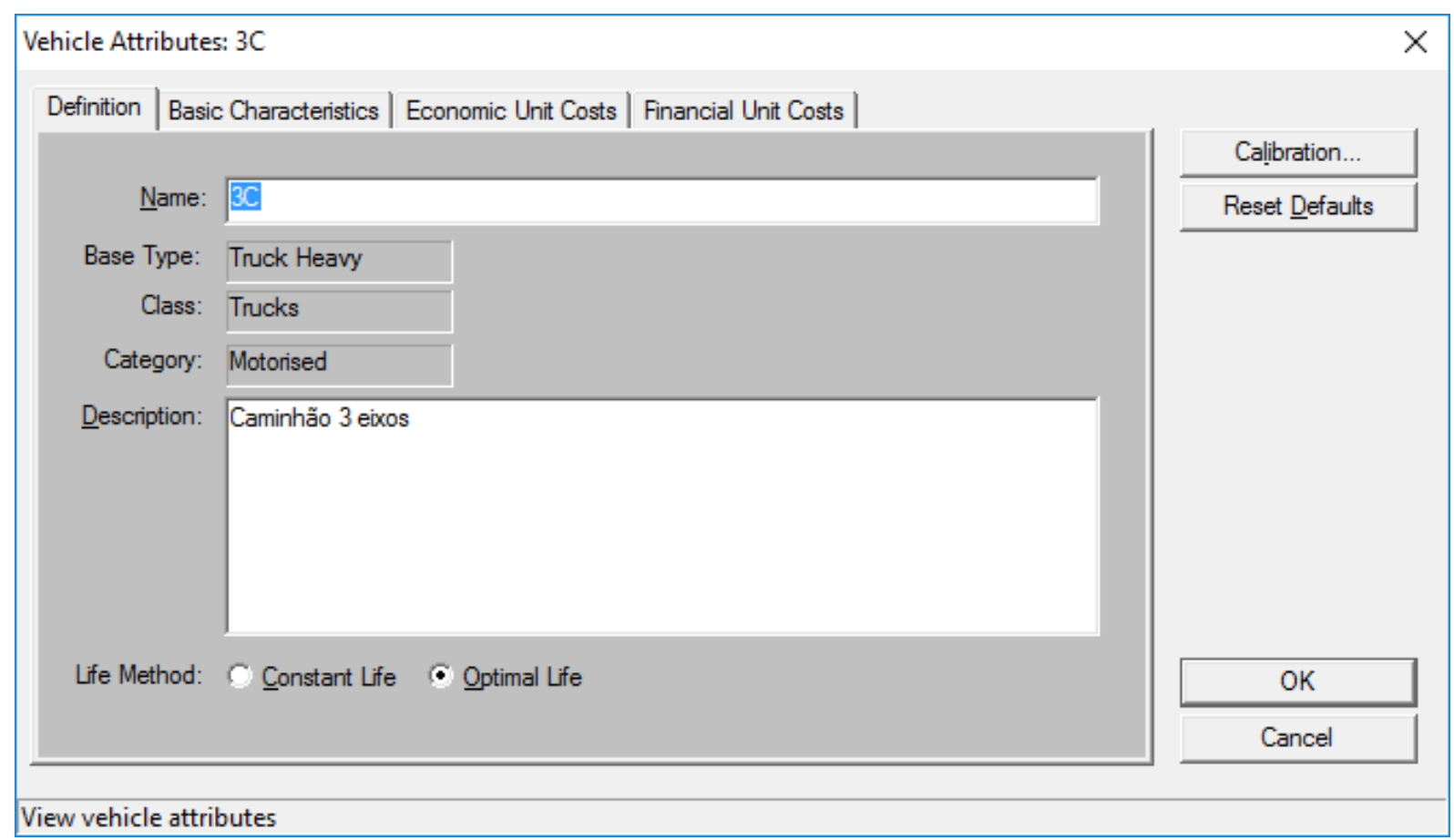

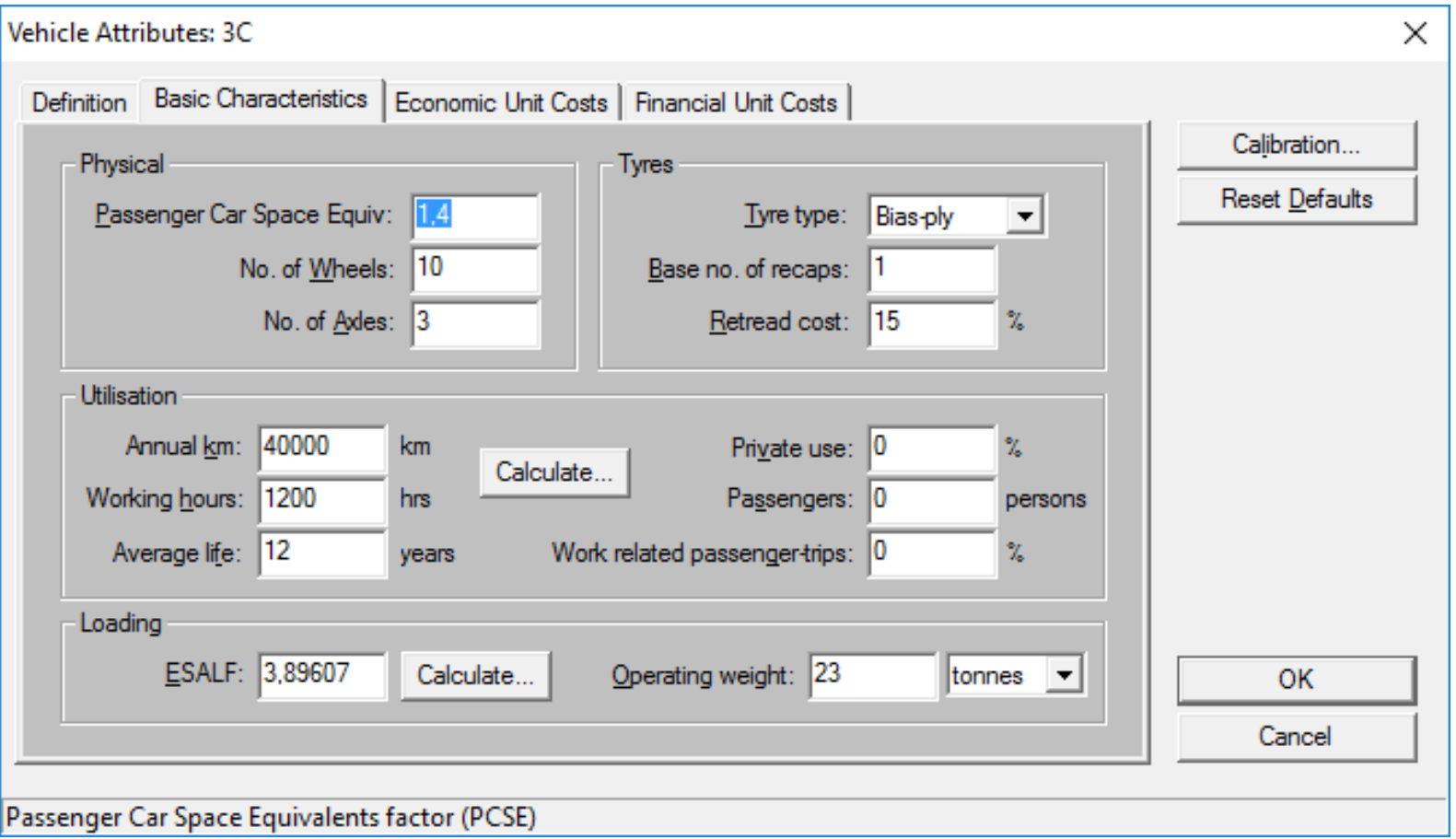




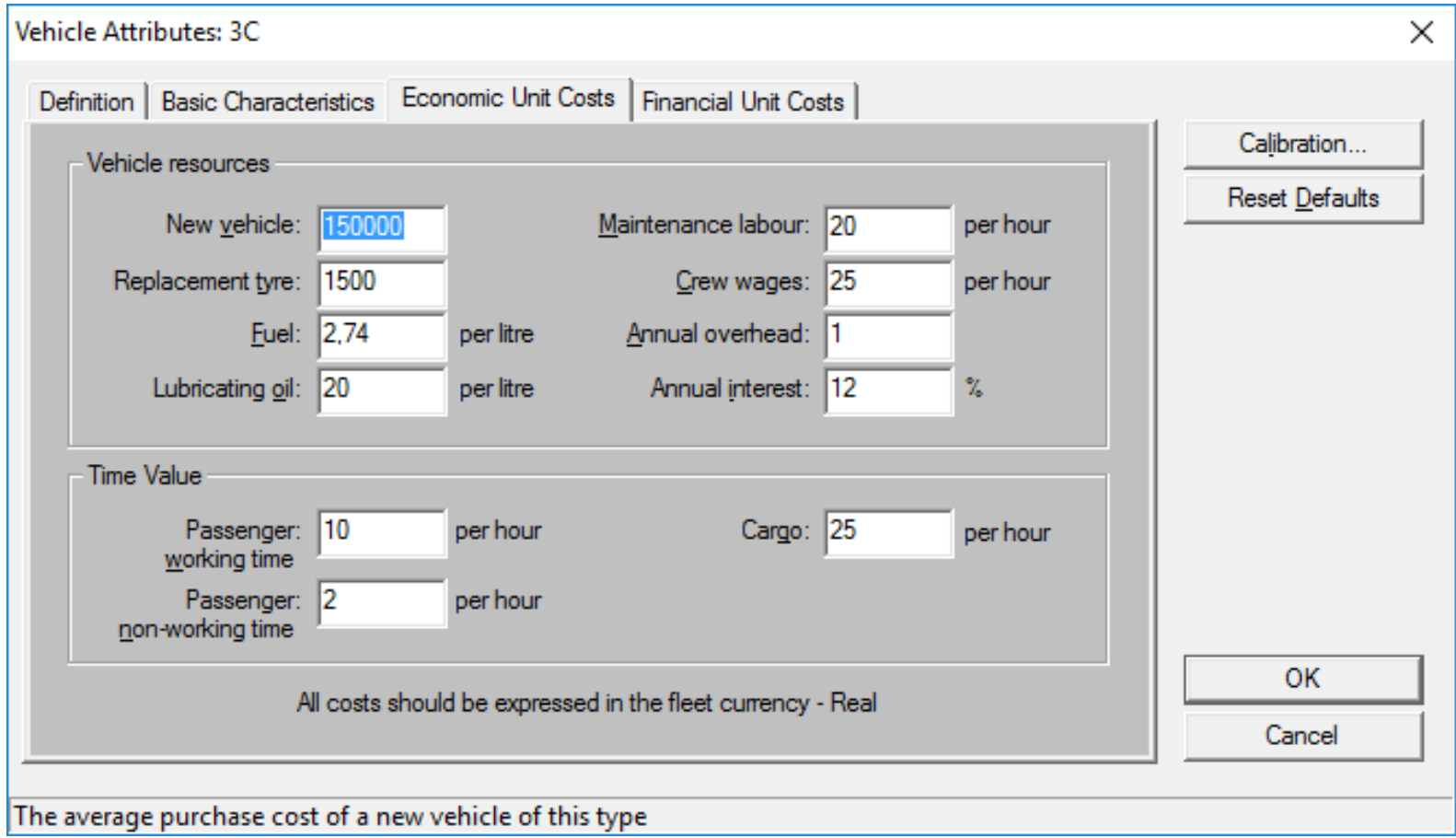

- Veículos do tipo 3S3

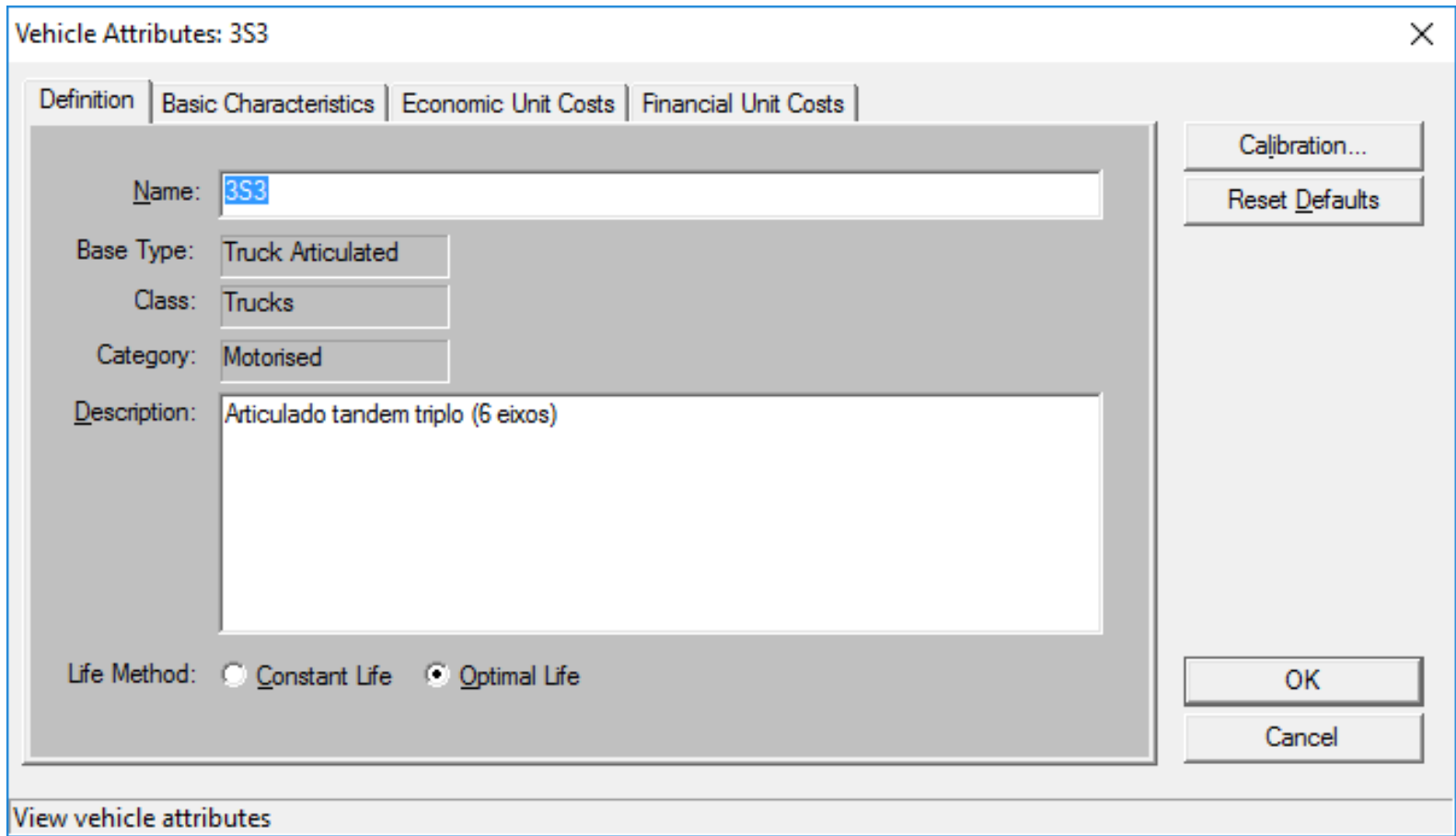




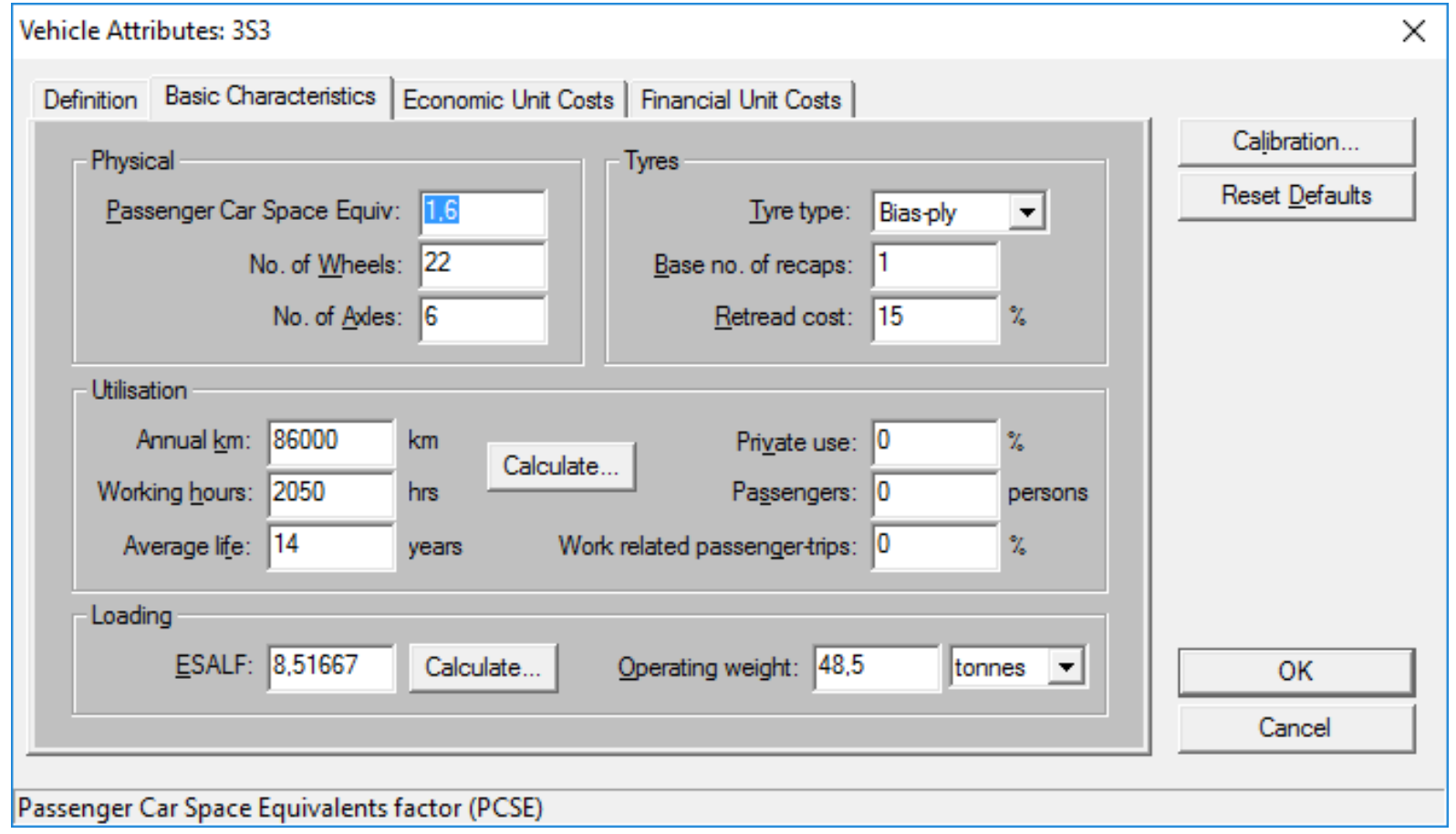

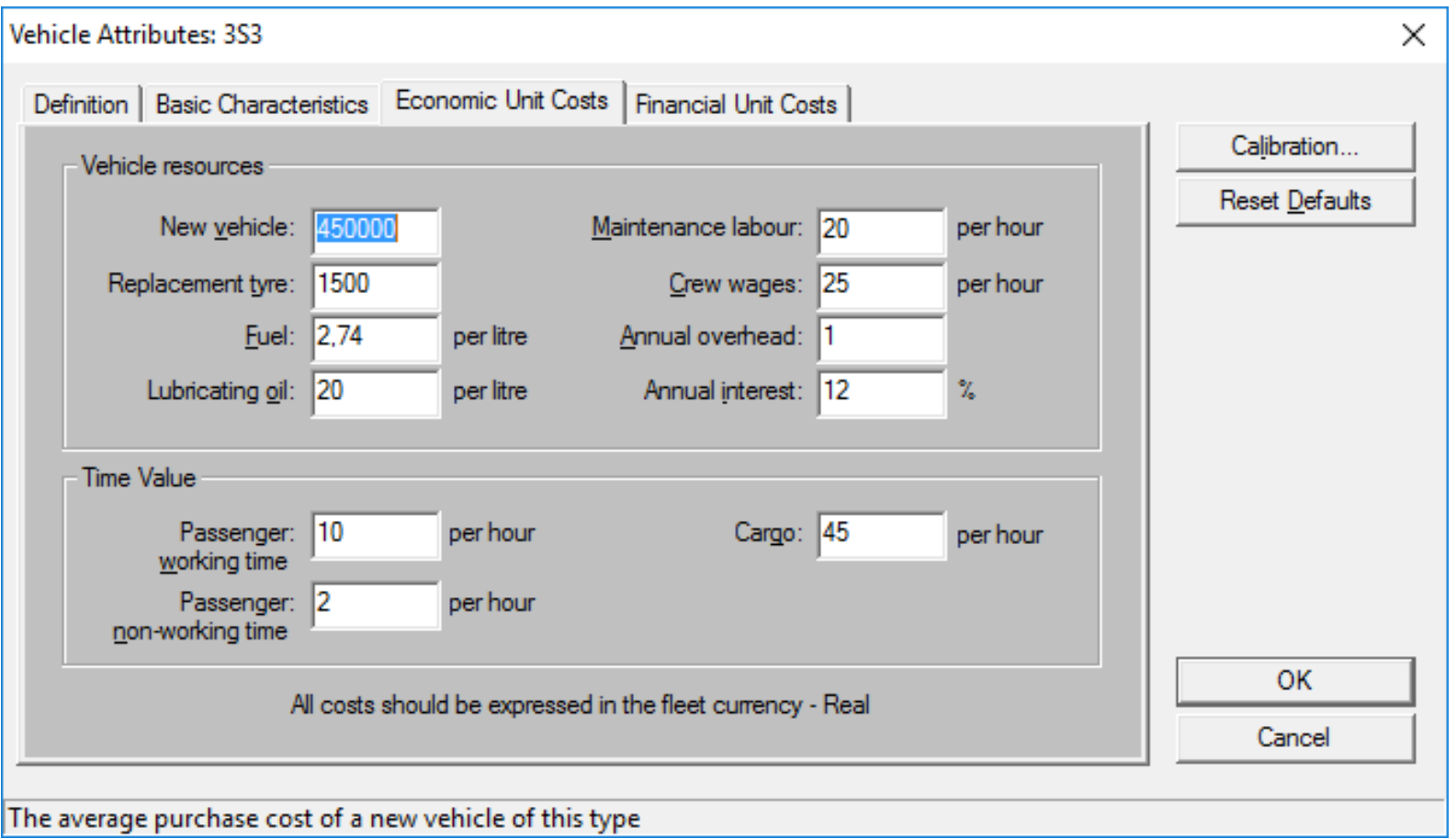


- Veículos do tipo 3T4

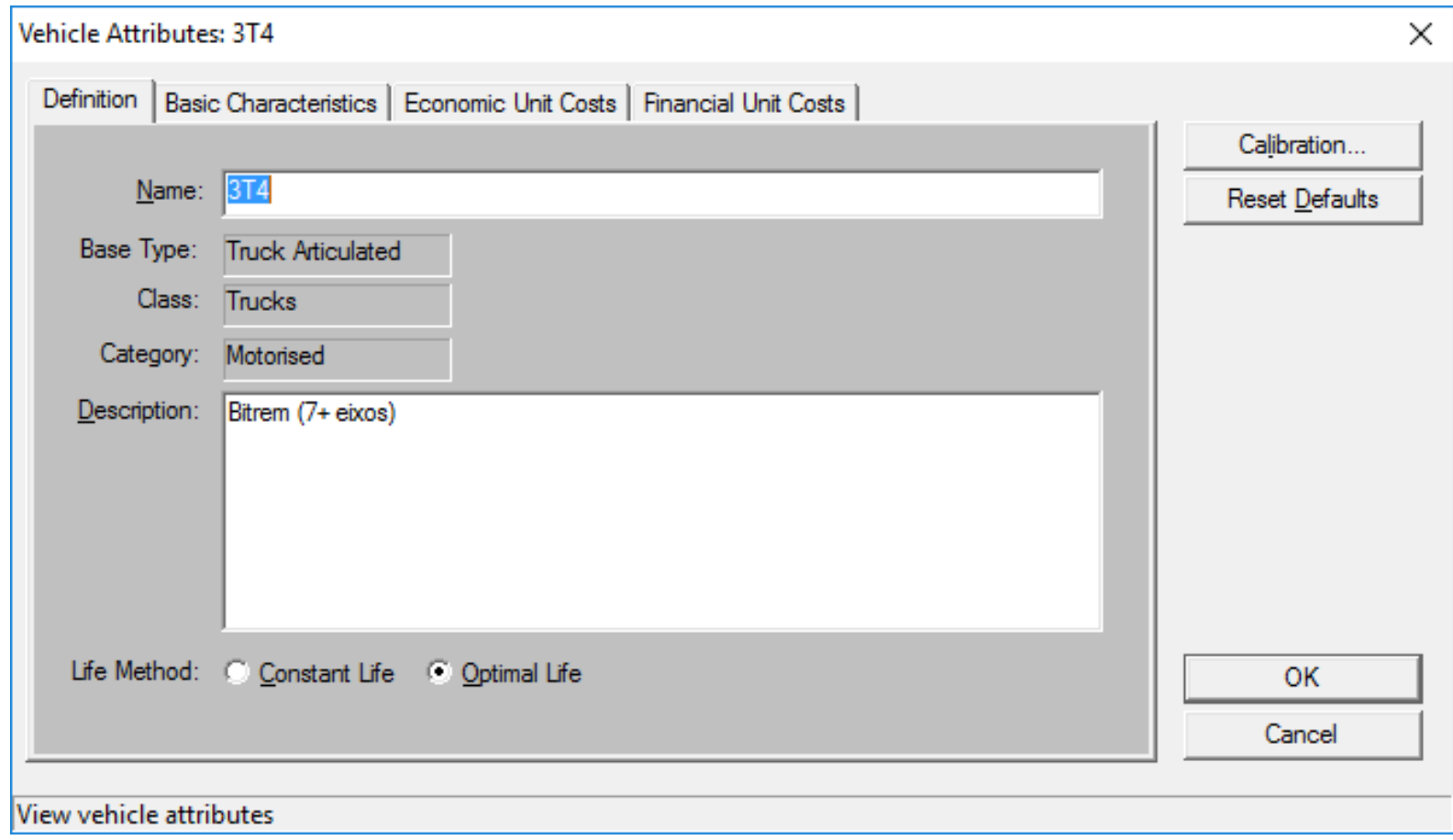

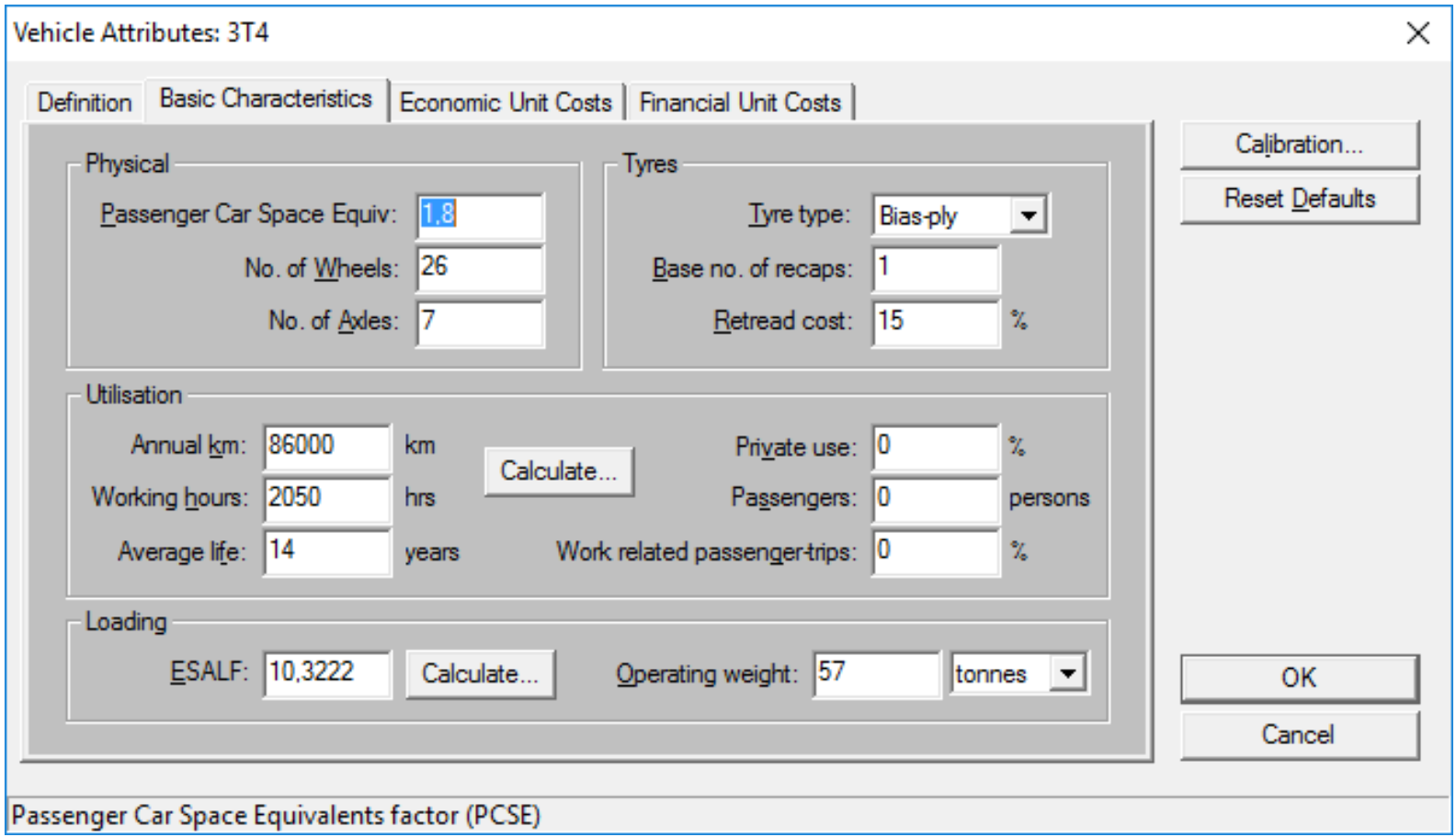




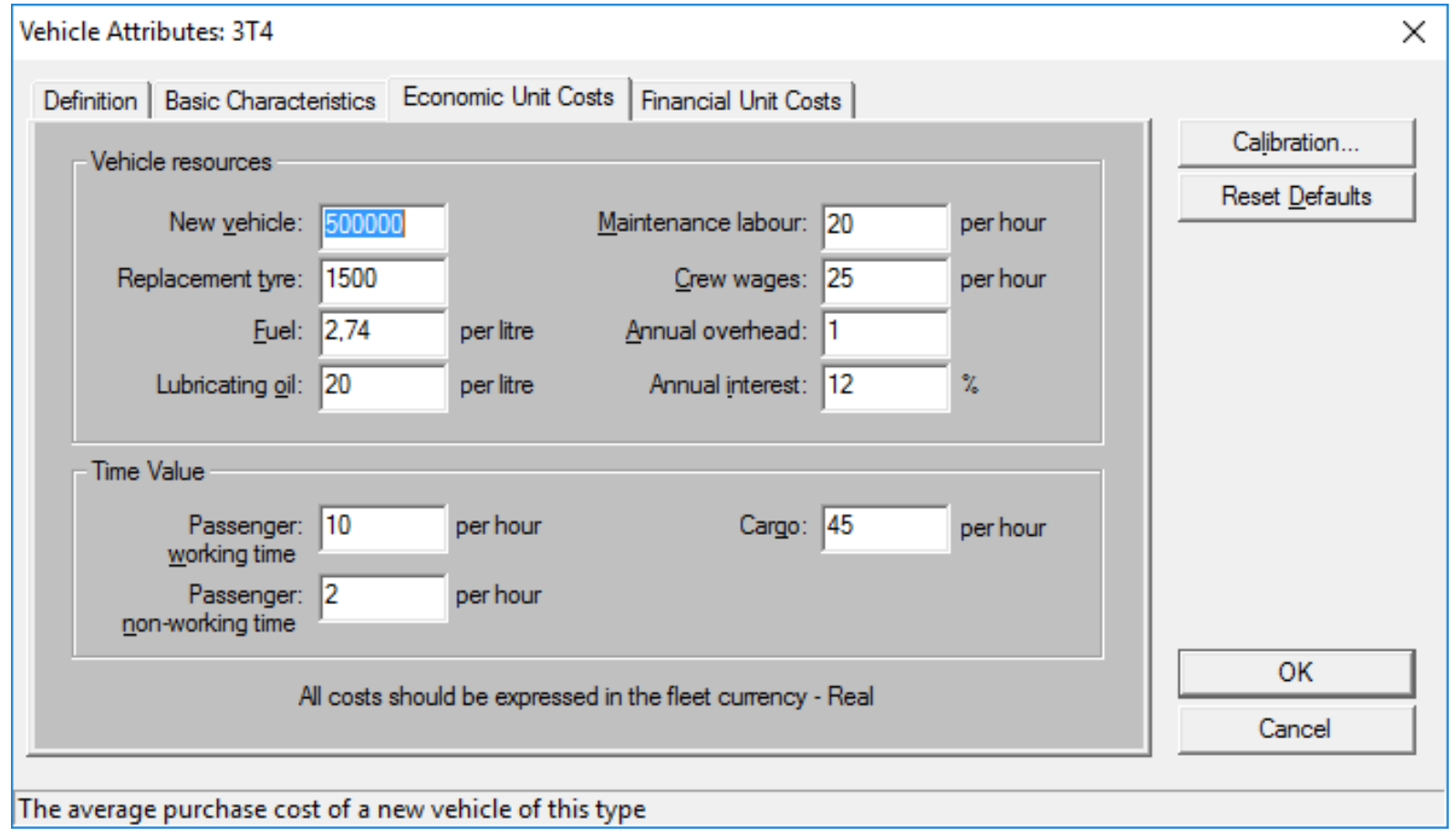

- Veículos do tipo M

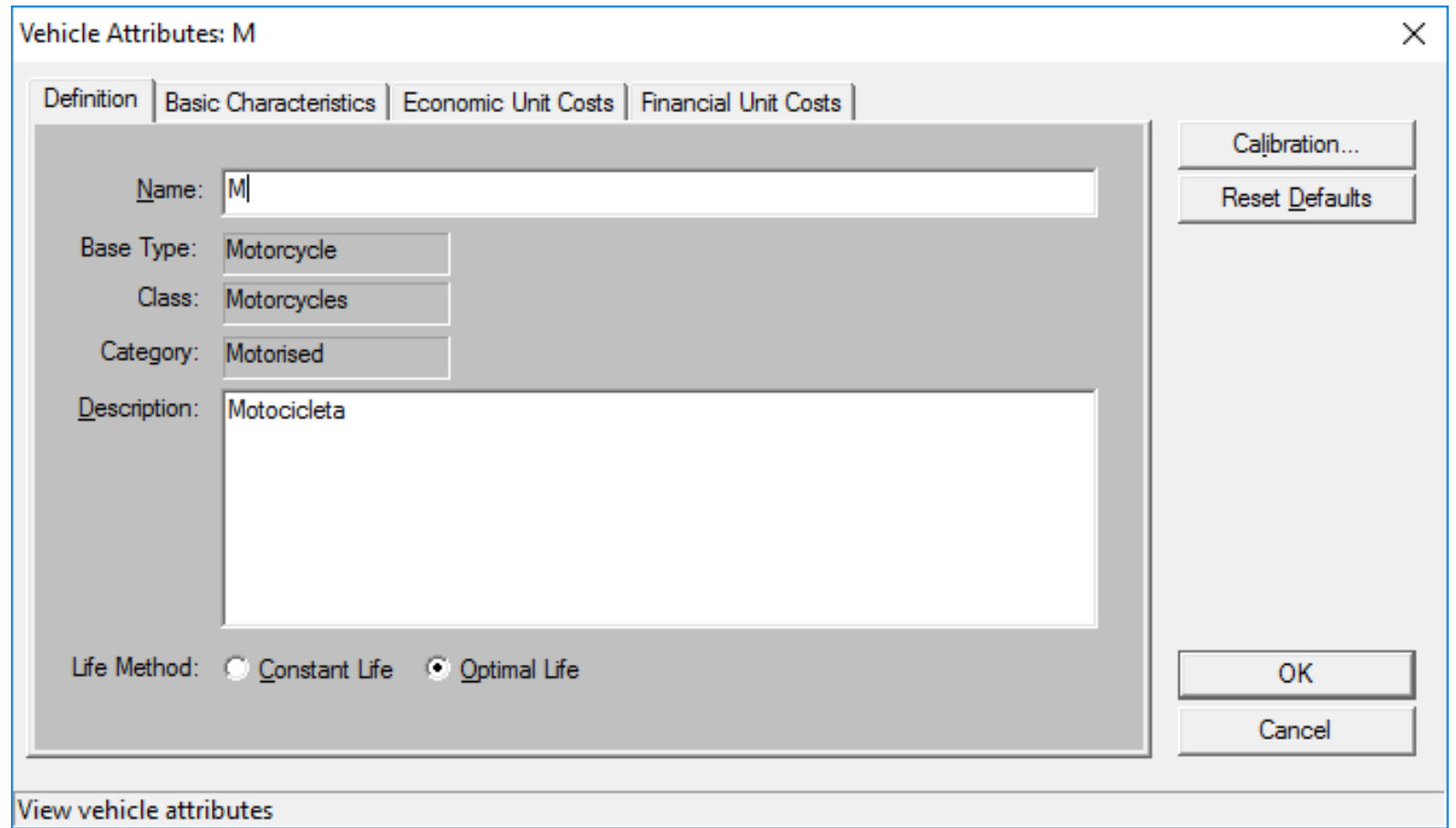




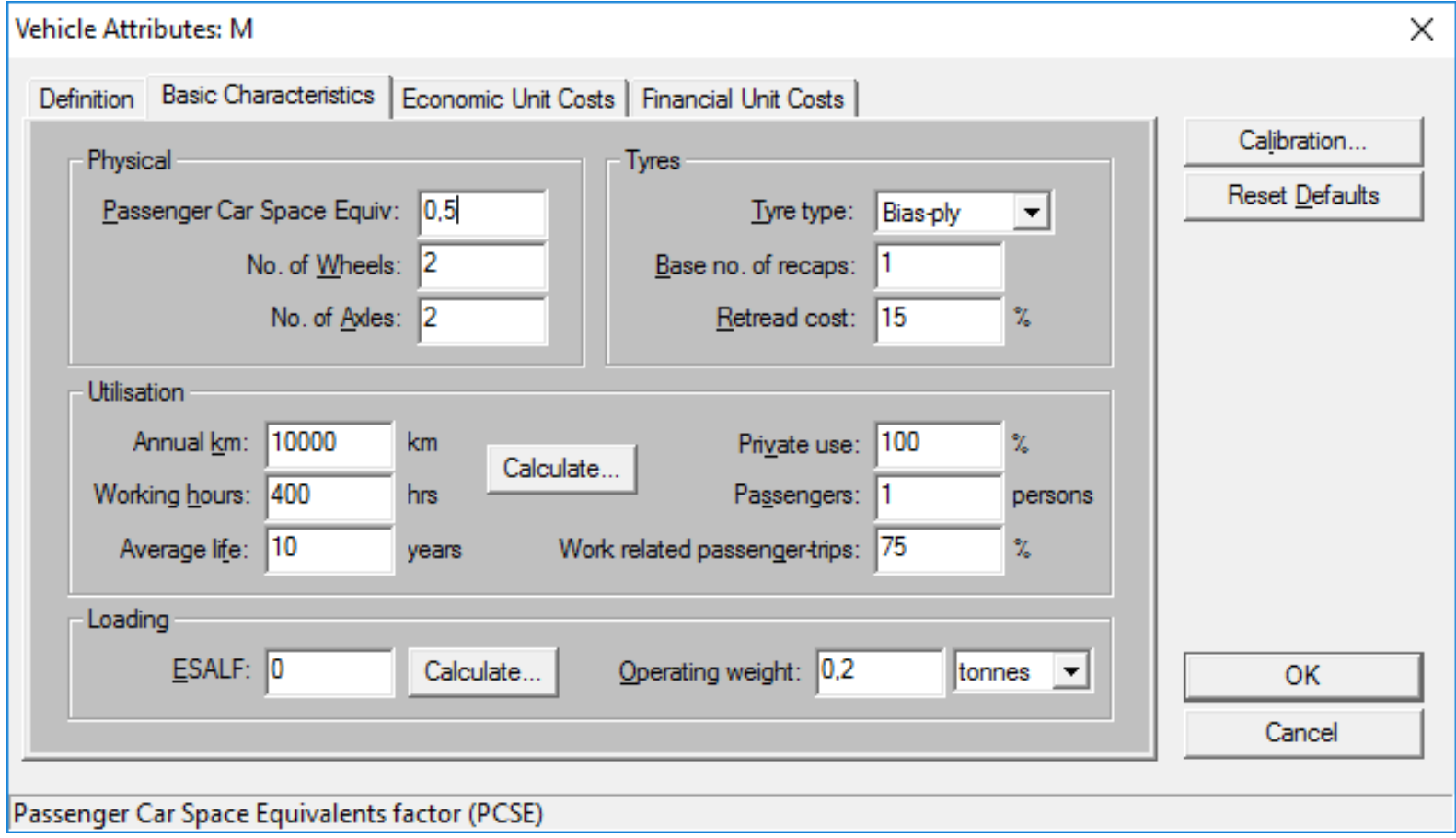

\begin{tabular}{|c|c|c|c|c|}
\hline \multicolumn{4}{|l|}{ Vehicle Attributes: M } & \multirow[b]{3}{*}{ Calibration... } \\
\hline Definition | Basic Characteristics & Economic Unit Costs & |Financial Unit Costs | & & \\
\hline \multicolumn{4}{|l|}{ Vehicle resources } & \\
\hline & \multirow{2}{*}{\multicolumn{2}{|c|}{ Maintenance labour: 20}} & \multirow{3}{*}{$\begin{array}{l}\text { per hour } \\
\text { per hour }\end{array}$} & Reset Defaults \\
\hline New vehicle: $7000 \mid$ & & & & \\
\hline Replacement tyre: 150 & \multirow{3}{*}{$\begin{array}{l}\text { per litre } \\
\text { per litre }\end{array}$} & Crew wages: 0 & & \\
\hline Fuel: 3.19 & & Annual overhead: 1 & \multirow[b]{2}{*}{$\%$} & \\
\hline Lubricating gil: 20 & & Annual interest: 12 & & \\
\hline \multicolumn{4}{|l|}{-Time Value - } & \\
\hline $\begin{array}{l}\text { Passenger: } 10 \\
\text { working time }\end{array}$ & \multirow{2}{*}{\multicolumn{2}{|c|}{ Cargo: 0}} & \multirow[t]{2}{*}{ per hour } & \\
\hline $\begin{array}{l}\text { Passenger: } 2 \\
\text { non-working time }\end{array}$ & & & & \\
\hline \multirow{2}{*}{\multicolumn{4}{|c|}{ All costs should be expressed in the fleet currency - Real }} & $\mathrm{OK}$ \\
\hline & & & & Cancel \\
\hline
\end{tabular}


- Veículos do tipo O

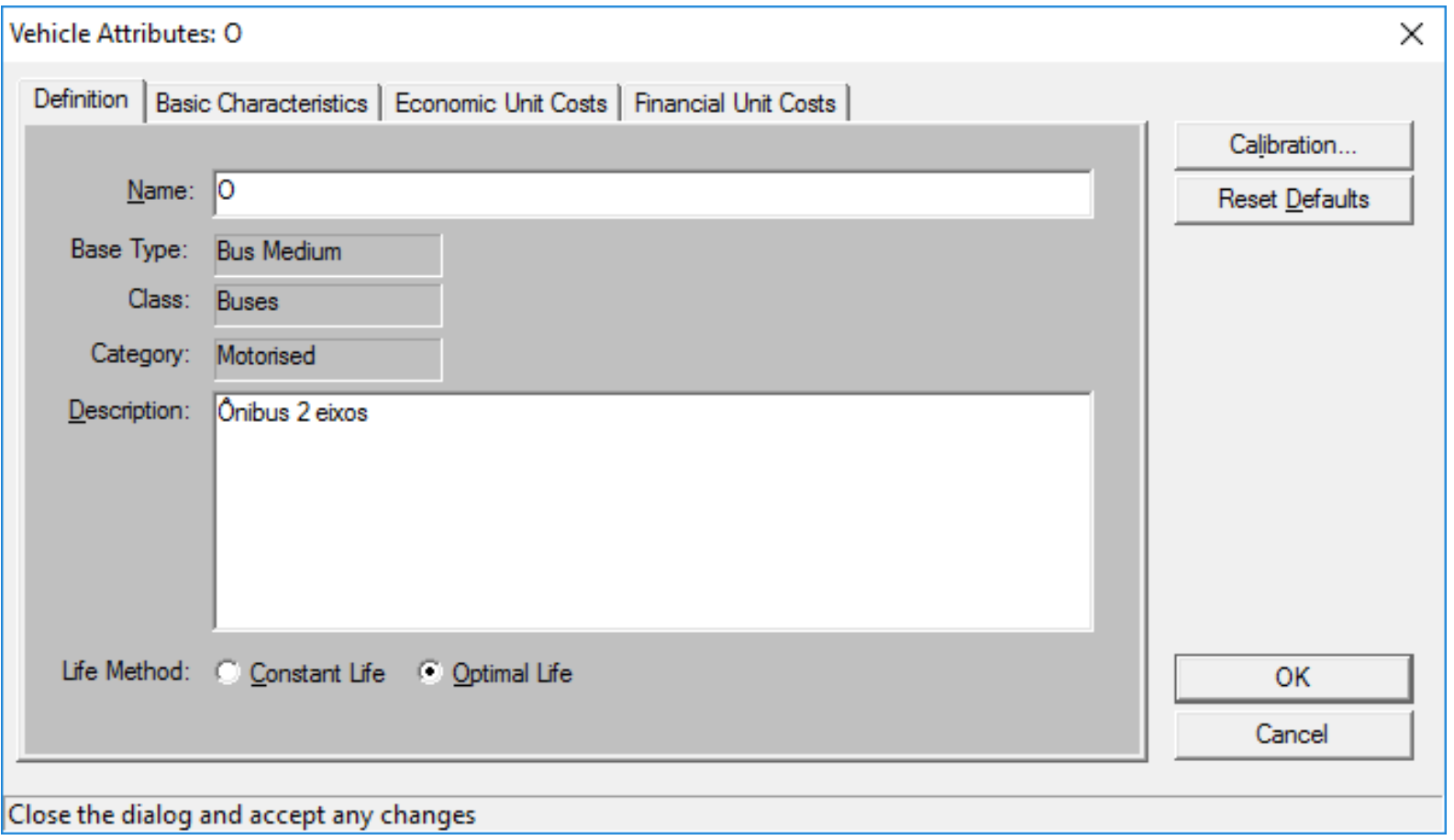

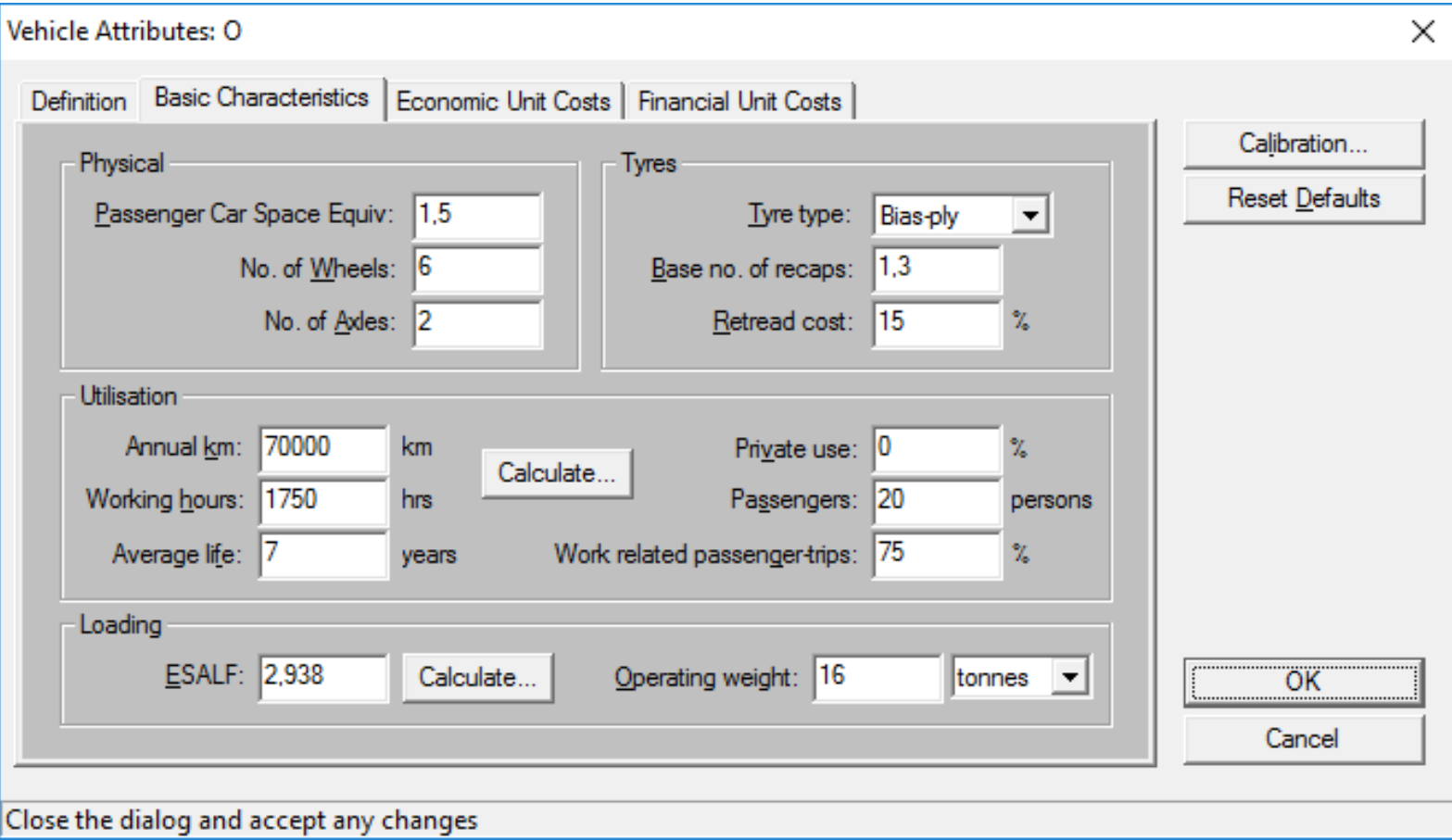




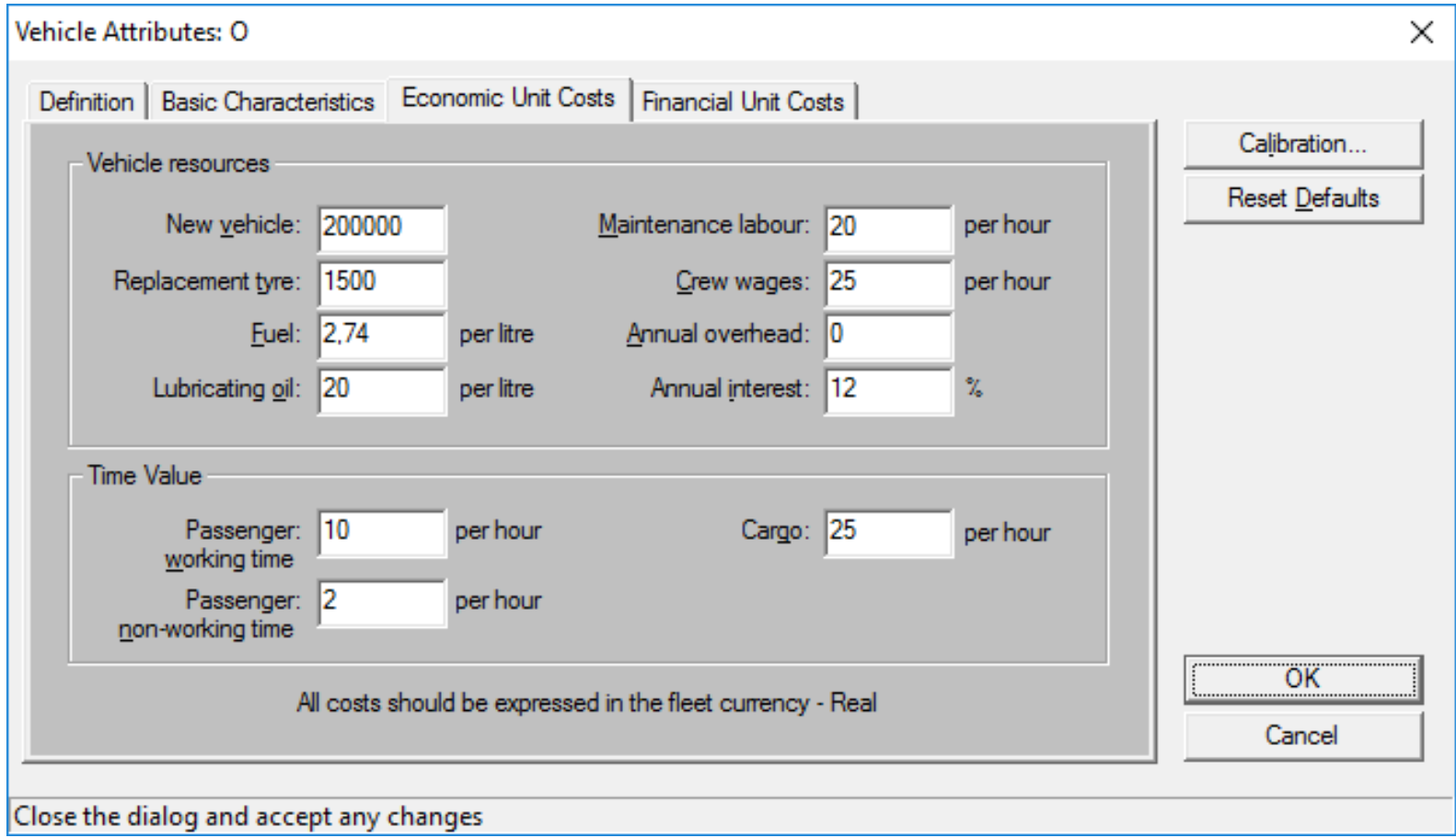

- Veículos do tipo P

\begin{tabular}{|c|c|c|}
\hline \multicolumn{2}{|c|}{ Vehicle Attributes: P } & \\
\hline Definition & Characteristics $\mid$ Economic Unit Costs Financial Unit Costs & \multirow[b]{2}{*}{ Calibration... } \\
\hline & \\
\hline \multicolumn{2}{|c|}{ Name: $\mathrm{P}$} & Reset Defaults \\
\hline Base Type: & Car Small & \\
\hline Class: & Passenger Cars & \\
\hline Category: & Motorised & \\
\hline Description: & Carro de passeio & \\
\hline \multirow{2}{*}{\multicolumn{2}{|c|}{ Life Method: $\bullet$ Constant Life $\bigcirc$ Optimal Life }} & OK \\
\hline & & Cancel \\
\hline
\end{tabular}




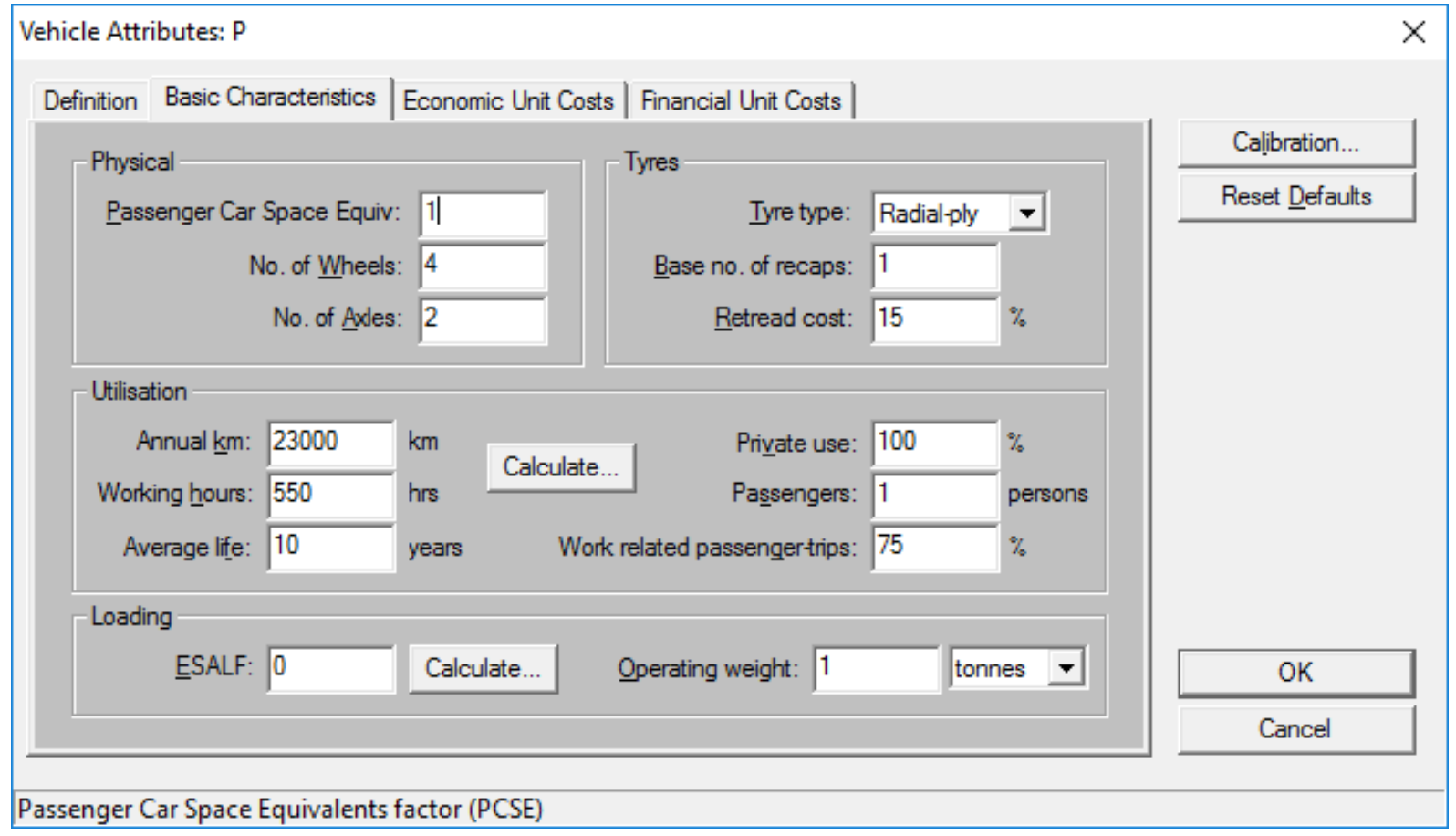

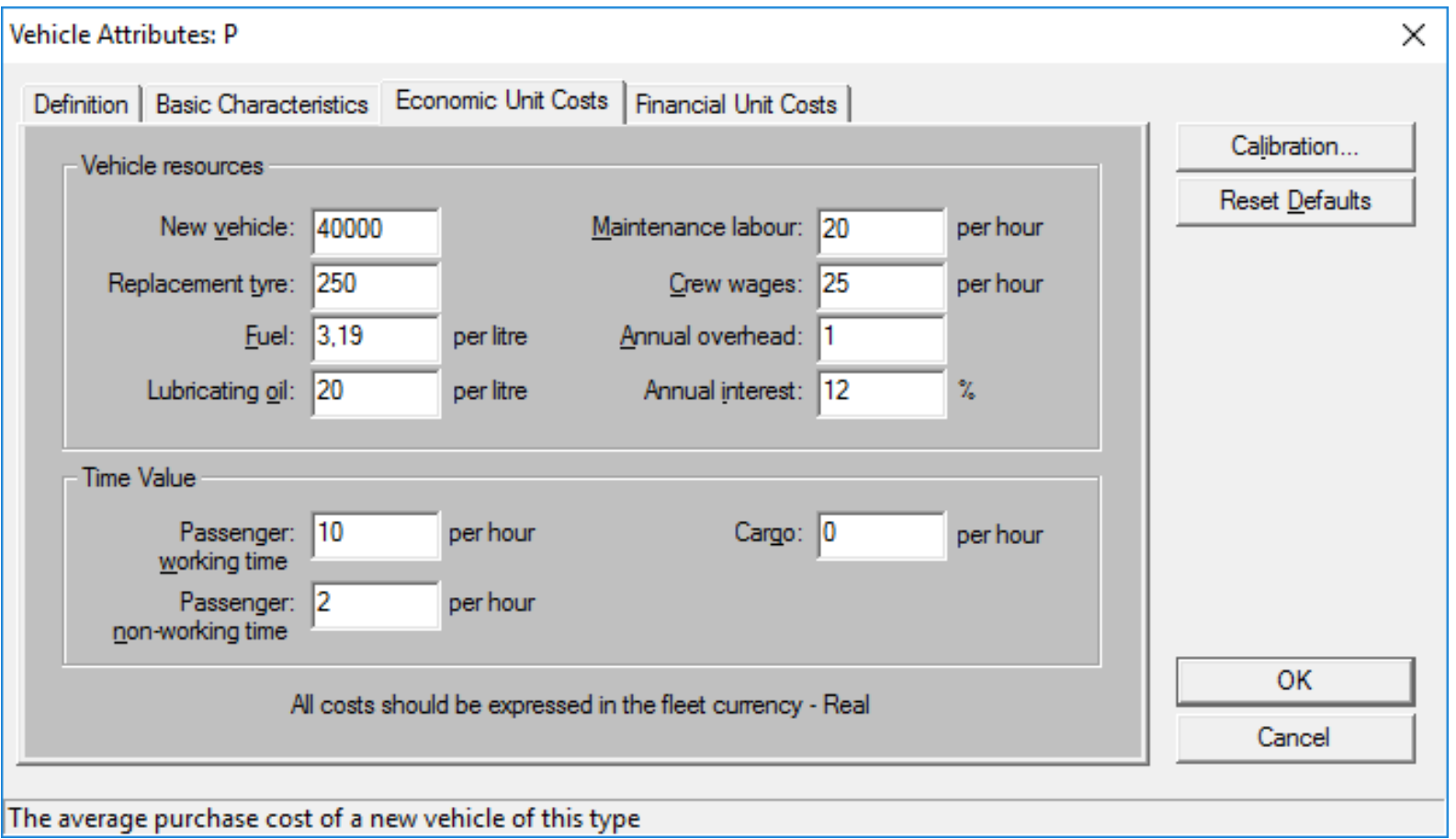


- Veículos do tipo P3

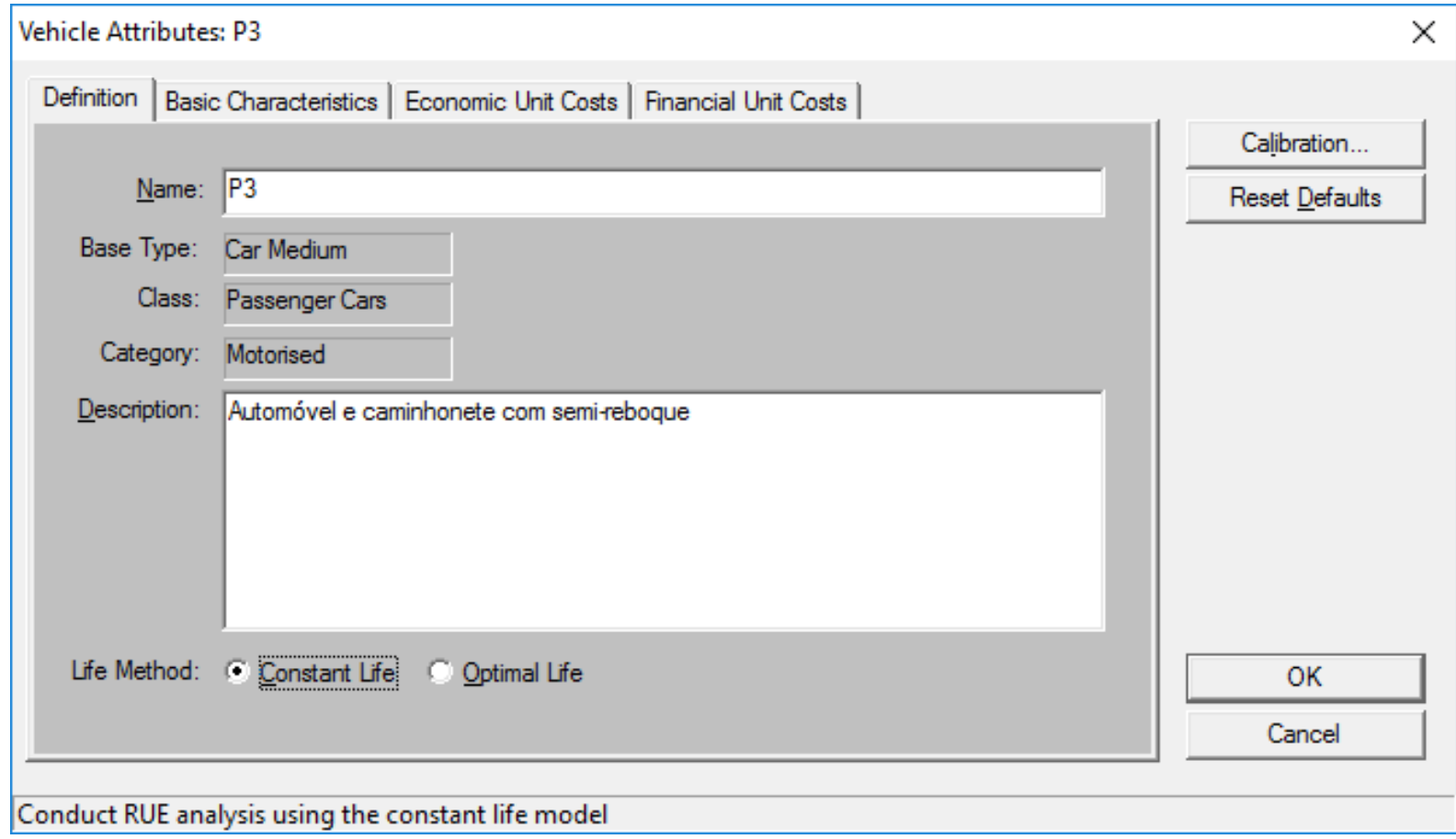

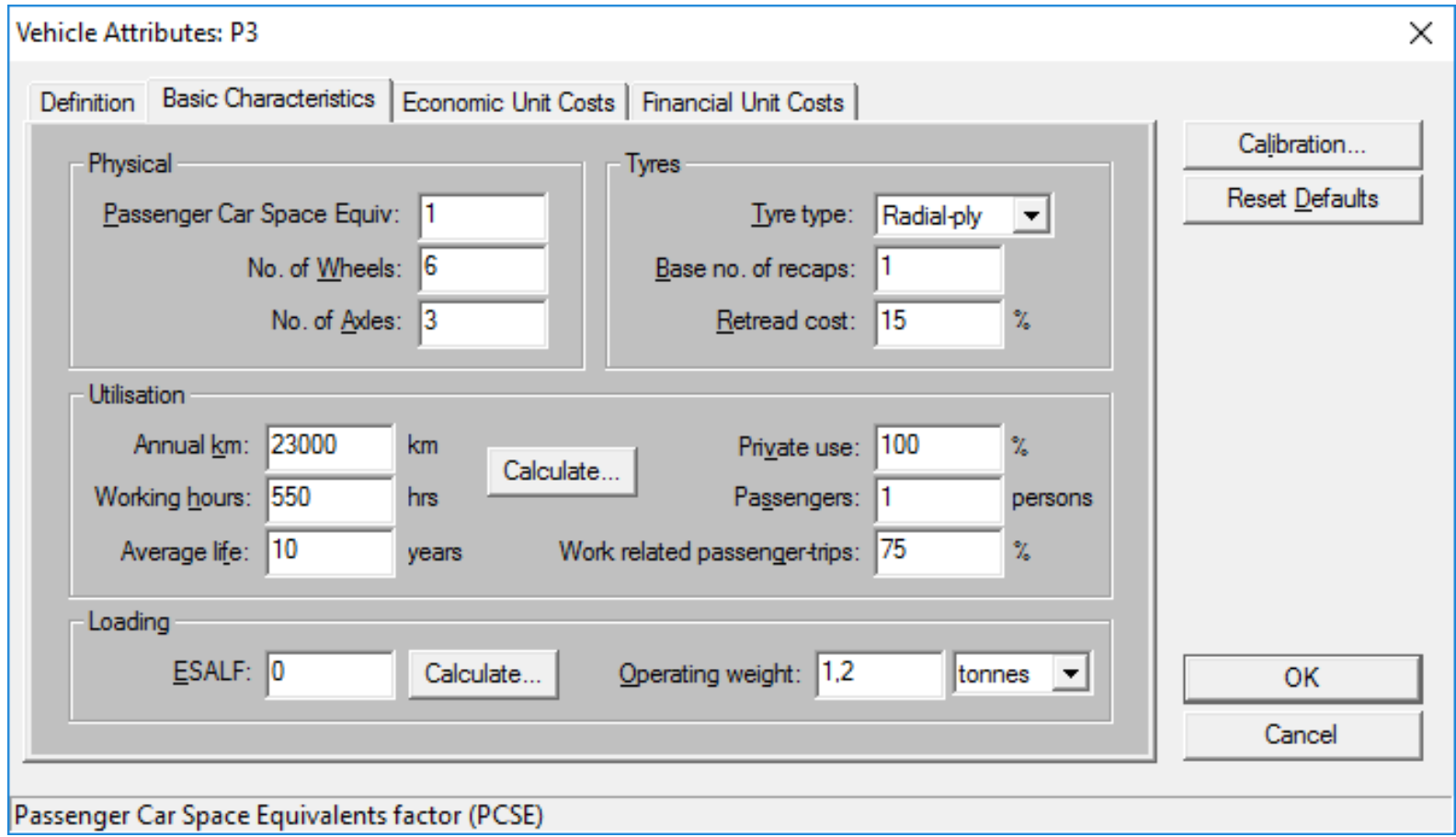




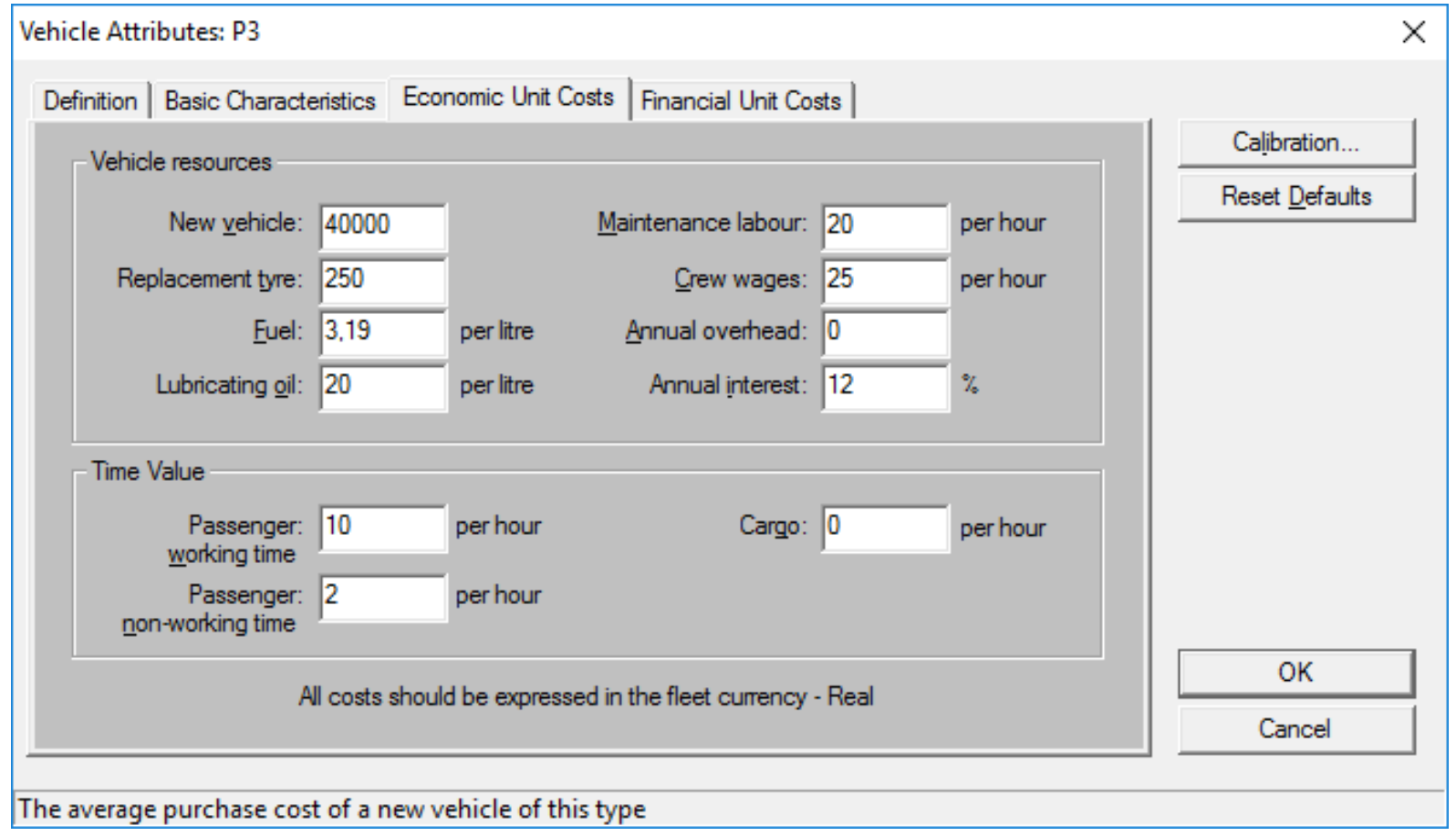

\section{- Veículos do tipo P4}

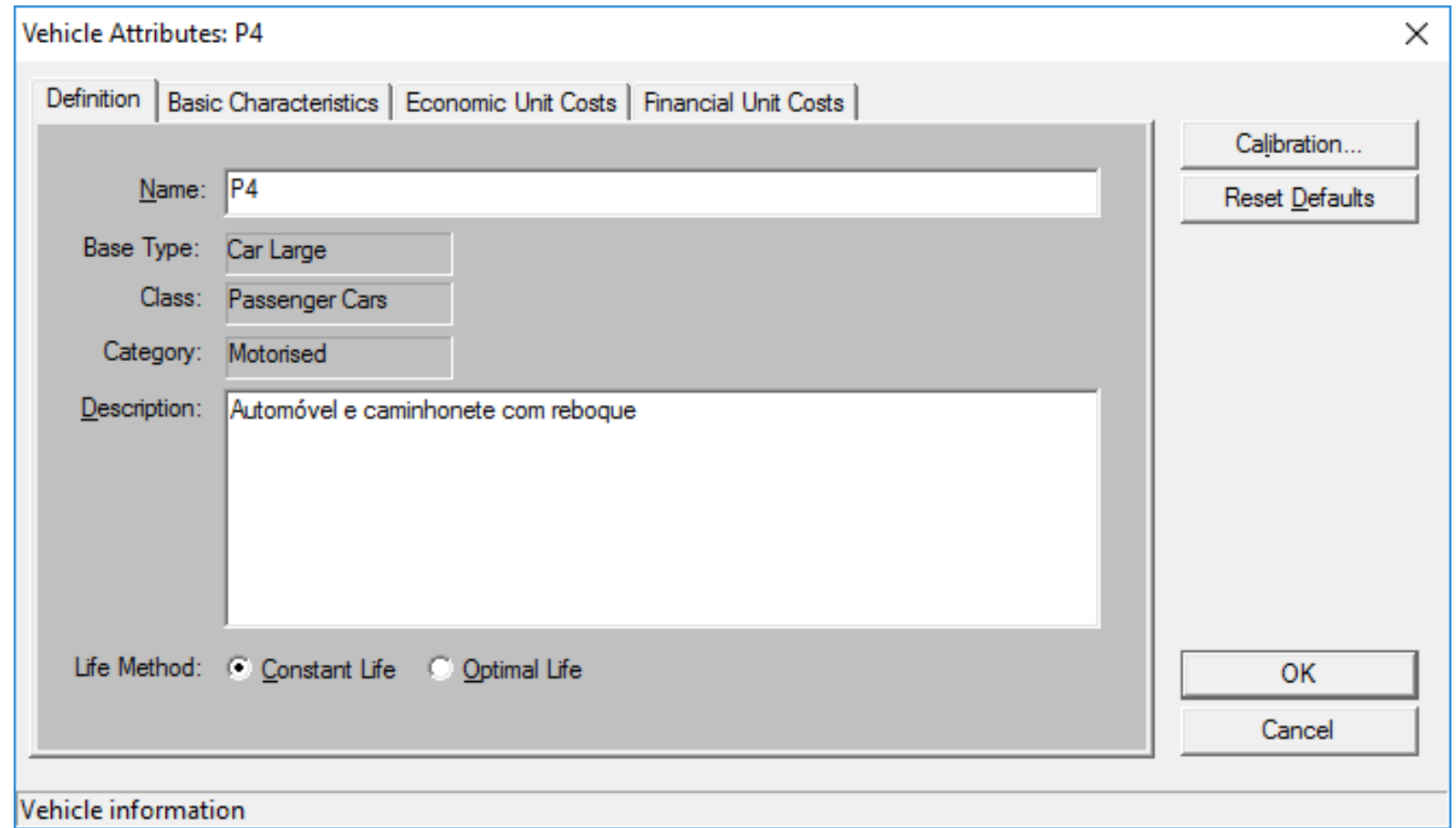




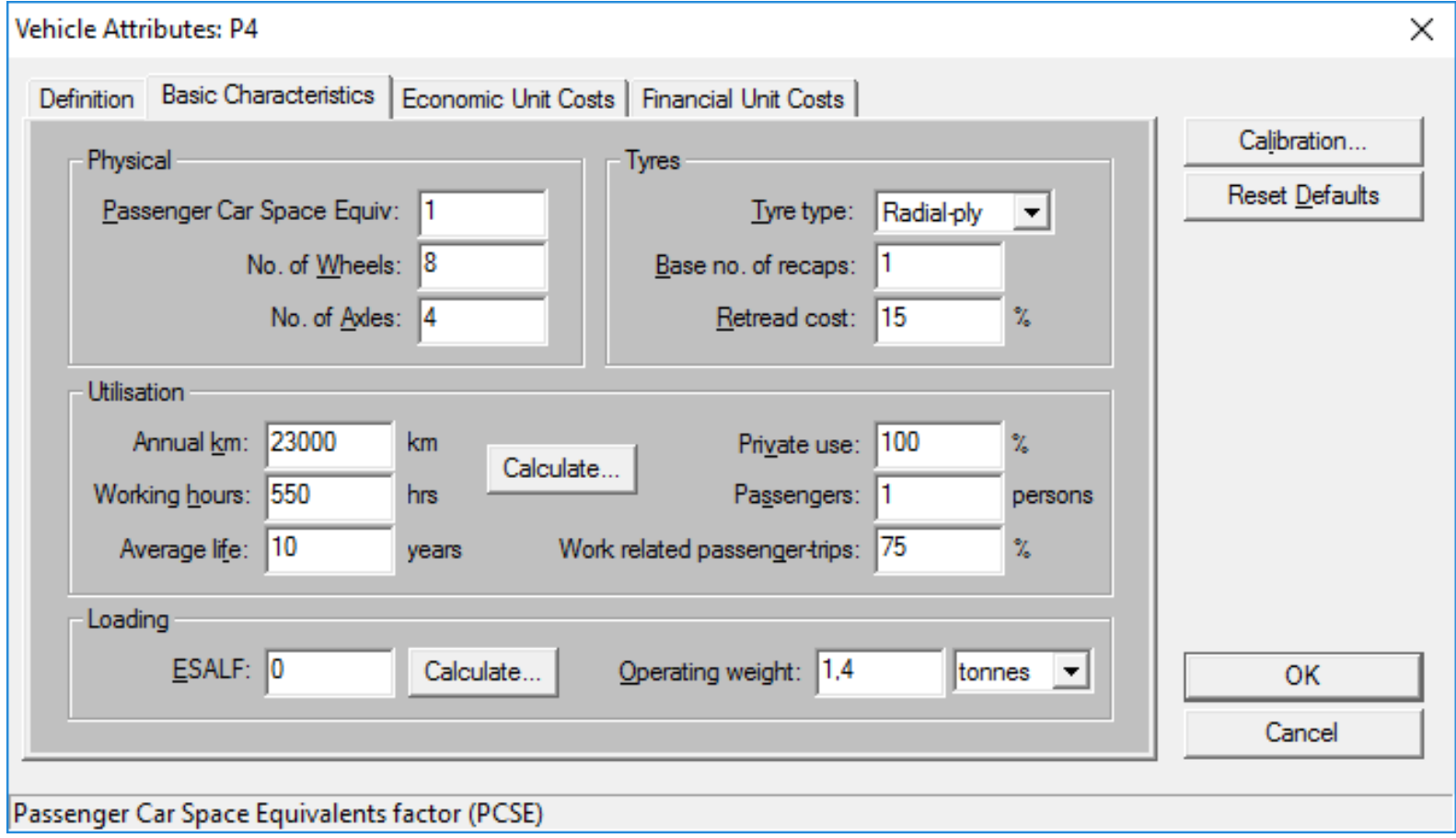

\begin{tabular}{|c|c|c|c|c|}
\hline \multicolumn{4}{|l|}{ Vehicle Attributes: P4 } & \multirow[b]{3}{*}{ Calibration... } \\
\hline Definition | Basic Characteristics & Economic Unit Costs & Financial Unit Costs & & \\
\hline \multicolumn{4}{|l|}{-Vehicle resources } & \\
\hline & \multirow{2}{*}{\multicolumn{2}{|c|}{ Maintenance labour: 20}} & \multirow{5}{*}{$\begin{array}{l}\text { per hour } \\
\text { per hour }\end{array}$} & Reset Defaults \\
\hline New vehicle: 40000 & & & & \\
\hline Replacement tyre: 250 & \multirow{3}{*}{$\begin{array}{l}\text { per litre } \\
\text { per litre }\end{array}$} & Crew wages: 0 & & \\
\hline Fuel: 3,19 & & Annual overhead: 0 & & \\
\hline Lubricating oil: 20 & & Annual interest: 12 & & \\
\hline \multicolumn{4}{|l|}{-Time Value - } & \\
\hline $\begin{array}{l}\text { Passenger: } 10 \\
\text { working time }\end{array}$ & \multirow{2}{*}{\multicolumn{2}{|c|}{ Cargo: 0}} & \multirow[t]{2}{*}{ per hour } & \\
\hline $\begin{array}{l}\text { Passenger: } 2 \\
\text { non-working time }\end{array}$ & & & & \\
\hline \multirow{2}{*}{\multicolumn{4}{|c|}{ All costs should be expressed in the fleet currency - Real }} & OK \\
\hline & & & & Cancel \\
\hline
\end{tabular}


Variáveis do item Maintenance Standards

- Atividades de Reforço do Pavimento (exemplo)
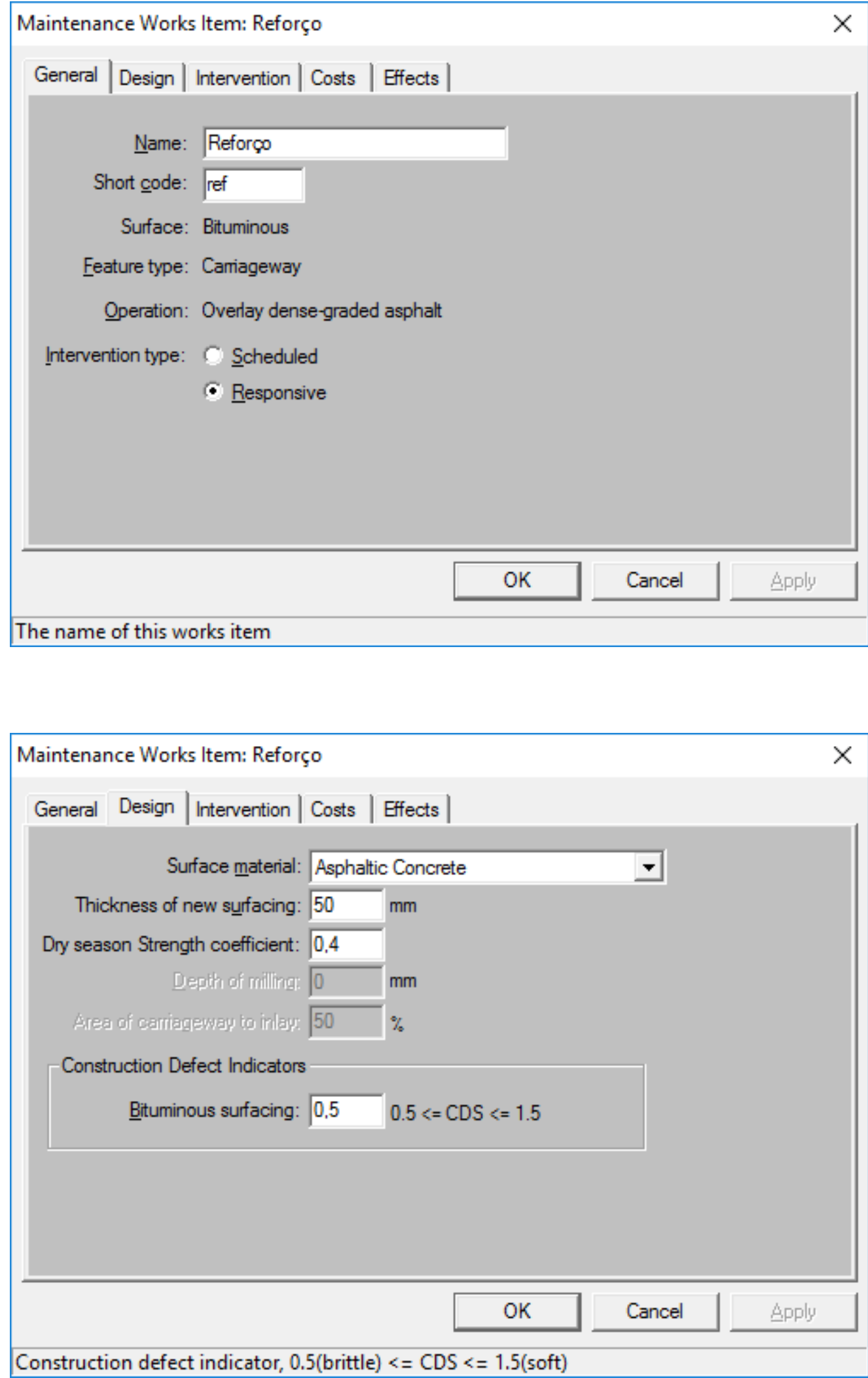

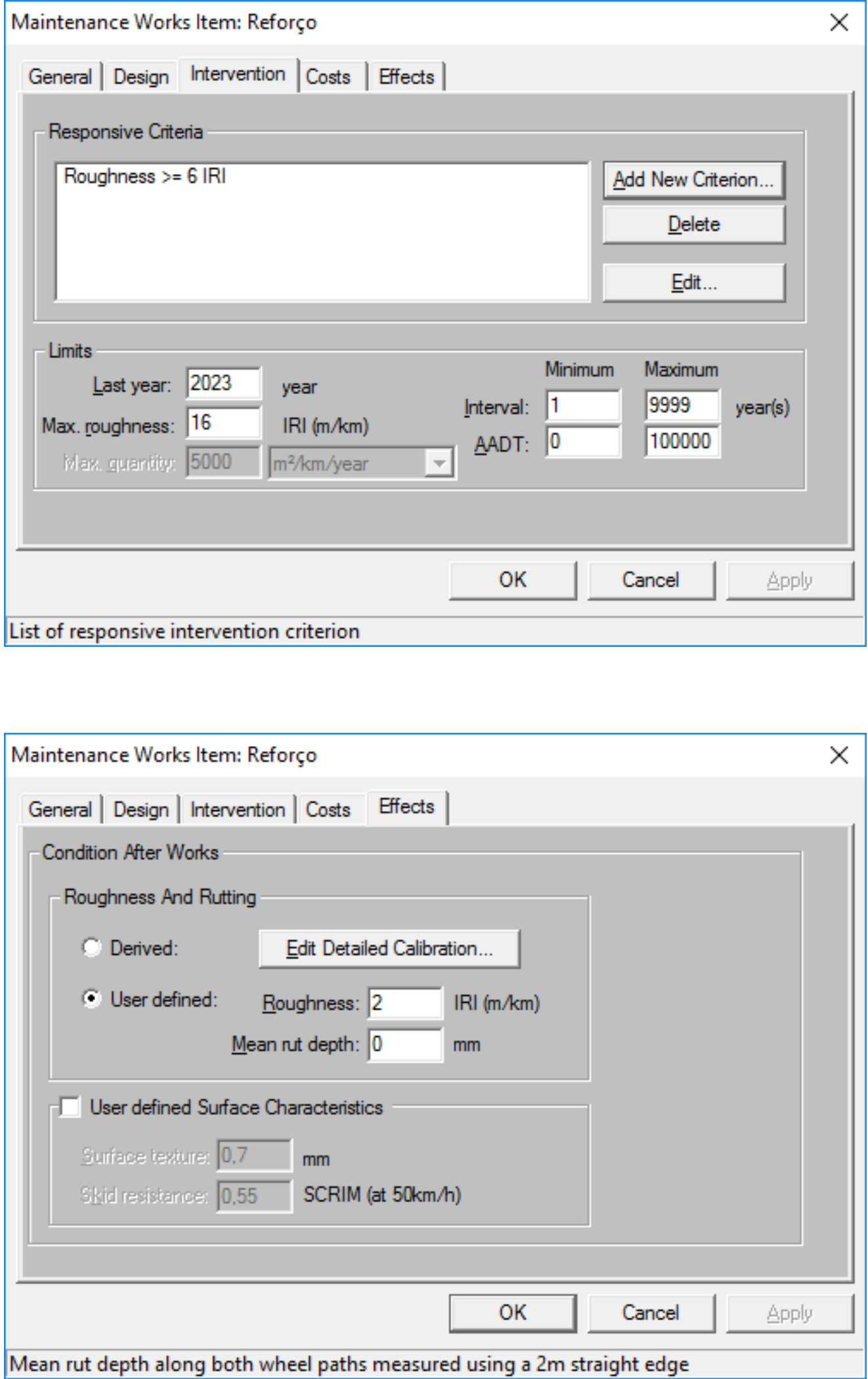
- Atividades de Microrrevestimento no Pavimento (exemplo)
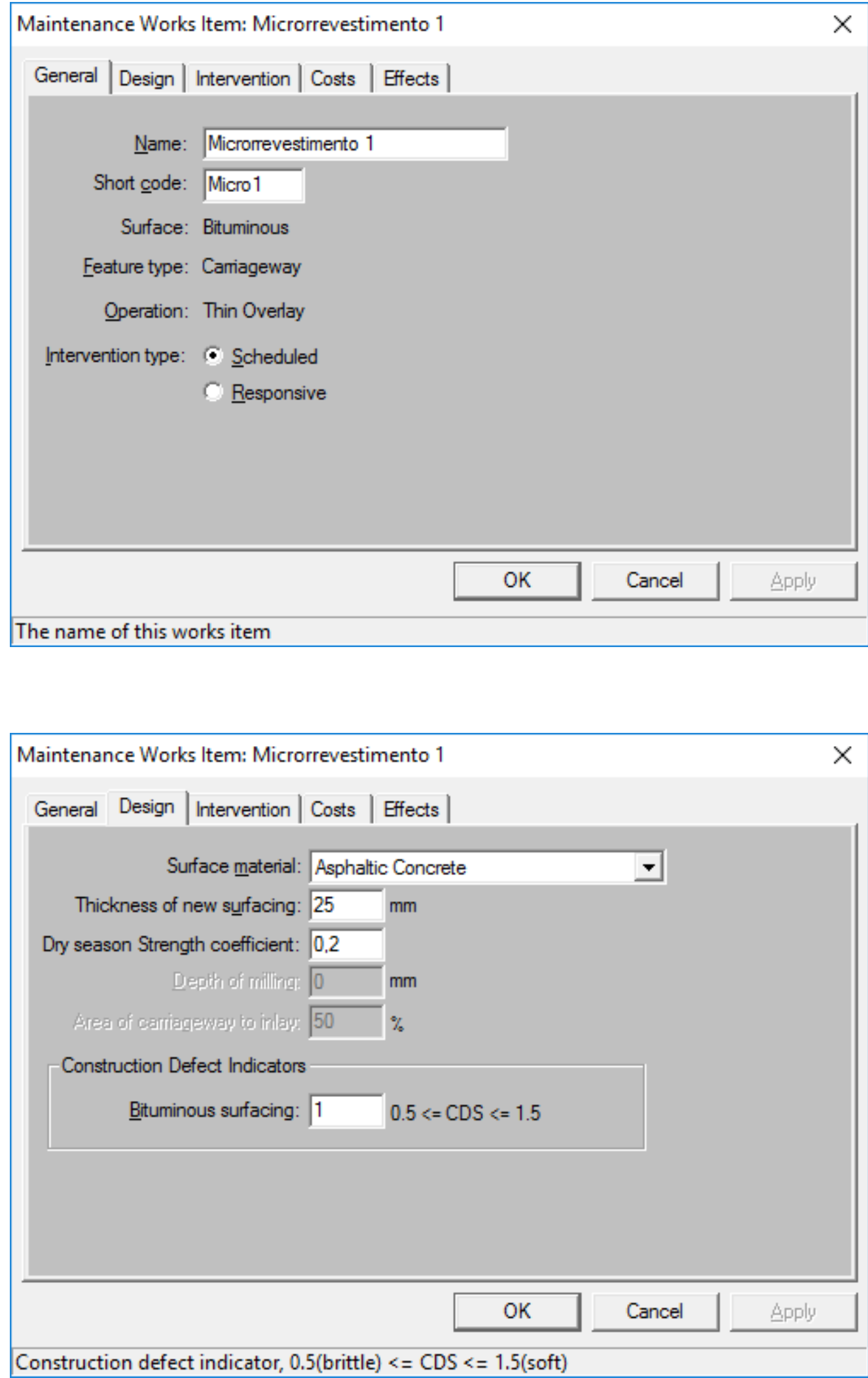


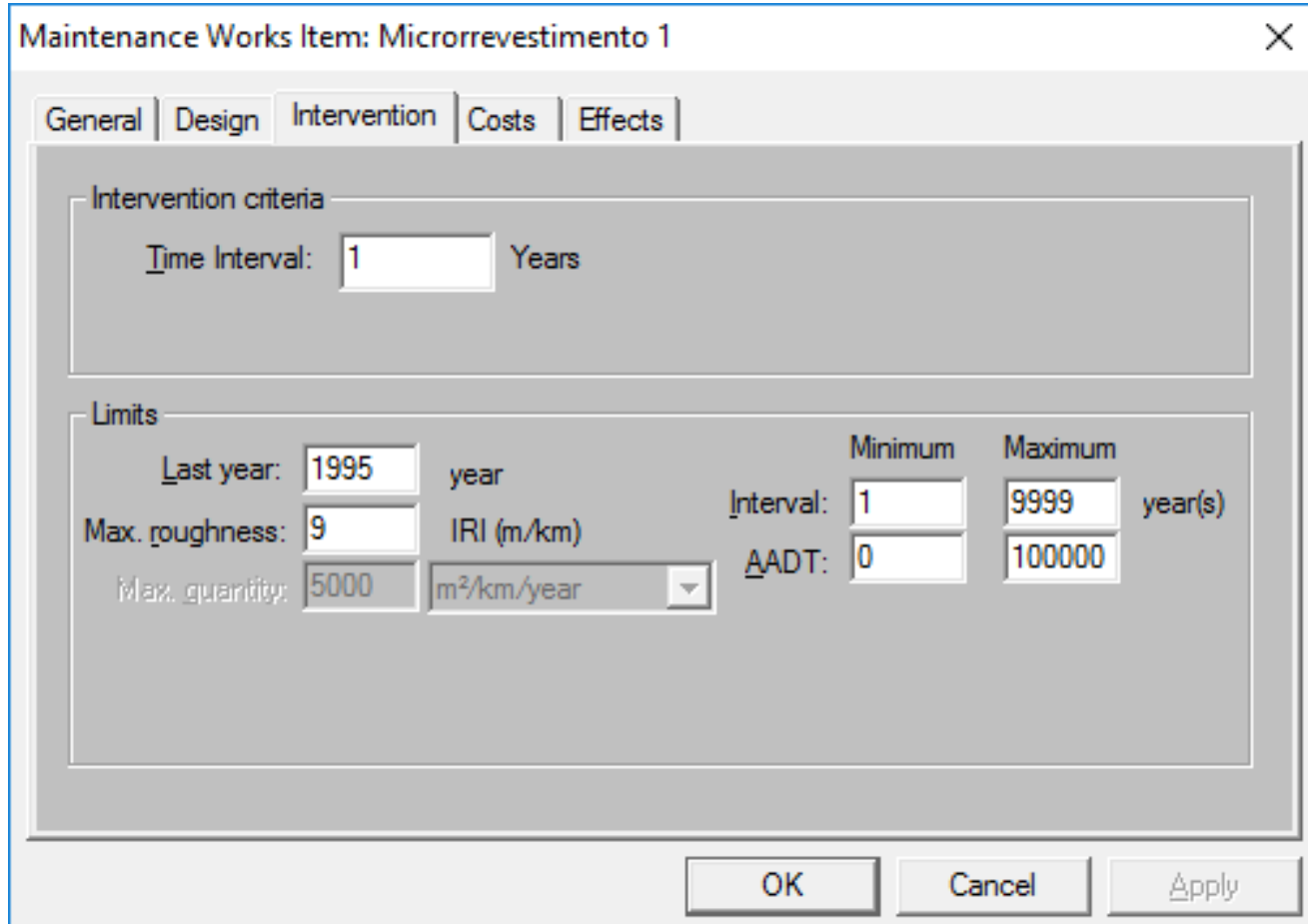

Frequency at which the work item will be performed (ie. every $\mathrm{X}$ years/days)

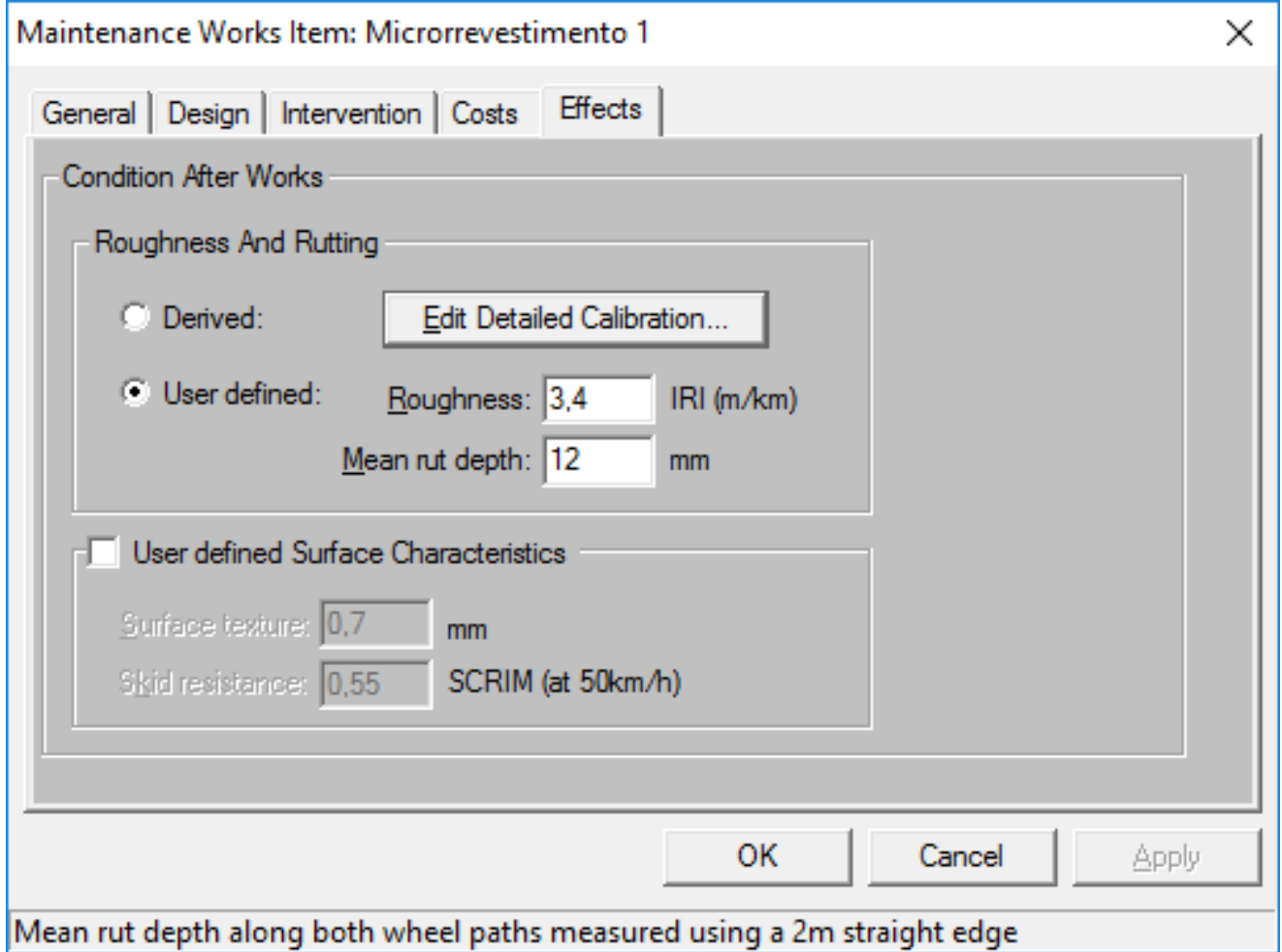




\section{APENDICE B - Custos operacionais totais, por tipo de veículo - Rodovia Dom Pedro I}

- Condição Base - IRI 6

\begin{tabular}{|c|c|c|c|c|c|c|c|c|c|c|c|c|}
\hline \multirow{2}{*}{ Ano } & \multicolumn{12}{|c|}{ Tipo de Veículo } \\
\hline & 2C & 2S2 & $2 \mathrm{S3}$ & $3 \mathrm{C}$ & $3 S 3$ & \begin{tabular}{|l|}
$3 T 4$ \\
\end{tabular} & $\mathbf{M}$ & $\mathbf{O}$ & $\mathbf{P}$ & P3 & P4 & Total \\
\hline 1995 & $\mathrm{R} \$ 5.505 .214$ & $\mathrm{R} \$ 3.364 .677$ & $\mathrm{R} \$ 6.357 .175$ & $\mathrm{R} \$ 7.721 .952$ & $\mathrm{R} \$ 7.345 .369$ & $\mathrm{R} \$ 157.362$ & $\mathrm{R} \$ 103.613$ & $\mathrm{R} \$ 1.095 .959$ & $\mathrm{R} \$ 10.312 .369$ & $\mathrm{R} \$ 79.880$ & $\mathrm{R} \$ 38.383$ & $\mathrm{R} \$ 42.081 .953$ \\
\hline 1996 & $\mathrm{R} \$ 6.583 .129$ & $\mathrm{R} \$ 3.989 .735$ & $\mathrm{R} \$ 7.591 .119$ & $\mathrm{R} \$ 9.157 .946$ & $\mathrm{R} \$ 8.817 .563$ & $\mathrm{R} \$ 202.379$ & $\mathrm{R} \$ 121.834$ & $\mathrm{R} \$ 1.302 .193$ & $\mathrm{R} \$ 12.205 .012$ & $\mathrm{R} \$ 94.982$ & $\mathrm{R} \$ 43.935$ & $\mathrm{R} \$ 50.109 .828$ \\
\hline 1997 & $\mathrm{R} \$ 7.521 .402$ & $\mathrm{R} \$ 4.534 .343$ & $\mathrm{R} \$ 8.702 .308$ & $\mathrm{R} \$ 10.346 .438$ & $\mathrm{R} \$ 10.173 .837$ & $\mathrm{R} \$ 228.915$ & $\mathrm{R} \$ 137.806$ & $\mathrm{R} \$ 1.487 .234$ & $\mathrm{R} \$ 13.778 .618$ & $\mathrm{R} \$ 107.445$ & $\mathrm{R} \$ 49.324$ & $\mathrm{R} \$ 57.067 .670$ \\
\hline 1998 & $\mathrm{R} \$ 7.944 .675$ & $\mathrm{R} \$ 4.756 .918$ & $\mathrm{R} \$ 9.252 .706$ & $\mathrm{R} \$ 10.772 .438$ & $\mathrm{R} \$ 10.817 .930$ & $\mathrm{R} \$ 237.474$ & $\mathrm{R} \$ 142.765$ & $\mathrm{R} \$ 1.563 .410$ & $\mathrm{R} \$ 14.292 .056$ & $\mathrm{R} \$ 110.884$ & $\mathrm{R} \$ 49.710$ & $\mathrm{R} \$ 59.940 .966$ \\
\hline 1999 & $\mathrm{R} \$ 7.635 .830$ & $\mathrm{R} \$ 4.708 .211$ & $\mathrm{R} \$ 8.728 .110$ & $\mathrm{R} \$ 10.792 .713$ & $\mathrm{R} \$ 10.038 .181$ & $\mathrm{R} \$ 222.974$ & $\mathrm{R} \$ 146.243$ & $\mathrm{R} \$ 1.524 .140$ & $\mathrm{R} \$ 14.554 .742$ & $\mathrm{R} \$ 112.306$ & $\mathrm{R} \$ 52.490$ & $\mathrm{R} \$ 58.515 .939$ \\
\hline 2000 & $\mathrm{R} \$ 7.643 .999$ & $\mathrm{R} \$ 4.714 .987$ & $\mathrm{R} \$ 8.733 .329$ & $\mathrm{R} \$ 10.797 .429$ & $\mathrm{R} \$ 10.044 .941$ & $\mathrm{R} \$ 223.805$ & $\mathrm{R} \$ 145.695$ & $\mathrm{R} \$ 1.529 .983$ & $\mathrm{R} \$ 14.561 .073$ & $\mathrm{R} \$ 112.696$ & $\mathrm{R} \$ 52.673$ & $\mathrm{R} \$ 58.560 .610$ \\
\hline 2001 & $\mathrm{R} \$ 7.752 .609$ & $\mathrm{R} \$ 4.779 .586$ & $\mathrm{R} \$ 8.868 .282$ & $\mathrm{R} \$ 10.961 .221$ & $\mathrm{R} \$ 10.201 .239$ & $\mathrm{R} \$ 223.498$ & $\mathrm{R} \$ 147.442$ & $\mathrm{R} \$ 1.555 .209$ & $\mathrm{R} \$ 14.763 .481$ & $\mathrm{R} \$ 114.789$ & $\mathrm{R} \$ 52.580$ & $\mathrm{R} \$ 59.419 .936$ \\
\hline 2002 & $\mathrm{R} \$ 8.015 .428$ & $\mathrm{R} \$ 4.943 .024$ & $\mathrm{R} \$ 9.168 .267$ & $\mathrm{R} \$ 11.324 .670$ & $\mathrm{R} \$ 10.548 .386$ & $\mathrm{R} \$ 224.058$ & $\mathrm{R} \$ 152.740$ & $\mathrm{R} \$ 1.599 .410$ & $\mathrm{R} \$ 15.245 .025$ & $\mathrm{R} \$ 119.544$ & $\mathrm{R} \$ 55.162$ & $\mathrm{R} \$ 61.395 .715$ \\
\hline 2003 & $\mathrm{R} \$ 7.913 .768$ & $\mathrm{R} \$ 4.872 .300$ & $\mathrm{R} \$ 9.058 .261$ & $\mathrm{R} \$ 11.163 .410$ & $\mathrm{R} \$ 10.428 .074$ & $\mathrm{R} \$ 225.727$ & $\mathrm{R} \$ 150.119$ & $\mathrm{R} \$ 1.578 .736$ & $\mathrm{R} \$ 15.011 .854$ & $\mathrm{R} \$ 117.656$ & $\mathrm{R} \$ 52.831$ & $\mathrm{R} \$ 60.572 .736$ \\
\hline 2004 & $\mathrm{R} \$ 8.370 .558$ & $\mathrm{R} \$ 5.139 .141$ & $\mathrm{R} \$ 9.623 .604$ & $\mathrm{R} \$ 11.791 .485$ & $\mathrm{R} \$ 11.095 .121$ & $\mathrm{R} \$ 230.456$ & $\mathrm{R} \$ 157.848$ & $\mathrm{R} \$ 1.666 .523$ & $\mathrm{R} \$ 15.807 .717$ & $\mathrm{R} \$ 123.575$ & $\mathrm{R} \$ 55.907$ & $\mathrm{R} \$ 64.061 .936$ \\
\hline 2005 & $\mathrm{R} \$ 8.805 .778$ & $\mathrm{R} \$ 5.379 .438$ & $\mathrm{R} \$ 10.151 .020$ & $\mathrm{R} \$ 12.357 .201$ & $\mathrm{R} \$ 11.721 .598$ & $\mathrm{R} \$ 253.777$ & $\mathrm{R} \$ 164.870$ & $\mathrm{R} \$ 1.748 .799$ & $\mathrm{R} \$ 16.534 .462$ & $\mathrm{R} \$ 128.866$ & $\mathrm{R} \$ 58.703$ & $\mathrm{R} \$ 67.304 .511$ \\
\hline 2006 & $\mathrm{R} \$ 9.206 .791$ & $\mathrm{R} \$ 5.585 .465$ & $\mathrm{R} \$ 10.618 .725$ & $\mathrm{R} \$ 12.847 .949$ & $\mathrm{R} \$ 12.307 .393$ & $\mathrm{R} \$ 260.362$ & $\mathrm{R} \$ 170.692$ & $\mathrm{R} \$ 1.817 .794$ & $\mathrm{R} \$ 17.135 .460$ & $\mathrm{R} \$ 132.323$ & $\mathrm{R} \$ 61.737$ & $\mathrm{R} \$ 70.144 .691$ \\
\hline 2007 & $\mathrm{R} \$ 10.189 .829$ & $\mathrm{R} \$ 6.122 .669$ & $\mathrm{R} \$ 11.819 .316$ & $\mathrm{R} \$ 13.938 .991$ & $\mathrm{R} \$ 13.818 .953$ & $\mathrm{R} \$ 295.456$ & $\mathrm{R} \$ 185.684$ & $\mathrm{R} \$ 2.004 .931$ & $\mathrm{R} \$ 18.560 .137$ & $\mathrm{R} \$ 143.757$ & $\mathrm{R} \$ 65.087$ & $\mathrm{R} \$ 77.144 .812$ \\
\hline 2008 & $\$ 9.798 .631$ & $\mathrm{R} \$ 6.037 .941$ & $\mathrm{R} \$ 11.207 .645$ & $\mathrm{R} \$ 13.855 .801$ & $\mathrm{R} \$ 12.890 .081$ & $\mathrm{R} \$ 279.537$ & $\mathrm{R} \$ 186.654$ & $\mathrm{R} \$ 1.965 .418$ & $\mathrm{R} \$ 18.678 .883$ & $\mathrm{R} \$ 144.811$ & $\mathrm{R} \$ 67.682$ & $\mathrm{R} \$ 75.113 .084$ \\
\hline 2009 & $\mathrm{R} \$ 9.934 .292$ & $\mathrm{R} \$ 6.125 .927$ & $\mathrm{R} \$ 11.356 .482$ & $\mathrm{R} \$ 14.044 .954$ & $\mathrm{R} \$ 13.062 .751$ & $\mathrm{R} \$ 279.192$ & $\mathrm{R} \$ 189.367$ & $\mathrm{R} \$ 1.990 .492$ & $\mathrm{R} \$ 18.923 .541$ & $\mathrm{R} \$ 146.861$ & $\mathrm{R} \$ 67.573$ & $\mathrm{R} \$ 76.121 .434$ \\
\hline 2010 & $\mathrm{R} \$ 10.946 .050$ & $\mathrm{R} \$ 6.752 .580$ & $\mathrm{R} \$ 12.522 .981$ & $\mathrm{R} \$ 15.467 .465$ & $\mathrm{R} \$ 14.407 .495$ & $\mathrm{R} \$ 298.582$ & $\mathrm{R} \$ 208.047$ & $\mathrm{R} \$ 2.186 .355$ & $\mathrm{R} \$ 20.824 .328$ & $\mathrm{R} \$ 160.887$ & $\mathrm{R} \$ 75.199$ & $\mathrm{R} \$ 83.849 .969$ \\
\hline 2011 & $\mathrm{R} \$ 11.790 .063$ & $\mathrm{R} \$ 7.261 .367$ & $\mathrm{R} \$ 13.500 .136$ & $\mathrm{R} \$ 16.641 .884$ & $\mathrm{R} \$ 15.541 .721$ & $\mathrm{R} \$ 338.609$ & $\mathrm{R} \$ 224.157$ & $\mathrm{R} \$ 2.347 .574$ & $\mathrm{R} \$ 22.377 .034$ & $\mathrm{R} \$ 173.023$ & $\mathrm{R} \$ 80.506$ & $\mathrm{R} \$ 90.276 .074$ \\
\hline 2012 & $\mathrm{R} \$ 12.432 .393$ & $\mathrm{R} \$ 7.626 .063$ & $\mathrm{R} \$ 14.293 .642$ & $\mathrm{R} \$ 17.499 .527$ & $\mathrm{R} \$ 16.481 .629$ & $\mathrm{R} \$ 346.295$ & $\mathrm{R} \$ 233.819$ & $\mathrm{R} \$ 2.474 .232$ & $\mathrm{R} \$ 23.466 .879$ & $\mathrm{R} \$ 181.994$ & $\mathrm{R} \$ 83.918$ & $\mathrm{R} \$ 95.120 .389$ \\
\hline 2013 & $\mathrm{R} \$ 13.086 .587$ & $\mathrm{R} \$ 7.980 .041$ & $\mathrm{R} \$ 15.081 .096$ & $\mathrm{R} \$ 18.339 .280$ & $\mathrm{R} \$ 17.422 .298$ & $\mathrm{R} \$ 372.924$ & $\mathrm{R} \$ 244.692$ & $\mathrm{R} \$ 2.582 .057$ & $\mathrm{R} \$ 24.522 .020$ & $\mathrm{R} \$ 190.155$ & $\mathrm{R} \$ 86.937$ & $\mathrm{R} \$ 99.908 .088$ \\
\hline 2014 & $\mathrm{R} \$ 13.511 .819$ & $\mathrm{R} \$ 8.182 .573$ & $\mathrm{R} \$ 15.588 .549$ & $\mathrm{R} \$ 18.798 .392$ & $\mathrm{R} \$ 18.113 .066$ & $\mathrm{R} \$ 383.895$ & $\mathrm{R} \$ 250.497$ & $\mathrm{R} \$ 2.656 .218$ & $\mathrm{R} \$ 25.066 .883$ & $\mathrm{R} \$ 194.233$ & $\mathrm{R} \$ 87.653$ & $\mathrm{R} \$ 102.833 .778$ \\
\hline 2015 & $\mathrm{R} \$ 13.878 .751$ & $\mathrm{R} \$ 8.320 .354$ & $\mathrm{R} \$ 16.129 .495$ & $\mathrm{R} \$ 18.900 .366$ & $\mathrm{R} \$ 18.858 .527$ & $\mathrm{R} \$ 405.941$ & $\mathrm{R} \$ 251.109$ & $\mathrm{R} \$ 2.725 .822$ & $\mathrm{R} \$ 25.116 .719$ & $\mathrm{R} \$ 194.686$ & $\mathrm{R} \$ 88.746$ & $\mathrm{R} \$ 104.870 .515$ \\
\hline \multicolumn{13}{|c|}{ Valor Presente dos Custos } \\
\hline $6 \%$ a.a. & $\mathrm{R} \$ 102.432 .957$ & $\mathrm{R} \$ 62.545 .566$ & $\mathrm{R} \$ 117.855 .610$ & $\mathrm{R} \$ 143.219 .848$ & $\mathrm{R} \$ 136.333 .656$ & $\mathrm{R} \$ 2.953 .483$ & $\mathrm{R} \$ 1.918 .056$ & $\mathrm{R} \$ 20.347 .494$ & $\mathrm{R} \$ 191.841 .006$ & $\mathrm{R} \$ 1.489 .693$ & $\mathrm{R} \$ 685.845$ & $\mathrm{R} \$ 781.623 .214$ \\
\hline $12 \%$ a.a. & $\mathrm{R} \$ 61.438 .476$ & $\mathrm{R} \$ 37.499 .387$ & $\mathrm{R} \$ 70.706 .901$ & $\mathrm{R} \$ 85.850 .179$ & $\mathrm{R} \$ 81.819 .670$ & $\mathrm{R} \$ 1.782 .217$ & $\mathrm{R} \$ 1.149 .755$ & $\mathrm{R} \$ 12.206 .501$ & $\mathrm{R} \$ 114.964 .354$ & $\mathrm{R} \$ 892.991$ & $\mathrm{R} \$ 411.713$ & $\mathrm{R} \$ 468.722 .144$ \\
\hline $18 \%$ a.a. & $\mathrm{R} \$ 41.457 .436$ & $\mathrm{R} \$ 25.287 .607$ & $\mathrm{R} \$ 47.730 .949$ & $\mathrm{R} \$ 57.882 .100$ & $\mathrm{R} \$ 55.257 .612$ & $\mathrm{R} \$ 1.209 .298$ & $\mathrm{R} \$ 775.064$ & $\mathrm{R} \$ 8.236 .117$ & $\mathrm{R} \$ 77.479 .006$ & $\mathrm{R} \$ 601.905$ & $\mathrm{R} \$ 277.937$ & $\mathrm{R} \$ 316.195 .032$ \\
\hline
\end{tabular}


- Condição Base - IRI 8

\begin{tabular}{|c|c|c|c|c|c|c|c|c|c|c|c|c|}
\hline \multirow{2}{*}{ Ano } & \multicolumn{12}{|c|}{ Tipo de Veículo } \\
\hline & $2 \mathrm{C}$ & $2 \mathrm{~S} 2$ & $2 \mathrm{S3}$ & $3 \mathrm{C}$ & $3 \mathrm{S3}$ & $3 T 4$ & $\mathbf{M}$ & $\mathbf{O}$ & $\mathbf{P}$ & $\mathbf{P 3}$ & P4 & Total \\
\hline 1995 & $\mathrm{R} \$ 5.505 .214$ & $\mathrm{R} \$ 3.364 .677$ & $\mathrm{R} \$ 6.357 .175$ & $\mathrm{R} \$ 7.721 .952$ & $\mathrm{R} \$ 7.345 .369$ & $\mathrm{R} \$ 157.362$ & $\mathrm{R} \$ 103.613$ & $\mathrm{R} \$ 1.095 .959$ & $\mathrm{R} \$ 10.312 .369$ & $\mathrm{R} \$ 79.880$ & $\mathrm{R} \$ 38.383$ & $\mathrm{R} \$ 42.081 .953$ \\
\hline 1996 & $\mathrm{R} \$ 6.583 .129$ & $\mathrm{R} \$ 3.989 .735$ & $\mathrm{R} \$ 7.591 .119$ & $\mathrm{R} \$ 9.157 .946$ & $\mathrm{R} \$ 8.817 .563$ & 202.379 & $\$ 121.834$ & $\mathrm{R} \$ 1.302 .193$ & $\mathrm{R} \$ 12.205 .012$ & $\mathrm{R} \$ 94.982$ & $\mathrm{R} \$ 43.935$ & $\mathrm{R} \$ 50.109 .828$ \\
\hline 1997 & 21.402 & 4.534.343 & $\$ 8.702 .308$ & $\mathrm{R} \$ 10.346 .438$ & 10.173 .837 & 228.915 & 137.806 & $\$ 1.487 .234$ & 13.778 .618 & 107.445 & 499.324 & $\$ 57.067 .670$ \\
\hline 1998 & $\mathrm{R} \$ 7.944 .675$ & $\mathrm{R} \$ 4.756 .918$ & $\mathrm{R} \$ 9.252 .706$ & $\mathrm{R} \$ 10.772 .438$ & $\mathrm{R} \$ 10.817 .930$ & $\mathrm{R} \$ 237.474$ & $\mathrm{R} \$ 142.765$ & $\mathrm{R} \$ 1.563 .410$ & $\mathrm{R} \$ 14.292 .056$ & $\mathrm{R} \$ 110.884$ & $\mathrm{R} \$ 49.710$ & $\mathrm{R} \$ 59.940 .966$ \\
\hline 1999 & $\mathrm{R} \$ 8.959 .415$ & $\mathrm{R} \$ 5.379 .264$ & $\mathrm{R} \$ 10.438 .102$ & $\mathrm{R} \$ 11.958 .086$ & $\mathrm{R} \$ 12.197 .220$ & $\mathrm{R} \$ 270.359$ & $\$ 157.504$ & $\mathrm{R} \$ 1.755 .570$ & $\mathrm{R} \$ 15.765 .092$ & $\mathrm{R} \$ 120.103$ & $\mathrm{R} \$ 55.709$ & $\mathrm{R} \$ 67.056 .423$ \\
\hline 2000 & $\mathrm{R} \$ 7.636 .068$ & $\mathrm{R} \$ 4.709 .571$ & $\$ 8.723 .355$ & $\mathrm{R} \$ 10.786 .814$ & $\mathrm{R} \$ 10.032 .730$ & $\$ 223.593$ & $\$ 145.618$ & $\mathrm{R} \$ 1.528 .376$ & $\mathrm{R} \$ 14.552 .974$ & $\mathrm{R} \$ 112.616$ & $\mathrm{R} \$ 52.635$ & $\mathrm{R} \$ 58.504 .349$ \\
\hline 2001 & $\mathrm{R} \$ 7.742 .552$ & $\mathrm{R} \$ 4.772 .984$ & $\mathrm{R} \$ 8.855 .390$ & $\mathrm{R} \$ 10.947 .970$ & $\mathrm{R} \$ 10.185 .384$ & $\mathrm{R} \$ 223.215$ & $\mathrm{R} \$ 147.352$ & $\mathrm{R} \$ 1.553 .206$ & $\mathrm{R} \$ 14.753 .171$ & $\mathrm{R} \$ 114.690$ & $\mathrm{R} \$ 52.533$ & $\mathrm{R} \$ 59.348 .446$ \\
\hline 2002 & $\mathrm{R} \$ 7.998 .685$ & $\mathrm{R} \$ 4.933 .118$ & $\mathrm{R} \$ 9.145 .866$ & $\mathrm{R} \$ 11.303 .610$ & $\mathrm{R} \$ 10.520 .668$ & $\mathrm{R} \$ 223.538$ & $\$ 152.580$ & $\mathrm{R} \$ 1.596 .398$ & $\mathrm{R} \$ 15.227 .015$ & $\mathrm{R} \$ 119.387$ & $\mathrm{R} \$ 55.090$ & $\mathrm{R} \$ 61.275 .955$ \\
\hline 2003 & $\mathrm{R} \$ 7.871 .149$ & $\mathrm{R} \$ 4.850 .462$ & $\mathrm{R} \$ 8.997 .554$ & $\mathrm{R} \$ 11.112 .651$ & $\mathrm{R} \$ 10.352 .348$ & $\mathrm{R} \$ 224.155$ & 149.691 & $\mathrm{R} \$ 1.572 .541$ & $\mathrm{R} \$ 14.962 .243$ & $\mathrm{R} \$ 117.271$ & $\mathrm{R} \$ 52.666$ & $\mathrm{R} \$ 60.262 .732$ \\
\hline 2004 & $\mathrm{R} \$ 8.270 .323$ & $\mathrm{R} \$ 5.092 .057$ & $\mathrm{R} \$ 9.479 .574$ & $\mathrm{R} \$ 11.676 .125$ & $\mathrm{R} \$ 10.914 .503$ & $\mathrm{R} \$ 226.711$ & $\mathrm{R} \$ 156.813$ & $\mathrm{R} \$ 1.653 .183$ & $\mathrm{R} \$ 15.689 .200$ & $\mathrm{R} \$ 122.692$ & $\mathrm{R} \$ 55.536$ & $\mathrm{R} \$ 63.336 .717$ \\
\hline 2005 & $\mathrm{R} \$ 8.696 .921$ & $\mathrm{R} \$ 5.334 .253$ & $\mathrm{R} \$ 10.003 .790$ & $\mathrm{R} \$ 12.239 .730$ & $\mathrm{R} \$ 11.535 .446$ & 249.507 & $\$ 163.768$ & $\mathrm{R} \$ 1.733 .093$ & $\mathrm{R} \$ 16.414 .283$ & $\mathrm{R} \$ 127.996$ & $\mathrm{R} \$ 58.337$ & $\mathrm{R} \$ 66.557 .123$ \\
\hline 2006 & $\mathrm{R} \$ 9.054 .467$ & $\mathrm{R} \$ 5.530 .647$ & $\mathrm{R} \$ 10.430 .584$ & $\mathrm{R} \$ 12.706 .566$ & $\mathrm{R} \$ 12.046 .997$ & $\mathrm{R} \$ 254.429$ & $\$ 169.213$ & $\mathrm{R} \$ 1.793 .329$ & $\mathrm{R} \$ 16.987 .968$ & $\mathrm{R} \$ 131.324$ & $\mathrm{R} \$ 61.309$ & $\mathrm{R} \$ 69.166 .833$ \\
\hline 2007 & $\mathrm{R} \$ 9.823 .878$ & $\mathrm{R} \$ 5.950 .411$ & $\mathrm{R} \$ 11.330 .784$ & $\mathrm{R} \$ 13.682 .264$ & $\mathrm{R} \$ 13.146 .814$ & $\mathrm{R} \$ 281.461$ & $\mathrm{R} \$ 182.526$ & $\mathrm{R} \$ 1.936 .010$ & $\mathrm{R} \$ 18.253 .370$ & $\mathrm{R} \$ 141.929$ & $\mathrm{R} \$ 64.372$ & $\mathrm{R} \$ 74.793 .820$ \\
\hline 2008 & $\mathrm{R} \$ 10.845 .344$ & $R \$ 6.512 .095$ & $\mathrm{R} \$ 12.607 .671$ & $\mathrm{R} \$ 14.810 .251$ & $\mathrm{R} \$ 14.740 .865$ & $\mathrm{R} \$ 319.674$ & $\$ 196.338$ & $\mathrm{R} \$ 2.141 .166$ & $\mathrm{R} \$ 19.690 .389$ & $\mathrm{R} \$ 151.627$ & $\mathrm{R} \$ 70.590$ & $\mathrm{R} \$ 82.086 .010$ \\
\hline 2009 & $\mathrm{R} \$ 12.063 .677$ & $\mathrm{R} \$ 7.264 .487$ & $\mathrm{R} \$ 14.052 .888$ & $\mathrm{R} \$ 15.997 .956$ & $\mathrm{R} \$ 16.403 .367$ & $\mathrm{R} \$ 349.473$ & $\mathrm{R} \$ 208.226$ & $\mathrm{R} \$ 2.373 .197$ & $\mathrm{R} \$ 20.965 .035$ & $\mathrm{R} \$ 160.109$ & $\mathrm{R} \$ 72.920$ & $\mathrm{R} \$ 89.911 .335$ \\
\hline 2010 & $\mathrm{R} \$ 10.903 .059$ & $\mathrm{R} \$ 6.725 .212$ & $\mathrm{R} \$ 12.467 .163$ & $\mathrm{R} \$ 15.411 .615$ & $\mathrm{R} \$ 14.338 .767$ & $\mathrm{R} \$ 297.389$ & $\mathrm{R} \$ 207.634$ & $\mathrm{R} \$ 2.178 .085$ & $\mathrm{R} \$ 20.778 .965$ & $\mathrm{R} \$ 160.474$ & $\mathrm{R} \$ 75.004$ & $\mathrm{R} \$ 83.543 .369$ \\
\hline 2011 & $\mathrm{R} \$ 11.691 .669$ & $\mathrm{R} \$ 7.208 .129$ & $\mathrm{R} \$ 13.362 .997$ & $\mathrm{R} \$ 16.522 .230$ & $\mathrm{R} \$ 15.371 .118$ & $\mathrm{R} \$ 335.140$ & $\$ 223.179$ & $\mathrm{R} \$ 2.332 .097$ & $\mathrm{R} \$ 22.265 .317$ & $\mathrm{R} \$ 172.148$ & $\mathrm{R} \$ 80.105$ & $\mathrm{R} \$ 89.564 .129$ \\
\hline 2012 & $\mathrm{R} \$ 12.186 .136$ & $\mathrm{R} \$ 7.507 .643$ & $\mathrm{R} \$ 13.940 .934$ & $\mathrm{R} \$ 17.213 .565$ & $\mathrm{R} \$ 16.039 .956$ & $\mathrm{R} \$ 337.127$ & $\mathrm{R} \$ 231.314$ & $\mathrm{R} \$ 2.440 .555$ & $\mathrm{R} \$ 23.176 .627$ & $\mathrm{R} \$ 179.849$ & $\mathrm{R} \$ 82.984$ & $\mathrm{R} \$ 93.336 .689$ \\
\hline 2013 & $\mathrm{R} \$ 12.721 .483$ & $\mathrm{R} \$ 7.823 .058$ & $\mathrm{R} \$ 14.579 .267$ & $\mathrm{R} \$ 17.938 .897$ & $\mathrm{R} \$ 16.789 .340$ & $\mathrm{R} \$ 358.814$ & $\mathrm{R} \$ 240.981$ & $\mathrm{R} \$ 2.530 .775$ & $\mathrm{R} \$ 24.111 .032$ & $\mathrm{R} \$ 187.199$ & $\mathrm{R} \$ 85.676$ & $\mathrm{R} \$ 97.366 .524$ \\
\hline 2014 & $\mathrm{R} \$ 13.061 .495$ & $\mathrm{R} \$ 8.008 .932$ & $\mathrm{R} \$ 15.022 .791$ & $\mathrm{R} \$ 18.372 .712$ & $\mathrm{R} \$ 17.329 .551$ & $\mathrm{R} \$ 366.371$ & $\mathrm{R} \$ 246.106$ & $\mathrm{R} \$ 2.585 .072$ & $\mathrm{R} \$ 24.622 .134$ & $\mathrm{R} \$ 191.199$ & $\mathrm{R} \$ 86.392$ & $\mathrm{R} \$ 99.892 .753$ \\
\hline 2015 & $\mathrm{R} \$ 13.065 .566$ & $\mathrm{R} \$ 7.952 .784$ & $\mathrm{R} \$ 15.063 .962$ & $\mathrm{R} \$ 18.294 .860$ & $\mathrm{R} \$ 17.411 .449$ & $\mathrm{R} \$ 375.252$ & $\mathrm{R} \$ 244.226$ & $\mathrm{R} \$ 2.577 .210$ & $\mathrm{R} \$ 24.437 .348$ & $\mathrm{R} \$ 190.567$ & $\mathrm{R} \$ 87.110$ & $\mathrm{R} \$ 99.700 .334$ \\
\hline & & & & & Valor $\mathbf{P}$ & sente dos & Custos & & & & & \\
\hline $6 \%$ a.a. & $\mathrm{R} \$ 103.724 .872$ & $\mathrm{R} \$ 63.260 .185$ & $\mathrm{R} \$ 119.479 .475$ & $\mathrm{R} \$ 144.341 .499$ & $\mathrm{R} \$ 138.310 .405$ & $\mathrm{R} \$ 2.996 .401$ & $\mathrm{R} \$ 1.928 .756$ & $\mathrm{R} \$ 20.585 .990$ & $\mathrm{R} \$ 193.009 .457$ & $\mathrm{R} \$ 1.496 .937$ & $\mathrm{R} \$ 688.775$ & $\mathrm{R} \$ 789.822 .752$ \\
\hline $12 \%$ a.a. & $\mathrm{R} \$ 62.357 .783$ & $\mathrm{R} \$ 37.988 .022$ & $\mathrm{R} \$ 71.875 .034$ & $\mathrm{R} \$ 86.648 .944$ & $\mathrm{R} \$ 83.267 .239$ & $\mathrm{R} \$ 1.813 .795$ & $\mathrm{R} \$ 1.157 .460$ & $\mathrm{R} \$ 12.372 .578$ & $\mathrm{R} \$ 115.798 .166$ & $\mathrm{R} \$ 898.222$ & $\mathrm{R} \$ 413.844$ & $\mathrm{R} \$ 474.591 .085$ \\
\hline $18 \%$ a.a. & $\mathrm{R} \$ 42.117 .798$ & $\mathrm{R} \$ 25.631 .620$ & $\mathrm{R} \$ 48.574 .854$ & $\mathrm{R} \$ 58.456 .023$ & $\mathrm{R} \$ 56.312 .060$ & $\mathrm{R} \$ 1.232 .372$ & $\mathrm{R} \$ 780.624$ & $\mathrm{R} \$ 8.354 .044$ & $\mathrm{R} \$ 78.078 .390$ & $\mathrm{R} \$ 605.688$ & $\mathrm{R} \$ 279.484$ & $\mathrm{R} \$ 320.422 .955$ \\
\hline
\end{tabular}


- Concessão Programada

\begin{tabular}{|c|c|c|c|c|c|c|c|c|c|c|c|c|}
\hline \multirow{2}{*}{ Ano } & \multicolumn{12}{|c|}{ Tipo de Veículo } \\
\hline & $2 \mathrm{C}$ & $2 \mathrm{~S} 2$ & $2 \mathrm{S3}$ & 3C & $3 \mathrm{S3}$ & $3 \mathrm{~T} 4$ & $\mathbf{M}$ & $\mathbf{O}$ & $\mathbf{P}$ & P3 & P4 & Total \\
\hline 1995 & $\mathrm{R} \$ 5.505 .214$ & $\mathrm{R} \$ 3.364 .677$ & $\mathrm{R} \$ 6.357 .175$ & $\mathrm{R} \$ 7.721 .952$ & $\mathrm{R} \$ 7.345 .369$ & $\mathrm{R} \$ 157.362$ & $\mathrm{R} \$ 103.613$ & $\mathrm{R} \$ 1.095 .959$ & $\mathrm{R} \$ 10.312 .369$ & $\mathrm{R} \$ 79.880$ & $\mathrm{R} \$ 38.383$ & $\mathrm{R} \$ 42.081 .953$ \\
\hline 1996 & $\mathrm{R} \$ 6.440 .339$ & $\mathrm{R} \$ 3.936 .225$ & $\mathrm{R} \$ 7.416 .737$ & $\mathrm{R} \$ 9.030 .365$ & $\mathrm{R} \$ 8.566 .332$ & $\mathrm{R} \$ 196.323$ & $\mathrm{R} \$ 120.470$ & $\mathrm{R} \$ 1.278 .746$ & $\mathrm{R} \$ 12.070 .294$ & $\mathrm{R} \$ 94.078$ & $\mathrm{R} \$ 43.554$ & $\mathrm{R} \$ 49.193 .465$ \\
\hline 1997 & $\mathrm{R} \$ 7.169 .182$ & $\mathrm{R} \$ 4.387 .757$ & $\mathrm{R} \$ 8.262 .796$ & $\mathrm{R} \$ 10.062 .909$ & $\mathrm{R} \$ 9.540 .102$ & $\mathrm{R} \$ 214.429$ & $\mathrm{R} \$ 134.535$ & $\mathrm{R} \$ 1.425 .957$ & $\mathrm{R} \$ 13.458 .863$ & $\mathrm{R} \$ 105.378$ & $\mathrm{R} \$ 48.471$ & $\mathrm{R} \$ 54.810 .379$ \\
\hline 1998 & $\mathrm{R} \$ 7.200 .457$ & $\mathrm{R} \$ 4.425 .682$ & $\mathrm{R} \$ 8.272 .963$ & $\mathrm{R} \$ 10.153 .329$ & $\mathrm{R} \$ 9.532 .012$ & $\mathrm{R} \$ 209.069$ & $\mathrm{R} \$ 136.289$ & $\mathrm{R} \$ 1.434 .945$ & $\mathrm{R} \$ 13.625 .632$ & $\mathrm{R} \$ 106.614$ & $\mathrm{R} \$ 48.006$ & $\mathrm{R} \$ 55.144 .998$ \\
\hline 1999 & 7.728 .349 & $\mathrm{R} \$ 4.759 .984$ & $\mathrm{R} \$ 8.855 .635$ & $\mathrm{R} \$ 10.906 .761$ & $\mathrm{R} \$ 10.196 .496$ & $\mathrm{R} \$ 226.191$ & $\mathrm{R} \$ 147.155$ & $\mathrm{R} \$ 1.539 .144$ & $\mathrm{R} \$ 14.659 .014$ & $\mathrm{R} \$ 113.153$ & $\mathrm{R} \$ 52.878$ & $\mathrm{R} \$ 59.184 .762$ \\
\hline 2000 & $\mathrm{R} \$ 7.683 .720$ & $\mathrm{R} \$ 4.738 .767$ & $\mathrm{R} \$ 8.786 .269$ & $\mathrm{R} \$ 10.847 .650$ & $\mathrm{R} \$ 10.110 .380$ & $\mathrm{R} \$ 225.083$ & $\mathrm{R} \$ 146.078$ & $\mathrm{R} \$ 1.537 .146$ & $\mathrm{R} \$ 14.604 .064$ & $\mathrm{R} \$ 113.068$ & $\mathrm{R} \$ 52.847$ & $\mathrm{R} \$ 58.845 .072$ \\
\hline 2001 & $\mathrm{R} \$ 7.734 .021$ & $\mathrm{R} \$ 4.767 .161$ & $\mathrm{R} \$ 8.844 .619$ & $\mathrm{R} \$ 10.936 .550$ & $\mathrm{R} \$ 10.172 .217$ & $\mathrm{R} \$ 222.988$ & $\mathrm{R} \$ 147.270$ & $\mathrm{R} \$ 1.551 .473$ & $\mathrm{R} \$ 14.744 .334$ & $\mathrm{R} \$ 114.603$ & $\mathrm{R} \$ 52.493$ & $\mathrm{R} \$ 59.287 .729$ \\
\hline 2002 & $\mathrm{R} \$$ 7.988.208 & $\mathrm{R} \$ 4.926 .305$ & $\mathrm{R} \$ 9.132 .365$ & $\mathrm{R} \$ 11.289 .872$ & $\mathrm{R} \$ 10.504 .094$ & $\mathrm{R} \$ 223.248$ & $\mathrm{R} \$ 152.477$ & $\mathrm{R} \$ 1.594 .332$ & $\mathrm{R} \$ 15.215 .948$ & $\mathrm{R} \$ 119.290$ & $\mathrm{R} \$ 55.041$ & $\mathrm{R} \$ 61.201 .181$ \\
\hline 2003 & $\mathrm{R} \$ 7.854 .881$ & $\mathrm{R} \$ 4.841 .041$ & $\mathrm{R} \$ 8.975 .636$ & $\mathrm{R} \$ 11.092 .362$ & $\mathrm{R} \$ 10.325 .195$ & $\mathrm{R} \$ 223.628$ & $\mathrm{R} \$ 149.534$ & $\mathrm{R} \$ 1.569 .688$ & $\mathrm{R} \$ 14.944 .571$ & $\mathrm{R} \$ 117.126$ & $\mathrm{R} \$ 52.599$ & $\mathrm{R} \$ 60.146 .260$ \\
\hline 2004 & $\mathrm{R} \$ 8.223 .451$ & $\mathrm{R} \$ 5.068 .444$ & $\mathrm{R} \$ 9.412 .082$ & $\mathrm{R} \$ 11.620 .534$ & $\mathrm{R} \$ 10.830 .254$ & $\mathrm{R} \$ 225.018$ & $\mathrm{R} \$ 156.343$ & $\mathrm{R} \$ 1.646 .596$ & $\mathrm{R} \$ 15.633 .832$ & $\mathrm{R} \$ 122.277$ & $\mathrm{R} \$ 55.355$ & $\mathrm{R} \$ 62.994 .185$ \\
\hline 2005 & $\mathrm{R} \$ 8.600 .802$ & $\mathrm{R} \$ 5.289 .721$ & $\mathrm{R} \$ 9.866 .586$ & $\mathrm{R} \$ 12.129 .920$ & $\mathrm{R} \$ 11.363 .250$ & $\mathrm{R} \$ 245.765$ & $\mathrm{R} \$ 162.784$ & $\mathrm{R} \$ 1.720 .152$ & $\mathrm{R} \$ 16.301 .254$ & $\mathrm{R} \$ 127.165$ & $\mathrm{R} \$ 57.983$ & $\mathrm{R} \$ 65.865 .382$ \\
\hline 2006 & $\mathrm{R} \$ 8.704 .585$ & $\mathrm{R} \$ 5.365 .329$ & $\mathrm{R} \$ 9.946 .228$ & $\mathrm{R} \$ 12.306 .260$ & $\mathrm{R} \$ 11.439 .269$ & $\mathrm{R} \$ 241.600$ & $\mathrm{R} \$ 165.688$ & $\mathrm{R} \$ 1.742 .238$ & $\mathrm{R} \$ 16.590 .944$ & $\mathrm{R} \$ 128.368$ & $\mathrm{R} \$ 59.997$ & $\mathrm{R} \$ 66.690 .505$ \\
\hline 2007 & $\mathrm{R} \$ 9.277 .317$ & $\mathrm{R} \$ 5.715 .025$ & $\mathrm{R} \$ 10.601 .934$ & $\mathrm{R} \$ 13.104 .049$ & $\mathrm{R} \$ 12.194 .822$ & $\mathrm{R} \$ 260.573$ & $\mathrm{R} \$ 177.079$ & $\mathrm{R} \$ 1.854 .104$ & $\mathrm{R} \$ 17.665 .779$ & $\mathrm{R} \$ 137.684$ & $\mathrm{R} \$ 62.566$ & $\mathrm{R} \$ 71.050 .931$ \\
\hline 2008 & $\mathrm{R} \$ 9.837 .566$ & $\mathrm{R} \$ 6.062 .823$ & $\mathrm{R} \$ 11.258 .154$ & $\mathrm{R} \$ 13.906 .528$ & $\mathrm{R} \$ 12.952 .221$ & $\mathrm{R} \$ 280.659$ & $\mathrm{R} \$ 187.025$ & $\mathrm{R} \$ 1.972 .968$ & $\mathrm{R} \$ 18.719 .663$ & $\mathrm{R} \$ 145.178$ & $\mathrm{R} \$ 67.861$ & $\mathrm{R} \$ 75.390 .648$ \\
\hline 2009 & $\mathrm{R} \$ 10.014 .008$ & $\mathrm{R} \$ 6.169 .782$ & $\mathrm{R} \$ 11.466 .815$ & $\mathrm{R} \$ 14.142 .522$ & $\mathrm{R} \$ 13.199 .871$ & $\mathrm{R} \$ 281.901$ & $\mathrm{R} \$ 190.148$ & $\mathrm{R} \$ 2.003 .391$ & $\mathrm{R} \$ 19.013 .111$ & $\mathrm{R} \$ 147.585$ & $\mathrm{R} \$ 67.899$ & $\mathrm{R} \$ 76.697 .033$ \\
\hline 2010 & $\mathrm{R} \$ 11.154 .364$ & $\mathrm{R} \$ 6.854 .267$ & $\mathrm{R} \$ 12.821 .497$ & $\mathrm{R} \$ 15.710 .769$ & $\mathrm{R} \$ 14.781 .002$ & $\mathrm{R} \$ 306.178$ & $\mathrm{R} \$ 210.168$ & $\mathrm{R} \$ 2.215 .021$ & $\mathrm{R} \$ 21.069 .819$ & $\mathrm{R} \$ 162.701$ & $\mathrm{R} \$ 76.003$ & $\mathrm{R} \$ 85.361 .789$ \\
\hline 2011 & $\mathrm{R} \$ 11.670 .889$ & $\mathrm{R} \$ 7.194 .217$ & $\mathrm{R} \$ 13.336 .534$ & $\mathrm{R} \$ 16.494 .579$ & $\mathrm{R} \$ 15.338 .756$ & $\mathrm{R} \$ 334.575$ & $\mathrm{R} \$ 222.983$ & $\mathrm{R} \$ 2.327 .926$ & $\mathrm{R} \$ 22.243 .735$ & $\mathrm{R} \$ 171.941$ & $\mathrm{R} \$ 80.006$ & $\mathrm{R} \$ 89.416 .143$ \\
\hline 2012 & $\mathrm{R} \$ 12.154 .443$ & $\mathrm{R} \$ 7.488 .937$ & $\mathrm{R} \$ 13.898 .487$ & $\mathrm{R} \$ 17.173 .647$ & $\mathrm{R} \$ 15.987 .448$ & $\mathrm{R} \$ 336.150$ & $\mathrm{R} \$ 231.010$ & $\mathrm{R} \$ 2.434 .849$ & $\mathrm{R} \$ 23.142 .324$ & $\mathrm{R} \$ 179.554$ & $\mathrm{R} \$ 82.850$ & $\mathrm{R} \$ 93.109 .699$ \\
\hline 2013 & $\mathrm{R} \$ 12.630 .221$ & $\mathrm{R} \$ 7.777 .664$ & $\mathrm{R} \$ 14.447 .545$ & $\mathrm{R} \$ 17.831 .293$ & $\mathrm{R} \$ 16.624 .783$ & $\mathrm{R} \$ 355.396$ & $\mathrm{R} \$ 240.056$ & $\mathrm{R} \$ 2.518 .279$ & $\mathrm{R} \$ 24.002 .824$ & $\mathrm{R} \$ 186.380$ & $\mathrm{R} \$ 85.325$ & $\mathrm{R} \$ 96.699 .766$ \\
\hline 2014 & $\mathrm{R} \$ 12.921 .609$ & $\mathrm{R} \$ 7.945 .873$ & $\mathrm{R} \$ 14.826 .057$ & $\mathrm{R} \$ 18.214 .988$ & $\mathrm{R} \$ 17.082 .104$ & $\mathrm{R} \$ 361.044$ & $\mathrm{R} \$ 244.680$ & $\mathrm{R} \$ 2.565 .983$ & $\mathrm{R} \$ 24.460 .187$ & $\mathrm{R} \$ 190.031$ & $\mathrm{R} \$ 85.894$ & $\mathrm{R} \$ 98.898 .450$ \\
\hline 2015 & $\mathrm{R} \$ 12.918 .800$ & $\mathrm{R} \$ 7.898 .084$ & $\mathrm{R} \$ 14.875 .637$ & $\mathrm{R} \$ 18.147 .423$ & $\mathrm{R} \$ 17.171 .739$ & $\mathrm{R} \$ 369.480$ & $\mathrm{R} \$ 242.761$ & $\mathrm{R} \$ 2.554 .852$ & $\mathrm{R} \$ 24.285 .321$ & $\mathrm{R} \$ 189.495$ & $\mathrm{R} \$ 86.662$ & $\mathrm{R} \$ 98.740 .252$ \\
\hline & & & & & Valor $\mathbf{P}$ & resente dos & Custos & & & & & \\
\hline $6 \%$ a.a. & $\mathrm{R} \$ 99.959 .580$ & $\mathrm{R} \$ 61.474 .884$ & $\mathrm{R} \$ 114.598 .588$ & $\mathrm{R} \$ 140.961 .106$ & $\mathrm{R} \$ 131.988 .283$ & $\mathrm{R} \$ 2.857 .632$ & $\mathrm{R} \$ 1.894 .935$ & $\mathrm{R} \$ 19.943 .581$ & $\mathrm{R} \$ 189.435 .830$ & $\mathrm{R} \$ 1.473 .473$ & $\mathrm{R} \$ 679.125$ & $\mathrm{R} \$ 765.267 .017$ \\
\hline $12 \%$ a.a. & $\mathrm{R} \$ 59.988 .627$ & $\mathrm{R} \$ 36.876 .146$ & $\mathrm{R} \$ 68.810 .421$ & $\mathrm{R} \$ 84.556 .674$ & $\mathrm{R} \$ 79.271 .892$ & $\mathrm{R} \$ 1.725 .599$ & $\mathrm{R} \$ 1.136 .315$ & $\mathrm{R} \$ 11.967 .091$ & $\mathrm{R} \$ 113.577 .365$ & $\mathrm{R} \$ 883.737$ & $\mathrm{R} \$ 407.900$ & $\mathrm{R} \$ 459.201 .767$ \\
\hline $18 \%$ a.a. & $\mathrm{R} \$ 40.482 .193$ & $\mathrm{R} \$ 24.871 .402$ & $\mathrm{R} \$ 46.463 .803$ & $\mathrm{R} \$ 57.031 .620$ & $\mathrm{R} \$ 53.543 .485$ & $\mathrm{R} \$ 1.170 .945$ & $\mathrm{R} \$ 766.095$ & $\mathrm{R} \$ 8.073 .356$ & $\mathrm{R} \$ 76.560 .937$ & $\mathrm{R} \$ 595.845$ & $\mathrm{R} \$ 275.453$ & $\mathrm{R} \$ 309.835 .134$ \\
\hline
\end{tabular}


- CREMA

\begin{tabular}{|c|c|c|c|c|c|c|c|c|c|c|c|c|}
\hline \multirow{2}{*}{ Ano } & \multicolumn{12}{|c|}{ Tipo de Veículo } \\
\hline & $2 \mathrm{C}$ & $2 \mathrm{~S} 2$ & $2 \mathrm{S3}$ & 3C & 353 & 3T4 & $\mathbf{M}$ & $\mathbf{O}$ & $\mathbf{P}$ & $\mathbf{P 3}$ & P4 & Total \\
\hline 1995 & .214 & 4.677 & $\$ 6.357 .175$ & 7.721 .952 & $\$ 7.345 .369$ & & $\mathrm{R} \$ 103.613$ & 1.095 .959 & $\$ 10.312 .369$ & $\$ 79.880$ & $\$ 38.383$ & $\$ 42.081 .953$ \\
\hline 1996 & 6.343 .074 & .896 .137 & 285.911 & 8.926 .018 & 8.400 .851 & & 119.487 & 1.264 .643 & \$11.963.495 & $\mathrm{R} \$ 93.311$ & $\$ 43.223$ & $\$ 48.528 .440$ \\
\hline 1997 & 963.901 & 1.294 .914 & 1.974 .413 & $\$ 9.831 .705$ & 9.177 .511 & 206.136 & 132.439 & 1.397 .560 & 13.222 .334 & $R \$ 103.636$ & $\$ 47.723$ & $\$ 53.352 .271$ \\
\hline 1998 & .098 .666 & .374 .800 & 8.126 .920 & $\$ 10.033 .135$ & 9.349 .545 & 205.185 & 135.254 & 1.420 .680 & 13.505 .810 & $\$ 105.697$ & $\$ 47.616$ & 4.403 .307 \\
\hline 1999 & 7.649 .628 & 4.717 .596 & $\mathrm{R} \$ 8.745 .580$ & $\mathrm{R} \$ 10.811 .209$ & $\mathrm{R} \$ 10.059 .549$ & $\$ 223.348$ & $\$ 146.371$ & $\$ 1.526 .916$ & $\$ 14.569 .074$ & $\$ 112.443$ & $\$ 52.556$ & $\$ 58.614 .270$ \\
\hline 2000 & 636.068 & 1.709 .571 & 723.373 & $\mathrm{R} \$ 10.786 .814$ & 10.032 .748 & 93 & 45.618 & 1.528 .380 & 14.552.974 & $\$ 112.616$ & 35 & 89 \\
\hline 2001 & 42.917 & 773.252 & .855 .865 & 10.948 .519 & 10.185 .987 & 223.225 & 147.356 & 1.553 .281 & 14.753 .381 & 114.693 & 2.535 & 351.012 \\
\hline 2002 & 999.918 & 1.933 .898 & 9.147 .487 & $\mathrm{R} \$ 11.305 .196$ & $\mathrm{R} \$ 10.522 .686$ & 223.574 & $\mathrm{R} \$ 152.589$ & $\$ 1.596 .636$ & $\$ 15.228 .100$ & $\$ 119.405$ & 5.095 & 884.583 \\
\hline 2003 & & & 01.106 & 15.798 & 6.769 & 4.244 & 9.717 & 1.572 .961 & 14.965.011 & 117.292 & 52.676 & .179 \\
\hline 2004 & 276.217 & 094.889 & 9.488 .136 & 11.682 .973 & 10.925 .230 & 226.930 & 156.877 & 653.947 & 15.696 .315 & 2.745 & 5.559 & \\
\hline 2005 & 698.886 & 5.335 .134 & 10.006 .597 & $\mathrm{R} \$ 12.241 .976$ & $\mathrm{R} \$ 11.538 .995$ & 249.586 & $\$ 163.787$ & 733.370 & $\$ 16.416 .590$ & $2 \$ 128.019$ & $\$ 58.344$ & 1.283 \\
\hline 2006 & 949.506 & 88.358 & 90.475 & 12.595.164 & .869 .506 & 250.402 & 68.156 & 778.035 & $\$ 16.873 .619$ & 30.526 & 0.959 & 8.454 .707 \\
\hline 2007 & 60.348 & 60.341 & 7.192 & 13.205 .374 & 338.107 & & 7.897 & 67.325 & 9.471 & 38.444 & & \\
\hline 2008 & 9.853 .082 & $\mathrm{R} \$ 6.071 .539$ & $\mathrm{R} \$ 11.279 .400$ & $\mathrm{R} \$ 13.925 .678$ & $\mathrm{R} \$ 12.978 .611$ & $\mathrm{R} \$ 281.182$ & $\mathrm{R} \$ 187.178$ & $\mathrm{R} \$ 1.975 .570$ & $\$ 18.736 .988$ & $\mathrm{R} \$ 145.329$ & $\mathrm{R} \$ 67.926$ & 5.502 .483 \\
\hline 2009 & 9.948 .167 & $\$ 6.134 .802$ & $\mathrm{R} \$ 11.374 .551$ & $\mathrm{R} \$ 14.063 .022$ & $\mathrm{R} \$ 13.084 .991$ & $\$ 279.590$ & $\mathrm{R} \$ 189.500$ & $\mathrm{R} \$ 1.993 .183$ & $\$ 18.938 .110$ & $\mathrm{R} \$ 147.001$ & $R \$ 67.636$ & $\$ 76.220 .553$ \\
\hline 2010 & 0.903 .246 & 5.350 & 67.395 & 15.411 .873 & 339.051 & 7.394 & 07.640 & 178.123 & 9.262 & 160.476 & 75.004 & 4.815 \\
\hline 2011 & & & & & & & & & & & & $\$ 89.577 .633$ \\
\hline 2012 & 12.194.306 & 7.512 .090 & $\mathrm{R} \$ 13.952 .255$ & $\mathrm{R} \$ 17.223 .544$ & $\mathrm{R} \$ 16.054 .029$ & $\mathrm{R} \$ 337.401$ & $\mathrm{R} \$ 231.388$ & $\mathrm{R} \$ 2.441 .874$ & $\$ 23.185 .862$ & $\mathrm{R} \$ 179.922$ & $\mathrm{R} \$ 83.017$ & $\mathrm{R} \$ 93.395 .689$ \\
\hline 2013 & 12.749 .228 & 7.836 .352 & 14.619 .487 & 17.971.066 & $\$ 16.839 .674$ & 359.877 & $\$ 241.268$ & 2.534.382 & \$24.144.144 & $\$ 187.435$ & $\$ 85.781$ & $R \$ 97.568 .694$ \\
\hline 2014 & & & & & $\mathrm{R} \$ 17.376 .215$ & & & & & $\mathrm{R} \$ 191.425$ & $R \$ 86.482$ & $\mathrm{R} \$ 100.080 .343$ \\
\hline 2015 & 13.102.137 & \$ 7.965.409 & 15.109.156 & $\mathrm{R} \$ 18.328 .975$ & $\$ 17.469 .144$ & $\mathrm{R} \$ 376.705$ & 244.581 & $\$ 2.583 .054$ & $\$ 24.472 .979$ & $\mathrm{R} \$ 190.817$ & $\mathrm{R} \$ 87.212$ & $\$ 99.930 .168$ \\
\hline & & & & & & & & & & & & \\
\hline & & \$ 61.419 .673 & $\mathrm{R} \$ 114.430 .613$ & $\mathrm{R} \$ 140.825 .362$ & $\mathrm{R} \$ 131.777 .550$ & $\mathrm{R} \$ 2.852 .407$ & 1.893 .723 & $\mathrm{R} \$ 19.927 .490$ & $\mathrm{R} \$ 189.297 .689$ & $\mathrm{R} \$ 1.472 .455$ & $\mathrm{R} \$ 678.671$ & $\$$ \$ 764.417.699 \\
\hline $12 \%$ a.a. & 59.780 .871 & 36.780 .533 & $\mathrm{R} \$ 68.520 .361$ & $\mathrm{R} \$$ 84.321.211 & $\mathrm{R} \$ 78.907 .487$ & 1.717 .082 & 1.134 .201 & $\mathrm{R} \$ 11.937 .583$ & $\$ 113.339 .720$ & $\mathrm{R} \$ 881.974$ & $\mathrm{R} \$ 407.132$ & $\$ 457.728 .155$ \\
\hline $18 \%$ a.a. & $\$ 40.260 .757$ & $\mathrm{R} \$ 24.769 .676$ & $\$ 46.155 .687$ & $\mathrm{R} \$ 56.781 .195$ & $\$ 53.156 .342$ & KQ 1.102.010 & $\mathrm{R} \$ 763.846$ & & K\$ 10.308 .029 & ב טוקית & $\mathrm{R} \$ 274.640$ & $\mathrm{R} \$ 308.268 .485$ \\
\hline
\end{tabular}


- Concessão Responsiva

\begin{tabular}{|c|c|c|c|c|c|c|c|c|c|c|c|c|}
\hline \multirow{2}{*}{ Ano } & \multicolumn{12}{|c|}{ Tipo de Veículo } \\
\hline & $2 \mathrm{C}$ & $2 \mathrm{~S} 2$ & $2 \mathrm{S3}$ & $3 \mathrm{C}$ & $3 \mathrm{S3}$ & 3 T4 & $\mathbf{M}$ & $\mathbf{O}$ & $\mathbf{P}$ & P3 & P4 & Total \\
\hline 1995 & $\mathrm{R} \$ 5.505 .214$ & $\mathrm{R} \$ 3.364 .677$ & 6.357.175 & $\mathrm{R} \$ 7.721 .952$ & $\mathrm{R} \$ 7.345 .369$ & $\mathrm{R} \$ 157.362$ & $\mathrm{R} \$ 103.613$ & $\mathrm{R} \$ 1.095 .959$ & $\mathrm{R} \$ 10.312 .369$ & $\mathrm{R} \$ 79.880$ & $\$ 38.383$ & $\mathrm{R} \$ 42.081 .953$ \\
\hline 1996 & 6.440 .339 & $\mathrm{R} \$ 3.936 .225$ & 7.416 .737 & $\$ 9.030 .365$ & $\$ 8.566 .332$ & 196.323 & $\mathrm{R} \$ 120.470$ & $\mathrm{R} \$ 1.278 .746$ & $\mathrm{R} \$ 12.070 .294$ & $\mathrm{R} \$ 94.078$ & $\$ 43.554$ & $\$ 49.193 .465$ \\
\hline 1997 & 9.182 & 87.757 & 262.796 & 10.062 .909 & 9.540 .102 & 14.429 & 134.535 & $\$ 1.425 .957$ & 13.458 .863 & 105.378 & 48.471 & 10.379 \\
\hline 1998 & 7.200.457 & 4.425.682 & 8.272 .963 & $\mathrm{R} \$ 10.153 .329$ & $\mathrm{R} \$ 9.532 .012$ & 209.069 & $\mathrm{R} \$ 136.289$ & $\mathrm{R} \$ 1.434 .945$ & $R \$ 13.625 .632$ & $\$ 106.614$ & $\$ 48.006$ & $\$ 55.144 .998$ \\
\hline 1999 & 728.349 & $\mathrm{R} \$ 4.759 .984$ & $\mathrm{R} \$ 8.855 .635$ & $\mathrm{R} \$ 10.906 .761$ & 10.196 .496 & $\mathrm{R} \$ 226.191$ & $\mathrm{R} \$ 147.155$ & $\mathrm{R} \$ 1.539 .144$ & $\mathrm{R} \$ 14.659 .014$ & $\mathrm{R} \$ 113.153$ & $\$ 52.878$ & $\$ 59.184 .762$ \\
\hline 2000 & 3.720 & $\mathrm{R} \$ 4.738 .767$ & $\$ 8.786 .269$ & $\mathrm{R} \$ 10.847 .650$ & \$ 10.110 .380 & $\$ 225.083$ & $\mathrm{R} \$ 146.078$ & $\mathrm{R} \$ 1.537 .146$ & $\mathrm{R} \$ 14.604 .064$ & $\mathrm{R} \$ 113.068$ & $\$ 52.847$ & $\$ 58.845 .072$ \\
\hline 2001 & 7.734 .021 & $\mathrm{R} \$ 4.767 .161$ & 8.844 .619 & $\mathrm{R} \$ 10.936 .550$ & \$10.172.217 & 222.988 & $\mathrm{R} \$ 147.270$ & $\mathrm{R} \$ 1.551 .473$ & $\mathrm{R} \$ 14.744 .334$ & \$114.603 & $\$ 52.493$ & $\$ 59.287 .729$ \\
\hline 2002 & 8.208 & 4.926 .305 & 9.132 .365 & $\mathrm{R} \$ 11.289 .872$ & 10.504.094 & 223.248 & $\$ 152.477$ & 1.594.332 & 15.215.948 & 119.290 & 41 & 201.181 \\
\hline 2003 & 54.881 & 341.041 & 8.975 .636 & 11.092 .362 & 10.325 .195 & 223.628 & 149.534 & 1.569 .688 & $\$ 14.944 .571$ & $\$ 117.126$ & 2.599 & 46.260 \\
\hline 2004 & 8.184 .472 & $\mathrm{R} \$ 5.045 .255$ & $\mathrm{R} \$ 9.360 .090$ & $\mathrm{R} \$ 11.571 .326$ & $\mathrm{R} \$ 10.765 .950$ & 223.843 & $\mathrm{R} \$ 155.969$ & $\mathrm{R} \$ 1.639 .563$ & $\mathrm{R} \$ 15.591 .807$ & \$121.911 & $\$ 55.189$ & $\$ 62.715 .375$ \\
\hline 2005 & 543.152 & $\mathrm{R} \$ 5.261 .395$ & 9.782 .905 & $\mathrm{R} \$ 12.062 .260$ & 11.258 .633 & 243.554 & $\mathrm{R} \$ 162.193$ & 1.712 .400 & $\$ 16.232 .514$ & $\$ 126.651$ & 57.762 & 5.443 .421 \\
\hline 2006 & 5.902 & 3.060 & 9.960 .559 & 321.498 & 11.456 .808 & 241.891 & 165.795 & 1.744 .525 & 5.602 .781 & 128.480 & 50.052 & 1.353 \\
\hline 2007 & 9.276 .204 & 5.714 .325 & $\mathrm{R} \$ 10.600 .534$ & $\$ 13.102 .648$ & 12.193.094 & 260.542 & 177.073 & 1.853 .880 & 17.664 .520 & $\$ 137.675$ & 2.562 & 71.043 .056 \\
\hline 2008 & 9.814.819 & $\mathrm{R} \$ 6.048 .924$ & 11.228.196 & $\mathrm{R} \$ 13.877 .455$ & 12.915.243 & $\$ 279.969$ & $\mathrm{R} \$ 186.807$ & $\mathrm{R} \$ 1.968 .690$ & $\$ 18.695 .675$ & $\$ 144.974$ & $\$ 67.762$ & 75.228 .513 \\
\hline 2009 & 6.803 & 5.127 .646 & 11.359 .740 & 14.048 .333 & 13.066 .759 & 279.262 & 189.389 & 1.990 .994 & $\mathrm{R} \$ 18.925 .970$ & $\$ 146.888$ & $\$ 67.585$ & $\$ 76.139 .368$ \\
\hline 2010 & 10.924 .624 & $\mathrm{R} \$ 6.739 .695$ & $\mathrm{R} \$ 12.494 .608$ & 15.440 .288 & 14.372 .423 & 297.947 & 207.841 & 2.182 .405 & 20.801 .498 & 160.688 & \$75.106 & 83.697 .123 \\
\hline 2011 & 1.696.426 & 7.211 .235 & 13.369.172 & 16.528 .466 & 15.378 .699 & 335.276 & $\$ 223.231$ & 2.333 .018 & $\$ 22.270 .395$ & $\$ 172.193$ & $\$ 80.127$ & $\$ 89.598 .237$ \\
\hline 2012 & 159.491 & 7.492 .220 & 13.905.107 & $\mathrm{R} \$ 17.180 .358$ & 15.995 .588 & 336.292 & 231.064 & 2.435 .832 & $\mathrm{R} \$ 23.147 .931$ & $\$ 179.604$ & 82.872 & 93.146 .360 \\
\hline 2013 & 12.591 .808 & $\mathrm{R} \$ 7.756 .132$ & $\mathrm{R} \$ 14.395 .045$ & $\mathrm{R} \$ 17.783 .991$ & 16.559.589 & $\$ 354.122$ & 239.685 & 2.511 .803 & $\mathrm{R} \$ 23.960 .155$ & $\$ 186.041$ & $\$ 85.167$ & $\mathrm{R} \$ 96.423 .538$ \\
\hline 2014 & 6.184 & 2.865 & 4.560 .797 & 17.996.024 & 6.750 .746 & 354.257 & 242.800 & 2.539 .935 & $\$ 24.242 .301$ & 188.367 & $\$ 85.1$ & $\$ 97.549 .462$ \\
\hline 2015 & $\mathrm{R} \$ 12.524 .336$ & $\mathrm{R} \$ 7.714 .799$ & $\mathrm{R} \$ 14.320 .508$ & $\mathrm{R} \$ 17.697 .322$ & $\mathrm{R} \$ 16.474 .895$ & $\mathrm{R} \$ 354.416$ & $\mathrm{R} \$ 238.751$ & & & & & \\
\hline & & & & & & & & & & & & \\
\hline 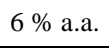 & & & & & & & & & & & & \\
\hline $12 \%$ a.a. & 59.850 .101 & 36.806 .929 & 68.614 .605 & $\$ 84.393 .647$ & 79.027 .141 & $\mathrm{R} \$ 1.720 .561$ & $\mathrm{R} \$ 1.134 .922$ & $\mathrm{R} \$ 11.947 .002$ & $\mathrm{R} \$ 113.417 .143$ & $\$ 882.520$ & $\mathrm{R} \$ 407.366$ & $\mathrm{R} \$ 458.201 .937$ \\
\hline $18 \%$ a.a. & $\mathrm{k} \$ 40.423 .046$ & $\mathrm{R} \$ 24.841 .562$ & $\mathrm{R} \$ 46.380 .267$ & $\mathrm{R} \$ 56.961 .733$ & $\$ 53.439 .133$ & $\mathrm{R} \$ 1.168 .808$ & $\mathrm{R} \$ 765.501$ & $\mathrm{R} \$ 8.064 .704$ & $\mathrm{R} \$ 76.492 .625$ & $\mathrm{R} \$ 595.323$ & $\mathrm{R} \$ 275.224$ & $\mathrm{R} \$ 309.407 .92$ \\
\hline
\end{tabular}




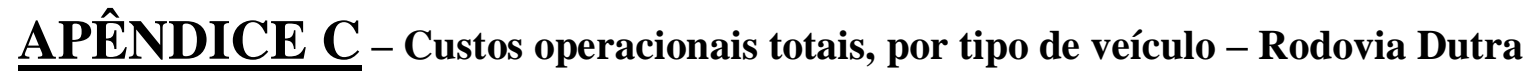

- Condição Base - IRI 6

\begin{tabular}{|c|c|c|c|c|c|c|c|c|c|c|c|c|}
\hline \multirow{2}{*}{ Ano } & \multicolumn{12}{|c|}{ Tipo de Veículo } \\
\hline & $2 \mathrm{C}$ & $2 S 2$ & $2 \mathrm{S3}$ & $3 \mathrm{C}$ & 353 & $3 \mathrm{~T} 4$ & $\mathbf{M}$ & O & $\mathbf{P}$ & $\mathbf{P 3}$ & P4 & Total \\
\hline 1995 & $\mathrm{R} \$ 2.353 .254$ & 688.030 & .023 .230 & $\mathrm{R} \$ 6.260 .374$ & $\mathrm{R} \$ 5.744 .139$ & $\mathrm{R} \$ 142.455$ & $\mathrm{R} \$ 95.835$ & $\$ 4.387 .978$ & $\mathrm{R} \$ 9.592 .499$ & $\mathrm{R} \$ 74.328$ & $\$ 35.013$ & $\$ 36.397 .135$ \\
\hline 1996 & 2.810 .069 & 3.184 .175 & & 7.416.082 & 6.872 .696 & 62.201 & $\mathrm{R} \$ 113.385$ & 5.234 .096 & $\$ 11.354 .876$ & 89.347 & 39.789 & 43.269 .401 \\
\hline 1997 & 3.228 .595 & 3.612 .792 & 6.866 .112 & $\mathrm{R} \$ 8.373 .395$ & $\$ 7.902 .460$ & $\$ 183.272$ & 128.375 & $\$ 6.013 .428$ & $\$ 12.846 .896$ & $\mathrm{R} \$ 100.197$ & $\$ 46.681$ & $\mathrm{R} \$ 49.302 .204$ \\
\hline 1998 & & 3.492 .783 & 95.074 & 8.108 .040 & 7.270 .451 & 164.082 & 126.057 & 5.669 .125 & 12.540 .549 & $\mathrm{R} \$ 98.026$ & 44.903 & $\$ 46.927 .626$ \\
\hline 1999 & 3.264 .439 & 3.785 .050 & 6.912 .560 & $\$ 8.776 .112$ & 7.859 .935 & $\$ 179.390$ & $\$ 135.785$ & $\$ 6.133 .605$ & $\$ 13.554 .235$ & $\mathrm{R} \$ 105.975$ & $\$ 49.232$ & 0.756 .318 \\
\hline 2000 & 3.263 .693 & 783.703 & & & & & & 6.133 .652 & $\$ 13.535 .513$ & $\$ 106.410$ & 49.437 & 36.675 \\
\hline 2001 & & & & & & & & & & & & \\
\hline 2002 & 49.144 & 6.519 & & 40.267 & 8.374 .646 & & 2.526 & 9.037 & 17.116 & 111.202 & 49.791 & 86.657 \\
\hline 2003 & 448.910 & 3.953 .118 & 7.363 .284 & 9.187 .610 & 8.415 .751 & $\$ 189.140$ & 40.361 & 6.432 .244 & 4.085 .359 & $\$ 110.301$ & .252 & 3.376 .329 \\
\hline 2004 & & 190.723 & 914.903 & 744.305 & 9.093 .399 & & & 6.925 .998 & & & & \\
\hline 2005 & 80.785 & .145 .053 & & 626.714 & 8.626 .054 & & 148.834 & 6.735 .363 & 4.881 .923 & 115.689 & & 5.695 .156 \\
\hline 2006 & & & & & & & & & & & & \\
\hline 2007 & 39.153 & 4.556 .994 & 3.361 .002 & $\mathrm{R} \$ 10.578 .088$ & $\mathrm{R} \$ 9.512 .437$ & 210.803 & & 7.406 .294 & & $\$ 127.954$ & 57.972 & 1.234 .556 \\
\hline 2008 & 4.224.828 & $\$ 4.876 .217$ & $\$ 8.990 .440$ & $\mathrm{R} \$ 11.316 .460$ & $\mathrm{R} \$ 10.245 .901$ & $\mathrm{R} \$ 230.697$ & 173.795 & 7.916 .253 & $\mathrm{R} \$ 17.417 .442$ & $\mathrm{R} \$ 135.242$ & $\$ 62.883$ & $\$ \$ 65.590 .159$ \\
\hline 2009 & & & & & & & & & & & & $\$ 67.594 .969$ \\
\hline 2010 & .898 .390 & 5.554 .149 & 10.452 .068 & $\mathrm{R} \$ 12.945 .910$ & $\mathrm{R} \$ 11.983 .183$ & & 97.894 & $\mathrm{R} \$ 9.110 .816$ & $\$ 19.821 .786$ & $\$ 153.787$ & 70.493 & 5.462 .841 \\
\hline 2011 & .511 .649 & 6.141 .957 & $\mathrm{R} \$ 11.694 .347$ & $\mathrm{R} \$ 14.108 .797$ & $\mathrm{R} \$ 13.481 .719$ & $\mathrm{R} \$ 305.997$ & $\mathrm{R} \$ 217.198$ & $\mathrm{R} \$ 10.286 .617$ & $\mathrm{R} \$ 21.695 .385$ & $\mathrm{R} \$ 166.607$ & & $\$ 83.686 .203$ \\
\hline 2012 & & 5.949 .332 & $\mathrm{R} \$ 10.891 .106$ & & $\mathrm{R} \$ 12.382 .517$ & & & & & $\mathrm{R} \$ 165.189$ & & $\$ 79.928 .875$ \\
\hline 2013 & 5.101 & 78.612 & 10.762 & 342.057 & 12.863 .653 & 84.828 & 1.856 & $\mathrm{R} \$ 10.040 .614$ & $\mathrm{R} \$ 22.142 .065$ & $\mathrm{R} \$ 172.911$ & \$ 79.299 & 2.971.757 \\
\hline 2014 & & & 11.599 .282 & 14.649.022 & $\mathrm{R} \$ 13.205 .504$ & & & & & & & $\$ 84.852 .548$ \\
\hline 2015 & 5.473 .237 & $\mathrm{R} \$ 6.301 .040$ & 11.680 .425 & $\$ 14.638 .234$ & $\mathrm{R} \$ 13.330 .011$ & $\mathrm{R} \$ 295.499$ & $\mathrm{R} \$ 224.933$ & $\$ 10.232 .452$ & $\mathrm{R} \$ 22.485 .708$ & $\$ 175.533$ & $\$ 80.436$ & $\mathrm{R} \$ 84.917 .507$ \\
\hline & & & & & Valor 1 & Presente dos C & osito & & & & & \\
\hline $6 \%$ a.a. & & & & & $\mathrm{R} \$ 104.725 .837$ & $\mathrm{R} \$ 2.403 .579$ & $\mathrm{R} \$ 1.768 .893$ & & & & & \\
\hline $12 \%$ a.a. & 25.897 .263 & 29.691 .780 & $\mathrm{R} \$ 55.056 .435$ & $\mathrm{R} \$ 68.925 .008$ & 62.867.882 & $\mathrm{R} \$ 1.450 .486$ & $\mathrm{R} \$ 1.060 .912$ & 48.478 .849 & $\mathrm{R} \$ 106.049 .054$ & 827.146 & $\mathrm{R} \$ 380.083$ & $\mathrm{R} \$ 400.684 .897$ \\
\hline $18 \%$ a.a. & $\mathrm{R} \$ 17.476 .904$ & $\mathrm{R} \$ 20.021 .108$ & $\mathrm{R} \$ 37.159 .310$ & $\mathrm{R} \$ 46.486 .278$ & $\mathrm{R} \$ 42.442 .668$ & $\mathrm{R} \$ 984.023$ & $\mathrm{R} \$ 715.349$ & $\mathrm{R} \$ 32.704 .504$ & $\mathrm{R} \$ 71.505 .852$ & $\mathrm{R} \$ 558.010$ & $\mathrm{R} \$ 256.622$ & $\mathrm{R} \$ 270.310 .629$ \\
\hline
\end{tabular}


- $\quad$ Condição Base - IRI 8

\begin{tabular}{|c|c|c|c|c|c|c|c|c|c|c|c|c|}
\hline \multirow{2}{*}{ Ano } & \multicolumn{12}{|c|}{ Tipo de Veículo } \\
\hline & $2 \mathrm{C}$ & $2 \mathrm{~S} 2$ & $2 \mathrm{S3}$ & 3C & $3 \mathrm{S3}$ & 3T4 & $\mathbf{M}$ & $\mathbf{O}$ & $\mathbf{P}$ & $\mathbf{P 3}$ & P4 & Total \\
\hline 1995 & $\mathrm{R} \$ 2.353 .254$ & $\mathrm{R} \$ 2.688 .030$ & $\mathrm{R} \$ 5.023 .230$ & $\mathrm{R} \$ 6.260 .374$ & $\mathrm{R} \$ 5.744 .139$ & $\mathrm{R} \$ 142.455$ & $\mathrm{R} \$ 95.835$ & $\mathrm{R} \$ 4.387 .978$ & $\mathrm{R} \$ 9.592 .499$ & $\mathrm{R} \$ 74.328$ & $\mathrm{R} \$ 35.013$ & $\mathrm{R} \$ 36.397 .135$ \\
\hline 1996 & $\mathrm{R} \$ 2.810 .069$ & $\mathrm{R} \$ 3.184 .175$ & $\mathrm{R} \$ 5.992 .686$ & $\mathrm{R} \$ 7.416 .082$ & $\mathrm{R} \$ 6.872 .696$ & $\mathrm{R} \$ 162.201$ & $\mathrm{R} \$ 113.385$ & $\mathrm{R} \$ 5.234 .096$ & $\mathrm{R} \$ 11.354 .876$ & $\mathrm{R} \$ 89.347$ & $\mathrm{R} \$ 39.789$ & $\mathrm{R} \$ 43.269 .401$ \\
\hline 1997 & $\mathrm{R} \$ 3.228 .595$ & $\mathrm{R} \$ 3.612 .792$ & $\mathrm{R} \$ 6.866 .112$ & $\mathrm{R} \$ 8.373 .395$ & $\mathrm{R} \$ 7.902 .460$ & $\mathrm{R} \$ 183.272$ & $\mathrm{R} \$ 128.375$ & $\mathrm{R} \$ 6.013 .428$ & $\mathrm{R} \$ 12.846 .896$ & $\mathrm{R} \$ 100.197$ & $\mathrm{R} \$ 46.681$ & $\mathrm{R} \$ 49.302 .204$ \\
\hline 1998 & $\mathrm{R} \$ 3.477 .244$ & $\mathrm{R} \$ 3.855 .340$ & $\mathrm{R} \$ 7.373 .415$ & $\mathrm{R} \$ 8.757 .168$ & $\mathrm{R} \$ 8.516 .444$ & $\mathrm{R} \$ 193.330$ & $\mathrm{R} \$ 134.887$ & $\mathrm{R} \$ 6.505 .165$ & $\mathrm{R} \$ 13.467 .811$ & $\mathrm{R} \$ 104.064$ & $\mathrm{R} \$ 47.347$ & $\mathrm{R} \$ 52.432 .214$ \\
\hline 1999 & $\mathrm{R} \$ 3.259 .336$ & $\mathrm{R} \$ 3.779 .198$ & $\mathrm{R} \$ 6.900 .505$ & $\mathrm{R} \$ 8.763 .977$ & $\mathrm{R} \$ 7.845 .123$ & $\mathrm{R} \$ 179.016$ & $\mathrm{R} \$ 135.690$ & $\mathrm{R} \$ 6.122 .739$ & $\mathrm{R} \$ 13.544 .012$ & $\mathrm{R} \$ 105.873$ & $\mathrm{R} \$ 49.182$ & $\mathrm{R} \$ 50.684 .651$ \\
\hline 2000 & $\mathrm{R} \$ 3.256 .776$ & $\mathrm{R} \$ 3.776 .333$ & $\mathrm{R} \$ 6.896 .837$ & $\mathrm{R} \$ 8.755 .796$ & $\mathrm{R} \$ 7.842 .237$ & $\mathrm{R} \$ 179.930$ & $\mathrm{R} \$ 135.294$ & $\mathrm{R} \$ 6.120 .029$ & $\mathrm{R} \$ 13.520 .892$ & $\mathrm{R} \$ 106.278$ & $\mathrm{R} \$ 49.374$ & $\mathrm{R} \$ 50.639 .775$ \\
\hline 2001 & $\mathrm{R} \$ 3.296 .420$ & $\mathrm{R} \$ 3.824 .284$ & $\mathrm{R} \$ 6.994 .787$ & $\mathrm{R} \$ 8.865 .642$ & $\mathrm{R} \$ 7.955 .710$ & $\mathrm{R} \$ 180.058$ & $\mathrm{R} \$ 136.840$ & $\mathrm{R} \$ 6.204 .102$ & $\mathrm{R} \$ 13.681 .406$ & $\mathrm{R} \$ 106.146$ & $\mathrm{R} \$ 49.313$ & $\mathrm{R} \$ 51.294 .709$ \\
\hline 2002 & $\mathrm{R} \$ 3.409 .174$ & $\mathrm{R} \$ 3.952 .427$ & $\mathrm{R} \$ 7.241 .744$ & $\mathrm{R} \$ 9.155 .733$ & $\mathrm{R} \$ 8.242 .751$ & $\mathrm{R} \$ 196.734$ & $\mathrm{R} \$ 141.654$ & $\mathrm{R} \$ 6.415 .791$ & $\mathrm{R} \$ 14.117 .564$ & $\mathrm{R} \$ 110.465$ & $\mathrm{R} \$ 49.481$ & $\mathrm{R} \$ 53.033 .518$ \\
\hline 2003 & $\mathrm{R} \$ 3.393 .279$ & $\mathrm{R} \$ 3.913 .094$ & $\mathrm{R} \$ 7.232 .291$ & $\mathrm{R} \$ 9.079 .461$ & $\mathrm{R} \$ 8.247 .276$ & $\mathrm{R} \$ 185.221$ & $\mathrm{R} \$ 139.166$ & $\mathrm{R} \$ 6.352 .002$ & $\mathrm{R} \$ 13.956 .428$ & $\mathrm{R} \$ 109.369$ & $\mathrm{R} \$ 49.857$ & $\mathrm{R} \$ 52.657 .443$ \\
\hline 2004 & $\mathrm{R} \$ 3.601 .183$ & $\mathrm{R} \$ 4.123 .745$ & $\mathrm{R} \$ 7.685 .666$ & $\mathrm{R} \$ 9.587 .584$ & $\mathrm{R} \$ 8.788 .210$ & $\mathrm{R} \$ 206.234$ & $\mathrm{R} \$ 147.260$ & $\mathrm{R} \$ 6.718 .039$ & $\mathrm{R} \$ 14.700 .957$ & $\mathrm{R} \$ 114.796$ & $\mathrm{R} \$ 52.654$ & $\mathrm{R} \$ 55.726 .328$ \\
\hline 2005 & $\mathrm{R} \$ 3.885 .085$ & $\mathrm{R} \$ 4.356 .893$ & $\mathrm{R} \$ 8.254 .248$ & $\mathrm{R} \$ 10.135 .155$ & $\mathrm{R} \$ 9.489 .036$ & $\mathrm{R} \$ 214.255$ & $\mathrm{R} \$ 155.159$ & $\mathrm{R} \$ 7.224 .715$ & $\mathrm{R} \$ 15.534 .823$ & $\mathrm{R} \$ 120.251$ & $\mathrm{R} \$ 55.421$ & $\mathrm{R} \$ 59.425 .040$ \\
\hline 2006 & $\mathrm{R} \$ 4.426 .115$ & $\mathrm{R} \$ 4.938 .973$ & $\mathrm{R} \$ 9.429 .631$ & $\mathrm{R} \$ 11.068 .673$ & $\mathrm{R} \$ 10.893 .913$ & $\mathrm{R} \$ 257.979$ & $\mathrm{R} \$ 168.490$ & $\mathrm{R} \$ 8.363 .673$ & $\mathrm{R} \$ 16.913 .413$ & $\mathrm{R} \$ 130.309$ & $\mathrm{R} \$ 59.956$ & $\mathrm{R} \$ 66.651 .124$ \\
\hline 2007 & $\mathrm{R} \$ 3.913 .762$ & $\mathrm{R} \$ 4.530 .760$ & $\mathrm{R} \$ 8.298 .382$ & $\mathrm{R} \$ 10.520 .157$ & $\mathrm{R} \$ 9.434 .656$ & $\mathrm{R} \$ 208.953$ & $\mathrm{R} \$ 162.852$ & $\mathrm{R} \$ 7.358 .766$ & $\mathrm{R} \$ 16.264 .923$ & $\mathrm{R} \$ 127.469$ & $\mathrm{R} \$ 57.750$ & $\mathrm{R} \$ 60.878 .431$ \\
\hline 2008 & $\mathrm{R} \$ 4.153 .988$ & $\mathrm{R} \$ 4.812 .946$ & $\mathrm{R} \$ 8.806 .053$ & $\mathrm{R} \$ 11.163 .824$ & $\mathrm{R} \$ 10.014 .437$ & $\mathrm{R} \$ 225.303$ & $\mathrm{R} \$ 172.293$ & $\mathrm{R} \$ 7.814 .366$ & $\mathrm{R} \$ 17.245 .060$ & $\mathrm{R} \$ 133.932$ & $\mathrm{R} \$ 62.302$ & $\mathrm{R} \$$ 64.604.505 \\
\hline 2009 & $\mathrm{R} \$ 4.240 .774$ & $\mathrm{R} \$ 4.911 .293$ & $\mathrm{R} \$ 8.998 .452$ & $\mathrm{R} \$ 11.383 .867$ & $\mathrm{R} \$ 10.239 .935$ & $\mathrm{R} \$ 226.421$ & $\mathrm{R} \$ 175.804$ & $\mathrm{R} \$ 7.969 .128$ & $\mathrm{R} \$ 17.559 .471$ & $\mathrm{R} \$ 135.966$ & $\mathrm{R} \$ 62.327$ & $\mathrm{R} \$ 65.903 .437$ \\
\hline 2010 & $\mathrm{R} \$ 4.716 .489$ & $\mathrm{R} \$ 5.439 .256$ & $\mathrm{R} \$ 10.059 .225$ & $\mathrm{R} \$ 12.632 .417$ & $\mathrm{R} \$ 11.469 .800$ & $\mathrm{R} \$ 262.127$ & $\mathrm{R} \$ 194.050$ & $\mathrm{R} \$ 8.829 .871$ & $\mathrm{R} \$ 19.429 .083$ & $\mathrm{R} \$ 151.064$ & $\mathrm{R} \$ 69.338$ & $\mathrm{R} \$ 73.252 .721$ \\
\hline 2011 & $\mathrm{R} \$ 5.145 .901$ & $\mathrm{R} \$ 5.899 .355$ & $\mathrm{R} \$ 10.987 .392$ & $\mathrm{R} \$ 13.709 .833$ & $\mathrm{R} \$ 12.560 .836$ & $\mathrm{R} \$ 284.268$ & $\mathrm{R} \$ 210.275$ & $\mathrm{R} \$ 9.601 .246$ & $\mathrm{R} \$ 21.022 .472$ & $\mathrm{R} \$ 162.569$ & $\mathrm{R} \$ 74.340$ & $\mathrm{R} \$ 79.658 .487$ \\
\hline 2012 & $\mathrm{R} \$ 5.495 .172$ & $\mathrm{R} \$ 6.205 .010$ & $\mathrm{R} \$ 11.702 .792$ & $\mathrm{R} \$ 14.465 .535$ & $\mathrm{R} \$ 13.429 .023$ & $\mathrm{R} \$ 309.487$ & $\mathrm{R} \$ 220.855$ & $\mathrm{R} \$ 10.217 .868$ & $\mathrm{R} \$ 22.143 .256$ & $\mathrm{R} \$ 170.826$ & $\mathrm{R} \$ 77.469$ & $\mathrm{R} \$ 84.437 .292$ \\
\hline 2013 & $\mathrm{R} \$ 6.016 .751$ & $\mathrm{R} \$ 6.682 .305$ & $\mathrm{R} \$ 12.756 .304$ & $\mathrm{R} \$ 15.286 .649$ & $\mathrm{R} \$ 14.717 .067$ & $\mathrm{R} \$ 327.620$ & $\mathrm{R} \$ 235.088$ & $\mathrm{R} \$ 11.243 .674$ & $\mathrm{R} \$ 23.512 .803$ & $\mathrm{R} \$ 181.815$ & $\mathrm{R} \$ 82.924$ & $\mathrm{R} \$ 91.043 .001$ \\
\hline 2014 & $\mathrm{R} \$ 7.244 .645$ & $\mathrm{R} \$ 8.201 .094$ & $\mathrm{R} \$ 15.560 .131$ & $\mathrm{R} \$ 18.056 .525$ & $\mathrm{R} \$ 17.915 .074$ & $\mathrm{R} \$ 410.422$ & $\mathrm{R} \$ 270.848$ & $\mathrm{R} \$ 13.914 .299$ & $\mathrm{R} \$ 27.236 .243$ & $\mathrm{R} \$ 207.277$ & $\mathrm{R} \$ 92.462$ & $\mathrm{R} \$ 109.109 .021$ \\
\hline 2015 & $\mathrm{R} \$ 5.313 .293$ & $\mathrm{R} \$ 6.161 .042$ & $\mathrm{R} \$ 11.272 .146$ & $\mathrm{R} \$ 14.296 .902$ & $\mathrm{R} \$ 12.815 .868$ & $\mathrm{R} \$ 283.675$ & $\mathrm{R} \$ 221.546$ & $\mathrm{R} \$$ 9.997.286 & $\mathrm{R} \$ 22.101 .522$ & $\mathrm{R} \$ 172.601$ & $\mathrm{R} \$ 79.150$ & $\mathrm{R} \$ 82.715 .031$ \\
\hline \multicolumn{13}{|c|}{ Valor Presente dos Custos } \\
\hline $6 \%$ a.a. & $\$ 44.459 .502$ & $\mathrm{R} \$ 50.720 .972$ & $\mathrm{R} \$ 94.562 .544$ & $\mathrm{R} \$ 117.043 .059$ & $\mathrm{R} \$ 108.201 .451$ & $\mathrm{R} \$ 2.484 .400$ & $\mathrm{R} \$ 1.797 .763$ & $\mathrm{R} \$ 83.362 .401$ & $\mathrm{R} \$ 179.835 .327$ & $\mathrm{R} \$ 1.397 .988$ & $\mathrm{R} \$ 640.645$ & $\mathrm{R} \$ 684.506 .053$ \\
\hline $12 \%$ a.a. & $\mathrm{R} \$ 26.549 .258$ & $\mathrm{R} \$ 30.273 .094$ & $\mathrm{R} \$ 56.458 .030$ & $\mathrm{R} \$ 69.943 .487$ & $\mathrm{R} \$ 64.605 .946$ & $\mathrm{R} \$ 1.491 .063$ & $\mathrm{R} \$ 1.074 .728$ & $\mathrm{R} \$ 49.736 .617$ & $\mathrm{R} \$ 107.493 .256$ & $\mathrm{R} \$ 836.575$ & $\mathrm{R} \$ 383.885$ & $\mathrm{R} \$ 408.845 .939$ \\
\hline $18 \%$ a.a. & $\mathrm{R} \$ 17.861 .871$ & $\mathrm{R} \$ 20.351 .776$ & $\mathrm{R} \$ 37.982 .287$ & $\mathrm{R} \$ 47.062 .540$ & $\mathrm{R} \$ 43.472 .025$ & $\mathrm{R} \$ 1.008 .115$ & $\mathrm{R} \$ 723.221$ & $\mathrm{R} \$ 33.437 .064$ & $\mathrm{R} \$ 72.330 .716$ & $\mathrm{R} \$ 563.357$ & $\mathrm{R} \$ 258.775$ & $\mathrm{R} \$ 275.051 .747$ \\
\hline
\end{tabular}


- Concessão Programada

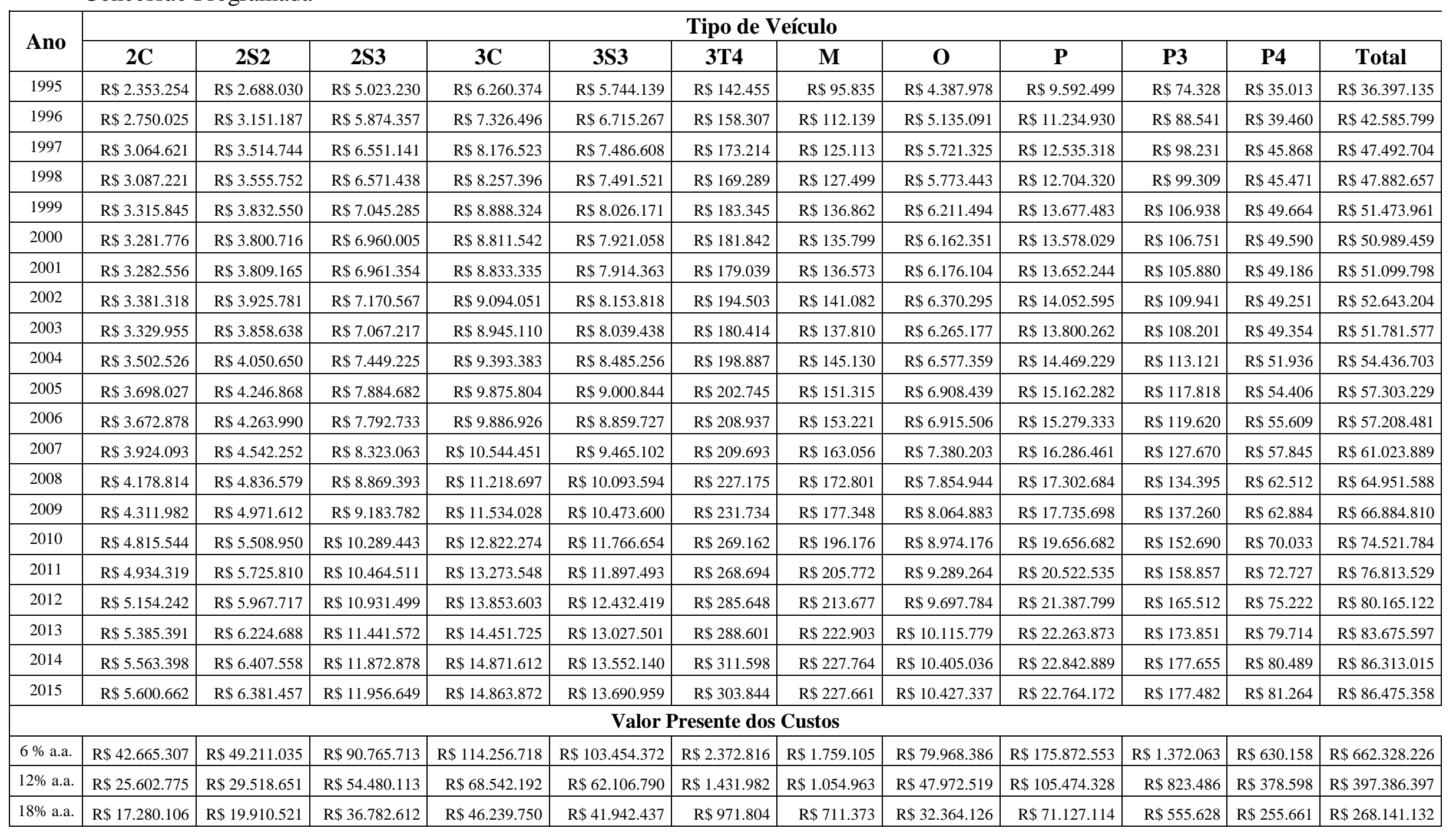


- CREMA

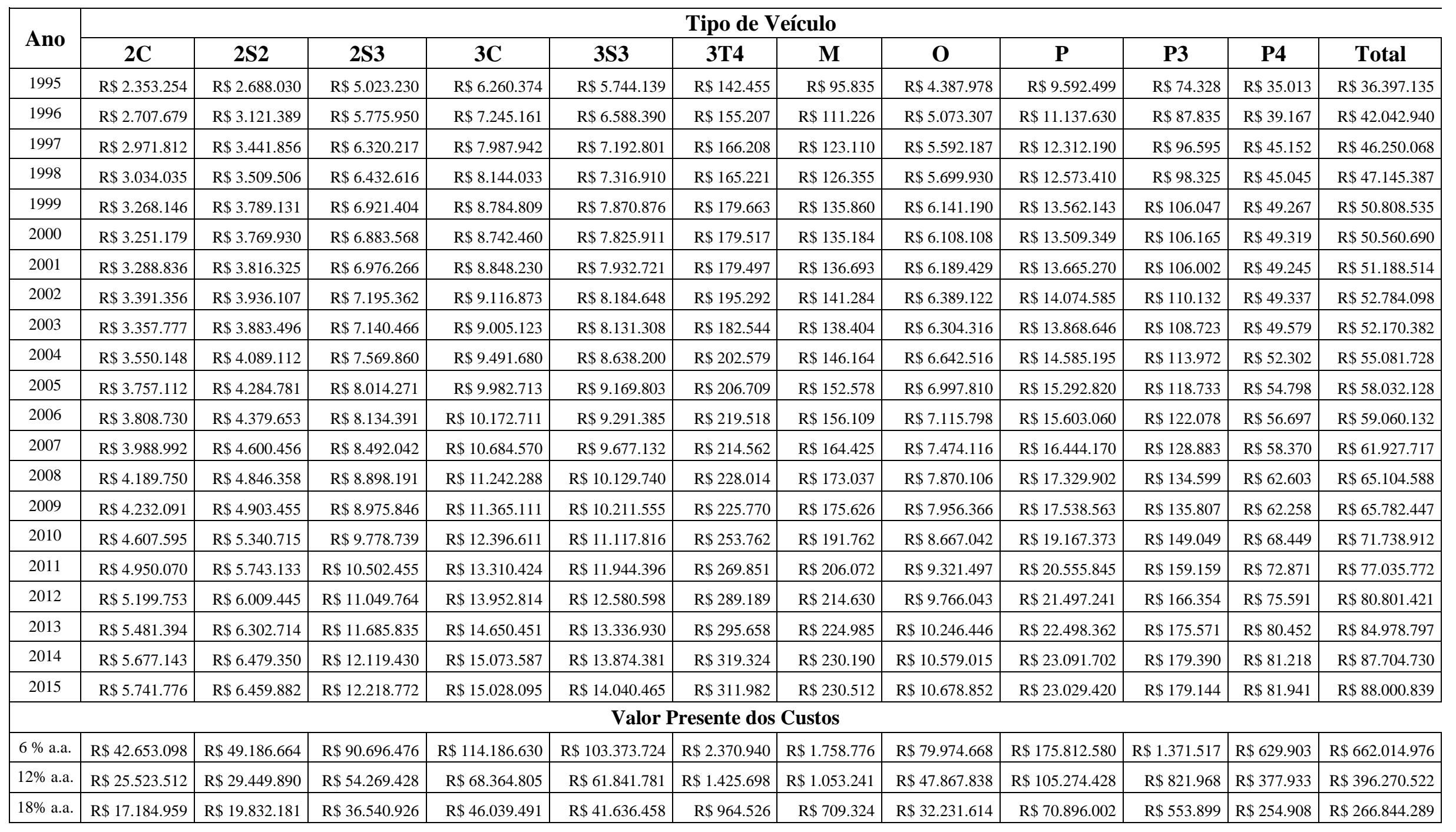


- Concessão Responsiva

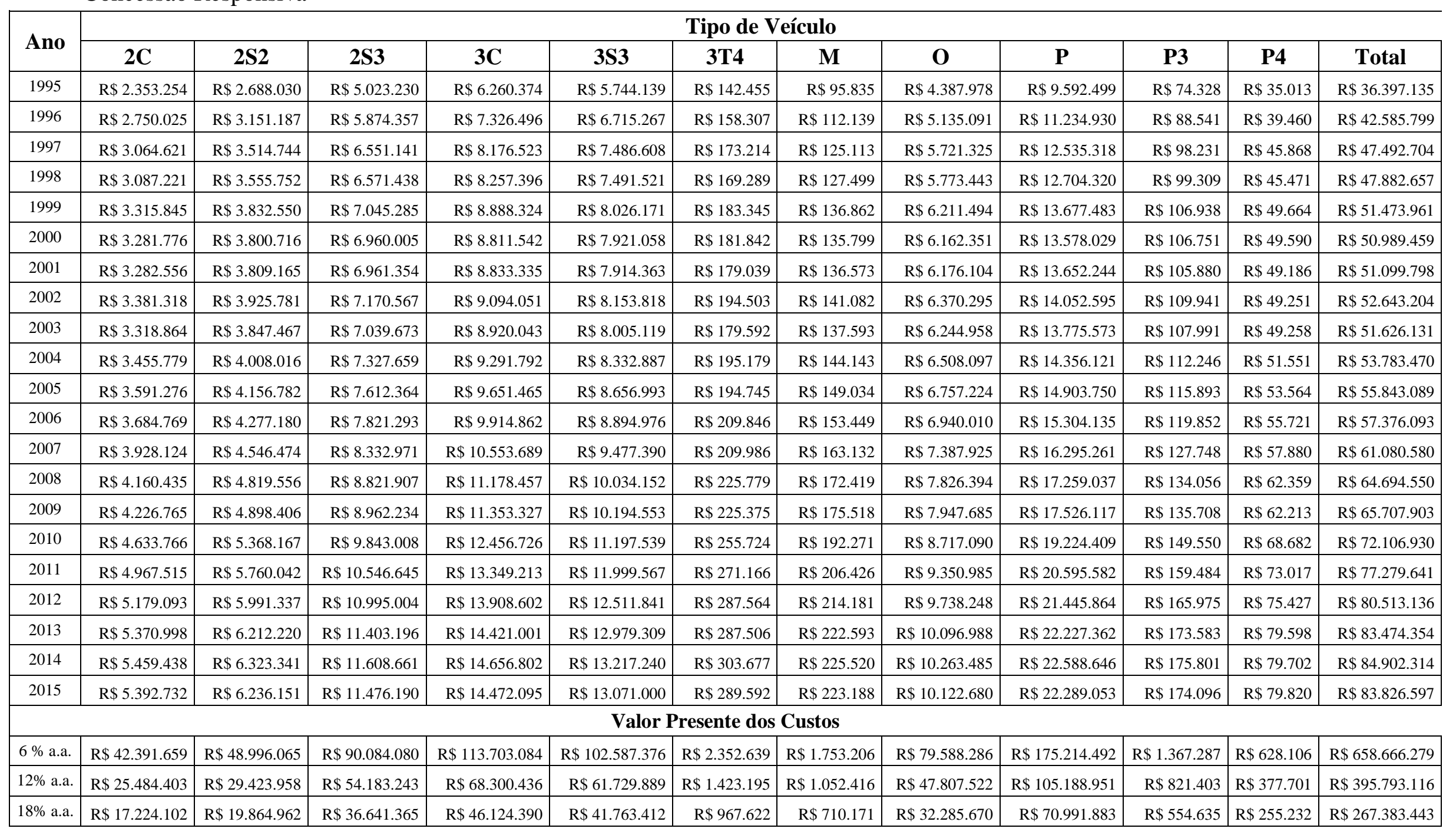




\section{APÊNDICE D - Custos operacionais totais, por tipo de veículo - Rodovia Fernão Dias}

- Condição Base - IRI 6

\begin{tabular}{|c|c|c|c|c|c|c|c|c|c|c|c|c|}
\hline \multirow{2}{*}{ Ano } & \multicolumn{12}{|c|}{ Tipo de Veículo } \\
\hline & $2 \mathrm{C}$ & $2 \mathrm{~S} 2$ & $2 \mathrm{S3}$ & $3 \mathrm{C}$ & $3 S 3$ & 3T4 & $\mathbf{M}$ & $\mathbf{O}$ & $\mathbf{P}$ & P3 & P4 & Total \\
\hline 1995 & $\mathrm{R} \$ 4.126 .109$ & $\mathrm{R} \$ 3.150 .989$ & $\mathrm{R} \$ 5.973 .541$ & $\mathrm{R} \$ 7.253 .689$ & $\mathrm{R} \$ 6.914 .757$ & $\mathrm{R} \$ 153.382$ & $\mathrm{R} \$ 97.390$ & $\mathrm{R} \$ 3.086 .769$ & $\mathrm{R} \$ 9.686 .037$ & $\mathrm{R} \$ 75.508$ & $\mathrm{R} \$ 34.031$ & $\mathrm{R} \$ 40.552 .201$ \\
\hline 1996 & $\mathrm{R} \$ 4.931 .889$ & $\mathrm{R} \$ 3.745 .744$ & $\mathrm{R} \$ 7.145 .589$ & $\mathrm{R} \$ 8.597 .056$ & $\mathrm{R} \$ 8.319 .211$ & $\mathrm{R} \$ 180.171$ & $\mathrm{R} \$ 115.003$ & $\mathrm{R} \$ 3.668 .219$ & $\mathrm{R} \$ 11.465 .008$ & $\mathrm{R} \$ 89.469$ & $\mathrm{R} \$ 40.098$ & $\mathrm{R} \$ 48.297 .457$ \\
\hline 1997 & $\mathrm{R} \$ 5.626 .115$ & $\mathrm{R} \$ 4.255 .434$ & $\mathrm{R} \$ 8.178 .601$ & $\mathrm{R} \$ 9.711 .264$ & $\mathrm{R} \$ 9.563 .164$ & $\mathrm{R} \$ 208.129$ & $\mathrm{R} \$ 128.945$ & $\mathrm{R} \$ 4.187 .977$ & $\mathrm{R} \$ 12.939 .489$ & $\mathrm{R} \$ 100.539$ & $\mathrm{R} \$ 46.029$ & $\mathrm{R} \$ 54.945 .686$ \\
\hline 1998 & $\mathrm{R} \$ 5.943 .033$ & $\mathrm{R} \$ 4.475 .038$ & $\mathrm{R} \$ 8.678 .085$ & $\mathrm{R} \$ 10.107 .937$ & $\mathrm{R} \$ 10.148 .245$ & $\mathrm{R} \$ 215.494$ & $\mathrm{R} \$ 134.090$ & $\mathrm{R} \$ 4.408 .897$ & $\mathrm{R} \$ 13.413 .635$ & $\mathrm{R} \$ 104.140$ & $\mathrm{R} \$ 46.379$ & $\mathrm{R} \$ 57.674 .975$ \\
\hline 1999 & $\mathrm{R} \$ 5.726 .162$ & $\mathrm{R} \$ 4.419 .823$ & $\mathrm{R} \$ 8.207 .551$ & $\mathrm{R} \$ 10.135 .172$ & $\mathrm{R} \$ 9.460 .930$ & $\mathrm{R} \$ 207.147$ & $\mathrm{R} \$ 137.077$ & $\mathrm{R} \$ 4.326 .731$ & $\mathrm{R} \$ 13.672 .037$ & $\mathrm{R} \$ 106.671$ & $\mathrm{R} \$ 49.858$ & $\mathrm{R} \$ 56.449 .158$ \\
\hline 2000 & $\mathrm{R} \$ 5.724 .204$ & $\mathrm{R} \$ 4.410 .827$ & $\mathrm{R} \$ 8.206 .794$ & $\mathrm{R} \$ 10.132 .772$ & $\mathrm{R} \$ 9.457 .602$ & $\mathrm{R} \$ 207.902$ & $\mathrm{R} \$ 136.380$ & $\mathrm{R} \$ 4.327 .676$ & $\mathrm{R} \$ 13.665 .439$ & $\mathrm{R} \$ 107.036$ & $\mathrm{R} \$ 50.030$ & $\mathrm{R} \$ 56.426 .662$ \\
\hline 2001 & $\mathrm{R} \$ 5.801 .350$ & $\mathrm{R} \$ 4.482 .864$ & $\mathrm{R} \$ 8.324 .992$ & $\mathrm{R} \$ 10.276 .164$ & $\mathrm{R} \$ 9.591 .095$ & $\mathrm{R} \$ 207.589$ & $\mathrm{R} \$ 138.367$ & $\mathrm{R} \$ 4.382 .224$ & $\mathrm{R} \$ 13.847 .091$ & $\mathrm{R} \$ 106.836$ & $\mathrm{R} \$ 49.937$ & $\mathrm{R} \$ 57.208 .510$ \\
\hline 2002 & 5.991 .917 & $\mathrm{R} \$ 4.621 .964$ & $\mathrm{R} \$ 8.602 .549$ & $\mathrm{R} \$ 10.603 .073$ & $\mathrm{R} \$ 9.908 .313$ & $\mathrm{R} \$ 208.035$ & $\mathrm{R} \$ 143.046$ & $\mathrm{R} \$ 4.527 .475$ & $\mathrm{R} \$ 14.282 .080$ & $\mathrm{R} \$ 112.065$ & $\mathrm{R} \$ 50.001$ & $\mathrm{R} \$ 59.050 .515$ \\
\hline 2003 & $\mathrm{R} \$ 5.902 .826$ & $\mathrm{R} \$ 4.549 .355$ & $\mathrm{R} \$ 8.490 .224$ & $\mathrm{R} \$ 10.446 .006$ & $\mathrm{R} \$ 9.779 .203$ & $\mathrm{R} \$ 209.258$ & $\mathrm{R} \$ 141.122$ & $\mathrm{R} \$ 4.451 .834$ & $\mathrm{R} \$ 14.051 .566$ & $\mathrm{R} \$ 109.829$ & $\mathrm{R} \$ 50.139$ & $\mathrm{R} \$ 58.181 .362$ \\
\hline 2004 & $\mathrm{R} \$ 6.238 .550$ & $\mathrm{R} \$ 4.805 .286$ & $\mathrm{R} \$ 8.994 .893$ & $\mathrm{R} \$ 11.016 .866$ & $\mathrm{R} \$ 10.373 .020$ & $\mathrm{R} \$ 234.683$ & $\mathrm{R} \$ 148.207$ & $\mathrm{R} \$ 4.686 .049$ & $\mathrm{R} \$ 14.778 .931$ & $\mathrm{R} \$ 116.111$ & $\mathrm{R} \$ 53.439$ & $\mathrm{R} \$ 61.446 .035$ \\
\hline 2005 & $\mathrm{R} \$ 6.563 .996$ & $\mathrm{R} \$ 5.027 .254$ & $\mathrm{R} \$ 9.488 .824$ & $\mathrm{R} \$ 11.554 .524$ & $\mathrm{R} \$ 10.964 .186$ & $\mathrm{R} \$ 238.392$ & $\mathrm{R} \$ 154.679$ & $\mathrm{R} \$ 4.905 .239$ & $\mathrm{R} \$ 15.460 .844$ & $\mathrm{R} \$ 119.269$ & $\mathrm{R} \$ 56.499$ & $\mathrm{R} \$ 64.533 .706$ \\
\hline 2006 & $\mathrm{R} \$ 6.849 .134$ & $\mathrm{R} \$ 5.222 .445$ & $\mathrm{R} \$ 9.928 .739$ & $\mathrm{R} \$ 12.004 .594$ & $\mathrm{R} \$ 11.523 .480$ & $\mathrm{R} \$ 243.993$ & $\mathrm{R} \$ 159.589$ & $\mathrm{R} \$ 5.113 .274$ & $\mathrm{R} \$ 16.017 .732$ & $\mathrm{R} \$ 125.494$ & $\mathrm{R} \$ 56.933$ & $\mathrm{R} \$ 67.245 .405$ \\
\hline 2007 & $\mathrm{R} \$ 7.534 .753$ & $\mathrm{R} \$ 5.700 .818$ & $\mathrm{R} \$ 10.966 .357$ & $\mathrm{R} \$ 12.998 .064$ & $\mathrm{R} \$ 12.823 .136$ & $\mathrm{R} \$ 278.156$ & $\mathrm{R} \$ 172.861$ & $\mathrm{R} \$ 5.593 .819$ & $\mathrm{R} \$ 17.311 .991$ & $\mathrm{R} \$ 135.014$ & $\mathrm{R} \$ 60.443$ & $\mathrm{R} \$ 73.575 .412$ \\
\hline 2008 & $\mathrm{R} \$ 7.328 .326$ & $\mathrm{R} \$ 5.654 .898$ & $\mathrm{R} \$ 10.503 .229$ & $\mathrm{R} \$ 12.976 .867$ & $\mathrm{R} \$ 12.106 .528$ & $\mathrm{R} \$ 270.077$ & $\mathrm{R} \$ 174.954$ & $\mathrm{R} \$ 5.527 .088$ & $\mathrm{R} \$ 17.498 .720$ & $\mathrm{R} \$ 134.997$ & $\mathrm{R} \$ 63.891$ & $\mathrm{R} \$ 72.239 .573$ \\
\hline 2009 & $\mathrm{R} \$ 7.435 .436$ & $\mathrm{R} \$ 5.739 .505$ & $\mathrm{R} \$ 10.668 .558$ & $\mathrm{R} \$ 13.157 .873$ & $\mathrm{R} \$ 12.292 .625$ & $\mathrm{R} \$ 269.704$ & $\mathrm{R} \$ 178.011$ & $\mathrm{R} \$ 5.611 .342$ & $\mathrm{R} \$ 17.741 .723$ & $\mathrm{R} \$ 137.304$ & $\mathrm{R} \$ 63.782$ & $\mathrm{R} \$ 73.295 .863$ \\
\hline 2010 & $\mathrm{R} \$ 8.182 .620$ & $\mathrm{R} \$ 6.311 .759$ & $\mathrm{R} \$ 11.743 .487$ & $\mathrm{R} \$ 14.476 .345$ & $\mathrm{R} \$ 13.526 .510$ & $\mathrm{R} \$ 291.098$ & $\mathrm{R} \$ 195.224$ & $\mathrm{R} \$ 6.171 .355$ & $\mathrm{R} \$ 19.507 .622$ & $\mathrm{R} \$ 152.772$ & $\mathrm{R} \$ 69.426$ & $\mathrm{R} \$ 80.628 .218$ \\
\hline 2011 & $\mathrm{R} \$ 8.801 .700$ & $\mathrm{R} \$ 6.783 .728$ & $\mathrm{R} \$ 12.642 .920$ & $\mathrm{R} \$ 15.566 .553$ & $\mathrm{R} \$ 14.562 .238$ & $\mathrm{R} \$ 313.807$ & $\mathrm{R} \$ 209.382$ & $R \$ 6.638 .596$ & $\mathrm{R} \$ 20.944 .125$ & $\mathrm{R} \$ 163.443$ & $\mathrm{R} \$ 75.201$ & $\mathrm{R} \$ 86.701 .693$ \\
\hline 2012 & $\mathrm{R} \$ 9.269 .420$ & $\mathrm{R} \$ 7.125 .916$ & $\mathrm{R} \$ 13.372 .334$ & $\mathrm{R} \$ 16.358 .002$ & $\mathrm{R} \$ 15.422 .352$ & $\mathrm{R} \$ 320.340$ & $\mathrm{R} \$ 219.534$ & $\mathrm{R} \$ 6.962 .941$ & $\mathrm{R} \$ 21.957 .529$ & $\mathrm{R} \$ 170.371$ & $\mathrm{R} \$ 78.783$ & $\mathrm{R} \$ 91.257 .522$ \\
\hline 2013 & $\mathrm{R} \$ 9.747 .207$ & $\mathrm{R} \$ 7.456 .327$ & $\mathrm{R} \$ 14.098 .369$ & $\mathrm{R} \$ 17.151 .484$ & $\mathrm{R} \$ 16.300 .636$ & $\mathrm{R} \$ 348.174$ & $\mathrm{R} \$ 228.930$ & $\mathrm{R} \$ 7.288 .592$ & $\mathrm{R} \$ 22.941 .661$ & $\mathrm{R} \$ 179.199$ & $\mathrm{R} \$ 82.044$ & $\mathrm{R} \$ 95.822 .624$ \\
\hline 2014 & $\mathrm{R} \$ 10.024 .963$ & $\mathrm{R} \$ 7.633 .489$ & $\mathrm{R} \$ 14.534 .238$ & $\mathrm{R} \$ 17.545 .356$ & $\mathrm{R} \$ 16.877 .732$ & $\mathrm{R} \$ 355.701$ & $\mathrm{R} \$ 233.176$ & $\mathrm{R} \$ 7.475 .023$ & $\mathrm{R} \$ 23.425 .387$ & $\mathrm{R} \$ 180.526$ & $\mathrm{R} \$ 82.606$ & $\mathrm{R} \$ 98.368 .196$ \\
\hline 2015 & $\mathrm{R} \$ 10.082 .580$ & $\mathrm{R} \$ 7.636 .457$ & $\mathrm{R} \$ 14.637 .755$ & $\mathrm{R} \$ 17.469 .700$ & $\mathrm{R} \$ 17.113 .866$ & $\mathrm{R} \$ 366.462$ & $\mathrm{R} \$ 232.243$ & $\mathrm{R} \$ 7.495 .029$ & $\mathrm{R} \$ 23.282 .496$ & $\mathrm{R} \$ 179.450$ & $\mathrm{R} \$ 83.242$ & $\mathrm{R} \$ 98.579 .280$ \\
\hline \multicolumn{13}{|c|}{ Valor Presente dos Custos } \\
\hline $6 \%$ a.a. & $\mathrm{R} \$ 76.411 .027$ & $\mathrm{R} \$ 58.497 .122$ & $\mathrm{R} \$ 110.308 .022$ & $\mathrm{R} \$ 134.058 .278$ & $\mathrm{R} \$ 127.726 .513$ & $\mathrm{R} \$ 2.761 .715$ & $\mathrm{R} \$ 1.797 .042$ & $\mathrm{R} \$ 57.288 .393$ & $\mathrm{R} \$ 179.669 .427$ & $\mathrm{R} \$ 1.398 .460$ & $\mathrm{R} \$ 641.284$ & $\mathrm{R} \$ 750.557 .282$ \\
\hline $12 \%$ a.a. & $\mathrm{R} \$ 45.883 .929$ & $\mathrm{R} \$ 35.103 .229$ & $\mathrm{R} \$ 66.261 .559$ & $\mathrm{R} \$ 80.419 .531$ & $\mathrm{R} \$ 76.759 .452$ & $\mathrm{R} \$ 1.662 .996$ & $\mathrm{R} \$ 1.077 .984$ & $\mathrm{R} \$ 34.390 .431$ & $\mathrm{R} \$ 107.741 .909$ & $\mathrm{R} \$ 838.979$ & $\mathrm{R} \$ 384.044$ & $\mathrm{R} \$ 450.524 .044$ \\
\hline $18 \%$ a.a. & $\mathrm{R} \$ 30.987 .776$ & $\mathrm{R} \$ 23.687 .305$ & $\mathrm{R} \$ 44.770 .552$ & $\mathrm{R} \$ 54.253 .059$ & $\mathrm{R} \$ 51.891 .834$ & $\mathrm{R} \$ 1.125 .890$ & $\mathrm{R} \$ 727.081$ & $\mathrm{R} \$ 23.214 .249$ & $\mathrm{R} \$ 72.650 .456$ & $\mathrm{R} \$ 565.866$ & $\mathrm{R} \$ 258.559$ & $\mathrm{R} \$ 304.132 .628$ \\
\hline
\end{tabular}


- $\quad$ Condição Base - IRI 8

\begin{tabular}{|c|c|c|c|c|c|c|c|c|c|c|c|c|}
\hline \multirow{2}{*}{ Ano } & \multicolumn{12}{|c|}{ Tipo de Veículo } \\
\hline & $2 \mathrm{C}$ & $2 \mathrm{~S} 2$ & $2 \mathrm{S3}$ & $3 \mathrm{C}$ & $3 \mathrm{S3}$ & $3 \mathrm{~T} 4$ & $\mathbf{M}$ & $\mathbf{O}$ & $\mathbf{P}$ & P3 & P4 & Total \\
\hline 1995 & $\mathrm{R} \$ 4.126 .109$ & 3.150 .989 & $\$ 5.973 .541$ & 7.253 .689 & $\mathrm{R} \$ 6.914 .757$ & 53.382 & $\$ 97.390$ & $\$ 3.086 .769$ & $\$ 9.686 .037$ & $\$ 75.508$ & $\$ 34.031$ & $\$ 40.552 .201$ \\
\hline 1996 & 4.931 .889 & 3.745 .744 & $\mathrm{R} \$ 7.145 .589$ & 8.597 .056 & 8.319 .211 & & 115.003 & 3.668 .219 & $\mathrm{R} \$ 11.465 .008$ & & $\$ 40.098$ & \\
\hline 1997 & & & & & & & & 4.187.977 & & 100.539 & 46.029 & \\
\hline 1998 & 5.943 .033 & 4.475 .038 & $\mathrm{R} \$ 8.678 .085$ & $\mathrm{R} \$ 10.107 .937$ & $\mathrm{R} \$ 10.148 .245$ & $\mathrm{R} \$ 215.494$ & $\mathrm{R} \$ 134.090$ & $R \$ 4.408 .897$ & $\mathrm{R} \$ 13.413 .635$ & $\$ 104.140$ & $\$ 46.379$ & $\$ 57.674 .975$ \\
\hline 1999 & 683.550 & 5.039 .440 & $\mathrm{R} \$ 9.775 .182$ & $\mathrm{R} \$ 11.198 .713$ & $\mathrm{R} \$ 11.426 .336$ & $\mathrm{R} \$ 249.190$ & $\mathrm{R} \$ 147.289$ & $\$ 4.944 .936$ & $\mathrm{R} \$ 14.767 .871$ & $\$ 113.843$ & $\mathrm{R} \$ 52.827$ & $\mathrm{R} \$ 64.399 .176$ \\
\hline 2000 & & 290.285 & 10.240 .294 & $\$ 11.628 .829$ & 11.952 .912 & 261171 & $\$ 150.752$ & 5.181 .625 & $\$ 15.220 .774$ & $\$ 117.290$ & $\$ 54.245$ & 8.220 \\
\hline 2001 & 38.622 & 472.081 & 3.304 .643 & $\mathrm{R} \$ 10.254 .816$ & 9.572 .652 & 207.162 & $\$ 138.213$ & $\$ 4.372 .630$ & $\mathrm{R} \$ 13.830 .688$ & $\$ 106.677$ & $\$ 49.860$ & 57.098 .043 \\
\hline 2002 & & 07.519 & 8.572 .382 & $\mathrm{R} \$ 10.573 .401$ & 9.878 .394 & & $\mathrm{R} \$ 142.825$ & 4.514 .424 & $\mathrm{R} \$ 14.257 .850$ & $\$ 111.844$ & $\mathrm{R} \$ 49.901$ & $\$ 58.889 .521$ \\
\hline 2003 & 365.862 & & 8.425 .516 & 10.389.271 & 9.706 .191 & & 140.665 & 4.429 .612 & & 09.408 & $\$ 49.951$ & \\
\hline 2004 & 138.810 & 743.083 & 8.813 .836 & $\mathrm{R} \$ 10.870 .225$ & $\$ 10.151 .196$ & 29.711 & $\$ 146.922$ & $\$ 4.635 .136$ & .506 & 990 & 2.953 & 7.368 \\
\hline 2005 & 6.416 .083 & 4.941.403 & 9.226 .173 & $\mathrm{R} \$ 11.345 .362$ & $\$ 10.629 .345$ & & $\mathrm{R} \$ 152.770$ & 4.829 .290 & $\mathrm{R} \$ 15.246 .494$ & $\$ 117.725$ & $2 \$ 55.813$ & 63.191 .640 \\
\hline 2006 & & & $\$ 9.634 .754$ & $\mathrm{R} \$ 11.776 .682$ & $\$ 11.116 .429$ & & & & & $\$ 123.840$ & $\$ 56.236$ & \\
\hline 2007 & 7.201 .393 & 5.512 .436 & $\mathrm{R} \$ 10.419 .891$ & $\mathrm{R} \$ 12.661 .644$ & $\mathrm{R} \$ 12.052 .701$ & $\mathrm{R} \$ 261.804$ & $\mathrm{R} \$ 168.982$ & 5.376 .645 & $\mathrm{R} \$ 16.933 .086$ & $\mathrm{R} \$ 132.571$ & $\mathrm{R} \$ 59.465$ & 70.780 .618 \\
\hline 2008 & & 5.913 .597 & $\mathrm{R} \$ 11.249 .265$ & $\mathrm{R} \$ 13.571 .697$ & $\mathrm{R} \$ 13.084 .551$ & & $\mathrm{R} \$ 180.478$ & $\mathrm{R} \$ 5.775 .926$ & $\mathrm{R} \$ 18.096 .787$ & $\mathrm{R} \$ 139.320$ & $\mathrm{R} \$ 65.813$ & $\$ 76.138 .527$ \\
\hline 2009 & 8.191 .924 & 6.179 .569 & 11.951 .225 & $\$ 14.031 .644$ & 13.975.952 & & $\$ 186.871$ & 6.073 .320 & $\$ 18.663 .220$ & $\$ 143.523$ & $\mathrm{R} \$ 66.418$ & 79.769.658 \\
\hline 2010 & 9.769 .519 & 7.375 .261 & $\mathrm{R} \$ 14.301 .133$ & $\mathrm{R} \$ 16.269 .815$ & $\mathrm{R} \$ 16.705 .934$ & $\mathrm{R} \$ 357.647$ & $\mathrm{R} \$ 212.437$ & $\mathrm{R} \$ 7.213 .581$ & $\mathrm{R} \$ 21.370 .286$ & $\mathrm{R} \$ 164.889$ & $\mathrm{R} \$ 74.249$ & $\mathrm{R} \$ 93.814 .751$ \\
\hline 2011 & & & $\mathrm{R} \$ 12.516 .730$ & $\mathrm{R} \$ 15.450 .458$ & $\mathrm{R} \$ 14.426 .837$ & & $\mathrm{R} \$ 208.478$ & $\mathrm{R} \$ 6.590 .997$ & $\mathrm{R} \$ 20.841 .691$ & $\mathrm{R} \$ 162.585$ & $\mathrm{R} \$ 74.804$ & $\$ 86.040 .648$ \\
\hline 2012 & $\mathrm{R} \$ 9.086 .157$ & 7.008 .316 & $\$ 13.043 .478$ & $\mathrm{R} \$ 16.085 .606$ & $\mathrm{R} \$ 15.027 .752$ & $\$ 312.175$ & $\mathrm{R} \$ 217.192$ & $\mathrm{R} \$ 6.864 .636$ & $\mathrm{R} \$ 21.688 .504$ & $\$ 168.320$ & $\mathrm{R} \$ 77.882$ & $\$ 89.580 .021$ \\
\hline 2013 & & & $\mathrm{R} \$ 13.533 .307$ & $\mathrm{R} \$ 16.697 .691$ & $\mathrm{R} \$ 15.587 .024$ & & $\mathrm{R} \$ 224.840$ & $\mathrm{R} \$ 7.121 .969$ & $\mathrm{R} \$ 22.480 .617$ & $\mathrm{R} \$ 175.793$ & $\mathrm{R} \$ 80.582$ & $\mathrm{R} \$ 92.931 .606$ \\
\hline 2014 & & & 42.419 & 17.005 .560 & $\mathrm{R} \$ 15.947 .909$ & 6.345 & 228.034 & 7.252 .434 & $\mathrm{R} \$ 22.869 .671$ & $\$ 176.604$ & $\mathrm{R} \$ 80.938$ & $\mathrm{R} \$ 94.764 .526$ \\
\hline 2015 & & & .874 .279 & 16.932 .482 & 16.011 .280 & $2 \$ 343.280$ & $R \$ 226.479$ & 7.202.393 & $\$ 22.703 .775$ & $\$ 175.592$ & $\$ 81.612$ & \\
\hline & & & & & & & & & & & & \\
\hline & 968 & 348 & & 36.097.038 & 31.364.164 & & .816 .754 & $R \$ 58.554 .855$ & $\mathrm{R} \$ 181.792 .012$ & $\mathrm{R} \$ 1.411 .905$ & $\$ 646.713$ & $\mathrm{R} \$ 765.861 .741$ \\
\hline $12 \%$ a.a. & & & & & & & & & & & & \\
\hline & $\mathrm{R} \$ 31.917 .380$ & $\$ 24.313 .911$ & $\mathrm{R} \$ 46.263 .203$ & $\mathrm{R} \$ 55.294 .308$ & $\mathrm{R} \$ 53.738 .038$ & $\mathrm{R} \$ 1.165 .351$ & $\mathrm{R} \$ 737.135$ & $\mathrm{R} \$ 23.832 .901$ & $\mathrm{R} \$ 73.732 .830$ & $R \$ 572.858$ & $\mathrm{R} \$ 261.418$ & $\mathrm{R} \$ 311.829 .333$ \\
\hline
\end{tabular}


- Concessão Programada

\begin{tabular}{|c|c|c|c|c|c|c|c|c|c|c|c|c|}
\hline \multirow{2}{*}{ Ano } & \multicolumn{12}{|c|}{ Tipo de Veículo } \\
\hline & C & $2 \mathrm{~S} 2$ & $2 \mathrm{S3}$ & 3C & $3 \mathrm{S3}$ & $3 T 4$ & $\mathbf{M}$ & $\mathbf{O}$ & $\mathbf{P}$ & P3 & P4 & Total \\
\hline 1995 & $\mathrm{R} \$ 4.126 .109$ & $\$ 3.150 .989$ & $\mathrm{R} \$ 5.973 .541$ & $\mathrm{R} \$ 7.253 .689$ & $\mathrm{R} \$ 6.914 .757$ & $\mathrm{R} \$ 153.382$ & $\mathrm{R} \$ 97.390$ & $\mathrm{R} \$ 3.086 .769$ & $\mathrm{R} \$ 9.686 .037$ & $\mathrm{R} \$ 75.508$ & $\$ 34.031$ & $\mathrm{R} \$ 40.552 .201$ \\
\hline 1996 & 4.827 .082 & 3.689 .397 & $\mathrm{R} \$ 6.981 .721$ & $\$ 8.477 .467$ & $\mathrm{R} \$ 8.075 .246$ & 174.984 & $\mathrm{R} \$ 113.727$ & $\mathrm{R} \$ 3.604 .485$ & 11.339 .552 & $\$ 88.622$ & $\$ 39.750$ & $\$ 47.412 .034$ \\
\hline 1997 & 370.602 & 4.112 .702 & .762 .497 & 9.447 .069 & 8.972 .568 & $\$ 195.544$ & 125.948 & 4.023 .375 & $\$ 12.644 .571$ & $\mathrm{R} \$ 98.627$ & $\$ 5.242$ & $\$ 52.798 .744$ \\
\hline 1998 & 5.399 .775 & 4.163 .215 & $\mathrm{R} \$ 7.773 .558$ & $\mathrm{R} \$ 9.533 .608$ & $\mathrm{R} \$ 8.961 .946$ & 190.797 & $\$ 128.138$ & $\mathrm{R} \$ 4.064 .601$ & $\$ 12.802 .773$ & $\mathrm{R} \$ 100.199$ & $\$ 44.814$ & $R \$ 53.163 .423$ \\
\hline 1999 & 97.493 & 4.470 .327 & 8.331 .487 & $\mathrm{R} \$ 10.245 .569$ & 9.598 .681 & 210.209 & 37.965 & $\mathrm{R} \$ 4.369 .992$ & 13.772 .848 & 107.498 & $\$ 50.238$ & 7.092 .308 \\
\hline 2000 & 752.786 & $\$ 4.432 .652$ & $\$ 8.254 .516$ & $\$ 10.178 .420$ & $\$ 9.506 .681$ & $\$ 209.021$ & $\$ 136.728$ & $\$ 4.347 .218$ & $\$ 13.704 .083$ & $\$ 107.373$ & $\$ 50.190$ & $\$ 56.679 .668$ \\
\hline 2001 & 5.788 .473 & $4.4 / 1.900$ & 8.304 .437 & $\$ 10.254 .609$ & 9.572 .463 & 7.157 & 3.209 & 4.372 .525 & $\$ 13.830 .490$ & $\$ 106.675$ & $\$ 49.859$ & 996.864 \\
\hline 2002 & 3.477 & 607.425 & 72.187 & 0.573 .189 & .878 .199 & & & & 14.257.647 & & & \\
\hline 2003 & 5.937 & 4.523 .822 & 425.637 & 10.389 .410 & 9.706 .330 & 7.678 & 140.665 & 4.429 .670 & 999.430 & 109.408 & 9.951 & 47.938 \\
\hline 2004 & 6.138 .548 & $\mathrm{R} \$ 4.742 .901$ & $\mathrm{R} \$ 8.813 .401$ & $\mathrm{R} \$ 10.869 .826$ & $\mathrm{R} \$ 10.150 .688$ & $\mathrm{R} \$ 229.700$ & $\mathrm{R} \$ 146.918$ & $\mathrm{R} \$ 4.634 .975$ & $\mathrm{R} \$ 14.630 .089$ & $\mathrm{R} \$ 114.984$ & & 0.524 .983 \\
\hline 2005 & 5.411 .410 & 4.938.523 & 9.217 .601 & 11.338 .513 & 10.618 .836 & 230.954 & $\$ 152.707$ & 4.827 .030 & $\$ 15.239 .357$ & $\mathrm{R} \$ 117.675$ & 55.790 & 3.148 .396 \\
\hline 2006 & 2.269 & $P_{2}$ & 33.861 & 11.524 .358 & 10.758 .684 & 227.901 & 155.211 & 4.919 .768 & 15.537 .748 & 121.927 & 5.405 & 4.154 .283 \\
\hline 2007 & 6.931 .003 & 534007 & $\$ 9.944 .530$ & $\mathrm{R} \$ 12.274 .810$ & $\mathrm{R} \$ 11.458 .366$ & $\mathrm{R} \$ 248.959$ & $\$ 165.539$ & $\mathrm{R} \$ 5.231 .193$ & & & & \\
\hline 2008 & 7.355 .273 & 5.676 .862 & $\mathrm{R} \$ 10.546 .942$ & $\mathrm{R} \$ 13.021 .148$ & $\mathrm{R} \$ 12.148 .222$ & $\mathrm{R} \$ 271.061$ & $\$ 175.278$ & $\mathrm{R} \$ 5.546 .759$ & $\mathrm{R} \$ 17.533 .974$ & $\$ 135.323$ & $\$ 64.048$ & $\$ 72.474 .889$ \\
\hline 2009 & 7.490 .007 & $\$ 5.778 .233$ & 10.763 .008 & $\mathrm{R} \$ 13.242 .304$ & $\$ 12.397 .073$ & $\$ 272.037$ & $\mathrm{R} \$ 178.678$ & $\$ 5.645 .121$ & $\mathrm{R} \$ 17.818 .219$ & $\mathrm{R} \$ 137.923$ & $\mathrm{R} \$ 64.067$ & $\mathrm{R} \$ 73.786 .671$ \\
\hline 2010 & 8.335 .946 & $\$ 6.408 .044$ & $\mathrm{R} \$ 12.020 .475$ & $\mathrm{R} \$ 14.702 .191$ & $\mathrm{R} \$ 13.863 .780$ & & $\mathrm{R} \$ 197.184$ & $\mathrm{R} \$ 6.250 .951$ & $\mathrm{R} \$ 19.734 .335$ & $\mathrm{R} \$ 154.490$ & & $\mathrm{R} \$ 82.035 .862$ \\
\hline 2011 & 8.727 .760 & 6.729 .478 & $\mathrm{R} \$ 12.516 .679$ & 15.450 .406 & 14.426 .785 & 310.813 & 208.478 & $\mathrm{R} \$ 6.590 .982$ & $\$ 20.841 .691$ & $\$ 162.585$ & $\$ 74.804$ & $\mathrm{R} \$ 86.040 .460$ \\
\hline 2012 & 9.086 .818 & $\$ 7.008 .871$ & $\mathrm{R} \$ 13.044 .582$ & $\mathrm{R} \$ 16.086 .737$ & $\mathrm{R} \$ 15.028 .802$ & $\mathrm{R} \$ 312.198$ & $\mathrm{R} \$ 217.199$ & $\mathrm{R} \$$ 6.865.131 & $\mathrm{R} \$ 21.689 .433$ & $\mathrm{R} \$ 168.329$ & $\mathrm{R} \$ 77.885$ & $\mathrm{R} \$ 89.585 .985$ \\
\hline 2013 & 9.432 .339 & 0 & $\mathrm{R} \$ 13.540 .210$ & $\mathrm{R} \$ 16.703 .822$ & $\mathrm{R} \$ 15.594 .678$ & $\mathrm{R} \$ 333.215$ & $\mathrm{R} \$ 224.892$ & $\mathrm{R} \$ 7.124 .435$ & $\mathrm{R} \$ 22.486 .064$ & $\mathrm{R} \$ 175.839$ & $R \$ 80.602$ & $\mathrm{R} \$ 92.967 .213$ \\
\hline 2014 & 37.009 & $\begin{array}{l}7.418 .294 \\
\end{array}$ & $\begin{array}{l}3.877 .358 \\
\end{array}$ & 7.033.365 & 15.991.477 & 337.242 & 8.287 & 7.261 .703 & $\$ 22.898 .544$ & 76.808 & $\$ 1.028$ & $\mathrm{R} \$ 94.941 .114$ \\
\hline 2015 & $\mathrm{R} \$ 9.631 .054$ & $\mathrm{R} \$ 7.388 .937$ & 13918987 & $\mathrm{R} \$ 16.967 .982$ & $\mathrm{R} \$ 16.069 .467$ & $\mathrm{R} \$ 344.514$ & $\mathrm{R} \$ 226.806$ & $\mathrm{R} \$ 7.215 .939$ & $\mathrm{R} \$ 22.740 .145$ & & & \\
\hline & & & & & & & & & & & & \\
\hline $6 \%$ a.a. & & & & & & & & & & & & \\
\hline$\%$ a.a. & 44.885 .592 & 34.536 .990 & $\$ 64.597 .229$ & 79.273.876 & 74.508 .110 & 1.615 .542 & $\mathrm{R} \$ 1.066 .215$ & $\mathrm{R} \$ 33.785 .235$ & R\$ 106.524.684 & $\mathrm{R} \$ 830.767$ & $\mathrm{R} \$ 380.666$ & $\mathrm{R} \$ 442.004 .905$ \\
\hline $18 \%$ a.a. & $\$ 30.302 .323$ & $\$ 23.300 .509$ & $\mathrm{R} \$ 43.634 .086$ & $R \$ 53.487 .905$ & $\mathrm{R} \$ 50.344 .841$ & $\mathrm{R} \$ 1.093 .303$ & $\mathrm{R} \$ 719.090$ & $\mathrm{R} \$ 22.793 .250$ & $\mathrm{R} \$ 71.831 .949$ & $R \$ 560.418$ & $\mathrm{R} \$ 256.336$ & $\mathrm{R} \$ 298.324 .0$ \\
\hline
\end{tabular}


- CREMA

\begin{tabular}{|c|c|c|c|c|c|c|c|c|c|c|c|c|}
\hline \multirow{2}{*}{ Ano } & \multicolumn{12}{|c|}{ Tipo de Veículo } \\
\hline & $2 \mathrm{C}$ & $2 \mathrm{~S} 2$ & $2 \mathrm{S3}$ & $3 \mathrm{C}$ & $3 \mathrm{S3}$ & 3T4 & $\mathbf{M}$ & $\mathbf{O}$ & $\mathbf{P}$ & P3 & P4 & Total \\
\hline 1995 & $\mathrm{R} \$ 4.126 .109$ & 150.989 & $\$ 5.973 .541$ & $\$ 7.253 .689$ & $\mathrm{R} \$ 6.914 .757$ & $\$ 153.382$ & $\mathrm{R} \$ 97.390$ & $\$ 3.086 .769$ & $\$ 9.686 .037$ & $\mathrm{R} \$ 75.508$ & $\$ 34.031$ & $\$ 40.552 .201$ \\
\hline 1996 & 4.754.248 & 3.649 .738 & 6.856 .987 & 8.378 .841 & 7.910 .388 & 171.440 & $\$ 112.797$ & $\$ 3.565 .210$ & $\$ 11.238 .777$ & 87.894 & $\$ 39.448$ & 46.765 .767 \\
\hline 1997 & 216.554 & 4.022 .625 & .488 .843 & 9.228 .623 & 8.625 .119 & & 123.975 & $\mathrm{R} \$ 3.943 .824$ & 12.421 .040 & $\$ 96.994$ & $\$ 4.539$ & $\$ 51.400 .174$ \\
\hline 1998 & 5.321 .599 & 4.113 .464 & $\$ 7.632 .240$ & 9.417 .760 & $\mathrm{R} \$ 8.790 .715$ & $\$ 187.184$ & $\$ 127.137$ & $\$ 4.023 .721$ & $\$ 12.687 .004$ & $\$ 99.318$ & $\$ 44.440$ & 2.444 .583 \\
\hline 1999 & 5.737 .110 & 4.429 .189 & $\mathrm{R} \$ 8.224 .949$ & $\mathrm{R} \$ 10.153 .588$ & $\mathrm{R} \$ 9.476 .477$ & $\mathrm{R} \$ 207.513$ & $\$ 137.209$ & $\mathrm{R} \$ 4.335 .014$ & $\$ 13.686 .103$ & $\mathrm{R} \$ 106.810$ & 49.925 & $\$ 56.543 .888$ \\
\hline 2000 & .718 .688 & 406.073 & 8.198 .064 & $\mathrm{R} \$ 10.123 .473$ & 9.449 .923 & 1.720 & 136.316 & 4.323 .476 & 13.658 .413 & 106.965 & 49.995 & 379.105 \\
\hline 2001 & 794.527 & 177.180 & 8.314 .019 & 10.264 .820 & 9.580 .895 & 7.355 & 138.286 & 4.377 .126 & 3.838 .198 & 106.750 & & \\
\hline 2002 & 5.981 .379 & 613.934 & $\$ 8.584 .951$ & $\$ 10.586 .254$ & 9.890 .149 & \$ 207.639 & $\$ 142.921$ & $\$ 4.520 .205$ & $\$ 14.268 .031$ & $\$ 111.941$ & 49.945 & 557.348 \\
\hline 2003 & & & 8.445 .823 & 79 & 7.523 & & 809 & 4.437 .751 & 511 & 9.549 & .015 & 7.954.321 \\
\hline 2004 & 9.334 & 63.055 & 8.868 .608 & 10.915.998 & 10.215 .806 & 231.176 & 147.305 & 4.651 .818 & 4.675 .117 & 15.339 & .106 & 0.806 .662 \\
\hline 2005 & 5.095 & 83.052 & $\mathrm{R} \$ 9.351 .530$ & $\$ 11.445 .389$ & $\mathrm{R} \$ 10.786 .153$ & 234.543 & $\$ 153.664$ & $\mathrm{R} \$ 4.863 .556$ & .349 .451 & $\$ 118.477$ & 56.146 & 7.056 \\
\hline 2006 & 5.675 .716 & .129 .381 & 9.642 .107 & 1.782 .747 & 1.125 .634 & & 57.414 & 5.015 .084 & 5.789 .506 & & & \\
\hline 2007 & 5.985 .105 & 8.276 & 0.038 .378 & 2.358 .545 & 662.457 & & 6.203 & 264.477 & 621.978 & 0.307 & & \\
\hline 2008 & $\mathrm{R} \$ 7.364 .538$ & 5.683 .613 & $\mathrm{R} \$ 10.562 .707$ & $\mathrm{R} \$ 13.035 .633$ & $\mathrm{R} \$ 12.165 .225$ & $\mathrm{R} \$ 271.449$ & $\mathrm{R} \$ 175.390$ & $\mathrm{R} \$ 5.552 .731$ & .546 .975 & $\$ 135.429$ & $\$ 64.099$ & 2.557 .790 \\
\hline 2009 & 7.444 .027 & 5.746 .507 & $\mathrm{R} \$ 10.682 .453$ & $\$ 13.171 .967$ & $\mathrm{R} \$ 12.305 .838$ & & $\$ 178.110$ & 5.617 .630 & $\$ 17.752 .868$ & $\$ 137.407$ & & 3.370 .650 \\
\hline 2010 & 4.002 & 288.481 & 11.696 .940 & 4.429 .338 & 482.067 & 0.087 & 194.881 & 437 & .469 .790 & 52.421 & 9.262 & \\
\hline 2011 & & & & & & & & & & & & $\mathrm{R} \$ 86.172 .183$ \\
\hline 2012 & 9.111 .655 & 7.027.686 & $\mathrm{R} \$ 13.086 .186$ & $\mathrm{R} \$ 16.126 .296$ & $\$ 15.071 .994$ & & $\mathrm{R} \$ 217.504$ & $\mathrm{R} \$ 6.882 .097$ & $\$ 21.723 .177$ & \$168.619 & $\$ 78.021$ & $\$ 89.806 .363$ \\
\hline 2013 & 1.684 & 15.692 & 13.665 .548 & 16.807 .210 & 744.343 & 336.408 & 225.780 & 7.161 .088 & $\$ 22.588 .910$ & & \$80.944 & \\
\hline 2014 & & 7.491 .314 & & & & & & & & $\$ 178.126$ & 81.593 & $\$ 96.066 .619$ \\
\hline 2015 & 2.937 & 3.656 & 5.674 & 53.138 & $\$ 16.393 .795$ & & 228.592 & \$7.295.171 & 929.649 & \$ \$ & $\$ 82.298$ & 96.003 .479 \\
\hline & & & & & & & & & & & & \\
\hline $6 \%$ a.a. & 74.647.558 & 57.490.207 & $\mathrm{R} \$ 107.340 .560$ & $\mathrm{R} \$ 131.942 .102$ & $\mathrm{R} \$ 123.750 .615$ & 2.677 .629 & 1.775 .866 & $\mathrm{R} \$ 56.245 .227$ & $\mathrm{R} \$ 177.443 .443$ & $\mathrm{R} \$ 1.383 .134$ & $\$ 634.906$ & $\mathrm{R} \$ 735.331 .247$ \\
\hline $12 \%$ a.a. & 44.718.129 & 34.437 .990 & $\mathrm{R} \$$ 64.301.926 & $\mathrm{R} \$ 79.035 .851$ & $\mathrm{R} \$ 74.135 .429$ & & 1.064 .081 & $\mathrm{R} \$ 33.696 .549$ & $\mathrm{R} \$ 106.284 .157$ & $\mathrm{R} \$ 828.990$ & $\$ 379.904$ & $\mathrm{R} \$ 440.490 .465$ \\
\hline $18 \%$ a.a. & $\mathrm{R} \$ 30.129 .758$ & & $\mathrm{R} \$ 43.330 .286$ & $\mathrm{R} \$ 53.242 .491$ & $\mathrm{R} \$ 49.961 .990$ & 101.000 .000 & 20 & & 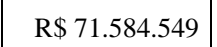 & R\$ 558.587 & K\$ 255.550 & 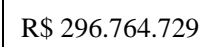 \\
\hline
\end{tabular}


- Concessão Responsiva

\begin{tabular}{|c|c|c|c|c|c|c|c|c|c|c|c|c|}
\hline \multirow{2}{*}{ Ano } & \multicolumn{12}{|c|}{ Tipo de Veículo } \\
\hline & $2 \mathrm{C}$ & $\mathbf{S 2}$ & $2 S 3$ & $3 \mathrm{C}$ & $3 \mathrm{S3}$ & $3 \mathrm{~T} 4$ & $\mathbf{M}$ & $\mathbf{O}$ & $\mathbf{P}$ & $\mathbf{P 3}$ & P4 & Total \\
\hline 1995 & $\mathrm{R} \$ 4.126 .109$ & $\$ 3.150 .989$ & $\mathrm{R} \$ 5.973 .541$ & $\mathrm{R} \$ 7.253 .689$ & $\mathrm{R} \$ 6.914 .757$ & $\$ 153.382$ & $\mathrm{R} \$ 97.390$ & $\mathrm{R} \$ 3.086 .769$ & $\mathrm{R} \$ 9.686 .037$ & $\mathrm{R} \$ 75.508$ & $\$ 34.031$ & $\mathrm{R} \$ 40.552 .201$ \\
\hline 1996 & 4.827 .082 & 3.689 .397 & $\mathrm{R} \$ 6.981 .721$ & $\mathrm{R} \$ 8.477 .467$ & $\mathrm{R} \$ 8.075 .246$ & & 113.727 & $\$ 3.604 .485$ & $\mathrm{R} \$ 11.339 .552$ & 88.622 & 39.750 & $\$ 47.412 .034$ \\
\hline 1997 & 5.370 .602 & 4.112 .702 & 7.762 .497 & 9.447 .069 & $\$ 8.972 .568$ & & 25.948 & 4.023 .375 & 12.644.571 & $\$ 98.627$ & 45.242 & 2.798 .744 \\
\hline 1998 & 5.399 .775 & $\mathrm{R} \$ 4.163 .215$ & $\mathrm{R} \$ 7.773 .558$ & $\mathrm{R} \$ 9.533 .608$ & $\mathrm{R} \$ 8.961 .946$ & $\mathrm{R} \$ 190.797$ & $\$ 128.138$ & $\mathrm{R} \$ 4.064 .601$ & $\$ 12.802 .773$ & $\mathrm{R} \$ 100.199$ & $\$ 44.814$ & $\mathrm{R} \$ 53.163 .423$ \\
\hline 1999 & .797 .493 & & & $\mathrm{R} \$ 10.245 .569$ & 9.598 .681 & & 137.965 & 4.369.992 & $\$ 13.772 .848$ & 107.498 & 50.238 & 92.308 \\
\hline 2000 & 752.786 & 4.432 .652 & .254 .516 & $\$ 10.178 .420$ & 9.506 .681 & 209.021 & 136.728 & 4.347.218 & 13.704 .083 & 107.373 & 50.190 & 6.679 .668 \\
\hline 2001 & 5.788 .473 & 4.471 .966 & 8.304 .437 & $\mathrm{R} \$ 10.254 .609$ & 9.572 .463 & $\mathrm{R} \$ 207.157$ & $\$ 138.209$ & $\$ 4.372 .525$ & $\$ 13.830 .490$ & $\$ 106.675$ & 49.859 & 57.096 .864 \\
\hline 2002 & 3.477 & & 72.187 & $\$ 10.573 .189$ & .199 & & & & 4.257 .647 & 1.843 & 49.900 & 8.888 .398 \\
\hline 2003 & 865.937 & 4.523 .822 & 425.637 & 10.389 .410 & 9.706 .330 & 207.678 & 140.665 & 4.429 .670 & 3.999 .430 & 109.408 & 49.951 & 7.847 .938 \\
\hline 2004 & 6.113 .364 & $\mathrm{R} \$ 4.723 .340$ & $\mathrm{R} \$ 8.771 .547$ & $\mathrm{R} \$ 10.829 .313$ & $\mathrm{R} \$ 10.108 .273$ & $\mathrm{R} \$ 228.700$ & $\mathrm{R} \$ 146.613$ & $\mathrm{R} \$ 4.617 .395$ & $\mathrm{R} \$ 14.596 .110$ & $\$ 114.684$ & $\$ 52.811$ & 3.302 .150 \\
\hline 2005 & 5.372 .802 & 4.913.617 & 9.147 .892 & $\$ 11.280 .897$ & 10.535 .835 & 229.150 & 152.218 & 4.806 .471 & 15.182.254 & 117.243 & 55.595 & 62.793 .973 \\
\hline 2006 & 6.509 .069 & 33.012 & $\mathrm{R} \$ 9.344 .649$ & $\mathrm{R} \$ 11.535 .830$ & $\mathrm{R} \$ 10.768 .198$ & $\mathrm{R} \$ 228.119$ & $\mathrm{R} \$ 155.298$ & $\mathrm{R} \$ 4.924 .934$ & $\$ 15.546 .628$ & $\$ 122.013$ & $\$ 55.446$ & 64.213 .197 \\
\hline 2007 & $\mathrm{R} \$ 6.967 .842$ & $\mathrm{R} \$ 5.377 .041$ & $\mathrm{R} \$ 10.007 .321$ & $\mathrm{R} \$ 12.332 .660$ & $\mathrm{R} \$ 11.525 .694$ & $\mathrm{R} \$ 250.461$ & $\mathrm{R} \$ 165.980$ & $\mathrm{R} \$ 5.255 .187$ & $\mathrm{R} \$ 16.596 .702$ & $\$ 130.108$ & $\$ 58.429$ & $\$ 68.667 .426$ \\
\hline 2008 & 7.337 .654 & 5.662 .924 & $\$ 10.518 .017$ & $\mathrm{R} \$ 12.992 .570$ & $\mathrm{R} \$ 12.119 .644$ & 270.392 & $\mathrm{R} \$ 175.067$ & $\mathrm{R} \$ 5.534 .136$ & $\mathrm{R} \$ 17.510 .721$ & $\mathrm{R} \$ 135.113$ & 63.948 & $\mathrm{R} \$ 72.320 .187$ \\
\hline 2009 & 5.213 & 39.328 & 10.668 .161 & 13.157.477 & 12.292.206 & 269.695 & 178.006 & 5.611 .146 & $\$ 17.741 .470$ & \$137.301 & 63.781 & 73.293.784 \\
\hline 2010 & $\mathrm{R} \$ 8.166 .197$ & & $\mathrm{R} \$ 11.716 .381$ & $\mathrm{R} \$ 14.449 .844$ & $\mathrm{R} \$ 13.499 .477$ & $\mathrm{R} \$ 290.490$ & & $\mathrm{R} \$ 6.159 .651$ & & $\mathrm{R} \$ 152.574$ & & $\$ 80.483 .513$ \\
\hline 2011 & & & $\mathrm{R} \$ 12.539 .888$ & & $\mathrm{R} \$ 14.447 .717$ & 311.298 & 208.655 & $\mathrm{R} \$ 6.601 .996$ & $\mathrm{R} \$ 20.860 .749$ & $\$ 162.767$ & $\$ 74.892$ & $\mathrm{R} \$ 86.167 .025$ \\
\hline 2012 & 9.087 .401 & & 13.045 .470 & 16.087 .759 & 15.029 .555 & 312.215 & $\$ 217.212$ & $\mathrm{R} \$ 6.865 .551$ & $\$ 21.690 .362$ & $\$ 168.338$ & $\$ 77.890$ & $\$ 89.591 .125$ \\
\hline 2013 & & & $\mathrm{R} \$ 13.496 .372$ & & & & & & & $\mathrm{R} \$ 175.534$ & $\$ 80.464$ & $R \$ 92.736 .185$ \\
\hline 2014 & .525 .309 & 7.344 .748 & 13.677.479 & 16.865 .409 & 15.756 .293 & & 226.878 & 7.200 .102 & 22.735 .689 & 75.564 & 80.476 & 93.920 .228 \\
\hline 2015 & & 29820 & $\mathrm{R} \$ 13.456 .265$ & 16.591.569 & $\mathrm{R} \$ 15.500 .771$ & $\mathrm{R} \$ 332.377$ & $\mathrm{R} \$ 223.508$ & & & 173.051 & & \\
\hline \multicolumn{13}{|c|}{ Valor Presente dos Custos } \\
\hline $6 \%$ a.a. & & & & & 3.521 .873 & 2.672 .834 & $\mathrm{R} \$ 1.774$ & & & $\mathrm{R} \$ 1.381 .815$ & & $\mathrm{R} \$ 734.287 .117$ \\
\hline $12 \%$ a.a. & 44.798.944 & & & & 324.782 & & & & & 29.801 & & $\mathrm{R} \$ 441.215 .043$ \\
\hline $18 \%$ a.a. & $\mathrm{R} \$ 30.265 .860$ & $\$ 23.276 .672$ & $\mathrm{R} \$ 43.569 .227$ & $\mathrm{R} \$ 53.433 .359$ & $\mathrm{R} \$ 50.268 .193$ & $\mathrm{R} \$ 1.091 .639$ & $\mathrm{R} \$ 718.631$ & $\mathrm{R} \$ 22.773 .003$ & $\mathrm{R} \$ 71.779 .050$ & $\mathrm{R} \$ 560.011$ & $\mathrm{R} \$ 256.155$ & $\mathrm{R} \$ 297.991 .74$ \\
\hline
\end{tabular}

